\title{
Drug-induced movement disorders in long-stay psychiatric patients : genetic and non-genetic risk factors : a prospective study
}

Citation for published version (APA):

Bakker, P. R. (2012). Drug-induced movement disorders in long-stay psychiatric patients : genetic and non-genetic risk factors : a prospective study. [Doctoral Thesis, Maastricht University]. Maastricht University. https://doi.org/10.26481/dis.20120523pb

Document status and date:

Published: 01/01/2012

DOI:

10.26481/dis.20120523pb

Document Version:

Publisher's PDF, also known as Version of record

Please check the document version of this publication:

- A submitted manuscript is the version of the article upon submission and before peer-review. There can be important differences between the submitted version and the official published version of record.

People interested in the research are advised to contact the author for the final version of the publication, or visit the DOI to the publisher's website.

- The final author version and the galley proof are versions of the publication after peer review.

- The final published version features the final layout of the paper including the volume, issue and page numbers.

Link to publication

\footnotetext{
General rights rights.

- You may freely distribute the URL identifying the publication in the public portal. please follow below link for the End User Agreement:

www.umlib.nl/taverne-license

Take down policy

If you believe that this document breaches copyright please contact us at:

repository@maastrichtuniversity.nl

providing details and we will investigate your claim.
}

Copyright and moral rights for the publications made accessible in the public portal are retained by the authors and/or other copyright owners and it is a condition of accessing publications that users recognise and abide by the legal requirements associated with these

- Users may download and print one copy of any publication from the public portal for the purpose of private study or research.

- You may not further distribute the material or use it for any profit-making activity or commercial gain

If the publication is distributed under the terms of Article 25fa of the Dutch Copyright Act, indicated by the "Taverne" license above, 


\title{
Drug-induced movement disorders in long-stay psychiatric patients
}

\author{
Genetic and non-genetic risk factors: \\ A prospective study
}


This work was supported by grant from the Foundation 'the Open Ankh', the Netherlands [grant number SG 21.02], and by Innova GGZ Centraal.

(C) Pieter Roberto Bakker, Maastricht 2012

Alle rechten voorbehouden. Niets uit deze uitgave mag worden verveelvoudigd, opgeslagen in een geautomatiseerd gegevensbestand, of openbaar gemaakt, in enige vorm of op enige wijze, hetzij elektronisch, mechanisch, door fotokopieën, opnamen, of op enig andere manier, zonder voorafgaande schriftelijke toestemming van de rechthebbende.

ISBN 9789075579994

Production: Datawyse | Universitaire Pers Maastricht

Cover photo: Loïc Trujillo 


\title{
Drug-induced movement disorders in long-stay psychiatric patients
}

\section{Genetic and non-genetic risk factors: A prospective study}

\author{
PROEFSCHRIFT \\ ter verkrijging van de graad van doctor aan de Universiteit Maastricht, \\ op gezag van de Rector Magnificus, Prof. mr. G.P.M.F. Mols, \\ volgens het besluit van het College van Decanen, \\ in het openbaar te verdedigen op \\ woensdag 23 mei 2012 om 14.00 uur \\ door \\ Pieter Roberto Bakker \\ geboren op 22 juli 1962 te Caracas, Venezuela
}




\section{Promotores}

Prof. dr. P.N. van Harten

Prof. dr. J. van Os

\section{Beoordelingscommissie}

Prof. dr. I. Myin-Germeys (voorzitter)

Prof. dr. C.M. van Duijn (Erasmus Universiteit Rotterdam)

Dr. A.F.G. Leentjens

Prof. dr. Y. Temel

Dr. D.E. Tenback (GGZ Centraal, Amersfoort) 
Aan Koen 


\section{Canto Lacrado}

No pude separar el pájaro del canto.

Oí murmullos, ráfagas, acordes,

gotas de oráculo amarillo,

cosas indescifrables;

anoté cuanto pude sin espantarlo.

Me detuve abstraído ante sus ecos

sin indagar si modulaba un son antiguo

o si su voz se contamina

en esta hora llena de máquinas.

Lo oí después, lo seguí oyendo muchos días,

otro o el mismo, ya no supe, un canto

lacrado entre los pliegues de los aires.

Ignoro aún si trasmutaba en su inocencia

ruidos de goznes, pernos, hélices,

el zumbido de los taxis que van y vienen.

Ignoro si inventaba o traducía.

Sólo anoté una raya de su sombra

sin apartarla de sus alas.

\section{Hidden Song}

I couldn't distinguish the bird from the song.

I heard whispers, sudden blasts, chords,

golden oracles in droplets,

indecipherable things.

I jotted down as much as I could without startling it.

Absent-mindedly I stopped before its echoes

without worrying if it was modulating ancient sound

or if its voice was already contaminated

by this hour filled with machines.

I heard it later, I kept hearing it for many days,

another bird or the same, I didn't know,

a song hidden among the folds of the air.

I didn't even know if in its innocence

it was playing variations

on the sounds of hinges, bolts, screws,

the buzz of taxis as they come and go.

I don't know if it was inventing or translating.

I just got down one line of its shadow

without separating it from the wings.

Eugenio Montejo, Caracas Venezuela

Translated by Peter Boyle 


\section{Paranimfen}

Hanneke van Dijk-du Mortier Yvette Roke 



\section{Contents}

CHAPTER 1 Introduction

Part 1 - Meta-analyses

CHAPTER 2 Antipsychotic-induced tardive dyskinesia and the Ser9Gly polymorphism in the DRD3 gene: A meta-analysis

CHAPTER 3 Antipsychotic-induced tardive dyskinesia and polymorphic variations in COMT, DRD2, CYP1A2 and MnSOD genes: A meta-analysis of pharmacogenetic interactions

\section{Part 2 - Prospective naturalistic study}

Part 2a - Non-genetic risk factors

CHAPTER 4 Long-stay psychiatric patients: A prospective study revealing persistent antipsychotic-induced movement disorder

CHAPTER 5 Predicting the incidence of antipsychotic-induced movement disorders in long-stay patients: A prospective study

\section{Part 2b - Genetic risk factors}

CHAPTER 6 Candidate gene-based association study of antipsychoticinduced movement disorders in long-stay psychiatric patients: A prospective Study

CHAPTER 7 Antipsychotic-induced movement disorders in long-stay psychiatric patients and 45 tag single nucleotide polymorphisms (SNPs) in 7 candidate genes: A prospective study

CHAPTER 8 Discussion/conclusion 


\section{Chapter 1}

\section{Introduction}


Antipsychotics remain the basic arsenal for the treatment of psychotic disorders. However, they may induce a number of side effects, one of which is movement disorders. Antipsychotic-induced movement disorders constitute a major reason for non-compliance, which results in an increased risk of psychotic relapse (Casey, 2006; Lambert et al., 2004;Robinson et al., 2002). Furthermore, a meta-analysis (Ballesteros et al., 2000) and two recent studies have found a higher mortality in patients with tardive dyskinesia (TD) in particular (Chong et al., 2009; Dean and Thuras, 2009).

\section{Long-stay patients with chronic mental illness}

A high risk group for movement disorders consists of patients with chronic mental illness and therefore chronically exposed to antipsychotic medication, particularly long-stay patients (i.e. patients institutionalized for long periods) with supervised medication regimes (Bakker et al., 2011). Polypharmacy, in the form of combinations of first and second generation antipsychotics (FGAs and SGAs respectively), appear to be commonplace in tertiary psychiatric settings (Procyshyn et al., 2001). Broekema and colleagues (2007) reported that prescribing combinations of SGAs and FGAs and/or anticholinergics is a widespread practice, which observation supports the contention that SGA monotherapy may be inadequate to treat a significant number of patients in clinical practice, and that polypharmacy strategies, which entail a high risk of movement disorders (Taylor, 2010), remain common.

Although long-stay settings are not mainstream, the reality is that a considerable number of patients with severe and chronic mental illness are hospitalized long-term (Fisher et al., 2001). In the U.S., over 200 state hospitals care for a smaller but challenging patient population (Fisher et al., 2009). Furthermore, the findings are likely to apply to the considerably larger group of patients who live in supervised residential settings.

Following this logic, there is all the more reason to conduct a prospective study of movement disorders in the population currently most at risk: long-stay patients with chronic mental illness requiring long-term antipsychotic treatment.

\section{Second generation antipsychotics and movement disorders}

Factor and colleagues (2005) contend that movement disorders have been rather neglected since the introduction of these modern, possibly safer, antipsychotics, with a regrettable, wrong presumption that movement disorders had disappeared. 
While SGAs may be associated with a lower incidence of movement disorders, these medications nevertheless still carry risk (Kahn et al., 2008;Miller et al., 2008;Rosenheck et al., 2003;Lewis and Lieberman, 2008;Leucht et al., 2009a;Tenback et al., 2005;Lieberman et al., 2005;Correll et al., 2004; Jones et al., 2006;Weiden, 2007). For patients on long-term treatment with FGAs, the reported prevalence of antipsychotic-induced movement disorders was around 50 to 75\% (Janno et al., 2004;van Harten, 1998). Eleven long-term studies of SGAs (except clozapine) indicate that SGA reduced the risk of drug-induced movement disorder, but did not, as had been anticipated, eliminate them (Correll and Schenk, 2008). These studies had several limitations, such as a lack of equivalent dosage of haloperidol in the control arm, high drop-out rates, short study duration, and unreliable measurement of movement disorders. Three large, non-commercially funded trials comparing FGAs and SGAs published in the last five years found differences in the incidence of parkinsonism and akathisia, but no clear differences in the incidence of TD (CATIE, Cutlass and EUFEST trial) (Casey, 2006; Jones et al., 2006;Kahn et al., 2008;Lieberman et al., 2005). However, these studies also had methodological limitations, such as a relatively short time to detect TD (around one year), high drop-out rates, and, in the Cutlass trial, many patients in the FGA group were treated with sulpiride, which has a lower incidence of movement disorders and is classified by some researchers as an SGA. A recent prospective cohort study with TD as primary outcome found no significant difference in the incidence of TD between patients taking FGAs and SGAs (Woods et al., 2010). Leucht and colleagues (2009b) demonstrated that SGAs are a heterogeneous group, each agent displaying its own particular properties. Furthermore, from a global perspective, the three antipsychotic drugs listed in the most recent (Index 2011) World Health Organization Model List of Essential Medicines are FGAs, namely chlorpromazine, fluphenazine and haloperidol (http://www.who.int/medicines/en).

\section{Genetic studies}

\section{Pharmacogenetics and pharmacogenomics}

The key problem of drug safety and efficacy is the complex interplay of environmental and genetic factors. Since the mid-1980s the main question is no longer whether human drug responses are genetically controlled, but rather the extent to which they are. Pharmacogenetics bridges the gap between pharmacology and genetics (Weber, 2008)(p389). Pharmacogenetics is defined as "the study of genetically determined interindividual differences in response to drugs," pharmacogenomics as "the use of genome-based technologies in drug development." The fields overlap and the terms are used interchangeably. Still, they should be distinguished from each other, as pharmacogenetics focuses on 
the association between drug effects and the genetic profile of individuals, whereas pharmacogenomics starts from the human genome sequence resulting in the development of novel pharmacological agents (Lerer, 2002)(p6).

Pharmacogenetics explores pharmacokinetic and pharmacodynamic genetic factors, i.e. genetic based differences in processes affecting the drug bioavailability and genetic based differences in the proteins at which a drug acts on, respectively. Both factors are (interactively) responsible for the drug effect within an individual (Lerer, 2002)(p8).

Pharmacogenetic studies may identify genetic risk factors which underlie individual differences in response to antipsychotics (Reynolds, 2007;0hmori et al., 2003;Lerer, 2002), in theory paving the way for individually tailored medication prescriptions (Lerer and Segman, 2006).

\section{Population-based association study of complex genetic disorders}

\section{Background}

Genes are small units of DNA which usually code the makeup of a protein sequence or, in the case of non-coding RNA genes, regulate gene expression. Alleles are alternative forms of a gene. Each person has two alleles at each location of the gene; one inherited from the mother and the other from the father, except for mitochondrial DNA, which is inherited only from the mother. The sequence of base-pairs on DNA strands shows variations in human population and concerns differences between individuals in a single base (i.e. single nucleotide polymorphisms, SNPs), insertion/deletion, sequence repeats, or concerns larger sequences of DNA strands. DNA variations which occur in $1 \%$ or more in the population are called polymorphisms and are considered normal variations in a gene, whereas frequencies lower than $1 \%$ are called mutations (Faraone et al., 1999;Gelehrter et al., 1998; Van Waarde et al., 2002). Most polymorphisms do not result in changes in gene function or protein product; however others which do are called variants affecting protein structure or expression (VAPSE), e.g., catechol-0-methyltransferase (COMT) val158met genotypes associated with cerebral COMT activity.

Population-based association studies examine specific genes that may play a role in the etiology of a particular disorder. These 'candidate genes' are selected on a theoretical basis. Using a case-control design, associations are found through examination of the allele distribution in candidate genes. Any association suggests an etiologic involvement of the gene variant in the disorder. However, significant associations in studies of complex genetic disorders such as schizophrenia are difficult to replicate owing to genetic methodological problems, such as sample heterogeneity, small effects of multiple genes, (epi) genetic interactions, pleiotropy, and small sample size (Abdolmaleky et al., 2005). 
Given that a risk of TD/movement disorders is believed to be associated with schizophrenia (Koning et al., 2010;van Harten and Tenback, 2009;van Os et al., 1997), genes related to schizophrenia are attractive candidates for studying the genetic origins of TD/movement disorders.

\section{Movement disorders}

Antipsychotic-induced movement disorders (Owens, 1999;Factor et al., 2005) can be divided into acute syndromes, such as parkinsonism and akathisia, that occur within hours/days or weeks after initiating antipsychotic treatment or increasing the antipsychotic dose (or cessation of anticholinergics), and tardive syndromes, such as TD and tardive dystonia, that develop after months or years of treatment. Given that combinations of acute and chronic movement disorders occur in patients undergoing long-term treatment with antipsychotics, prediction models should include both syndromes, i.e., the four major types of movement disorders (TD, parkinsonism, akathisia and tardive dystonia).

Initially, the term 'tardive' (delayed) was introduced to emphasize the lateonset types of movement disorders occurring during antipsychotic use. Yet the definition of tardive disorders in the current study emphasizes their persistence, which is clinically more important than their late-onset (Sachdev, 2005; Factor et al., 2005).

Here follows the case definitions of movement disorders used in the current study:

Dyskinesia (APA, 1992) was defined as hyperkinetic choreiform involuntary movements which often fluctuates in severity. TD was assessed with the Abnormal Involuntary Movement Scale (AIMS) (Guy, 1975;Guy, 1976) and case definition was based on Schooler and Kane criteria (Schooler and Kane, 1982), requiring (i) the presence of moderate dyskinesia in at least one body area or mild dyskinesia in at least two body parts, and (ii) the absence of other conditions which result in abnormal involuntary movements.

Antipsychotic-induced parkinsonism (AIP) is clinically similar to Idiopathic Parkinson disease with the following core features: tremor, rigidity, bradykinesia (Owens, 1999) and postural instability (Factor et al., 2005). Parkinsonism was assessed with the Unified Parkinson Disease Rating Scale (UPDRS) (Fahn and Elton, 1987). A case definition of parkinsonism was based on (i) 'mild' expression of rest tremor or rigidity as both of these are typical of parkinsonism, and (ii) if no tremor or rigidity was rated, the cut-off point was one rating of 'moderate' or two ratings of 'mild' on items of bradykinesia and postural stability. The more stringent criteria for items of bradykinesia and postural stability were chosen as these symptoms may be a reflection of psychiatric syndromes or sedation instead. Besides this definition, another case definition of parkinson- 
ism was applied in accordance with the UK Brain Bank definition, using a score of 2 in the bradykinesia items of the motor UPDRS, and a score of 1 in the items rest tremor, rigidity, or postural instability of the motor UPDRS.

Akathisia (Factor et al., 2005) was defined as both a subjective inner feeling of restlessness and objective motor (leg) movements. A case definition of akathisia was based on a rating of at least 'mild' on the global akathisia item. Akathisia was assessed with the Barnes Akathisia Rating Scale comprising an objective and a subjective item (Barnes, 1989).

Dystonia was defined as a syndrome of sustained muscle contraction, frequently causing twisting and repetitive movements or abnormal postures (van Harten and Kahn, 1999). Tardive dystonia was diagnosed, in accordance with Burke's criteria (Burke, 1992), if contraction was rated at least 'mild' in one body area or else 'slight' in two or more body areas on the Fahn-Marsden scale (Burke et al., 1985). As frequent eye-blinking (rating of 'mild' on the item 'eye') has many causes, case definition of tardive dystonia required a rating of at least 'moderate' blepharospasm if 'eye' was the only symptom area.

In addition, subtypes of movement disorders were assessed using (i) the Abnormal Involuntary Movement Scale (AIMS) (Guy, 1975;Guy, 1976) with items 1-4 for orofacial and items 5-7 for limb truncal dyskinesia, (ii) the Unified Parkinson Disease Rating Scale (UPDRS) (Fahn and Elton, 1987) with item c3-c4 for 'rest tremor' (rest tremor, and action/postural tremor of hands); item c5 for rigidity; and items c1, c2, c6-c12, and c14 for bradykinesia. This approach has been described previously by 3 members of our research team (AAH, JvO and PvH) (Al Hadithy et al., 2009; Wilffert et al., 2009;Al Hadithy et al., 2008).

To determine the association between the combined movement disorder and variation in candidate genes, a principal-factor of the four major types of movement disorders and subtypes of TD and parkinsonism was calculated.

\section{Aims and outline of this thesis}

The overall aim of this thesis was to assess the frequency and the genetic and non-genetic risk factors of drug-induced movement disorders in long-stay patients with chronic mental illness and long-term antipsychotic treatment. Its prospective design extends hitherto cross-sectional work in the field of antipsychotic-induced movement disorders. Indeed, prospective assessment of both persistent and fluctuating (repeated) movement disorders measures the phenotype more specifically and that increases the validity of the associations between movement disorders and risk factors. 
The study was divided into two parts:

\section{Part 1 - Meta-analyses}

Meta-analyses were conducted of the genes that are thought to be associated with TD, namely DRD3 (Chapter 2), COMT, DRD2, CYP1A2, and MnSOD (Chapter 3).

\section{Part 2 - Prospective naturalistic study}

In keeping with the aim of this thesis, a 4-year prospective naturalistic study (July 2003 - May 2007) was conducted with 209 patients with chronic mental illness in order to determine the frequency of the four major types of movement disorders (TD, parkinsonism, akathisia, and tardive dystonia) and the genetic and non-genetic risk factors of incident movement disorders. To this end, a cohort was drawn from patients in a general psychiatric hospital (GGZ Centraal, Amersfoort, the Netherlands). Inclusion criteria were minimum age of 18 years and cumulative exposure to antipsychotics of at least 1 year. Exclusion criteria were a history of neurological disorders affecting motor function. The cohort was representative of the population of patients with the most severe chronic mental illness requiring long-stay care, given that the hospital serves an epidemiological catchment area, is the only institute providing this type of care in this area, and patients were selected from a comprehensive list of all inpatients.

\section{Part 2a-Non-genetic risk factor}

Assesses the frequency of persistent movement disorders (Chapter 4), and the risk factors for incident movement disorders (Chapter 5).

The aim was to provide clinicians with risk information regarding new occurrences of movement disorders to prevention purposes in the population currently most at risk: long-stay patients with chronic mental illness requiring long-term antipsychotic treatment.

\section{Part 2b-Genetic risk factors}

Focuses on the genetic association between movement disorders and variations in 17 candidate genes. Specifically, Chapter 6 examines the association between the four major types of movement disorders (TD, parkinsonism, akathisia, and tardive dystonia), subtypes of TD (orofacial and limb truncal dyskinesia) and parkinsonism (rest tremor, rigidity, and bradykinesia), as well as a principalfactor of the movement disorders and subtypes on the one hand, and variation in 10 candidate genes (PPP1R1B, BDNF, DRD3, DRD2, HTR2A, HTR2C, COMT, $M n S O D, C Y P 1 A 2$, and $R G S 2$ ) on the other. Chapter 7 examines the association between the same disorders and variation in 7 (GRIN1B, GRIN1A, HSPG2, DRD3, HTR2C, DRD4, and NQO1). 
It can be hypothesized that specific subtypes of movement disorders are more suitable for genetic analysis than a general movement disorder syndrome, as subtypes may better reflect the underlying biological heterogeneity in complex syndromes.

\section{References}

Abdolmaleky, H.M., Thiagalingam, S. and Wilcox, M., 2005. Genetics and epigenetics in major psychiatric disorders: dilemmas, achievements, applications, and future scope. Am J Pharmacogenomics. 5, 149-160.

Al Hadithy, A.F., Wilffert, B., Bruggeman, R., Stewart, R.E., Brouwers, J.R., Matroos, G.E., Hoek, H.W. and van Harten, P.N., 2009. Lack of association between antipsychotic-induced Parkinsonism or its subsymptoms and rs4606 SNP of RGS2 gene in African-Caribbeans and the possible role of the medication: the Curacao extrapyramidal syndromes study X. Hum Psychopharmacol. 24, 123-128.

Al Hadithy, A.F., Wilffert, B., Stewart, R.E., Looman, N.M., Bruggeman, R., Brouwers, J.R., Matroos, G.E., van Os, J., Hoek, H.W. and van Harten, P.N., 2008. Pharmacogenetics of parkinsonism, rigidity, rest tremor, and bradykinesia in African-Caribbean inpatients: differences in association with dopamine and serotonin receptors. Am J Med Genet B Neuropsychiatr Genet. 147B, 890-897.

APA, 1992. Tardive dyskinesia : a task force report of the American Psychiatric Association The American Psychiatric Association, Washington, p. 282.

Bakker, P.R., de Groot, I.W., van Os, J. and van Harten, P.N., 2011. Long-stay psychiatric patients: a prospective study revealing persistent antipsychotic-induced movement disorder. PLoS ONE. 6, e25588.

Ballesteros, J., Gonzalez-Pinto, A. and Bulbena, A., 2000. Tardive dyskinesia associated with higher mortality in psychiatric patients: results of a meta-analysis of seven independent studies. J Clin Psychopharmacol. 20, 188-194.

Barnes, T.R., 1989. A rating scale for drug-induced akathisia. Br J Psychiatry. 154, 672-6.

Broekema, W.J., de Groot, I.W. and van Harten, P.N., 2007. Simultaneous prescribing of atypical antipsychotics, conventional antipsychotics and anticholinergics-a European study. Pharm World Sci. 29, 126-130.

Burke, R.E., 1992. Neuroleptic-induced tardive dyskinesia variants. In: Lang A.E. and Weiner W.J. (Eds.), Drug-induced movement disorders, Futura publishing company, New York, pp. 167-98.

Burke, R.E., Fahn, S., Marsden, C.D., Bressman, S.B., Moskowitz, C. and Friedman, J., 1985. Validity and reliability of a rating scale for the primary torsion dystonias. Neurology. 35, 73-7.

Casey, D.E., 2006. Implications of the CATIE trial on treatment: extrapyramidal symptoms. CNS Spectr. 11, 25-31.

Chong, S.A., Tay, J.A., Subramaniam, M., Pek, E. and Machin, D., 2009. Mortality rates among patients with schizophrenia and tardive dyskinesia. J Clin Psychopharmacol. 29, 5-8.

Correll, C.U., Leucht, S. and Kane, J.M., 2004. Lower risk for tardive dyskinesia associated with second-generation antipsychotics: a systematic review of 1-year studies. Am J Psychiatry. 161, 41425.

Correll, C.U. and Schenk, E.M., 2008. Tardive dyskinesia and new antipsychotics. Curr Opin Psychiatry. 21, 151-156.

Dean, C.E. and Thuras, P.D., 2009. Mortality and tardive dyskinesia: long-term study using the US National Death Index. Br J Psychiatry. 194, 360-364.

Factor, S.A., Lang, A.E., and Weiner, W.J., 2005. Drug induced movement disorders, 2nd ed edn. Blackwell Futura, Malden, Mass. 
Fahn, S. and Elton, R., 1987. UPDRS Development Committee. Unified Parkinson's Disease Rating Scale. In: Fahn S, Marsden CD, Calne DB, Goldstein M, eds. Recent Developments in Parkinson's Disease. Florham Park, NJ: Macmillan, pp. 153-163.

Faraone, S.V., Tsuang, M.T. and Tsuang, B.W., 1999. Genetic of mental disorders The Guilford Press, New York.

Fisher, W.H., Barreira, P.J., Geller, J.L., White, A.W., Lincoln, A.K. and Sudders, M., 2001. Long-stay patients in state psychiatric hospitals at the end of the 20th century. Psychiatr Serv. 52, 10511056.

Fisher, W.H., Geller, J.L. and Pandiani, J.A., 2009. The changing role of the state psychiatric hospital. Health Aff (Millwood ). 28, 676-684.

Gelehrter, T.D., Collins, F.S. and Ginsburg, D., 1998. Principles of medical genetics, Second edition edn. Baltimore.

Guy, W., 1975. ECDEU assessment manual for psychopharmacology. Department of Health, Education and Welfare, Washington DC, pp. 534-537.

Guy, W., 1976. ECDEU assessment manual for psychopharmacology U.S. Dept. of Health, Education, and Welfare, Public Health Service, Alcohol, Drug Abuse, and Mental Health Administration, National Institute of Mental Health, Psychopharmacology Research Branch, Division of Extramural Research Programs, Rockville, Md, p. 603.

Janno, S., Holi, M., Tuisku, K. and Wahlbeck, K., 2004. Prevalence of neuroleptic-induced movement disorders in chronic schizophrenia inpatients. Am J Psychiatry. 161, 160-163.

Jones, P.B., Barnes, T.R., Davies, L., Dunn, G., Lloyd, H., Hayhurst, K.P., Murray, R.M., Markwick, A. and Lewis, S.W., 2006. Randomized controlled trial of the effect on Quality of Life of second- vs firstgeneration antipsychotic drugs in schizophrenia: Cost Utility of the Latest Antipsychotic Drugs in Schizophrenia Study (CUtLASS 1). Arch Gen Psychiatry. 63, 1079-1087.

Kahn, R.S., Fleischhacker, W.W., Boter, H., Davidson, M., Vergouwe, Y., Keet, I.P., Gheorghe, M.D., Rybakowski, J.K., Galderisi, S., Libiger, J., Hummer, M., Dollfus, S., Lopez-Ibor, J.J., Hranov, L.G., Gaebel, W., Peuskens, J., Lindefors, N., Riecher-Rossler, A. and Grobbee, D.E., 2008. Effectiveness of antipsychotic drugs in first-episode schizophrenia and schizophreniform disorder: an open randomised clinical trial. Lancet. 371, 1085-1097.

Koning, J.P., Tenback, D.E., van Os, J., Aleman, A., Kahn, R.S. and van Harten, P.N., 2010. Dyskinesia and parkinsonism in antipsychotic-naive patients with schizophrenia, first-degree relatives and healthy controls: a meta-analysis. Schizophr Bull. 36, 723-731.

Lambert, M., Conus, P., Eide, P., Mass, R., Karow, A., Moritz, S., Golks, D. and Naber, D., 2004. Impact of present and past antipsychotic side effects on attitude toward typical antipsychotic treatment and adherence. Eur Psychiatry. 19, 415-422.

Lerer, B. and Segman, R.H., 2006. Pharmacogenetics of antipsychotic therapy: pivotal research issues and the prospects for clinical implementation. Dialogues Clin Neurosci. 8, 85-94.

Lerer, B., 2002. Pharmacogenetics of psychotropic drugs Cambridge University Press, Cambridge, UK.

Leucht, S., Corves, C., Arbter, D., Engel, R.R., Li, C. and Davis, J.M., 2009a. Second-generation versus first-generation antipsychotic drugs for schizophrenia: a meta-analysis. Lancet. 373, 31-41.

Leucht, S., Kissling, W. and Davis, J.M., 2009b. Second-generation antipsychotics for schizophrenia: can we resolve the conflict? Psychol Med. 39, 1591-1602.

Lewis, S. and Lieberman, J., 2008. CATIE and CUtLASS: can we handle the truth? Br J Psychiatry. 192, 161-163.

Lieberman, J.A., Stroup, T.S., McEvoy, J.P., Swartz, M.S., Rosenheck, R.A., Perkins, D.O., Keefe, R.S., Davis, S.M., Davis, C.E., Lebowitz, B.D., Severe, J. and Hsiao, J.K., 2005. Effectiveness of antipsychotic drugs in patients with chronic schizophrenia. N Engl J Med. 353, 1209-1223.

Miller, D.D., Caroff, S.N., Davis, S.M., Rosenheck, R.A., McEvoy, J.P., Saltz, B.L., Riggio, S., Chakos, M.H., Swartz, M.S., Keefe, R.S., Stroup, T.S. and Lieberman, J.A., 2008. Extrapyramidal side-effects of antipsychotics in a randomised trial. Br J Psychiatry. 193, 279-288. 
Ohmori, O., Shinkai, T., Hori, H., Matsumoto, C. and Nakamura, J., 2003. A perspective on molecular genetic studies of tardive dyskinesia: one clue for individualized antipsychotic drug therapy. Prog Neuropsychopharmacol Biol Psychiatry. 27, 581-586.

Owens, D.G.C., 1999. A guide to the extrapyramidal side-effects of antipsychotic drugs Cambridge University Press UK, New York, p. 351.

Procyshyn, R.M., Kennedy, N.B., Tse, G. and Thompson, B., 2001. Antipsychotic polypharmacy: a survey of discharge prescriptions from a tertiary care psychiatric institution. Can J Psychiatry. 46, 334-339.

Reynolds, G.P., 2007. The impact of pharmacogenetics on the development and use of antipsychotic drugs. Drug Discov Today. 12, 953-959.

Robinson, D.G., Woerner, M.G., Alvir, J.M., Bilder, R.M., Hinrichsen, G.A. and Lieberman, J.A., 2002. Predictors of medication discontinuation by patients with first-episode schizophrenia and schizoaffective disorder. Schizophr Res. 57, 209-219.

Rosenheck, R., Perlick, D., Bingham, S., Liu-Mares, W., Collins, J., Warren, S., Leslie, D., Allan, E., Campbell, E.C., Caroff, S., Corwin, J., Davis, L., Douyon, R., Dunn, L., Evans, D., Frecska, E., Grabowski, J., Graeber, D., Herz, L., Kwon, K., Lawson, W., Mena, F., Sheikh, J., Smelson, D. and Smith-Gamble, V., 2003. Effectiveness and cost of olanzapine and haloperidol in the treatment of schizophrenia: a randomized controlled trial. Jama. 290, 2693-2702.

Sachdev, P.S., 2005. Neuroleptic-induced movement disorders: an overview. Psychiatr Clin North Am. 28, 255-74, $\mathrm{x}$.

Schooler, N.R. and Kane, J.M., 1982. Research diagnoses for tardive dyskinesia. Arch Gen Psychiatry. 39, 486-7.

Taylor, D., 2010. Antipsychotic polypharmacy - confusion reigns. The Psychiatrist. 34, 41-43.

Tenback, D.E., van Harten, P.N., Slooff, C.J., Belger, M.A. and van Os, J., 2005. Effects of antipsychotic treatment on tardive dyskinesia: a 6-month evaluation of patients from the European Schizophrenia Outpatient Health Outcomes (SOHO) Study. J Clin Psychiatry. 66, 1130-1133.

van Harten, P.N., 1998. Movement disorders associated with neuroleptics : the Curacao extrapyramidal syndromes study Utrecht, p. 124.

van Harten, P.N. and Kahn, R.S., 1999. Tardive dystonia. Schizophr Bull. 25, 741-8.

van Harten, P.N. and Tenback, D.E., 2009. Movement disorders should be a criterion for schizophrenia in DSM-V. Psychol Med. 39, 1754-1755.

van Os, J., Fahy, T., Jones, P., Harvey, I., Toone, B. and Murray, R., 1997. Tardive dyskinesia: who is at risk? Acta Psychiatr Scand. 96, 206-16.

Van Waarde, J.A., de Rijk, R.H. and Zitman, F.G., 2002. Genomics en psychiatrie: geen gemakkelijk huwelijk. Tijdschrift voor psychiatrie. 44, 560.

Weber, W.W., 2008. Pharmacogenetics, 2nd ed edn. Oxford University Press, Oxford.

Weiden, P.J., 2007. EPS profiles: the atypical antipsychotics are not all the same. J Psychiatr Pract. 13, 13-24.

Wilffert, B., Al Hadithy, A.F., Sing, V.J., Matroos, G., Hoek, H.W., van Os, J., Bruggeman, R., Brouwers, J.R. and van Harten, P.N., 2009. The role of dopamine D3, 5-HT2A and 5-HT2C receptor variants as pharmacogenetic determinants in tardive dyskinesia in African-Caribbean patients under chronic antipsychotic treatment: Curacao extrapyramidal syndromes study IX. J Psychopharmacol. 23, 652-659.

Woods, S.W., Morgenstern, H., Saksa, J.R., Walsh, B.C., Sullivan, M.C., Money, R., Hawkins, K.A., Gueorguieva, R.V. and Glazer, W.M., 2010. Incidence of tardive dyskinesia with atypical versus conventional antipsychotic medications: a prospective cohort study. J Clin Psychiatry. 



\section{Part 1 - Meta-analyses}




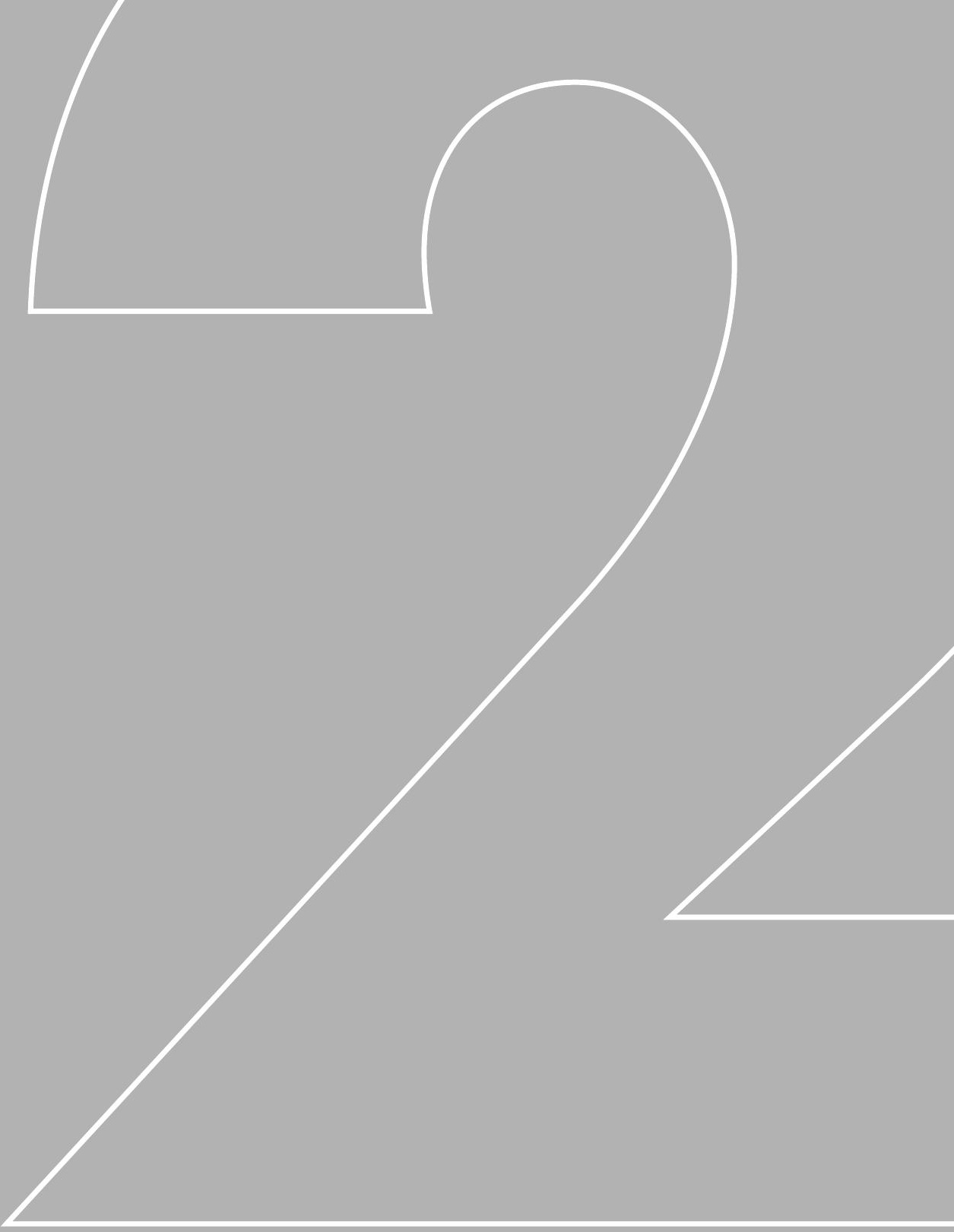




\title{
Chapter 2
}

\section{Antipsychotic-induced tardive dyskinesia and the Ser9Gly polymorphism in the DRD3 gene: A meta-analysis}

\author{
P. Roberto Bakker a, Peter N. van Harten a, Jim van Os b,c \\ ${ }^{\text {a }}$ Psychiatric Hospital Symfora Group, Amersfoort, The Netherlands \\ ${ }^{\mathrm{b}}$ Department of Psychiatry and Neuropsychology, South Limburg Mental Health Research and \\ Teaching Network, EURON, Maastricht University, Maastricht, The Netherlands \\ ${ }^{\mathrm{c}}$ Division of Psychological Medicine, Institute of Psychiatry, De Crespigny Park, London, UK
}

Schizophrenia Research 2006; 83(2-3): 185-192 


\section{Abstract}

\section{Background}

A polymorphic site in the gene encoding the dopamine 3 receptor (DRD3) resulting in a serine (Ser) into glycine (Gly) substitution has been shown to affect dopamine binding affinity, and may contribute to individual differences in susceptibility to antipsychotic-induced tardive dyskinesia (TD).

\section{Methods}

A Medline, EMBASE and PsychINFO search of literature published between 1976 and March 2005 yielded 11 studies from which data were extracted for calculation of pooled estimates using meta-analytic techniques.

\section{Results}

The Gly allele increased the risk relative to the Ser allele $(\mathrm{OR}=1.17 ; 95 \% \mathrm{CI}$ : 1.01-1.37) with evidence of publication bias. No significant genotype effects were apparent.

\section{Conclusions}

TD may be associated with functional variation in the DRD3 allele. However, caution is required in interpreting this finding, as there is evidence of publication bias, genetic methodology has shortcomings, and the relation between antipsychotics, schizophrenia and TD is complex.

\section{Keywords}

(Genetic) polymorphism; Extrapyramidal (syndrome/disorder); Tardive dyskinesia; Drug-induced; Antipsychotic; Dopamine 3 receptor. 


\section{Introduction}

Treatment with antipsychotic drugs is associated with tardive dyskinesia (TD), a potentially irreversible side effect that can be very distressing for patients due to motor performance difficulties, social stigmatization and poorer quality of life (Marsalek, 2000). TD is characterized by hyperkinetic involuntary movements of the choreoathetoid type with a fluctuating intensity in time (Sachdev, 2005). Most common are oro-facial and limb-truncal dyskinesia (Muller et al., 2004).

Since not all patients exposed to antipsychotics develop TD, research of risk factors is important. Although a lower incidence of TD is observed with the second generation antipsychotics (SGAs), they still carry a risk of movement disorder (Tenback et al., 2005; Correll et al., 2004). In addition, many patients continue to take first generation antipsychotics (FGAs) in combination with SGAs (Procyshyn et al., 2001).

Reported prevalence rates of TD vary widely with a median rate of $24 \%$ (Yassa and Jeste, 1992). The cumulative incidence rates are around 3-5\% in the first years, reaching a plateau at about 20-25\% (Sachdev, 2005; Jeste et al., 1995). Dosage, cumulative amount of antipsychotic treatment and drugintervals correlate positively with the prevalence and severity of TD (Friedman, 2004; Marsalek, 2000; van Harten et al., 1998).

Older age is the most important risk factor with a five to six times higher incidence of TD compared to younger patients (Jeste et al., 1995). Similarly, cognitive impairment also increases the risk (Waddington and Youssef, 1996), as does female sex in older age groups ( $>50$ years) and male sex in younger age groups (van Os et al., 1999). There is some evidence of a higher risk of TD in African-Caribbean and African-American populations and a lower risk in Chinese and other Asian populations (Sachdev, 2005; Glazer et al., 1994). Patients with affective disorders may be more susceptible to (more severe) TD compared to patients with other diagnoses (Kane et al., 1985), as are patients with diabetes mellitus or patients with a family member suffering from diabetes (Mukherjee and Mahadik, 1997). Furthermore, negative symptoms may be associated with a higher risk (van Os et al., 2000), as are the use of drugs and alcohol (Sachdev, 2005).

Some studies support familiality of the TD phenotype in that untreated siblings of schizophrenic patients may have a higher rate of abnormal movements (Lencer et al., 2004; McCreadie et al., 2003; Muller et al., 2001), but this evidence cannot be considered conclusive. However, as drug-related factors predict only a minor part of the variance in the development of TD, an important role for pharmacogenetic interactions can be hypothesized (Lerer, 2002).

Different candidate genes have been investigated that may be related to increased liability for TD, such as i) genes coding for the cytochrome P 450 2D6, $1 \mathrm{~A} 2$ and $3 \mathrm{~A} 4$ that are involved in the metabolism of antipsychotics (Patsopoulos et al., 2005; Tiwari et al., 2005a,b), ii) genes coding for free radical scavenging 
enzymes like manganese super oxide dismutase (Zhang et al., 2003), iii) genes coding for the dopamine 2 and 3 receptors as well 5-HT2A and -2C receptors (Lattuada et al., 2004; Basile et al., 2002; Kaiser et al., 2002).

Data from pharmacological and neuroimaging studies suggest dysregulation of the dopamine system in schizophrenia. This provides a rationale for the study of genes involved in dopamine signalling (Hoogendoorn et al., 2005). Several dopamine receptors have been examined and the $\mathrm{D}_{2}$-like dopamine 3 receptor (DRD3) is of particular interest because of its high density in areas thought to be implicated in schizophrenia (Lerer, 2002). Furthermore, the gene encoding DRD3 has one polymorphic site, resulting in a serine (Ser) to glycine (Gly) substitution causing significantly higher dopamine binding affinity (Lundstrom and Turpin, 1996). Various meta-analyses indeed showed a small but significant association between this DRD3 polymorphism and schizophrenia. Other polymorphisms in or near DRD3 did not result in significant associations with schizophrenia although haplotype-based association studies showed a trend among Japanese and UK patients (Jonsson et al., 2003).

The relation between DRD3 and TD is biologically plausible because DRD3 is selectively expressed in the ventral striatum and pallidum, a brain region implicated in motor function (Suzuki et al., 1998). DRD3 agonists inhibit locomotor brain activity, whereas DRD3 antagonists exert opposite effects (Accili et al., 1996). Although these conclusions are obtained from in vitro studies, they nevertheless provide an attractive hypothesis for genetic sources of variability in susceptibility to TD (Lerer et al., 2002; Basile et al., 1999). Given the fact that part of the risk for TD is thought to be associated with the illness itself (van Os et al., 1997), the Ser to Gly substitution polymorphism in DRD3 is an attractive candidate for study in the context of TD.

The DRD3 Ser9Gly polymorphism to date remains the only site within DRD3 that has been studied in relation to the risk of TD. Steen et al. (1997) showed a significant excess of Gly-allele and Gly-Gly homozygotes in patients with schizophrenia and TD, which was confirmed in other work (Lerer et al., 2002; Basile et al., 1999), whereas Segman et al. (1999) and Liao et al. (2001) showed an association between TD and Ser-Gly heterozygotes. These associations were not confirmed in subsequent reports (Lattuada et al., 2004; Liou et al., 2004; Zhang et al., 2003; Garcia-Barcelo et al., 2001; Rietschel et al., 2000; Lovlie et al., 2000; Inada et al., 1997). Chong and colleagues (2003) reported a negative association between TD and the Gly-allele.

Because the above mentioned data suggest a polygenic, multifactorial inheritance for the development of TD, with likely small true effect sizes, and given the fact that sample sizes are small in most studies, meta-analytic techniques applied to pooled data are necessary in order to examine the association between Ser9Gly polymorphism and TD. 


\section{Methods}

\section{Literature search}

A systematic literature review was conducted from 1976 to march 2005, with the help of Medline, EMBASE and PsychINFO using key words (genetic) polymorphism, extrapyramidal (syndrome/disorder), tardive dyskinesia, drug-induced, antipsychotic(s), adverse effect/event, dopamine 3 receptor. In addition, all relevant references cited in these articles were also investigated.

\section{Inclusion and exclusion criteria}

Only those studies examining associations with the Ser9Gly polymorphism in DRD3 and antipsychotic-induced TD were included. One study with clozapine alone and one of TD without antipsychotics were excluded given the very low risk for TD in these studies (Lovlie et al., 2001; Gaitonde et al., 1996). Four abstracts presented during meetings without subsequent publication were not included.

\section{Statistics}

Analyses were conducted using the METAN routine of the STATA statistical program [Stata-Corp (2002): STATA Statistical Software: Release 8.0. Texas: College Station], version 8, providing pooled estimates, confidence limits, and a test that the true pooled effect is zero, obtained from fixed and random-effects meta-analysis. A test for heterogeneity between studies and an estimator of between studies variance is provided. Pooled odds ratios (OR) were calculated by providing, for each study, the number of individuals in each of the four cells made up by the combination of a binary exposure (the genetic polymorphism) and a binary outcome (TD or not). Comparisons were conducted comparing both genotypes (with Ser-Ser genotype as reference category) and allelotypes (with Ser allelotype as reference category). Allele frequencies given genotypic frequencies of $\mathrm{a} 1 \mathrm{a} 1, \mathrm{a} 2 \mathrm{a} 1$ and $\mathrm{a} 2 \mathrm{a} 2$ were calculated as follows: frequency $\mathrm{a} 1=$ $2 *(\mathrm{a} 1 \mathrm{a} 1)+(\mathrm{a} 1 \mathrm{a} 2) ;$ frequency $\mathrm{a} 2=2 *(\mathrm{a} 2 \mathrm{a} 2)+(\mathrm{a} 1 \mathrm{a} 2)$.

For studies reporting on non-overlapping samples within one study, for example because of stratification for duration of illness, samples were entered separately into the meta-analysis. Meta-analytic results were assessed for heterogeneity in effect sizes between studies, and Egger's test for publication bias was carried out using the STATA METABIAS routine, yielding a regression coefficient (B) representing the bias estimate. Both fixed and random-effects methods were used with results being inspected for discrepancies, as recommended by the Cochrane Collaboration (http://www.cochrane-net.org/openlearning/HTML/mod13-4.htm). 


\section{Results}

\section{Studies included}

The search yielded 13 studies. Two studies could not be included either because categorical data were not used (Basile et al., 1999) or data were not reported (Lattuada et al., 2004). In one study (Rietschel et al., 2000) patients were subtyped with respect to duration of the psychiatric illness. To avoid overlap between the subgroups we selected one population, with the largest sample size for the maximum power. As the study of Steen et al. (1997) consisted of a crosssectional and longitudinal part, the 11 remaining studies yielded 12 samples for the meta-analysis (Table 1).

All groups (with and without TD) were in Hardy Weinberg equilibrium (HWE), except for the TD-group in the study of Segman et al. (1999). The study of Woo et al. (2002) did not provide information on HWE. Taking the allelic and genotypic part of the association studies together, a significant association was found between the DRD3 Ser9Gly polymorphism and TD in 5 of 12 samples. DRD3 genotype accounted for $5.2 \%$ to $30 \%$ of the explained variance in total AIMS scores (Basile et al., 1999; Segman et al., 1999). A meta-analysis of the 12 samples, yielding a total of 695 patients with TD and 915 without, was conducted (Liou et al., 2004; Chong et al., 2003; Zhang et al., 2003; Woo et al., 2002; Liao et al., 2001; Garcia-Barcelo et al., 2001; Rietschel et al., 2000; Lovlie et al., 2000; Segman et al., 1999; Steen et al., 1997; Inada et al., 1997).

\section{Heterogeneity and bias}

No significant heterogeneity was apparent for the allele analyses $\left(\chi^{2}=13.73, d f\right.$ $=11, P=0.248)$ and for the Ser-Ser versus Gly-Gly comparison $\left(\chi^{2}=16.84, d f=\right.$ $11, P=0.113)$. Heterogeneity was apparent for the Ser-Ser versus Ser-Gly comparison $\left(\chi^{2}=21.39, d f=11, P=0.030\right)$, which disappeared $\left(\chi^{2}=13.23, d f=9, P=\right.$ 0.15 ) after excluding two studies with very high effect sizes (ORs greater than 6.0 and 15.0 respectively). Egger's test showed evidence of publication bias within the allele analysis $(B=-1.82,95 \% \mathrm{CI}:-3.61$ to $-0.04, P=0.046)$, but not for the genotype analyses $(B=0.90,95 \% \mathrm{CI}:-0.27-2.06, P=0.115$ and $B=-0.44$, 95\% CI: $-1.79-0.91, P=0.478$ respectively).

\section{Meta-analytic results}

The fixed-effects model pooled odds ratio for the Gly variant versus the Ser variant was 1.17 (95\% CI: 1.01-1.37; $P=0.041$ ) (Fig. 1) which concurred with the random-effects model (OR $=1.21 ; 95 \% \mathrm{CI}: 1.01-1.44 ; P=0.036)$. Two studies showed an opposite tendency where the Gly-allele was a protective factor for TD (Chong et al., 2003; Rietschel et al., 2000). 


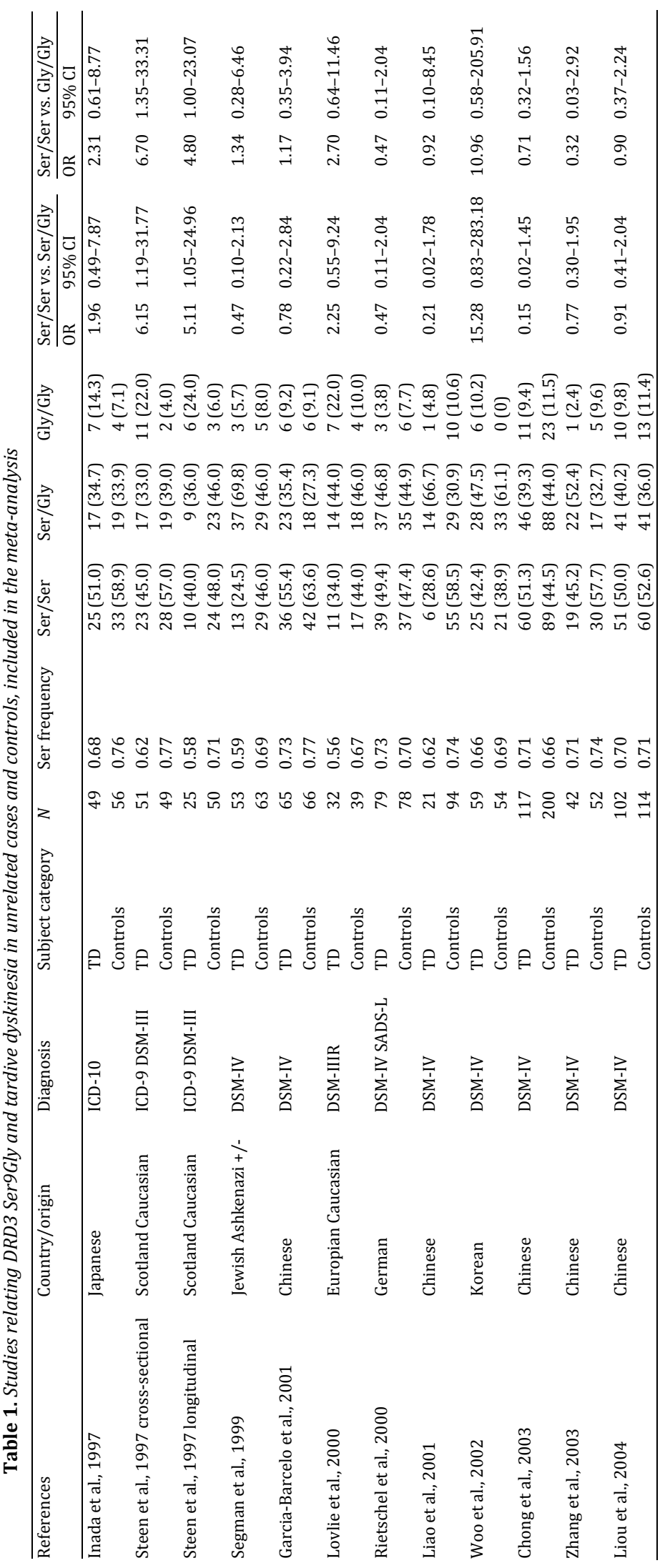




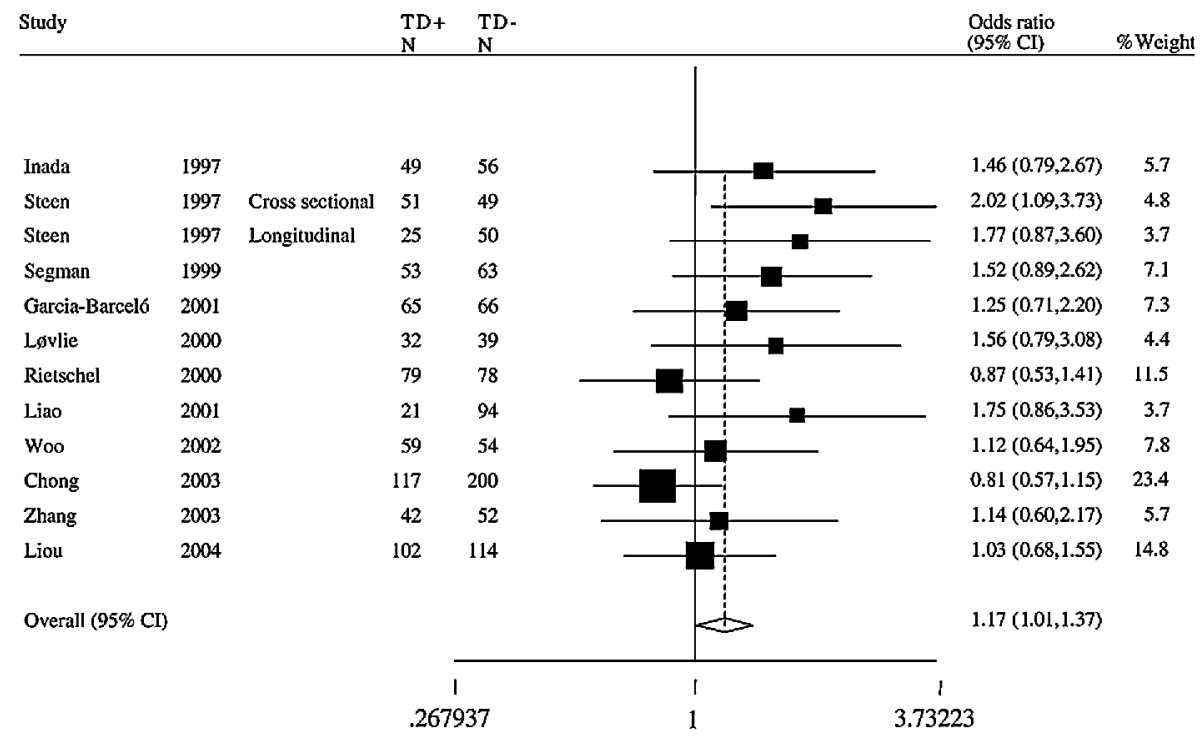

Figure 1. Meta-analysis: odds ratios (OR) and 95\% confidence intervals (CI) for tardive dyskinesia (TD) among carriers of the Ser9Gly allele in 12 samples included in the pooled analysis. Pooled OR= 1.17 (95\% CI: 1.01-1.37; $P=0.041$ ) in fixed effects model.

Using Ser-Ser homozygotes as the reference category, the pooled odds ratio was 1.11 (95\% CI: 0.78-1.58; $P=0.571$ ) for Gly-Ser heterozygotes and 1.33 (95\% CI: 0.93-1.90; $P=0.119$ ) for the Gly-Gly homozygotes using the fixed-effects model, and 1.12 (95\% CI: 0.63-2.01; $P=0.699$ ) for Gly-Ser heterozygotes and 1.40 (95\% CI: $0.84-2.32$; $P=0.199$ ) for the Gly-Gly homozygotes using the random effects model. Seven studies showed an opposite tendency where the Gly-allele was a protective factor for TD in a comparison between Ser-Ser homozygotes and heterozygotes, and five studies between the homozygotes (Liou et al., 2004; Chong et al., 2003; Zhang et al., 2003; Liao et al., 2001; Garcia-Barcelo et al., 2001; Rietschel et al., 2000; Segman et al., 1999).

\section{Discussion}

A meta-analysis of the association between the DRD3 Ser9Gly polymorphism and TD showed a risk-increasing effect of the Gly versus the Ser variant. However, there was some evidence of publication bias. We did not detect an association with genotypes possibly because genetic studies of small effect size usually need larger samples than the studies included in this meta-analysis typically had available. Furthermore, the inconclusive genotypic results may be due to ethnic diversity, given the fact that a result in the opposite direction as found in this 
meta-analysis (i.e. Gly is protective instead of risk-increasing) was reported in two studies including Asian subjects. Indeed, in a post-hoc stratified analysis of Gly versus Ser, a pooled OR of 1.07 (95\% CI: 0.88-1.29; $P=0.49$ ) was found in all studies including Asians $(n=1091)$, whereas in non-Asians $(n=519)$ the pooled OR was 1.39 (95\% CI: 1.07-1.81; $P=0.01$ ), both without evidence of heterogeneity $\left(\chi^{2}=6.09, d f=6, P=0.41\right.$ respectively $\left.\chi^{2}=5.65, d f=4, P=0.23\right)$. The reduced or even opposite tendency in Asians may reflect a different phenotypic expression of DRD3 or the existence of a true pathogenic mutation close to DRD3 which differs between these two ethnic groups. Moreover, the frequency of the Gly variant is higher in Chinese patients than in Whites (Chong et al., 2003).

Apart from differences between studies, covert ethnic stratification may exist within a defined ethnic population resulting in spurious association due to differences in allele frequencies and risk of TD. Therefore, it is preferable that association studies are replicated using within-family control methodology (transmission/disequilibrium test) (Thomas, 2004), as this was not used in any of the studies of DRD3 and TD.

Although the significant association between TD and DRD3 was small, a genetic factor may well exist. Future genetic research into antipsychotic-induced EPS will take advantage of new genomic knowledge, new statistical methods and more efficient methods of genotyping.

With the expanding numbers of single nucleotide polymorphisms, more effective linkage and association studies will be possible. Pharmacogenetics may increase our understanding of the pathogenesis and risk factors of EPS, and can contribute to the development of psychopharmacotherapeutics that are applicable at the level of the individual patient (Lerer, 2002).

\section{Acknowledgment}

This work was supported by grant from the Foundation "the Open Ankh", the Netherlands.

The authors thank Erik de Groot, MSc, for his assistance.

\section{References}

Accili, D., Fishburn, C.S., Drago, J., Steiner, H., Lachowicz, J.E., Park, B.H., Gauda, E.B., Lee, E.J., Cool, M.H., Sibley, D.R., Gerfen, C.R., Westphal, H., Fuchs, S., 1996. A targeted mutation of the D3 dopamine receptor gene is associated with hyperactivity in mice. Proc. Natl. Acad. Sci. U. S. A. 93, 1945 - 1949.

Basile, V.S., Masellis, M., Badri, F., Paterson, A.D., Meltzer, H.Y., Lieberman, J.A., Potkin, S.G., Macciardi, F., Kennedy, J.L., 1999. Association of the MscI polymorphism of the dopamine D3 receptor gene with tardive dyskinesia in schizophrenia. Neuropsychopharmacology 21, 17 - 27.

Basile, V.S., Masellis, M., Potkin, S.G., Kennedy, J.L., 2002. Pharmacogenomics in schizophrenia: the quest for individualized therapy. Hum. Mol. Genet. 11, 2517 - 2530. 
Chong, S.A., Tan, E.C., Tan, C.H., Mythily, Chan, Y.H., 2003. Polymorphisms of dopamine receptors and tardive dyskinesia among Chinese patients with schizophrenia. Am. J. Med. Genet. 116B, 51 - 54.

Correll, C.U., Leucht, S., Kane, J.M., 2004. Lower risk for tardive dyskinesia associated with secondgeneration antipsychotics: a systematic review of 1-year studies. Am. J. Psychiatry 161, $414-$ 425.

Friedman, J.H., 2004. Historical perspective on movement disorders. J. Clin. Psychiatry 65 (Suppl 9), $3-8$.

Gaitonde, E.J., Morris, A., Sivagnanasundaram, S., McKenna, P.J., Hunt, D.M., Mollon, J.D., 1996. Assessment of association of D3 dopamine receptor MscI polymorphism with schizophrenia: analysis of symptom ratings, family history, age at onset, and movement disorders. Am. J. Med. Genet. 67, $455-458$.

Garcia-Barcelo, M.M., Lam, L.C., Ungvari, G.S., Lam, V.K., Tang, W.K., 2001. Dopamine D3 receptor gene and tardive dyskinesia in Chinese schizophrenic patients. J. Neural. Transm. 108, 671 677.

Glazer, W.M., Morgenstern, H., Doucette, J., 1994. Race and tardive dyskinesia among outpatients at a CMHC. Hosp. Community Psychiatry 45, $38-42$.

Hoogendoorn, M.L., Bakker, S.C., Schnack, H.G., Selten, J.P., Otten, H.G., Verduijn, W., van der Heijden, F.M., Pearson, P.L., Kahn, R.S., Sinke, R.J., 2005. No association between 12 dopaminergic genes and schizophrenia in a large Dutch sample. Am. J. Med. Genet., Part B Neuropsychiatr. Genet. $134,6-9$.

Inada, T., Dobashi, I., Sugita, T., Inagaki, A., Kitao, Y., Matsuda, G., Kato S.Takano, T., Yagi, G., Asai, M., 1997. Search for a susceptibility locus to tardive dyskinesia. Hum. Psychopharmacol. 12, 35 39.

Jeste, D.V., Caligiuri, M.P., Paulsen, J.S., Heaton, R.K., Lacro, J.P., Harris, M.J., Bailey, A., Fell, R.L., McAdams, L.A., 1995. Risk of tardive dyskinesia in older patients. A prospective longitudinal study of 266 outpatients. Arch. Gen. Psychiatry 52, $756-765$.

Jonsson, E.G., Flyckt, L., Burgert, E., Crocq, M.A., Forslund, K., Mattila-Evenden, M., Rylander, G., Asberg, M., Nimgaonkar, V.L., Edman, G., Bjerkenstedt, L., Wiesel, F.A., Sedvall, G.C., 2003. Dopamine D3 receptor gene Ser9Gly variant and schizophrenia: association study and meta-analysis. Psychiatr. Genet. 13, $1-12$.

Kaiser, R., Tremblay, P.B., Klufmoller, F., Roots, I., Brockmoller, J., 2002. Relationship between adverse effects of antipsychotic treatment and dopamine $D(2)$ receptor polymorphisms in patients with schizophrenia. Mol. Psychiatry 7,695 - 705.

Kane, J.M., Woerner, M., Lieberman, J., 1985. Tardive dyskinesia: prevalence, incidence, and risk factors. In: Casey, D.E., Chase, T.N., Christensen, A.V. (Eds.), Dyskinesia-Research and Treatment. Springer-Verlag, Berlin, pp. 72 - 78.

Lattuada, E., Cavallaro, R., Serretti, A., Lorenzi, C., Smeraldi, E., 2004. Tardive dyskinesia and DRD2, DRD3, DRD4, 5-HT2A variants in schizophrenia: an association study with repeated assessment. Int. J. Neuropsychopharmacol. 7, $489-493$.

Lencer, R., Eismann, G., Kasten, M., Kabakci, K., Geithe, V., Grimm, J., Klein, C., 2004. Family history of primary movement disorders as a predictor for neuroleptic-induced extrapyramidal symptoms. Br. J. Psychiatry 185, $465-471$.

Lerer, B., 2002. Pharmacogenetics of Psychotropic Drugs. Cambridge University Press, Cambridge.

Lerer, B., Segman, R.H., Fangerau, H., Daly, A.K., Basile, V.S., Cavallaro, R., Aschauer, H.N., McCreadie, R.G., Ohlraun, S., Ferrier, N., Masellis, M., Verga, M., Scharfetter, J., Rietschel, M., Lovlie, R., Levy, U.H., Meltzer, H.Y., Kennedy, J.L., Steen, V.M., Macciardi, F., 2002. Pharmacogenetics of tardive dyskinesia: combined analysis of 780 patients supports association with dopamine D3 receptor gene Ser9Gly polymorphism. Neuropsychopharmacology 27, 105 - 119.

Liao, D.L., Yeh, Y.C., Chen, H.M., Chen, H., Hong, C.J., Tsai, S.J., 2001. Association between the Ser9Gly polymorphism of the dopamine D3 receptor gene and tardive dyskinesia in Chinese schizophrenic patients. Neuropsychobiology 44, 95 - 98. 
Liou, Y.J., Liao, D.L., Chen, J.Y., Wang, Y.C., Lin, C.C., Bai, Y.M., Yu, S.C., Lin, M.W., Lai, I.C., 2004. Association analysis of the dopamine D3 receptor gene ser9gly and brain-derived neurotrophic factor gene val66met polymorphisms with antipsychotic-induced persistent tardive dyskinesia and clinical expression in Chinese schizophrenic patients. Neuromol. Med. 5, 243 - 251.

Lovlie, R., Daly, A.K., Blennerhassett, R., Ferrier, N., Steen, V.M., 2000. Homozygosity for the Gly-9 variant of the dopamine D3 receptor and risk for tardive dyskinesia in schizophrenic patients. Int. J. Neuropsychopharmacol. 3, $61-65$.

Lovlie, R., Thara, R., Padmavathi, R., Steen, V.M., McCreadie, R.G., 2001. Ser9Gly dopamine D3 receptor polymorphism and spontaneous dyskinesia in never-medicated schizophrenic patients. Mol. Psychiatry 6, 6- 7.

Lundstrom, K., Turpin, M.P., 1996. Proposed schizophrenia-related gene polymorphism: expression of the Ser9Gly mutant human dopamine D3 receptor with the Semliki Forest virus system. Biochem. Biophys. Res. Commun. 225, 1068 - 1072.

Marsalek, M., 2000. Tardive drug-induced extrapyramidal syndromes. Pharmacopsychiatry 33 (Suppl 1), $14-33$.

McCreadie, R.G., Thara, R., Srinivasan, T.N., Padmavathi, R., 2003. Spontaneous dyskinesia in firstdegree relatives of chronically ill, never-treated people with schizophrenia. Br. J. Psychiatry 183, $45-49$.

Mukherjee, S., Mahadik, S.P., 1997. Diabetes mellitus and tardive dyskinesia. In: Yassa, R., Nair, N.P.V., Jeste, D.V. (Eds.), Neuroleptic-Induced Movement Disorders: A Comprehensive Survey. Cambridge University Press, New York.

Muller, D.J., Schulze, T.G., Knapp, M., Held, T., Krauss, H., Weber, T., Ahle, G., Maroldt, A., Alfter, D., Maier, W., Nothen, M.M., Rietschel, M., 2001. Familial occurrence of tardive dyskinesia. Acta Psychiatr. Scand. 104, 375 - 379.

Muller, D.J., Shinkai, T., De Luca, V., Kennedy, J.L., 2004. Clinical implications of pharmacogenomics for tardive dyskinesia. Pharmacogenomics J. 4, 77 - 87.

Patsopoulos, N.A., Ntzani, E.E., Zintzaras, E., Ioannidis, J.P., 2005. CYP2D6 polymorphisms and the risk of tardive dyskinesia in schizophrenia: a meta-analysis. Pharmacogenet. Genomics 15, 151 158.

Procyshyn, R.M., Kennedy, N.B., Tse, G., Thompson, B., 2001. Antipsychotic polypharmacy: a survey of discharge prescriptions from a tertiary care psychiatric institution. Can. J. Psychiatry 46, 334 $-339$.

Rietschel, M., Krauss, H., Muller, D.J., Schulze, T.G., Knapp, M., Marwinski, K., Maroldt, A.O., Paus, S., Grunhage, F., Propping, P., Maier, W., Held, T., Nothen, M.M., 2000. Dopamine D3 receptor variant and tardive dyskinesia. Eur. Arch. Psychiatry Clin. Neurosci. 250, 31 - 35.

Sachdev, P.S., 2005. Neuroleptic-induced movement disorders: an overview. Psychiatr. Clin. North Am. 28, 255 - 274 (x).

Segman, R., Neeman, T., Heresco-Levy, U., Finkel, B., Karagichev, L., Schlafman, M., Dorevitch, A., Yakir, A., Lerner, A., Shelevoy, A., Lerer, B., 1999. Genotypic association between the dopamine D3 receptor and tardive dyskinesia in chronic schizophrenia. Mol. Psychiatry 4, 247 - 253.

Steen, V.M., Lovlie, R., MacEwan, T., McCreadie, R.G., 1997. Dopamine D3-receptor gene variant and susceptibility to tardive dyskinesia in schizophrenic patients. Mol. Psychiatry 2, $139-145$.

Suzuki, M., Hurd, Y.L., Sokoloff, P., Schwartz, J.C., Sedvall, G., 1998. D3 dopamine receptor mRNA is widely expressed in the human brain. Brain Res. 779, 58 - 74.

Tenback, D.E., van Harten, P.N., Slooff, C.J., Belger, M.A., van Os, J., 2005. Effects of antipsychotic treatment on tardive dyskinesia: a 6-month evaluation of patients from the European Schizophrenia Outpatient Health Outcomes (SOHO) Study. J. Clin. Psychiatry 66, 1130 - 1133.

Thomas, D.C., 2004. Statistical Methods in Genetic Epidemiology. Oxford University Press, New York.

Tiwari, A.K., Deshpande, S.N., Rao, A.R., Bhatia, T., Lerer, B., Nimgaonkar, V.L., Thelma, B.K., 2005. Genetic susceptibility to tardive dyskinesia in chronic schizophrenia subjects: III. Lack of association of CYP3A4 and CYP2D6 gene polymorphisms. Schizophr. Res. 75, 21 - 26. 
Tiwari, A.K., Deshpande, S.N., Rao, A.R., Bhatia, T., Mukit, S.R., Shriharsh, V., Lerer, B., Nimagaonkar, V.L., Thelma, B.K., 2005. Genetic susceptibility to tardive dyskinesia in chronic schizophrenia subjects: I. Association of CYP1A2 gene polymorphism. Pharmacogenomics J. 5, 60 - 69.

van Harten, P.N., Hoek, H.W., Matroos, G.E., Koeter, M., Kahn, R.S., 1998. Intermittent neuroleptic treatment and risk for tardive dyskinesia: Curacao Extrapyramidal Syndromes Study III. Am. J. Psychiatry 155, 565 - 567.

van Os, J., Fahy, T., Jones, P., Harvey, I., Toone, B., Murray, R., 1997. Tardive dyskinesia: who is at risk? Acta Psychiatr. Scand. 96, 206 - 216.

van Os, J., Walsh, E., Horn, E.v., Tattan, T., Bale, R., Thompson, S.G., 1999. Tardive dyskinesia in psychosis: are women really more at risk? UK700 Group. Acta Psychiatr. Scand. 99, 288 - 293.

van Os, J., Walsh, E., van Horn, E., Tattan, T., Bale, R., Thompson, S.G., 2000. Changes in negative symptoms and the risk of tardive dyskinesia: a longitudinal study. UK700 Group. Acta Psychiatr. Scand. 101, $300-306$.

Waddington, J.L., Youssef, H.A., 1996. Cognitive dysfunction in chronic schizophrenia followed prospectively over 10 years and its longitudinal relationship to the emergence of tardive dyskinesia. Psychol. Med. 26, 681 - 688.

Woo, S.I., Kim, J.W., Rha, E., Han, S.H., Hahn, K.H., Park, C.S., Sohn, J.W., 2002. Association of the Ser9Gly polymorphism in the dopamine D3 receptor gene with tardive dyskinesia in Korean schizophrenics. Psychiatry Clin. Neurosci. 56, $469-474$.

Yassa, R., Jeste, D.V., 1992. Gender differences in tardive dyskinesia: a critical review of the literature. Schizophr. Bull. 18, 701 - 715.

Zhang, Z.J., Zhang, X.B., Hou, G., Yao, H., Reynolds, G.P., 2003. Interaction between polymorphisms of the dopamine D3 receptor and manganese superoxide dismutase genes in susceptibility to tardive dyskinesia. Psychiatr. Genet. 13, 187 - 192. 


\section{Antipsychotic-induced tardive dyskinesia and polymorphic variations in COMT, DRD2, CYP1A2 and MnSOD genes: A meta-analysis of pharmacogenetic interactions}

PR Bakkera, PN van Hartena and J van Os,c,

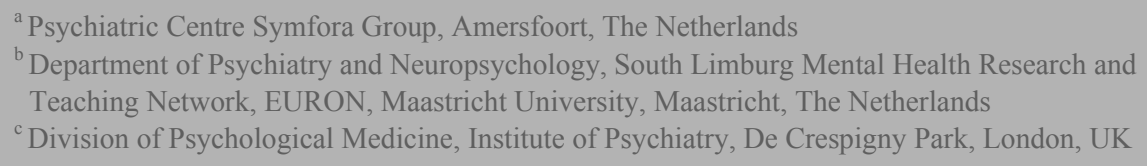

Molecular Psychiatry. 2008; 13(5): 544-56 


\begin{abstract}
Despite accumulating evidence pointing to a genetic basis for tardive dyskinesia, results to date have been inconsistent owing to limited statistical power and limitations in molecular genetic methodology. A Medline, EMBASE and PsychINFO search for literature published between 1976 and June 2007 was performed, yielding 20 studies from which data were extracted for calculation of pooled estimates using meta-analytic techniques. Evidence from pooled data for genetic association with tardive dyskinesia (TD) showed (1) in COMTval158met, using Val-Val homozygotes as reference category, a protective effect for Val-Met heterozygotes (OR $=0.63,95 \% \mathrm{CI}: 0.46-0.86, P=0.004)$ and Met carriers $(\mathrm{OR}=$ $0.66,95 \%$ CI: $0.49-0.88, P=0.005)$; (2) in Taq1A in DRD2, using the A1 variant as reference category, a risk-increasing effect for the $A 2$ variant $(O R=1.30,95 \%$ $\mathrm{CI}: 1.03-1.65, P=0.026)$, and $\mathrm{A} 2-\mathrm{A} 2$ homozygotes using $\mathrm{A} 1-\mathrm{A} 1$ as reference category (OR $=1.80,95 \%$ CI: $1.03-3.15, P=0.037$ ); (3) in MnSOD Ala-9Val, using Ala-Ala homozygotes as reference category, a protective effect for Ala-Val (OR $=0.37,95 \% \mathrm{CI}: 0.17-0.79, P=0.009)$ and for Val carriers $(\mathrm{OR}=0.49,95 \%$ CI: $0.24-1.00, P=0.047)$. These analyses suggest multiple genetic influences on TD, indicative of pharmacogenetic interactions. Although associations are small, the effects underlying them may be subject to interactions with other loci that, when identified, may have acceptable predictive power. Future genetic research will take advantage of new genomic knowledge.
\end{abstract}

\title{
Keywords
}

tardive dyskinesia; drug-induced; catechol- $O$-methyltransferase; dopamine D2 receptor; cytochrome $\mathrm{P}_{450}$ CYP1A2; manganese superoxide dismutase. 


\section{Introduction}

Since the introduction of antipsychotic medication in 1952, tardive dyskinesia (TD), characterized by hyperkinetic involuntary movements of the choreoathetoid type with a fluctuating intensity over time (Sachdev, 2005;Muller et al., 2004), is still a major concern as a potentially irreversible side effect, which can be distressing for patients owing to motor performance difficulties, social stigmatization and poorer quality of life (Marsalek, 2000).

Studies on genetic factors related to TD are often inconsistent owing to genetic methodological problems, such as sample heterogeneity, small effects of multiple genes, (epi) genetic interactions, pleiotropy and small sample size (Abdolmaleky et al., 2005). Meta-analyses may usefully increase the power to produce a more precise estimate, provided studies are comparable and methodologically sound (Egger et al., 1997;Egger and Smith, 1997). In this article, a metaanalysis of the genes that are thought to be associated with TD, namely COMT, $D R D 2, C Y P 1 A 2$ and $M n S O D$, is presented. Genetic variation in $D R D 3$ in relation to TD was already meta-analysed recently and therefore it is not included in this study (Bakker et al., 2006).

\section{Methods}

\section{Choice of candidate genes}

Attractive candidate genes for TD are (1) genes related to schizophrenia and dysregulation of the dopamine system because part of the risk for TD is thought to be associated with schizophrenia (van Os et al., 1997), (2) genes related to the metabolism of antipsychotics because these drugs are at least partly responsible for TD (Ellingrod et al., 2002; Patsopoulos et al., 2005;Tiwari et al., 2005a;Tiwari et al., 2005b) and (3) genes related to free radicals because several theories concerning TD are related to damage of the dopamine receptor (Ozdemir et al., 2006a; Tsai et al., 1998).

\section{Catechol-O-methyltransferase}

The catechol- $O$-methyltransferase gene (COMT), which encodes a central dopamine catabolic enzyme that co-regulates dopamine levels in the brain, contains an single nucleotide polymorphism (SNP) located in exon 4, a G-A substitution at codon 158 changing valine (Val) to methionine (Met), causing a missense mutation resulting in a lower metabolic activity and lower stability form Met of the COMT enzyme (Collier and Li, 2003;Harrison and Weinberger, 2005;Jann, 2004).

A haplotype combining COMTval158met (rs4680) with two common SNPs located in intron 1 (rs737865) and in the 3' flanking region (rs165599) was highly 
associated with schizophrenia (Shifman et al., 2002), and differentially affected expression of rs4680 alleles in human brain tissue (Bray et al., 2003). These findings have led to the hypothesis that COMTval158met may not directly result in disease, but may be in strong linkage disequilibrium (LD) with the etiological, not yet identified, variant (Handoko et al., 2005). In addition, this three-marker haplotype is significantly heterogeneous across populations worldwide, despite relatively equal prevalence of schizophrenia. An SNP in the 5' flanking region (rs2097603) in the P2 promoter, which is responsible for the transcription of the predominant form of COMT in the brain, is in LD with rs737865 and varies across populations, and may play an important role in schizophrenia (Palmatier et al., 2004; Williams et al., 2007).

Given the fact that part of the risk for TD is thought to be associated with dopaminergic function, polymorphisms in COMT are attractive candidates for the study of TD. It has been hypothesized that patients with the Met variant have a higher risk for TD, as a result of either post-synaptic dopamine receptor supersensitivity or elevated levels of free radicals owing to an increased level of dopamine in the brain (Elkashef and Wyatt, 1999).

\section{Dopamine 2 receptor}

Dopamine 2 receptor (DRD2) is of particular interest because of its high density in areas thought to be implicated in schizophrenia (Lerer, 2002). In addition, DRD2 is densely expressed in the basal ganglia (Accili et al., 1996; Suzuki et al., 1998;Zai et al., 2007).

\section{Taq1A}

The DRD2 Taq1A polymorphism resides in the overlapping ANKK1 gene, a kinase gene which is involved in signal transduction (Neville et al., 2004). Taq1A1 carrier status (A1A1 and A1A2 genotypes) was associated with a lower D2 receptor density in the striatum and related structures of the human brain in vitro (Noble et al., 1991;Thompson et al., 1997) and in vivo (Laruelle et al., 1998; Pohjalainen et al., 1998;Jonsson et al., 1999). The study by Laruelle (1998) showed an opposite trend in patients with schizophrenia compared to controls, which may be confounded by prior antipsychotics use in the former group. This was confirmed by another study, which did find a higher D2 receptor density in patients with schizophrenia after intake of antipsychotics (Silvestri et al., 2000;Noble, 2003;Young et al., 2004).

\section{DRD2 Ser311Cys and -141C Ins/Del}

The Ser311Cys polymorphism is an effective cAMP inhibitor in DRD2 leading to activation of intracellular signalling (Zai et al., 2007; Cravchik et al., 1996). The -141C Del allele of the $-141 \mathrm{C}$ Ins/Del polymorphism was associated with a decrease of $D R D 2$ promoter activity in vitro (Arinami et al., 1997) and an increase 
of striatal D2 binding in vivo (Jonsson et al., 1999), although this latter finding was not confirmed in another study (Ritchie and Noble, 2003).

\section{CYP1A2}

Cytochrome P450 1A2 (CYP1A2), a member of the cytochrome P450 mixedfunction oxidase system, metabolizes atypical antipsychotics, including clozapine and olanzapine. Although it has low-affinity for typical antipsychotics compared to the high affinity CYP2D6, this enzyme is much more abundant in the liver (high capacity) and is induced by smoking, making it an important enzyme during saturation during the long-term treatment with typical agents (Tiwari et al., 2005b). Prevalence rates of exonic SNPs of the CYP1A2 gene are too rare for association studies. On the other hand, regulatory and intronic regions contain several SNPs giving rise to more than 30 allelic variants, of which, however, only very few have been functionally characterized.

A putative polymorphism in intron 1 of $C Y P 1 A 2\left(-163 \mathrm{C}>\mathrm{A} ; C Y P 1 A 2^{*} 1 \mathrm{~F}\right.$ allele) appears to affect the inducibility of CYP1A2 (MacLeod SL et al., 1998). Thus, the $C Y P 1 A 2 * 1 \mathrm{~F} \mathrm{~A} / \mathrm{A}$ genotype may represent a CYP1A2 with high inducibility, which may either be a direct cause of increased CYP1A2 activity, or be genetically linked to polymorphisms conferring high inducibility. $C Y P 1 A 2 * 1 \mathrm{~F}$ thus was associated with a $40 \%$ lower activity in smokers carrying the CC compared to the AA genotype, but not in nonsmokers (Sachse et al., 1999). Patients with the CC genotype had 2.7- and 3.4-fold higher AIMS-scores compared to the A/C and A/A genotype, respectively. Among smokers, the AIMS-scores were 4.7and 5.4-fold higher, respectively (Basile et al., 2000). This result was not replicated in later studies in TD patients (Chong et al., 2003a; Fu et al., 2006; Matsumoto et al., 2004a). The $C Y P 1 A 2 * 1 \mathrm{C}$ allele $(-3860 \mathrm{G}>\mathrm{A})$ also results in a lower activity in smokers (Nakajima et al., 1999).

\section{Free radicals}

The neuronal degeneration hypothesis, in the context of neuronal death or neurotoxicity, has been proposed as an alternative to the 'dopamine supersensitivity hypothesis' (Tsai et al., 1998). One argument for the neuronal degeneration hypothesis is that the supersensitivity hypothesis may not fit the clinical course of TD because (1) although hypersensitivity seems to be a universal response to D2-receptor antagonists, not all patients develop TD, (2) TD tends to display an irreversible course, whereas dopamine supersensitivity diminishes gradually upon cessation of antipsychotics and (3) the risk for TD is markedly elevated with age, but the dopamine supersensitivity response may be dampened with increasing age (Ozdemir et al., 2006a). In one study, TD symptoms correlated positively with markers of excitatory neurotransmission and protein carbonyl group and negatively with CSF superoxide dismutase (SOD), suggesting elevated levels of oxidative stress are relevant to the pathophysiology of TD (Tsai et al., 1998). Thus, as toxic effects of free radicals may contribute to the development 
of TD, genetic variants of free radical scavenging enzymes like manganese superoxide dismutase (MnSOD) have been investigated, which is localized in the mitochondria. The gene encoding MnSOD has one polymorphic site, resulting in an alanine (Ala) to valine (Val) substitution causing less efficient transport of MnSOD in the mitochondrion in rat liver cells and HuH7 human hepatoma cells (Hitzeroth et al., 2007;Rosenblum et al., 1996;Shimoda-Matsubayashi et al., 1996;Sutton et al., 2003; Sutton et al., 2005).

\section{Literature search}

A systematic literature review of the literature published between 1976 and June 2007 was conducted with the help of Medline, EMBASE and PsychINFO using key words: (genetic) polymorphism(s), tardive dyskinesia, extrapyramidal (syndrome/disorder), drug-induced, antipsychotic(s), adverse effect/event, catechol-O-methyltransferase gene (COMT), dopamine D2 receptor (DRD2), cytochrome $\mathrm{P}_{450} 1 \mathrm{~A} 2$ (CYP1A2) and manganese superoxide dismutase (MnSOD). In addition, all relevant references cited in these articles were also retrieved.

\section{Inclusion and exclusion criteria}

Only those studies were included examining associations with antipsychoticinduced TD and the polymorphisms of COMT, DRD2, CYP1A2 and MnSOD.

\section{Statistics}

Analyses were conducted using the METAN routine of the STATA statistical program (StataCorp (2007): STATA Statistical Software: Release 9.0. Texas: College Station), version 9.2, providing pooled estimates, confidence limits and a test that the true pooled effect is zero, obtained from fixed and random-effects meta-analysis. A test for heterogeneity between studies and an estimator of between-studies variance is provided. Pooled odds ratios (ORs) were calculated by providing, for each study, the number of individuals in each of the four cells made up by the combination of a binary exposure (the genetic polymorphism) and a binary outcome (TD or not). Comparisons were conducted comparing both genotypes (with a1a1 genotype as reference category) and allelotypes (with a1 allelotype as reference category). Allele frequencies given genotypic frequencies of $\mathrm{a} 1 \mathrm{a} 1, \mathrm{a} 2 \mathrm{a} 1$ and $\mathrm{a} 2 \mathrm{a} 2$ were calculated as follows: frequency $\mathrm{a} 1=$ $2 *(\mathrm{a} 1 \mathrm{a} 1)+(\mathrm{a} 1 \mathrm{a} 2) ;$ frequency $\mathrm{a} 2=2 *(\mathrm{a} 2 \mathrm{a} 2)+(\mathrm{a} 1 \mathrm{a} 2)$.

For studies reporting on non-overlapping samples within one study, for example, because of stratification for duration of illness, samples were entered separately into the meta-analysis. Standard corrections of 0.5 to all cells in $2 \times 2$ tables were adopted in case of one or more zero cells to avoid computational difficulties. 
Meta-analytic results were assessed for heterogeneity in effect sizes between studies, and Egger's test for publication bias was carried out using the STATA METABIAS routine, yielding a regression coefficient $(B)$ representing the bias estimate. Both fixed and random-effects methods were used with results being inspected for discrepancies, as recommended by the Cochrane Collaboration Collaboration (http://www.cochrane-net.org/openlearning/HTML/mod13-4.htm).

\section{Results}

\section{Catechol-O-methyltransferase}

\section{Studies included}

Three studies reported inconclusive results on the association between COMTval158met and TD (Herken et al., 2003;Lai et al., 2005; Matsumoto et al., 2004b). Matsumoto et al. only carried out the allelic analysis. Han et al. (2005) included only male Korean patients and found a significant association between COMT val158met genotypes and alleles on the one hand and TD on the other with protective effect for the Met allele, Val-Met and Met-Met genotype compared to the Val and Val-Val reference groups, but not for EPS. Srivastava et al. (2006) studied four SNPs of COMT and TD, and found a significant genotypic association for COMTval158met with a protective effect for the Met-Met genotype, as well as significant allelic and genotypic association for genotype GG with $408 \mathrm{C}>\mathrm{G}$ (exon 4) with increased risk for the G allele, CG and GG genotype compared to the $\mathrm{C}$ and $\mathrm{CC}$ reference groups. Associated haplotypes also yielded significant results. However, results were not significant following linear and logistic regression analyses.

The search yielded five studies for the alleles and four for the genotypes as Matsumoto (Matsumoto et al., 2004b) did not include genotypes. All groups (with and without TD) were in Hardy-Weinberg equilibrium (HWE), except for the TD group in the study of Lai et al. (2005). The study of Srivastava et al. (2006) did not provide information on HWE. A meta-analysis of the five samples, yielding a total of 382 patients with TD and 707 without, was conducted (Herken et al., 2003;Lai et al., 2005;Matsumoto et al., 2004b;Han et al., 2005; Srivastava et al., 2006).

\section{Heterogeneity and bias}

Significant heterogeneity was apparent for the allelic analyses $\left(\chi^{2}=11.23\right.$, d.f. $=$ 4, $P=0.024$ ), but not for the Val-Val versus Met-Met, Val-Val versus Val-Met genotypic comparisons $\left(\chi^{2}=5.93\right.$, d.f. $=3, P=0.115$ and $\chi^{2}=5.65$, d.f. $=3, P=$ 0.130 , respectively). The comparison between Val-Val and Met carriers (Val- 
Met heterozygotes and Met-Met homozygotes taken together) showed a trend for heterogeneity $\left(\chi^{2}=7.83\right.$, d.f. $\left.=3, P=0.050\right)$.

Egger's test did not show evidence of publication bias within the allelic analysis $(B=-1.05,95 \% \mathrm{CI}:-7.53$ to $5.42, P=0.641)$ or the genotypic analyses $(B=-0.18,95 \% \mathrm{CI}:-1.55$ to $1.186, P=0.624 ; B=1.29,95 \% \mathrm{CI}:-4.61$ to $7.18, P=$ $0.447 ; B=0.93,95 \% \mathrm{CI}:-2.05$ to $3.91, P=0.312$, respectively).

\section{Meta-analytic results}

In the allelic analyses, using the Val variant as reference category, the fixedeffects model pooled OR for the Met variant was directionally protective at 0.84 , albeit not statistically significant at conventional $\alpha(95 \% \mathrm{CI}: 0.69-1.02, P=$ $0.075)$, with a similar result for the random-effects model $(\mathrm{OR}=0.82,95 \% \mathrm{CI}$ : $0.58-1.16, P=0.260)$.

In the genotypic analyses, using Val-Val homozygotes as reference category, the pooled OR was 0.73 (95\% CI: $0.47-1.13, P=0.157)$ for Met-Met homozygotes, 0.63 (95\% CI: $0.46-0.86, P=0.004$; Figure 1) for the Val-Met heterozygotes and 0.66 (95\% CI: $0.49-0.88, P=0.005$; Figure 2$)$ for the Met carriers using the fixed-effects model. In the random effects model, the ORs were 0.70 (95\% CI: $0.35-1.40, P=0.315$ ) for Met-Met homozygotes, 0.61 (95\% CI: 0.38$0.99, P=0.043)$ for the Val-Met heterozygotes and $0.62(95 \% \mathrm{CI}: 0.36-1.06, P=$ 0.078 ) for the Met carriers.

Study ID

OR $(95 \% \mathrm{Cl}) \quad$ Weight

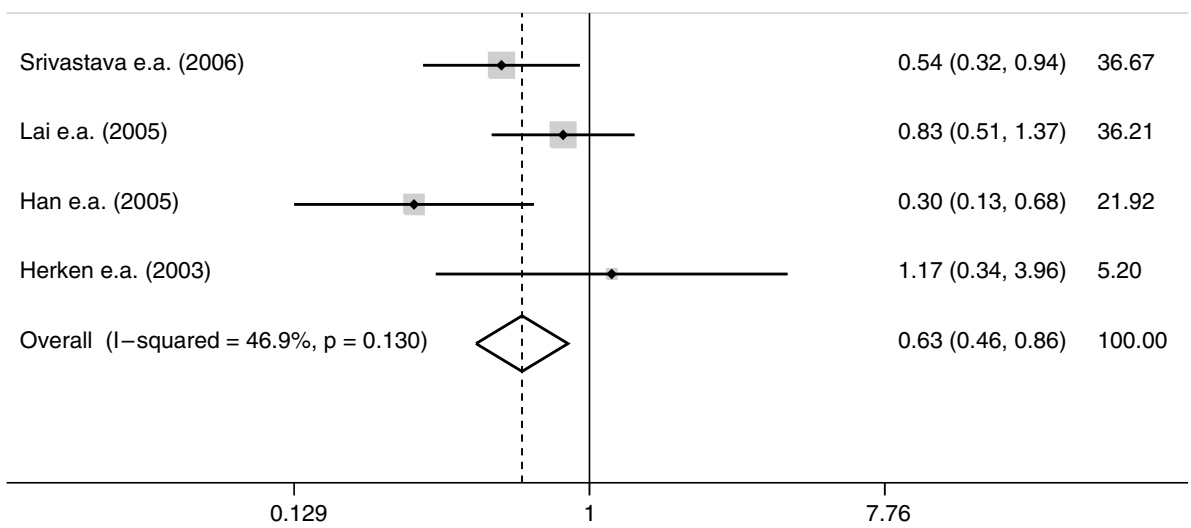

Figure 1. Meta-analysis: odds ratios (OR) and 95\% confidence intervals (CI) for tardive dyskinesia (TD) in COMTval158met using Val-Val homozygotes as reference category, a protective effect for Val-Met heterozygotes in four samples included in the pooled analysis. Pooled OR $=0.63$ (95\% CI: 0.46-0.86, $P=$ 0.004) in fixed effects model. 


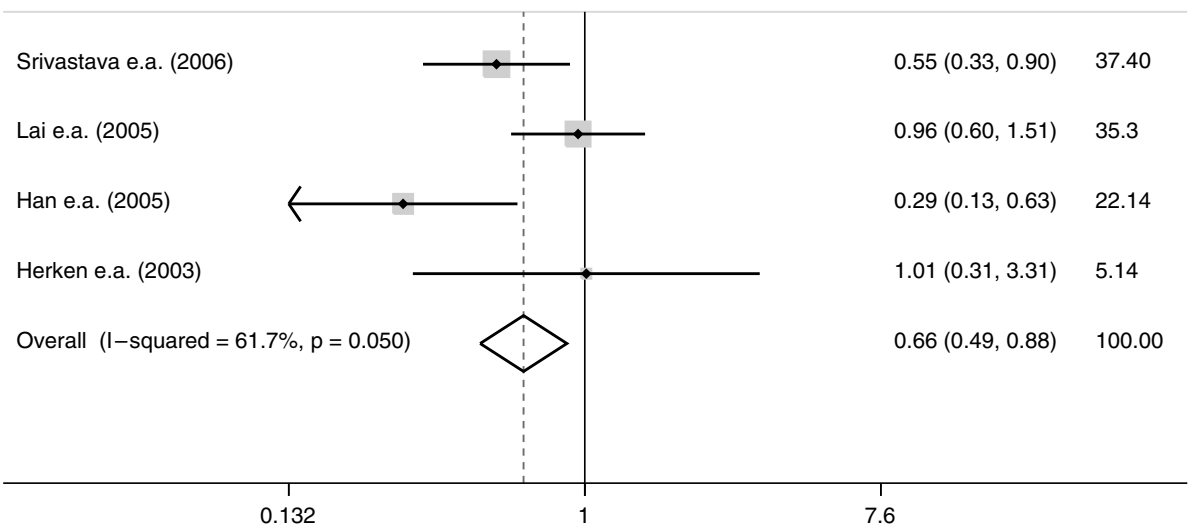

Figure 2. Meta-analysis: odds ratios (OR) and 95\% confidence intervals (CI) for tardive dyskinesia (TD) in COMTval158met met using Val-Val homozygotes as reference category, a protective effect for Met carriers in four samples included in the pooled analysis. Pooled OR $=0.66$ (95\% CI: 0.49-0.88, P= 0.005) in fixed effects model.

\section{Dopamine 2 receptor}

\section{Studies included}

Early studies did not show an association with Taq1A or other polymorphisms (Basile et al., 2002;Chong et al., 2003b;de Leon et al., 2005;Lattuada et al., 2004; Srivastava et al., 2006;Kaiser et al., 2002). One study found a significant association between the Taq1A polymorphism of the dopamine 2 receptor gene (DRD2) and TD in female patients (Chen et al., 1997). Another study showed an increased risk for EPS in patients with the $-141 \mathrm{C}$ Del allele of the DRD2 gene (Nakazono et al., 2005).

A recent study investigated 12 polymorphisms in the $D R D 2$ gene in relation to TD in European Caucasian $(n=202)$ and African-American $(n=30)$ patients, and found significant associations for the genotype frequencies for C957T and the adjacent C939T polymorphisms. Two-marker haplotypes containing C939T and C957T were significantly associated with both TD and total AIMS scores. C957T may be associated with TD in the African-American sample (Zai et al., 2007).

\section{Taq1A}

The search yielded 11 studies. Six studies could not be included because either categorical data were not used (Kaiser et al., 2002) or data were not reported (Srivastava et al., 2006; de Leon et al., 2005;Lattuada et al., 2004;Guzey et al., 
2007), or Chinese language was used in the article (Xu et al., 2006). As both Chen et al. (1997) and Liou et al. (2006) recruited patients in the same location in Taipei, Taiwan, only the latter study was included to avoid the risk of overlap.

All groups (with and without TD) were in HWE. Liou et al. (2006) did not provide information on HWE. As Zai et al. (2007) studied both alleles and genotypes in relation to TD in Caucasians, but only alleles in Afro-Americans, we included the Caucasian population in the meta-analysis.

A meta-analysis of the four samples, yielding a total of 297 patients with TD and 467 without, was conducted (Zai et al., 2007;Liou et al., 2006; Hori et al., 2001; Segman et al., 2003).

\section{Heterogeneity and bias}

No significant heterogeneity was apparent for the allelic analyses $\left(\chi^{2}=2.92\right.$, d.f. $=3, P=0.405)$ and for the comparison of A1-A1 as reference category on the one hand, versus A2-A2, A1-A2 and A2 carriers on the other $\left(\chi^{2}=3.19\right.$, d.f. $=3, P$ $=0.363 ; \chi^{2}=1.87$, d.f. $=3, P=0.600 ; \chi^{2}=2.71$, d.f. $=3, P=0.439$, respectively). Egger's test did not show evidence of publication bias within either the allelic $(B$ $=-0.96,95 \%$ CI: -12.24 to $10.33, P=0.751)$, or the genotypic analyses $(B=$ $-0.32,95 \%$ CI: -1.75 to $1.11, P=0.438 ; B=-0.10,95 \% \mathrm{CI}:-0.75$ to $0.54, P=$ $0.560 ; B=-0.11,95 \% \mathrm{CI}:-0.71$ to $0.49, P=0.512$, respectively).

\section{Meta-analytic results}

In the allelic analyses, using the $\mathrm{A} 1$ variant as reference category, the fixedeffects model pooled OR for the A2 variant was 1.30 (95\% CI: 1.03-1.65, $P=$ 0.026; Figure 3), which concurred with the random-effects model $(\mathrm{OR}=1.30$, 95\% CI: 1.03-1.65, $P=0.027$ ).

Using A1-A1 homozygotes as reference category, the pooled OR was 1.80 (95\% CI: 1.03-3.15, $P=0.037$; Figure 4) for A2-A2 homozygotes, 1.15 (95\% CI: $0.70-1.90, P=0.579$ ) for the A1-A2 heterozygotes and 1.33 (95\% CI: 0.83-2.14, $P=0.229$ ) for the A2 carriers using the fixed-effects model. In the random effects model, the ORs were 1.77 (95\% CI: 0.97-3.21, $P=0.062$ ) for A2-A2 homozygotes, 1.15 (95\% CI: $0.69-1.89, P=0.599$ ) for the A1-A2 heterozygotes and 1.32 (95\% CI: $0.82-2.13, P=0.249$ ) for the A2 carriers. 
Liou e.a. (2006)

Zai e.a. (2006)

Segman e.a. (2003)

Hori e.a. (2001)

Overall $(I-$ squared $=0.0 \%, p=0.405)$

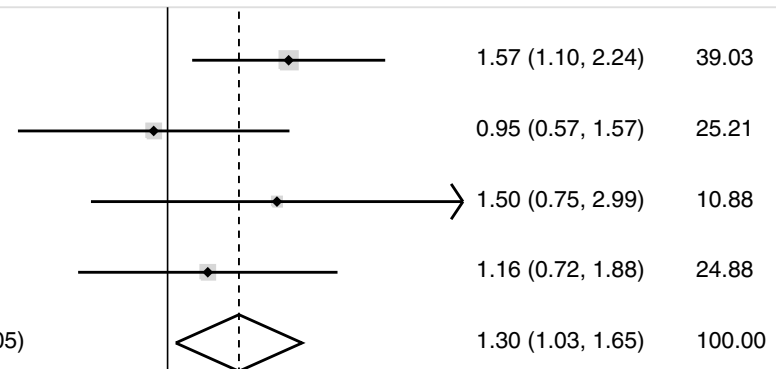

\begin{tabular}{ll|l|l}
\hline & & & \\
\hline & 1 & 2.99
\end{tabular}

Figure 3. Meta-analysis: odds ratios (OR) and 95\% confidence intervals (CI) for tardive dyskinesia (TD) in Taq1A in DRD2, using A1 variant as reference category, a risk increasing effect for A2 variant in four samples included in the pooled analysis. Pooled OR $=1.30$ (95\% CI: $1.03-1.65, P=0.026)$ in fixed effects model.

$\%$

Study ID OR $(95 \% \mathrm{Cl})$

Weight

Liou e.a. (2006)

Zai e.a. (2006)

Segman e.a. (2003)

Hori e.a. (2001)

Overall $(I-$ squared $=6.0 \%, p=0.363)$

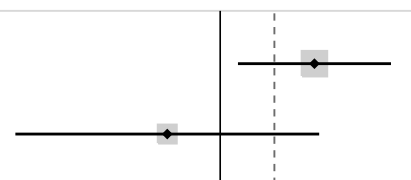

$2.78(1.21,6.37)$

37.1

$0.56(0.11,2.92)$

19.98

0.0407

Figure 4. Meta-analysis: odds ratios (OR) and 95\% confidence intervals (CI) for tardive dyskinesia (TD) in Taq1A in DRD2, using A1-A1 as reference category, a risk increasing effect for A2-A2 homozygotes in four samples included in the pooled analysis. Pooled OR = 1.80 (95\% CI: 1.03-3.15, P=0.037) in fixed effects model. 


\section{Ser311Cys and -141C Ins/Del}

For both polymorphisms, the search yielded nine studies. Five studies could not be included either because categorical data were not used (Kaiser et al., 2002;Dolzan et al., 2007) or data were not reported (Srivastava et al., 2006; de Leon et al., 2005;Lattuada et al., 2004). No large or significant pooled OR was found for the alleles or genotypes for Ser311Cys (Chong et al., 2003b;Liou et al., 2006; Hori et al., 2001;Segman et al., 2003) or for -141C Ins/Del (Zai et al., 2007; Liou et al., 2006;Hori et al., 2001;Segman et al., 2003) (results available upon request). There was no evidence of heterogeneity or publication bias, although there was some indication for publication bias for the Ser311Cys allele comparisons $(B=3.56,95 \% \mathrm{CI}:-0.25$ to $7.37, P=0.057)$.

\section{CYP1A2}

\section{CYP1A2*1F}

\section{Studies included}

One study on $C Y P 1 A 2^{*} 1 \mathrm{~F}$ showed a significant association with TD for the Calleles and C-containing genotypes (Fu et al., 2006), but this result was not replicated in others (Tiwari et al., 2005b;Chong et al., 2003a;Matsumoto et al., 2004a;Schulze et al., 2001). An opposite trend was found by Tsapakis et al. (2002).

The search for $C Y P 1 A 2 * 1 \mathrm{~F}$ yielded seven studies. One study could not be included because categorical data were not used (Basile et al., 2000). In the analyses, no significant pooled OR was evident for allelic or genotypic comparisons of this polymorphism (Tiwari et al., 2005b; Fu et al., 2006; Chong et al., 2003a;Matsumoto et al., 2004a;Schulze et al., 2001; Tsapakis et al., 2002).

To improve the signal-to-noise ratio, a meta-analysis was done of available data in the subgroup of smokers (Chong et al., 2003a;Matsumoto et al., 2004a;Schulze et al., 2001), which did not result in a large or significant effect. The fixed-effects model pooled OR for the alleles was 1.06 (95\% CI: $0.73-1.53, P$ $=0.771$ ), and 1.06 (95\% CI: $0.73-1.53, P=0.768)$ using the random-effects model. Using A-A homozygotes as reference category, the pooled OR was 1.41 (95\% CI: 0.58-3.42, $P=0.450$ ) for C-C homozygotes, 0.90 (95\% CI: 0.54-1.51, $P$ $=0.702$ ) for the $\mathrm{A}-\mathrm{C}$ heterozygotes and 0.97 (95\% CI: $0.59-1.59, P=0.902$ ) for the $\mathrm{C}$ carriers using the fixed-effects model, and 1.41 (95\% CI: 0.58-3.45, $P=$ 0.449 ) for $\mathrm{C}-\mathrm{C}$ homozygotes, 0.90 (95\% CI: $0.54-1.52, P=0.703$ ) for the A-C heterozygotes and 0.97 (95\% CI: $0.59-1.59, P=0.902)$ for the $C$ carriers using the random effects model. There was no evidence of heterogeneity or publication bias.

In Asians and even more pronounced in Asian smokers, CYP1A2 may play a more important role in antipsychotic metabolism, because Asians display lower 
mean CYP2D6 activity compared to Caucasians owing to high prevalence of the CYP2D6*10 allele (56.2\% of Chinese and 38.8\% of Japanese ) (Shen et al., 2007).

The pooled OR of all Asians (Tiwari et al., 2005b;Fu et al., 2006;Chong et al., 2003a; Matsumoto et al., 2004a) and available data in the subgroup of smokers (Chong et al., 2003a;Matsumoto et al., 2004a) did not result in a large or significant OR. There was no evidence of heterogeneity or publication bias.

In the subgroup of Asian smokers, both the fixed-effects and random-effects model pooled OR for the alleles were 1.16 (95\% CI: 0.75-1.81, $P=0.503$ ). Using A-A homozygotes as reference category, the pooled OR was 1.45 (95\% CI: 0.533.94, $P=0.472$ ) for $C-C$ homozygotes, 1.09 (95\% CI: $0.58-2.05, P=0.797$ ) for the A-C heterozygotes and $1.15(95 \% \mathrm{CI}: 0.63-2.11, P=0.650)$ for the $\mathrm{C}$ carriers using the fixed-effects model, and 1.45 (95\% CI: $0.53-3.99, P=0.471)$ for $\mathrm{C}-\mathrm{C}$ homozygotes, 1.09 (95\% CI: 0.58-2.05, $P=0.797)$ for the $\mathrm{A}-\mathrm{C}$ heterozygotes and 1.15 (95\% CI: $0.63-2.11, P=0.649$ ) for the $C$ carriers using the random effects model.

\section{CYP1A2*1C}

\section{Studies included}

Two studies with CYP1A2*1C (Tiwari et al., 2005b;Matsumoto et al., 2004a) showed no significant pooled OR for contrasting alleles or genotypes (results available upon request). With only two studies, publication bias could not be assessed.

\section{MnSOD}

\section{Studies included}

One study showed a significant association between a biallelic polymorphism and TD (Hori et al., 2000) and one study did not (Zhang et al., 2002). A pooled analysis of these two Asian samples performed by Pae (2006) resulted in inconclusive results. However, when Pae added an Eastern Turkish sample (Akyol et al., 2005) to the previous two Asian samples, the pooled analysis gave strong significant results. This effect was explained by the higher prevalence of -9Ala in Europeans compared to Asians, as well as methodological differences. It has been suggested to include other polymorphisms of MnSOD in the analyses (Pae, 2006). Hitzeroth et al. (2007) did a study with AIMS instead of TD-scores in a Xhosa population and found a significant association in the genotypic, but not the allelic analyses.

The search yielded six studies. Two studies could not be included because Polish language was used (Galecki et al., 2006) or data were not reported (Pae, 2006). Hitzeroth et al. (2007) provided us with TD data. All groups (with and without TD) were in HWE, except for the patients in the study by Akyol et al. 
(2005). A meta-analysis of the four samples, yielding a total of 134 patients with TD and 546 without, was conducted (Hitzeroth et al., 2007; Hori et al., 2000;Zhang et al., 2002;Akyol et al., 2005).

\section{Heterogeneity and bias}

Significant heterogeneity was apparent for the allelic analyses $\left(\chi^{2}=8.79\right.$, d.f. $=3$, $P=0.032$ ), but not, using Ala-Ala as reference category, for the Val-Val, Ala-Val and Val carriers comparisons $\left(\chi^{2}=4.03\right.$, d.f. $=3, P=0.258 ; \chi^{2}=1.68$, d.f. $=3, P=$ $0.641 ; \chi^{2}=3.21$, d.f. $=3, P=0.360$, respectively). Egger's test did show evidence of publication bias within the allelic analysis $(B=-0.20,95 \% \mathrm{CI}:-0.21$ to -0.18 , $P=0.000)$, but not for the genotypic analyses $(B=0.04,95 \%$ CI: -0.70 to $0.77, P$ $=0.857 ; B=0.02,95 \% \mathrm{CI}:-0.02$ to $0.05, P=0.150 ; B=0.04,95 \% \mathrm{CI}:-0.24$ to $0.31, P=0.612$, respectively).

\section{Meta-analytic results}

The fixed-effects model pooled OR for the Val variant versus the Ala variant was 1.23 (95\% CI: $0.88-1.72, P=0.240$ ), and 1.35 (95\% CI: $0.71-2.55, P=0.360$ ) using the random-effects model.

Using Ala-Ala homozygotes as reference category, the pooled OR was 0.75 (95\% CI: $0.34-1.63, P=0.460$ ) for Val-Val homozygotes, 0.37 (95\% CI: 0.17$0.79, P=0.009$; Figure 5) for the Ala-Val heterozygotes and 0.49 (95\% CI: $0.24-$ 1.00, $P=0.047$; Figure 6) for the Val carriers using the fixed-effects model, and 0.82 (95\% CI: $0.27-2.50, P=0.727$ ) for Val-Val homozygotes, 0.35 (95\% CI: $0.16-0.78, P=0.010$ ) for the Ala-Val heterozygotes and 0.47 (95\% CI: $0.21-$ $1.06, P=0.069$ ) for the Val carriers using the random effects model (see Table $1)$. 


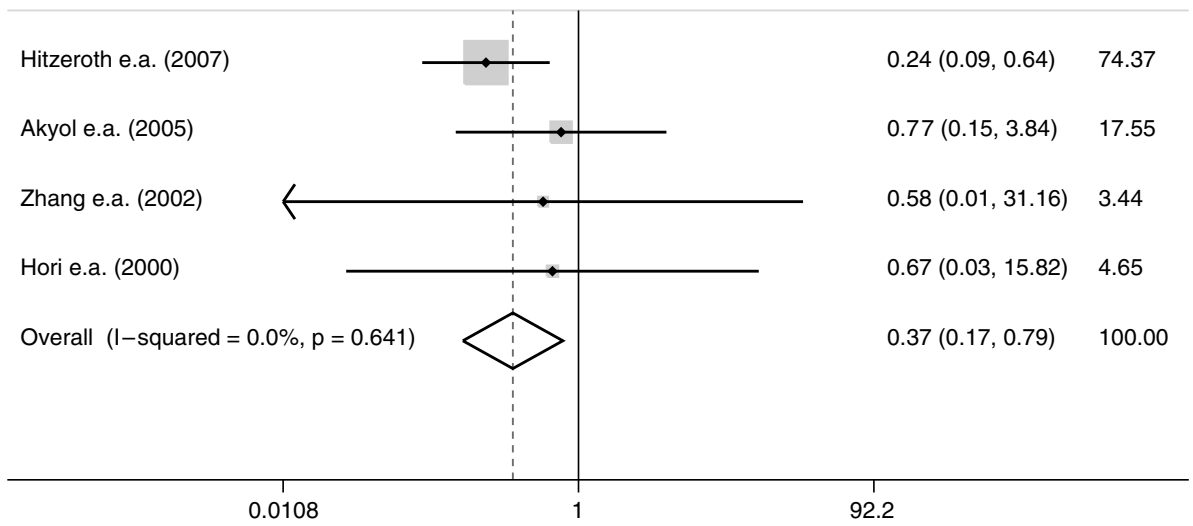

Figure 5. Meta-analysis: odds ratios (OR) and 95\% confidence intervals (CI) for tardive dyskinesia (TD) in MnSOD Ala-9Val, using Ala-Ala as reference category, a protective effect for Ala-Val heterozygotes in four samples included in the pooled analysis. Pooled OR =0.37 (95\% CI: 0.17-0.79, P=0.009) in fixed effects model.

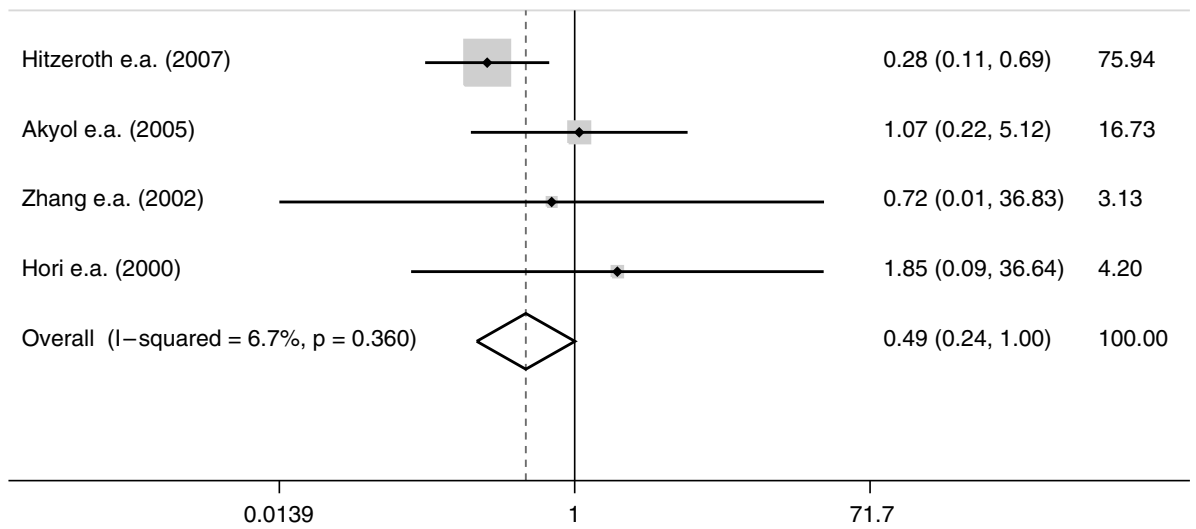

Figure 6. Meta-analysis: odds ratios (OR) and 95\% confidence intervals (CI) for tardive dyskinesia (TD) in MnSOD Ala-9Val, using Ala-Ala as reference category, a protective effect for Val carriers in four samples included in the pooled analysis. Pooled OR $=0.49$ (95\% CI: 0.24-1.00, P=0.047) in fixed effects model. 


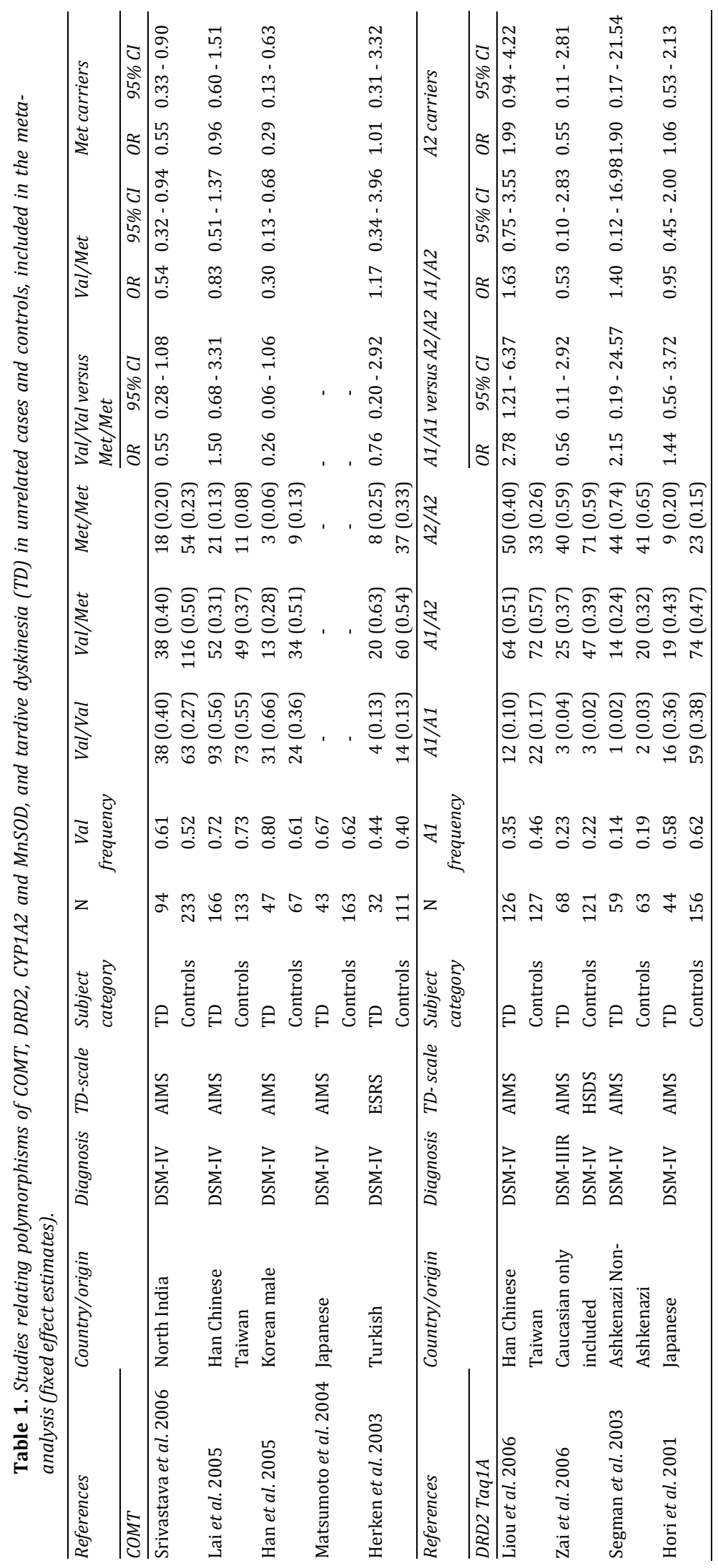




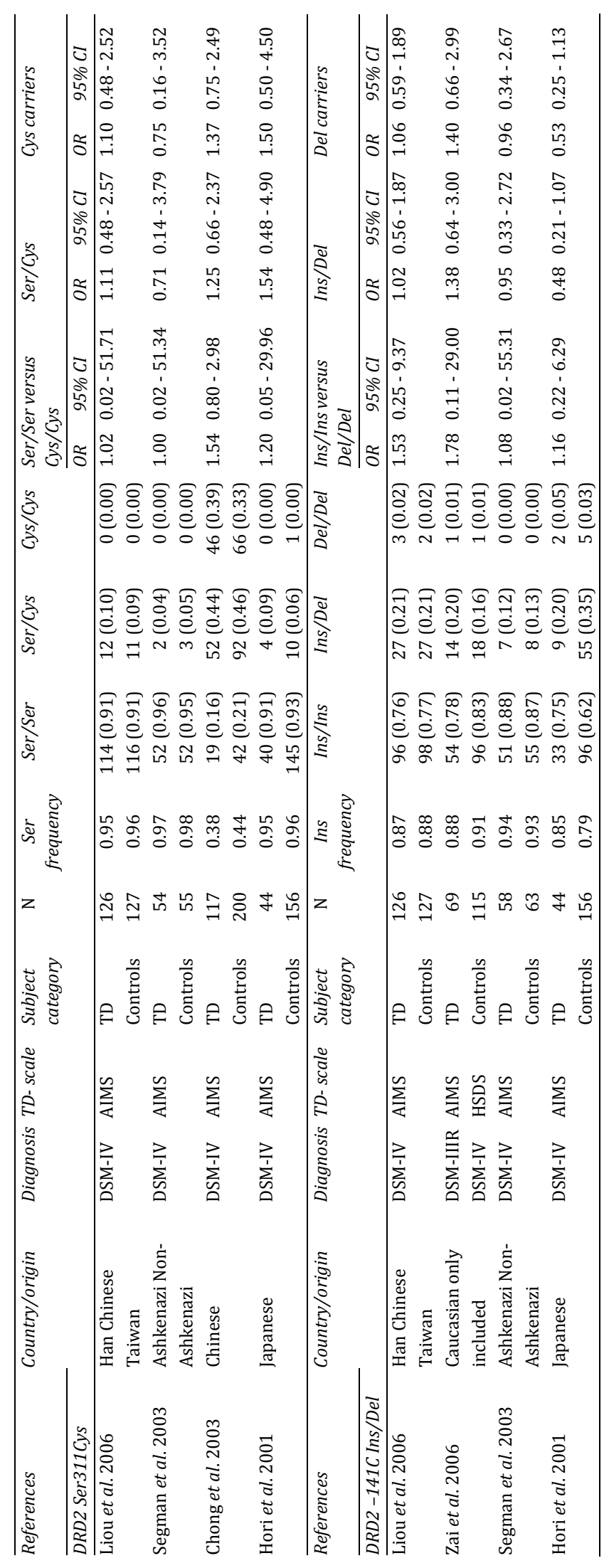




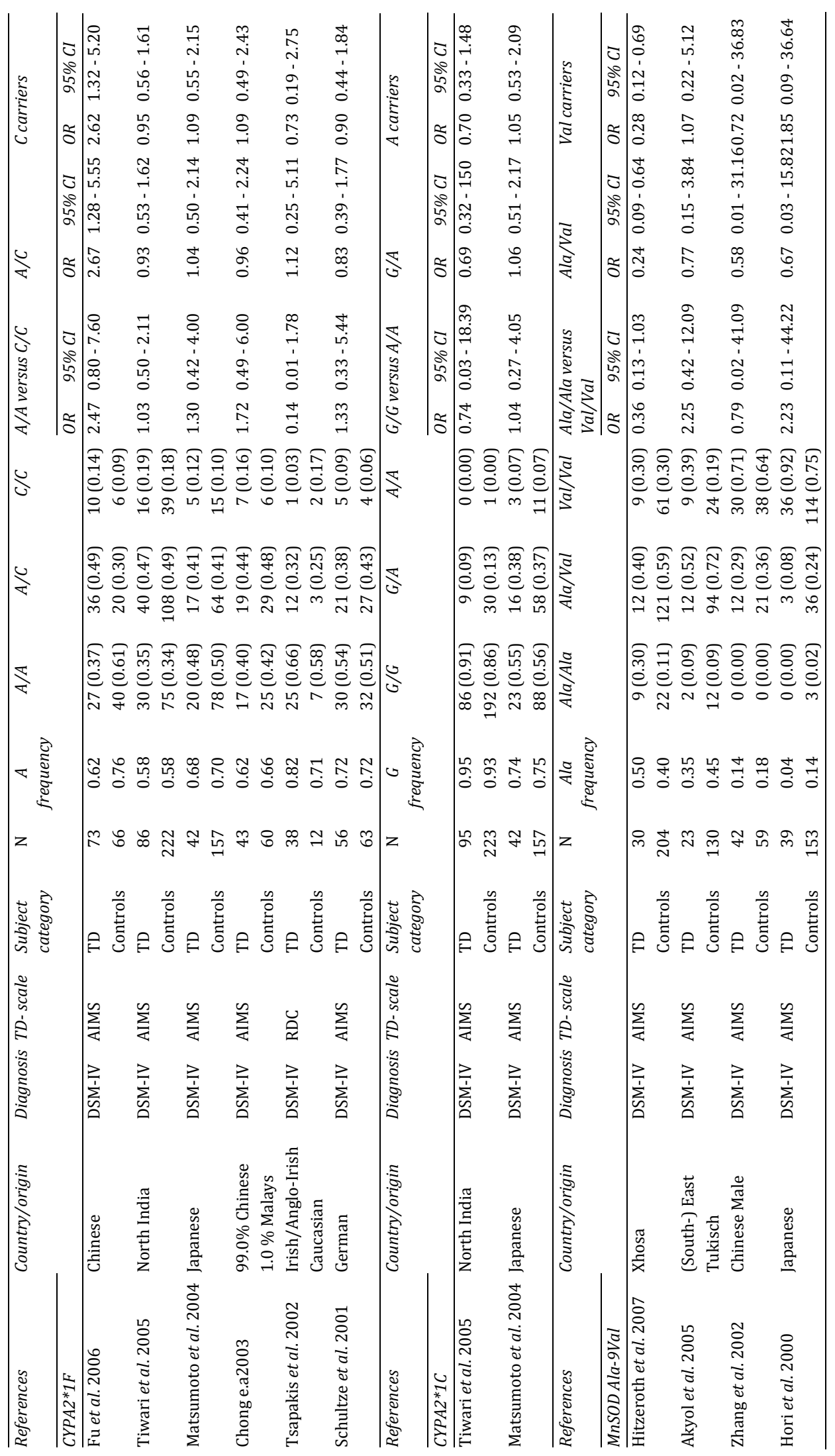




\section{Conclusions}

This study extends previous work in the pharmacogenetic field of TD as the meta-analysis offers a stronger basis for a polygenetic component for the pharmacogenetic interactions underlying TD. Evidence from pooled data for positive genetic association with TD shows significant effects for (1) COMTval158met with decreased risk for Val-Met heterozygotes and for Met carriers compared to the Val-Val reference group; (2) Taq1A in DRD2 with increased risk for the A2 allele and A2-A2 genotype compared to the A1 and A1-A1 reference groups; (3) $M n S O D$, with decreased risk for Ala-Val and Val carriers compared to the AlaAla reference group.

In contrast with the theory of a higher risk of TD in relation to the Metvariant in COMT and the Val-variant of MnSOD, the current meta-analysis shows an opposite effect. These results suggest different mechanism(s), such as less extra cellular dopamine production in patients with high activity COMT gene (Han et al., 2005). Alternatively, this result may be due to haplotypic heterogeneity across populations (Palmatier et al., 2004).

The meta-analysis of Taq1A in DRD2 resulted in convincing ORs with a higher risk in A2 for TD. On the other hand, the group of Zai et al. (2007) showed opposing trend which could be explained by inclusion of a Caucasian population; the other studies included Asian or a mix of Ashknazi/non-Ashknazi patients.

We found no heterogeneity in most analyses, possibly because of a lack of power. However, visual inspection of the forest plots does not suggest a large degree of heterogeneity. Not all studies could be included due to unavailable data, but little evidence for publication bias was found. Furthermore, caution is required in generalizing the findings to entire genes, as not all polymorphisms in the genes were studied. Nonsignificant results may be due to small effect size in genetic studies, which usually need larger samples than the studies included in this meta-analysis. In addition, the inconclusive results could reflect ethnic diversity with other functional polymorphisms in LD, that is, the existence of a true pathogenic mutation close to a studied candidate gene may differ between ethnic groups (Arranz and de, 2007). In future, association studies should be replicated using within-family control methodology (transmission/disequilibrium test) (Thomas, 2004), as this was not used in any of the studies of genes and TD.

Although the significant associations are small, various combinations of susceptibility genes may converge on synaptic processing in microcircuits, affecting a final common pathway of dysfunction and related symptoms, and secondary morphological alterations (Coyle, 2006; Ross et al., 2006). Furthermore, findings of small effects should be placed into the proper context with respect to interactions with other genetic susceptibility loci, including additive and epistatic types (Ozdemir et al., 2006a;Harrison and Weinberger, 2005;Lerer, 2002). Muller et 
al. (2004) calculated that the overall prediction model of patients' AIMS in their study, with more than half of the variance predicted by polymorphic variation in $D R D 3$ and CYP1A2 in addition to covariates, had a predictive power that was similar to the test for cardiac enzymes to detect myocardial infarction.

Moreover, the small effects indicate involvement of other genes in the development of TD. Previously, other genes were included in meta-analyses such as (1) the gene encoding for 5-HT2A (Lerer et al., 2005) (a) showing a small but significant association of the T102C genotype in several subgroups of TD and (b) the 5-HT2A His452Tyr polymorphism that showed a significant association with TD in a two-locus haplotype with T102C, (2) the joint comparison group of deficient alleles $(* 3, * 4, * 5)$ with TD (Patsopoulos et al., 2005) and (3) the gene encoding for DRD3 (Lerer et al., 2002;Bakker et al., 2006) showed a significant excess of the Gly-allel and Gly-Gly homozygotes of the Ser9Gly polymorphism in patients with schizophrenia and TD. The meta-analysis of Bakker et al. (2006) showed a reduced or even opposite tendency in Asians compared to non-Asians.

It has been suggested that with the introduction of SGAs, TD is disappearing and no longer of much clinical concern. However, SGAs still carry a risk of movement disorder (Correll et al., 2004;Jones et al., 2006;Lieberman et al., 2005; Tenback et al., 2005). In addition, many patients continue to take FGAs in combination with SGAs (Procyshyn et al., 2001;Broekema et al., 2007). Furthermore, the WHO (http://www.who.int/medicines/en) advocates the use of essential medicines; these are medicines with several characteristics such as serving priority health care needs and cost-effectiveness. As the three antipsychotic drugs enlisted in the most recent (15th) World Health Organization Model List of Essential Medicines are FGA, TD remains an important research topic, especially in developing countries but also in developed countries where health care coverage is not universal.

Future genetic research into antipsychotic-induced TD will take advantage of the expanding numbers of single nucleotide polymorphisms. In addition, genome wide association studies will be possible in the near future (Malhotra et al., 2004; Insel and Lehner, 2007). Furthermore, pharmacogenetics improved our understanding of the pathogenesis and risk factors of TD (Arranz and de Leon, 2007), and may contribute to the development of psychopharmacotherapeutics that are applicable at the level of the individual patient (Ozdemir et al., 2006b).

An important initiative is the creation of Investigator Networks in 2005 by the global Human Genome Epidemiology Network (HuGENet, www.cdc.gov/genomics/hugenet) for the integration of evidence, promoting up-to-date summaries, like meta-analyses, of published and unpublished, including 'negative' studies (Ioannidis et al., 2006).

This meta-analysis shows that several individual genes are related to TD. Therefore, in future studies genes should be assessed simultaneously to unravel the interaction between these genes and TD. Furthermore, knowledge of TD- 
related genes could change the focus on prevention of TD or treatment on existing TD, from receptor-based therapy to potentially more focused intracellular therapeutic targets.

\section{Acknowledgement}

This work was supported by grant from the Foundation 'the Open Ankh', the Netherlands. We thank Hitzevorth et al. for providing the TD data. We also thank Erik de Groot, MSc, for his assistance.

\section{References}

Abdolmaleky, H.M., Thiagalingam, S. and Wilcox, M., 2005. Genetics and epigenetics in major psychiatric disorders: dilemmas, achievements, applications, and future scope. Am J Pharmacogenomics. 5, 149-160.

Accili, D., Fishburn, C.S., Drago, J., Steiner, H., Lachowicz, J.E., Park, B.H., Gauda, E.B., Lee, E.J., Cool, M.H., Sibley, D.R., Gerfen, C.R., Westphal, H. and Fuchs, S., 1996. A targeted mutation of the D3 dopamine receptor gene is associated with hyperactivity in mice. Proc Natl Acad Sci U S A. 93, 1945-1949.

Akyol, O., Yanik, M., Elyas, H., Namli, M., Canatan, H., Akin, H., Yuce, H., Yilmaz, H.R., Tutkun, H., Sogut, S., Herken, H., Ozyurt, H., Savas, H.A. and Zoroglu, S.S., 2005. Association between Ala-9Val polymorphism of Mn-SOD gene and schizophrenia. Prog Neuropsychopharmacol Biol Psychiatry. 29, 123-131.

Arinami, T., Gao, M., Hamaguchi, H. and Toru, M., 1997. A functional polymorphism in the promoter region of the dopamine D2 receptor gene is associated with schizophrenia. Hum Mol Genet. 6, 577-582.

Arranz, M.J. and de Leon, J., 2007. Pharmacogenetics and pharmacogenomics of schizophrenia: a review of last decade of research. Mol Psychiatry. 12, 707-747.

Bakker, P.R., van Harten, P.N. and van Os, J., 2006. Antipsychotic-induced tardive dyskinesia and the Ser9Gly polymorphism in the DRD3 gene: a meta analysis. Schizophr Res. 83, 185-192.

Basile, V.S., Masellis, M., Potkin, S.G. and Kennedy, J.L., 2002. Pharmacogenomics in schizophrenia: the quest for individualized therapy. Hum Mol Genet. 11, 2517-30.

Basile, V.S., Ozdemir, V., Masellis, M., Walker, M.L., Meltzer, H.Y., Lieberman, J.A., Potkin, S.G., Alva, G., Kalow, W., Macciardi, F.M. and Kennedy, J.L., 2000. A functional polymorphism of the cytochrome P450 1A2 (CYP1A2) gene: association with tardive dyskinesia in schizophrenia. Mol Psychiatry. 5, 410-417.

Bray, N.J., Buckland, P.R., Williams, N.M., Williams, H.J., Norton, N., Owen, M.J. and O'Donovan, M.C., 2003. A haplotype implicated in schizophrenia susceptibility is associated with reduced COMT expression in human brain. Am J Hum Genet. 73, 152-161.

Broekema, W.J., de Groot, I.W. and van Harten, P.N., 2007. Simultaneous prescribing of atypical antipsychotics, conventional antipsychotics and anticholinergics-a European study. Pharm World Sci. 29, 126-130.

Chen, C.H., Wei, F.C., Koong, F.J. and Hsiao, K.J., 1997. Association of TaqI A polymorphism of dopamine D2 receptor gene and tardive dyskinesia in schizophrenia. Biol Psychiatry. 41, 827-829.

Chong, S.A., Tan, E.C., Tan, C.H. and Mythily, 2003a. Smoking and tardive dyskinesia: lack of involvement of the CYP1A2 gene. J Psychiatry Neurosci. 28, 185-189.

Chong, S.A., Tan, E.C., Tan, C.H., Mythily and Chan, Y.H., 2003b. Polymorphisms of dopamine receptors and tardive dyskinesia among Chinese patients with schizophrenia. Am J Med Genet. 116B, 51-54. 
Collier, D.A. and Li, T., 2003. The genetics of schizophrenia: glutamate not dopamine? Eur J Pharmacol. 480, 177-184.

Correll, C.U., Leucht, S. and Kane, J.M., 2004. Lower risk for tardive dyskinesia associated with second-generation antipsychotics: a systematic review of 1-year studies. Am J Psychiatry. 161, 41425.

Coyle, J.T., 2006. Glutamate and schizophrenia: beyond the dopamine hypothesis. Cell Mol Neurobiol. 26, 365-384.

Cravchik, A., Sibley, D.R. and Gejman, P.V., 1996. Functional analysis of the human D2 dopamine receptor missense variants. J Biol Chem. 271, 26013-26017.

de Leon, J., Susce, M.T., Pan, R.M., Koch, W.H. and Wedlund, P.J., 2005. Polymorphic variations in GSTM1, GSTT1, PgP, CYP2D6, CYP3A5, and dopamine D2 and D3 receptors and their association with tardive dyskinesia in severe mental illness. J Clin Psychopharmacol. 25, 448-456.

Dolzan, V., Plesnicar, B.K., Serretti, A., Mandelli, L., Zalar, B., Koprivsek, J. and Breskvar, K., 2007. Polymorphisms in dopamine receptor DRD1 and DRD2 genes and psychopathological and extrapyramidal symptoms in patients on long-term antipsychotic treatment. Am J Med Genet B Neuropsychiatr Genet. 144, 809-815.

Egger, M. and Smith, G.D., 1997. Meta-Analysis. Potentials and promise. Bmj. 315, 1371-1374.

Egger, M., Smith, G.D. and Phillips, A.N., 1997. Meta-analysis: principles and procedures. Bmj. 315, 1533-1537.

Elkashef, A.M. and Wyatt, R.J., 1999. Tardive dyskinesia: possible involvement of free radicals and treatment with vitamin E. Schizophr Bull. 25, 731-740.

Ellingrod, V.L., Schultz, S.K. and Arndt, S., 2002. Abnormal movements and tardive dyskinesia in smokers and nonsmokers with schizophrenia genotyped for cytochrome P450 2D6. Pharmacotherapy. 22, 1416-1419.

Fu, Y., Fan, C.H., Deng, H.H., Hu, S.H., Lv, D.P., Li, L.H., Wang, J.J. and Lu, X.Q., 2006. Association of CYP2D6 and CYP1A2 gene polymorphism with tardive dyskinesia in Chinese schizophrenic patients. Acta Pharmacol Sin. 27, 328-332.

Galecki, P., Pietras, T. and Szemraj, J., 2006. [Manganese superoxide dismutase gene (MnSOD) polimorphism in schizophrenics with tardive dyskinesia from central Poland]. Psychiatr Pol. 40, 937-948.

Guzey, C., Scordo, M.G., Spina, E., Landsem, V.M. and Spigset, O., 2007. Antipsychotic-induced extrapyramidal symptoms in patients with schizophrenia: associations with dopamine and serotonin receptor and transporter polymorphisms. Eur J Clin Pharmacol. 63, 233-241.

Han, D.H., Lee, J.H., Lee, Y.S., Kee, B.S., Min, K.J. and Na, C., 2005. The association between tardive dyskinesia induced by haloperidol and polymorphisms in the serotonin transporter gene and catecholamine-0- methyltransferase gene in Korean schizophrenic patients. Clinical Psychopharmacology and Neuroscience. 3, 16-21.

Handoko, H.Y., Nyholt, D.R., Hayward, N.K., Nertney, D.A., Hannah, D.E., Windus, L.C., McCormack, C.M., Smith, H.J., Filippich, C., James, M.R. and Mowry, B.J., 2005. Separate and interacting effects within the catechol-O-methyltransferase (COMT) are associated with schizophrenia. Mol Psychiatry. 10, 589-597.

Harrison, P.J. and Weinberger, D.R., 2005. Schizophrenia genes, gene expression, and neuropathology: on the matter of their convergence. Mol Psychiatry. 10, 40-68.

Herken, H., Erdal, M.E., Boke, O. and Savas, H.A., 2003. Tardive dyskinesia is not associated with the polymorphisms of 5-HT2A receptor gene, serotonin transporter gene and catechol-omethyltransferase gene. Eur Psychiatry. 18, 77-81.

Hitzeroth, A., Niehaus, D.J., Koen, L., Botes, W.C., Deleuze, J.F. and Warnich, L., 2007. Association between the MnSOD Ala-9Val polymorphism and development of schizophrenia and abnormal involuntary movements in the Xhosa population. Prog Neuropsychopharmacol Biol Psychiatry. 31, 664-672.

Hori, H., Ohmori, O., Shinkai, T., Kojima, H. and Nakamura, J., 2001. Association between three functional polymorphisms of dopamine D2 receptor gene and tardive dyskinesia in schizophrenia. Am J Med Genet. 105, 774-778. 
Hori, H., Ohmori, O., Shinkai, T., Kojima, H., Okano, C., Suzuki, T. and Nakamura, J., 2000. Manganese superoxide dismutase gene polymorphism and schizophrenia: relation to tardive dyskinesia. Neuropsychopharmacology. 23, 170-177.

Insel, T.R. and Lehner, T., 2007. A new era in psychiatric genetics? Biol Psychiatry. 61, 1017-1018.

Ioannidis, J.P., Gwinn, M., Little, J., Higgins, J.P., Bernstein, J.L., Boffetta, P., Bondy, M., Bray, M.S., Brenchley, P.E., Buffler, P.A., Casas, J.P., Chokkalingam, A., Danesh, J., Smith, G.D., Dolan, S., Duncan, R., Gruis, N.A., Hartge, P., Hashibe, M., Hunter, D.J., Jarvelin, M.R., Malmer, B., Maraganore, D.M., Newton-Bishop, J.A., O'Brien, T.R., Petersen, G., Riboli, E., Salanti, G., Seminara, D., Smeeth, L., Taioli, E., Timpson, N., Uitterlinden, A.G., Vineis, P., Wareham, N., Winn, D.M., Zimmern, R. and Khoury, M.J., 2006. A road map for efficient and reliable human genome epidemiology. Nat Genet. 38, 3-5.

Jann, M.W., 2004. Implications for atypical antipsychotics in the treatment of schizophrenia: neurocognition effects and a neuroprotective hypothesis. Pharmacotherapy. 24, 1759-1783.

Jones, P.B., Barnes, T.R., Davies, L., Dunn, G., Lloyd, H., Hayhurst, K.P., Murray, R.M., Markwick, A. and Lewis, S.W., 2006. Randomized controlled trial of the effect on Quality of Life of second- vs firstgeneration antipsychotic drugs in schizophrenia: Cost Utility of the Latest Antipsychotic Drugs in Schizophrenia Study (CUtLASS 1). Arch Gen Psychiatry. 63, 1079-1087.

Jonsson, E.G., Nothen, M.M., Grunhage, F., Farde, L., Nakashima, Y., Propping, P. and Sedvall, G.C., 1999. Polymorphisms in the dopamine D2 receptor gene and their relationships to striatal dopamine receptor density of healthy volunteers. Mol Psychiatry. 4, 290-296.

Kaiser, R., Tremblay, P.B., Klufmoller, F., Roots, I. and Brockmoller, J., 2002. Relationship between adverse effects of antipsychotic treatment and dopamine $D(2)$ receptor polymorphisms in patients with schizophrenia. Mol Psychiatry. 7, 695-705.

Lai, I.C., Wang, Y.C., Lin, C.C., Bai, Y.M., Liao, D.L., Yu, S.C., Lin, C.Y., Chen, J.Y. and Liou, Y.J., 2005. Negative association between Catechol-O-methyltransferase (COMT) gene Val158Met polymorphism and persistent tardive dyskinesia in schizophrenia. J Neural Transm. 112, 1107-1113.

Laruelle, M., Gelernter, J. and Innis, R.B., 1998. D2 receptors binding potential is not affected by Taq1 polymorphism at the D2 receptor gene. Mol Psychiatry. 3, 261-265.

Lattuada, E., Cavallaro, R., Serretti, A., Lorenzi, C. and Smeraldi, E., 2004. Tardive dyskinesia and DRD2, DRD3, DRD4, 5-HT2A variants in schizophrenia: an association study with repeated assessment. Int J Neuropsychopharmacol. 7, 489-493.

Lerer, B., Segman, R.H., Fangerau, H., Daly, A.K., Basile, V.S., Cavallaro, R., Aschauer, H.N., McCreadie, R.G., Ohlraun, S., Ferrier, N., Masellis, M., Verga, M., Scharfetter, J., Rietschel, M., Lovlie, R., Levy, U.H., Meltzer, H.Y., Kennedy, J.L., Steen, V.M. and Macciardi, F., 2002. Pharmacogenetics of tardive dyskinesia: combined analysis of 780 patients supports association with dopamine D3 receptor gene Ser9Gly polymorphism. Neuropsychopharmacology. 27, 105-19.

Lerer, B., Segman, R.H., Tan, E.C., Basile, V.S., Cavallaro, R., Aschauer, H.N., Strous, R., Chong, S.A., Heresco-Levy, U., Verga, M., Scharfetter, J., Meltzer, H.Y., Kennedy, J.L. and Macciardi, F., 2005. Combined analysis of 635 patients confirms an age-related association of the serotonin $2 \mathrm{~A}$ receptor gene with tardive dyskinesia and specificity for the non-orofacial subtype. Int J Neuropsychopharmacol. 8, 411-425.

Lerer, B., 2002. Pharmacogenetics of psychotropic drugs Cambridge University Press, Cambridge, UK.

Lieberman, J.A., Stroup, T.S., McEvoy, J.P., Swartz, M.S., Rosenheck, R.A., Perkins, D.O., Keefe, R.S., Davis, S.M., Davis, C.E., Lebowitz, B.D., Severe, J. and Hsiao, J.K., 2005. Effectiveness of antipsychotic drugs in patients with chronic schizophrenia. N Engl J Med. 353, 1209-1223.

Liou, Y.J., Lai, I.C., Liao, D.L., Chen, J.Y., Lin, C.C., Lin, C.Y., Chen, C.M., Bai, Y.M., Chen, T.T. and Wang, Y.C., 2006. The human dopamine receptor D2 (DRD2) gene is associated with tardive dyskinesia in patients with schizophrenia. Schizophr Res. 86, 323-325.

MacLeod, S.L., Tang, Y-M., Yokoi, T., Kamataki, T., Doublin, S. and Lawson, B., 1998. The role of a recently discovered genetic polymorphism in the regulation of the human CYP1A2 gene. Proc Am Assoc Cancer Res. 39, 396. 
Malhotra, A.K., Murphy, G.M., Jr. and Kennedy, J.L., 2004. Pharmacogenetics of psychotropic drug response. Am J Psychiatry. 161, 780-796.

Marsalek, M., 2000. Tardive drug-induced extrapyramidal syndromes. Pharmacopsychiatry. 33 Suppl 1, 14-33.

Matsumoto, C., Ohmori, O., Shinkai, T., Hori, H. and Nakamura, J., 2004a. Genetic association analysis of functional polymorphisms in the cytochrome P450 1A2 (CYP1A2) gene with tardive dyskinesia in Japanese patients with schizophrenia. Psychiatr Genet. 14, 209-213.

Matsumoto, C., Shinkai, T., Hori, H., Ohmori, O. and Nakamura, J., 2004b. Polymorphisms of dopamine degradation enzyme (COMT and MAO) genes and tardive dyskinesia in patients with schizophrenia. Psychiatry Res. 127, 1-7.

Muller, D.J., Shinkai, T., De Luca, V. and Kennedy, J.L., 2004. Clinical implications of pharmacogenomics for tardive dyskinesia. Pharmacogenomics J. 4, 77-87.

Nakajima, M., Yokoi, T., Mizutani, M., Kinoshita, M., Funayama, M. and Kamataki, T., 1999. Genetic polymorphism in the 5 '-flanking region of human CYP1A2 gene: effect on the CYP1A2 inducibility in humans. J Biochem (Tokyo). 125, 803-808.

Nakazono, Y., Abe, H., Murakami, H., Koyabu, N., Isaka, Y., Nemoto, Y., Murata, S., Tsutsumi, Y., Ohtani, H. and Sawada, Y., 2005. Association between neuroleptic drug-induced extrapyramidal symptoms and dopamine D2-receptor polymorphisms in Japanese schizophrenic patients. Int J Clin Pharmacol Ther. 43, 163-171.

Neville, M.J., Johnstone, E.C. and Walton, R.T., 2004. Identification and characterization of ANKK1: a novel kinase gene closely linked to DRD2 on chromosome band 11q23.1. Hum Mutat. 23, 540545.

Noble, E.P., 2003. D2 dopamine receptor gene in psychiatric and neurologic disorders and its phenotypes. Am J Med Genet B Neuropsychiatr Genet. 116, 103-125.

Noble, E.P., Blum, K., Ritchie, T., Montgomery, A. and Sheridan, P.J., 1991. Allelic association of the D2 dopamine receptor gene with receptor-binding characteristics in alcoholism. Arch Gen Psychiatry. 48, 648-654.

Ozdemir, V., Aklillu, E., Mee, S., Bertilsson, L., Albers, L.J., Graham, J.E., Caligiuri, M., Lohr, J.B. and Reist, C., 2006a. Pharmacogenetics for off-patent antipsychotics: reframing the risk for tardive dyskinesia and access to essential medicines. Expert Opin Pharmacother. 7, 119-133.

Ozdemir, V., Williams-Jones, B., Glatt, S.J., Tsuang, M.T., Lohr, J.B. and Reist, C., 2006b. Shifting emphasis from pharmacogenomics to theragnostics. Nat Biotechnol. 24, 942-946.

Pae, C.U., 2006. Comments on "Association between Ala-9Val polymorphism of MnSOD gene and schizophrenia" by 0. Akyol et al. Progress in Neuropsychopharmacology and Biological Psychiatry 29, 2005, 123-131. Prog Neuropsychopharmacol Biol Psychiatry. 30, 762-763.

Palmatier, M.A., Pakstis, A.J., Speed, W., Paschou, P., Goldman, D., Odunsi, A., Okonofua, F., Kajuna, S., Karoma, N., Kungulilo, S., Grigorenko, E., Zhukova, O.V., Bonne-Tamir, B., Lu, R.B., Parnas, J., Kidd, J.R., DeMille, M.M. and Kidd, K.K., 2004. COMT haplotypes suggest P2 promoter region relevance for schizophrenia. Mol Psychiatry. 9, 859-870.

Patsopoulos, N.A., Ntzani, E.E., Zintzaras, E. and Ioannidis, J.P., 2005. CYP2D6 polymorphisms and the risk of tardive dyskinesia in schizophrenia: a meta-analysis. Pharmacogenet Genomics. 15, 151158.

Pohjalainen, T., Rinne, J.O., Nagren, K., Lehikoinen, P., Anttila, K., Syvalahti, E.K. and Hietala, J., 1998. The A1 allele of the human D2 dopamine receptor gene predicts low D2 receptor availability in healthy volunteers. Mol Psychiatry. 3, 256-260.

Procyshyn, R.M., Kennedy, N.B., Tse, G. and Thompson, B., 2001. Antipsychotic polypharmacy: a survey of discharge prescriptions from a tertiary care psychiatric institution. Can J Psychiatry. 46, 334-339.

Ritchie, T. and Noble, E.P., 2003. Association of seven polymorphisms of the D2 dopamine receptor gene with brain receptor-binding characteristics. Neurochem Res. 28, 73-82.

Rosenblum, J.S., Gilula, N.B. and Lerner, R.A., 1996. On signal sequence polymorphisms and diseases of distribution. Proc Natl Acad Sci U S A. 93, 4471-4473. 
Ross, C.A., Margolis, R.L., Reading, S.A., Pletnikov, M. and Coyle, J.T., 2006. Neurobiology of schizophrenia. Neuron. 52, 139-153.

Sachdev, P.S., 2005. Neuroleptic-induced movement disorders: an overview. Psychiatr Clin North Am. 28, 255-74, $\mathrm{x}$.

Sachse, C., Brockmoller, J., Bauer, S. and Roots, I., 1999. Functional significance of a C-->A polymorphism in intron 1 of the cytochrome P450 CYP1A2 gene tested with caffeine. Br J Clin Pharmacol. 47, 445-449.

Schulze, T.G., Schumacher, J., Muller, D.J., Krauss, H., Alfter, D., Maroldt, A., Ahle, G., Maroldt, A.O., Fernandez, A., Weber, T., Held, T., Propping, P., Maier, W., Nothen, M.M. and Rietschel, M., 2001. Lack of association between a functional polymorphism of the cytochrome P450 1A2 (CYP1A2) gene and tardive dyskinesia in schizophrenia. Am J Med Genet. 105, 498-501.

Segman, R.H., Goltser, T., Heresco-Levy, U., Finkel, B., Shalem, R., Schlafman, M., Yakir, A., Greenberg, D., Strous, R., Lerner, A., Shelevoy, A. and Lerer, B., 2003. Association of dopaminergic and serotonergic genes with tardive dyskinesia in patients with chronic schizophrenia. Pharmacogenomics J. 3, 277-283.

Shen, H., He, M.M., Liu, H., Wrighton, S.A., Wang, L., Guo, B. and Li, C., 2007. Comparative Metabolic Capabilities and Inhibitory Profiles of CYP2D6.1, CYP2D6.10, and CYP2D6.17. Drug Metab Dispos. 35, 1292-1300.

Shifman, S., Bronstein, M., Sternfeld, M., Pisante-Shalom, A., Lev-Lehman, E., Weizman, A., Reznik, I., Spivak, B., Grisaru, N., Karp, L., Schiffer, R., Kotler, M., Strous, R.D., Swartz-Vanetik, M., Knobler, H.Y., Shinar, E., Beckmann, J.S., Yakir, B., Risch, N., Zak, N.B. and Darvasi, A., 2002. A highly significant association between a COMT haplotype and schizophrenia. Am J Hum Genet. 71, 12961302.

Shimoda-Matsubayashi, S., Matsumine, H., Kobayashi, T., Nakagawa-Hattori, Y., Shimizu, Y. and Mizuno, Y., 1996. Structural dimorphism in the mitochondrial targeting sequence in the human manganese superoxide dismutase gene. A predictive evidence for conformational change to influence mitochondrial transport and a study of allelic association in Parkinson's disease. Biochem Biophys Res Commun. 226, 561-565.

Silvestri, S., Seeman, M.V., Negrete, J.C., Houle, S., Shammi, C.M., Remington, G.J., Kapur, S., Zipursky, R.B., Wilson, A.A., Christensen, B.K. and Seeman, P., 2000. Increased dopamine D2 receptor binding after long-term treatment with antipsychotics in humans: a clinical PET study. Psychopharmacology (Berl). 152, 174-180.

Srivastava, V., Varma, P.G., Prasad, S., Semwal, P., Nimgaonkar, V.L., Lerer, B., Deshpande, S.N. and Thelma, B.K., 2006. Genetic susceptibility to tardive dyskinesia among schizophrenia subjects: IV. Role of dopaminergic pathway gene polymorphisms. Pharmacogenet Genomics. 16, 111-117.

Sutton, A., Imbert, A., Igoudjil, A., Descatoire, V., Cazanave, S., Pessayre, D. and Degoul, F., 2005. The manganese superoxide dismutase Ala16Val dimorphism modulates both mitochondrial import and mRNA stability. Pharmacogenet Genomics. 15, 311-319.

Sutton, A., Khoury, H., Prip-Buus, C., Cepanec, C., Pessayre, D. and Degoul, F., 2003. The Ala16Val genetic dimorphism modulates the import of human manganese superoxide dismutase into rat liver mitochondria. Pharmacogenetics. 13, 145-157.

Suzuki, M., Hurd, Y.L., Sokoloff, P., Schwartz, J.C. and Sedvall, G., 1998. D3 dopamine receptor mRNA is widely expressed in the human brain. Brain Res. 779, 58-74.

Tenback, D.E., van Harten, P.N., Slooff, C.J., Belger, M.A. and van Os, J., 2005. Effects of antipsychotic treatment on tardive dyskinesia: a 6-month evaluation of patients from the European Schizophrenia Outpatient Health Outcomes (SOHO) Study. J Clin Psychiatry. 66, 1130-1133.

Thomas, D.C., 2004. Statistical methods in genetic epidemiology Oxford University Press, Oxford.

Thompson, J., Thomas, N., Singleton, A., Piggott, M., Lloyd, S., Perry, E.K., Morris, C.M., Perry, R.H., Ferrier, I.N. and Court, J.A., 1997. D2 dopamine receptor gene (DRD2) Taq1 A polymorphism: reduced dopamine D2 receptor binding in the human striatum associated with the A1 allele. Pharmacogenetics. 7, 479-484. 
Tiwari, A.K., Deshpande, S.N., Rao, A.R., Bhatia, T., Lerer, B., Nimgaonkar, V.L. and Thelma, B.K., 2005a. Genetic susceptibility to tardive dyskinesia in chronic schizophrenia subjects: III. Lack of association of CYP3A4 and CYP2D6 gene polymorphisms. Schizophr Res. 75, 21-26.

Tiwari, A.K., Deshpande, S.N., Rao, A.R., Bhatia, T., Mukit, S.R., Shriharsh, V., Lerer, B., Nimagaonkar, V.L. and Thelma, B.K., 2005b. Genetic susceptibility to tardive dyskinesia in chronic schizophrenia subjects: I. Association of CYP1A2 gene polymorphism. Pharmacogenomics J. 5, 60-69.

Tsai, G., Goff, D.C., Chang, R.W., Flood, J., Baer, L. and Coyle, J.T., 1998. Markers of glutamatergic neurotransmission and oxidative stress associated with tardive dyskinesia. Am J Psychiatry. 155, 1207-1213.

Tsapakis, E.M., Meagher, D., Quinn, J., Waddington, J.L., Gill, M., Kerwin, R.W. and Aitchison, K.J. An association study of the CYP1A2-164A polymorphism and tardive dyskinesia. 2002.

van Os, J., Fahy, T., Jones, P., Harvey, I., Toone, B. and Murray, R., 1997. Tardive dyskinesia: who is at risk? Acta Psychiatr Scand. 96, 206-16.

Williams, H.J., Owen, M.J. and O'Donovan, M.C., 2007. Is COMT a Susceptibility Gene for Schizophrenia? Schizophr Bull. 33, 635-641.

Xu, X.F., Zhang, X.B., Sha, W.W. and Zhou, C.Y., 2006. Association of the gene polymorphism of dopamine and serotonin $2 \mathrm{~A}$ receptors with tardive dyskinesia in chronic schizophrenia. Zhongguo Linchuang Kangfu. 10, 106-108.

Young, R.M., Lawford, B.R., Nutting, A. and Noble, E.P., 2004. Advances in molecular genetics and the prevention and treatment of substance misuse: Implications of association studies of the A1 allele of the D2 dopamine receptor gene. Addict Behav. 29, 1275-1294.

Zai, C.C., Hwang, R.W., De Luca, V., Muller, D.J., King, N., Zai, G.C., Remington, G., Meltzer, H.Y., Lieberman, J.A., Potkin, S.G. and Kennedy, J.L., 2007. Association study of tardive dyskinesia and twelve DRD2 polymorphisms in schizophrenia patients. Int J Neuropsychopharmacol. 10, 639-651.

Zhang, Z., Zhang, X., Hou, G., Sha, W. and Reynolds, G.P., 2002. The increased activity of plasma manganese superoxide dismutase in tardive dyskinesia is unrelated to the Ala-9Val polymorphism. J Psychiatr Res. 36, 317-324. 



\section{Part 2 - Prospective naturalistic study}

\section{Part 2a - Non-genetic risk factors}




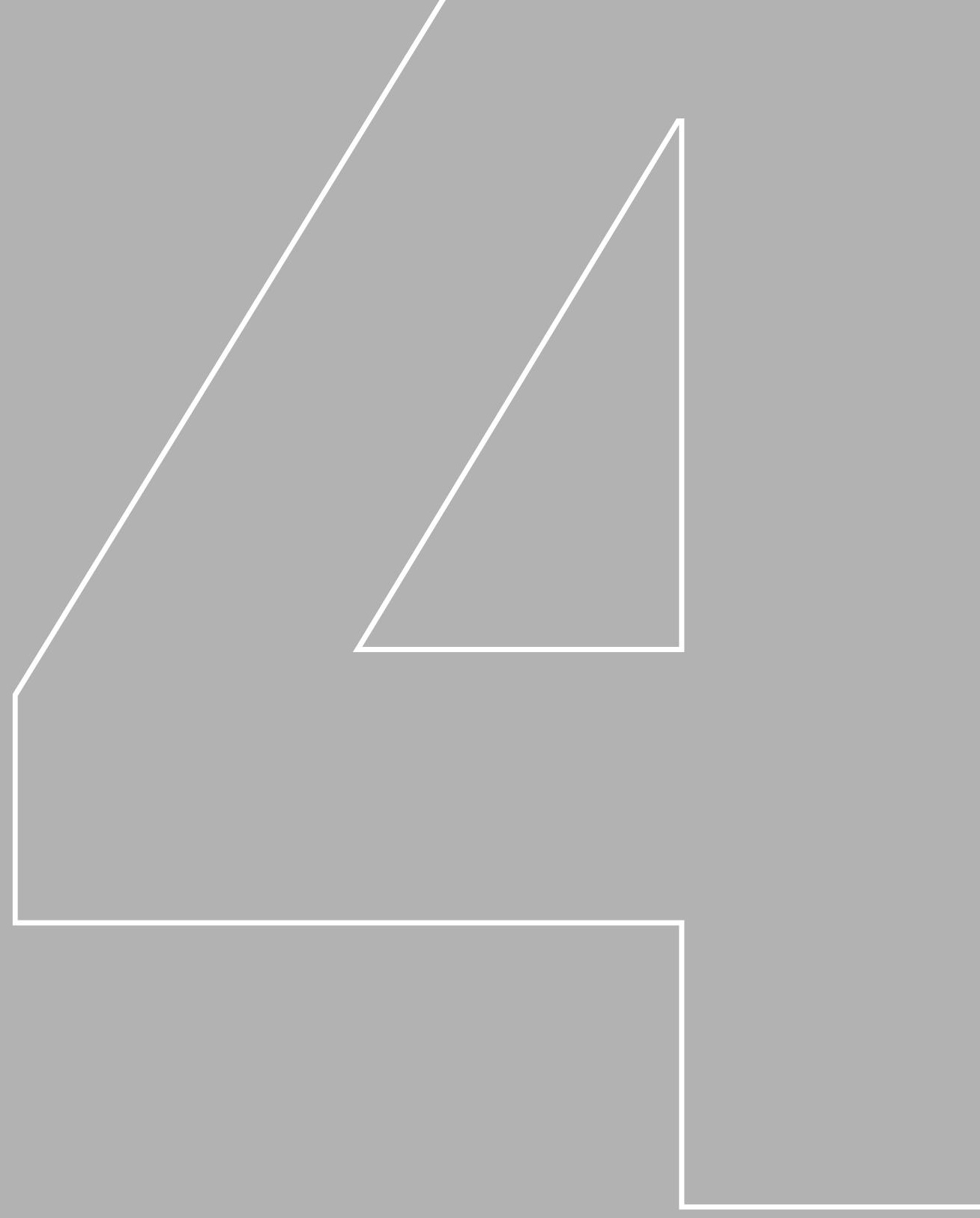




\title{
Chapter 4
}

\section{Long-stay psychiatric patients: A prospective study revealing persistent antipsychotic-induced movement disorder}

\author{
P. Roberto Bakkera, Izaäk W. de Groot ${ }^{b}$, Jim van Os, ${ }^{c, d}$, Peter N. van Harten ${ }^{a, c}$ \\ ${ }^{a}$ Psychiatric Centre GGZ Centraal, Amersfoort, The Netherlands \\ ${ }^{\mathrm{b}}$ Dimence, Centre for Mental Health Care, Deventer, The Netherlands \\ ${ }^{\mathrm{c}}$ Department of Psychiatry and Psychology, South Limburg Mental Health Research and Teaching \\ Network, EURON, Maastricht University, Maastricht, The Netherlands \\ ${ }^{d}$ King's Health Partners, Department of Psychosis Studies, Institute of Psychiatry, King's College \\ London, London, United Kingdom
}

PLoS One. 2011; 6(10): e25588 


\section{Abstract}

\section{Objective}

The purpose of this study was to assess the frequency of persistent druginduced movement disorders namely, tardive dyskinesia (TD), parkinsonism, akathisia and tardive dystonia in a representative sample of long-stay patients with chronic severe mental illness.

\section{Method}

Naturalistic study of 209, mainly white, antipsychotic-treated patients, mostly diagnosed with psychotic disorder. Of this group, the same rater examined 194 patients at least two times over a 4-year period, with a mean follow-up time of 1.1 years, with validated scales for TD, parkinsonism, akathisia, and tardive dystonia.

\section{Results}

The frequencies of persistent movement disorders in the sample were $28.4 \%$ for TD, 56.2\% for parkinsonism, 4.6\% for akathisia and 5.7\% for tardive dystonia. Two-thirds of the participants displayed at least one type of persistent movement disorder.

\section{Conclusions}

Persistent movement disorder continues to be the norm for long-stay patients with chronic mental illness and long-term antipsychotic treatment. Measures are required to remedy this situation. 


\section{Introduction}

Antipsychotics remain the cornerstone of treatment in psychotic disorder. However, they may induce several side effects, one of which is movement disorder. Antipsychotic-induced movement disorder constitutes a major reason for noncompliance, resulting in an increased risk of psychotic relapse (Casey, 2006; Lambert et al., 2004;Robinson et al., 2002). In addition, a meta-analysis (Ballesteros et al., 2000) and two recent studies showed a higher mortality in patients with tardive dyskinesia (TD) (Chong et al., 2009;Dean and Thuras, 2009).

Antipsychotic-induced movement disorders (Owens, 1999;Factor et al., 2005) can be divided in acute syndromes such as parkinsonism and akathisia, that occur within days or weeks after starting an antipsychotic, or after increasing the dose, and tardive syndromes, such as TD and tardive dystonia, that develop after months or years of antipsychotic treatment. In patients on long-term treatment with antipsychotics, combinations of acute and tardive syndromes may also occur.

Although second generation antipsychotics (SGAs) may be associated with a lower incidence rate of movement disorder, these medications nevertheless still carry risk (Kahn et al., 2008;Miller et al., 2008;Rosenheck et al., 2003;Lewis and Lieberman, 2008; Leucht et al., 2009a;Tenback et al., 2005;Lieberman et al., 2005; Correll et al., 2004; Jones et al., 2006;Weiden, 2007). In patients on longterm treatment with first generation antipsychotics (FGAs), the reported prevalence of antipsychotic-induced movement disorders was around 50 to $75 \%$ (Janno et al., 2004; van Harten, 1998). Eleven long-term studies with SGAs (except clozapine) showed a reduced risk of drug-induced movement disorder, but not their expected disappearance (Correll and Schenk, 2008). These studies had several limitations such as lack of equivalent dosage of haloperidol in the control arm, high drop-out rates, short study duration and unreliable measurement of movement disorder. Three large, non-commercially funded trials published in the last five years found differences in the incidence of parkinsonism and akathisia, but no clear differences in the incidence of TD in a comparison between FGAs and SGAs (CATIE, Cutlass and EUFEST trial) (Casey, 2006; Jones et al., 2006;Kahn et al., 2008;Lieberman et al., 2005). However, these studies also had methodological limitations such as a relatively short time to detect TD (around one year), high drop-out rates, and, in the Cutlass trial, many patients in the FGA group used sulpiride which has a lower incidence of movement disorder and is classified by some researchers as an SGA. A recent prospective cohort study with TD as primary outcome found no significant difference in the incidence of TD between patients taking FGAs and SGAs (Woods et al., 2010). Leucht and colleagues (2009b) demonstrated that SGAs are a heterogenous group, each agent displaying its own particular properties. Furthermore, from a global perspective, the three antipsychotic drugs listed in the most recent (Index 
2011) World Health Organization Model List of Essential Medicines are FGAs, namely chlorpromazine, fluphenazine and haloperidol (http://www.who.int/medicines/en).

Populations most at risk are those that are chronically exposed to antipsychotics, particularly when residing in hospital settings, where compliance likely is high and polypharmacy is common, further increasing risk for movement disorder (Taylor, 2010). Although long-stay settings are not mainstream, they remain a reality for a considerable number of patients with severe and chronic mental illness (Fisher et al., 2001), and can be extended to the population in supervised residences in the community, where intake of medication often is similarly supervised. One retrospective survey reported existence of an antipsychotic polypharmacy regimen in $27.5 \%$ of the discharged patients with schizophrenia, such as concurrent use of FGAs and SGAs, in a tertiary psychiatric setting (Procyshyn et al., 2001). Broekema and colleagues (2007) reported that the combination of SGAs and FGAs and/or anticholinergics constituted common practice in several European psychiatric hospitals. Routine cross-sectional data may not be suitable for the examination of rates of movement disorder in vulnerable populations with chronic mental illness, as drug-induced movement disorders fluctuate over time and remain underdiagnosed by both psychiatrists and neurologists (Factor et al., 2009;Esper and Factor, 2008;Friedman et al., 2004; Lerner et al., 2007).

For these reasons, a systematic and prospective assessment of movement disorder in a representative population of patients with long-term exposure to antipsychotics was used to examine the hypothesis that movement disorders remain highly prevalent in vulnerable populations.

\section{Methods}

\section{Ethics statement}

The protocol was approved by the standing Institutional Review Board, 'Medisch-ethische Toetsingscommissie Instellingen Geestelijke Gezondheidszorg' (Review Board for Human Research in Psychiatry), the Netherlands [protocol number 377].

Written informed consent was obtained from each patient; consent obtained from the next of kin was neither necessary nor recommended by the Review Board for Human Research in Psychiatry.

\section{Subjects}

A 4-year prospective naturalistic study (July 2003-May 2007) was conducted in order to determine the frequency of TD, parkinsonism, akathisia and tardive 
dystonia in 209 patients with chronic mental illness. To this end, a cohort was drawn from a general psychiatric hospital (GGZ Centraal, Amersfoort, the Netherlands). Inclusion criteria were: minimum age of 18 years and cumulative exposure to antipsychotics for at least 1 year. Exclusion criteria were: history of neurological disorders impacting on motor function. The cohort was representative of the population of patients with the most severe chronic mental illness requiring long-stay care, given that the hospital serves an epidemiological catchment area, is the only institute providing this type of care and patients were approached using a comprehensive list of all in-patient.

Of the patients assessed at baseline $(\mathrm{N}=207) 93.7 \%(\mathrm{n}=194)$ had one follow-up and $59.4 \%(n=123)$ had two follow-up assessments. Loss to follow-up was due to patients who were difficult to trace after leaving hospital, as well as patients dying or patients refusing assessment after inclusion.

\section{Assessment}

Patients were examined by a trained psychiatrist (PRB), using a standard protocol, described by van Harten and colleagues (1996). Patients were barefooted and seated in a chair without armrests. The researcher asked detailed questions about (i) use of chewing gum or candy at the moment of assessment as well as (ill-fitting) dentures, as both may be misdiagnosed as orofacial movement disorders, and (ii) subjective akathisia. The patient performed different tasks to assess the existence of movement disorders and to provoke abnormal movements. Thus, the following positions were adopted in succession: resting arms on the lap in different positions, arms hanging aside, stretching arms, making fast alternating hand and foot movements, opening the mouth, showing the tongue, rising from chair, and walking. Additionally, posture, rigidity and balance were assessed. Tongue dyskinesia was provoked by fingertip movements, and objective akathisia by talking conversationally while the patient was standing.

Originally, in addition to the term 'acute', the term 'tardive' (delayed) was introduced to emphasize the late-onset types of movement disorders during antipsychotic use. Yet, the definition in the current study emphasizes their persistence, which is more important (Sachdev, 2005; Factor et al., 2005).

Dyskinesia (APA, 1992) was defined as hyperkinetic choreiform involuntary movements which often fluctuates in severity. TD was assessed with the Abnormal Involuntary Movement Scale (AIMS) (Guy, 1975;Guy, 1976) and case definition was based on Schooler and Kane criteria (Schooler and Kane, 1982), requiring (i) the presence of moderate dyskinesia in at least one body area or mild dyskinesia in at least two body parts, and (ii) the absence of other conditions resulting in abnormal involuntary movements.

Parkinsonism was assessed with the Unified Parkinson Disease Rating Scale (UPDRS) (Fahn and Elton, 1987). A case definition of parkinsonism was based 
on (i) 'mild' expression of rest-tremor or rigidity as both are typical of parkinsonism, and (ii) if no tremor or rigidity was rated, the cut-off point was one rating of 'moderate' or two ratings of 'mild' on items of bradykinesia and postural stability. The more stringent criteria for items of bradykinesia and postural stability were chosen as these symptoms may be part of psychiatric syndromes or sedation. Besides this definition, an additional case definition of parkinsonism was applied in accordance with the UK Brain Bank definition, using a score of 2 in the bradykinesia items of the motor UPDRS, and a score of 1 in the items rest tremor, rigidity or postural instability of the motor UPDRS.

Akathisia (Factor et al., 2005) was defined as both subjective inner feelings of restlessness and objective motor (leg) movements. A case definition of akathisia was based on a rating of at least 'mild' on the global akathisia item. Akathisia was assessed with the Barnes Akathisia Rating Scale comprising an objective and a subjective item (Barnes, 1989).

Dystonia was defined as a syndrome of sustained muscle contraction, frequently causing twisting and repetitive movements or abnormal postures (van Harten and Kahn, 1999). Tardive dystonia was diagnosed, following Burke's criteria (Burke, 1992), if one body area attracted a rating of at least 'mild' or if two or more body areas attracted a rating of 'slight' on the Fahn-Marsden scale (Burke et al., 1985). As frequent eye-blinking (rating of 'mild' on the item 'eye') has many causes, case definition of tardive dystonia required a rating of at least 'moderate' (blepharospasm) when 'eye' was the only symptom area.

The case definition of a persistent movement disorder was based on 2 consecutive assessments over a period of minimally 3 months, and required that individuals met case definition criteria at two consecutive assessments (hereafter: persistent movement disorder).

Guided by previous literature, variables possibly affecting risk were extracted from patients' case notes including age, sex, diagnosis according to DSM-IV, ethnic group (classified as white and non-white) and duration of hospitalization. At baseline and at each follow-up assessment, current use of antipsychotic and anticholinergic medication was collected from the hospital and outpatient pharmacy databases.

The diagnosis 'schizophrenia' hereafter refers to DSM-IV codes 295.30, 295.10, $295.20,295.90,295.60,295.70$, and other diagnoses of 'psychotic disorder' to 295.40, 297.1, 298.8, 298.9.

\section{Statistical Analyses}

Frequency of persistent movement disorder was calculated in patients with minimally two assessments. Chi-squared tests and nonparametric trend tests were applied to categorical data. 
Antipsychotic doses were converted to defined daily dose (DDD), assigned and reviewed by researchers of the World Health Organisation Centre of Drug Statistics Methodology (WHO, Collaborating Centre for Drugs Statistics Methodology Available at: http://www.whocc.no/atcddd/. Accessed December 2010). DDD was chosen as it better reflects the observed multireceptor involvement of antipsychotics, unlike classic chlorpromazine (CPZ) equivalents which are based mainly on dopamine-2 receptor occupancy. In addition, DDD equivalents are updated periodically. Anticholinergic medication was modeled as a dichotomous variable (yes/no).

\section{Results}

\section{Sample Characteristics}

Of the 209 patients included, one patient developed a brain tumor, another patient died after inclusion. All patients had a history of cumulative antipsychotic intake of minimally 1 year. Attrition was $9.8 \%$.

Most patients were white (85.0\%) and had chronic mental illness requiring long-term admission. At baseline, the mean (SD) age was 47.4 (12.8) years; men 46.3 (12.8) and women 49.1 (12.7) of age. The mean (SD) age at first admission was 25.0 (8.4) years; men 23.8 (7.6) and women 26.7 (9.3) of age at first admission. The total duration of admission was 22.1 (13.1) years. Diagnoses according to DSM-IV Axis I as defined above were: schizophrenia 69.6\%, psychosis 5.3\%, affective disorder $13.5 \%$, other Axis I diagnosis $6.8 \%$ and no Axis I (with a Axis II) diagnosis $4.8 \%$.

At baseline and follow-up, antipsychotics were used by $89.3-98.5 \%$ of the patients; FGA and SGA in 64.8-67.5\% and 55.7-61.3\%, respectively; FGA only and SGA only in $33.0-37.3 \%$ and $24.6-32.8 \%$, respectively; $28.4 \%$ used both FGA and SGA at baseline; use of 0, 1, 2, 3 and 4 antipsychotic(s) was observed in $1.5-10.7 \%, 41.9-55.4 \%, 34.3-40.8 \%, 4.1-8.3 \%$ and $0.5-1.6 \%$, respectively; total DDD equivalent antipsychotic use was 2.3-2.5.

\section{Frequency over period of observation}

Over the period of observation (mean $=1.1$ years, $\mathrm{SD}=0.64$ ), at baseline and follow-up, the frequencies of movement disorder in the sample were 30.4$36.6 \%$ for TD, $21.7-32.5 \%$ for orofacial TD, $11.9-13.9 \%$ for limb truncal TD, 62.9-65.9\% for parkinsonism, $13.8-26.3 \%$ for rest tremor, $6.6-15.0 \%$ for rigidity, $53.6-61.0 \%$ for bradykinesia, $8.8-10.4 \%$ for akathisia and $8.1-16.0 \%$ for dystonia. The frequency of persistent movement disorder in the sample was $28.4 \%$ for TD, $20.1 \%$ for orofacial TD, 7.7\% for limb truncal TD, 56.2\% for parkinsonism, $12.9 \%$ for rest tremor, $6.7 \%$ for rigidity, $48.5 \%$ for bradykinesia, $4.6 \%$ 
for akathisia and 5.7\% for dystonia. Sixty-eight percent of the participants had at least one type of persistent movement disorder, $43.3 \%$ had a single type of persistent movement disorder, and $24.7 \%$ had at least 2 types of persistent movement disorder (Table 1). Using the UK Brain Bank definition, the frequencies of parkinsonism were $51.2-60.3 \%$ at baseline and follow-up, whereas the frequency of persistent parkinsonism was $53.1 \%$.

Table 1. Period frequency ${ }^{a}$ of persistent drug-induced movement disorders ${ }^{b, c}(N=194$, men=114, women=80)

\begin{tabular}{lrr}
\hline Movement disorder & N & \% \\
\hline Tardive dyskinesia & 55 & 28.4 \\
Orofacial TD & 39 & 20.1 \\
Limb truncal TD & 15 & 7.7 \\
Parkinsonism & 109 & 56.2 \\
Rest tremor & 25 & 12.9 \\
Rigidity & 13 & 6.7 \\
Bradykinesia & 94 & 48.5 \\
Akathisia & 9 & 4.6 \\
Tardive dystonia & 11 & 5.7 \\
\hline
\end{tabular}

aMean period was 1.1 year (SD 0.6)

bPersistent movement disorder: 2 consecutive positive assessments with an interval of at least 3 months

c132 (68.0\%) had at least one type of movement disorder

dTardive dyskinesia

Table 2 shows the frequency of persistent movement disorder, by age group defined by the tertile cut-offs of the age distribution. In the nonparametric test for trend, frequency of persistent TD, parkinsonism and tardive dystonia increased with increasing age $(p=0.005, p=0.000$ and $p=0.06$, respectively). Frequency of persistent akathisia decreased significantly with increasing age ( $p$ $=0.039$ ), such that the age group of 53 and older did not display any akathisia. Frequency of persistent parkinsonism in accordance with UK Brain Bank definition, by age group, was $32.3 \%, 56.9 \%$ and $70.3 \%$, respectively $(p=0.000)$.

Frequency of persistent TD, parkinsonism, akathisia and tardive dystonia did not differ between FGA only and SGA only, both at baseline and at follow-up (p-values 0.506-0.898, 0.392-0.962, 0.184-0.576 and 0.424-0.916, respectively). Parkinsonism in accordance with UK Brain Bank definition did not differ between FGA only and SGA only, both at baseline and at follow-up (p-values 0.705-0.929). 
Table 2. Period frequency ${ }^{a}$ of persistent drug-induced movement disorder ${ }^{b}$ in 194 patients, by tertile age group

\begin{tabular}{lcccrc}
\hline & \multicolumn{1}{c}{ Age (years) } & & & \\
\cline { 2 - 6 } Movement disorder (\%) & $\mathbf{5 4 0}(\mathbf{n = 6 5})$ & $\mathbf{4 1 - 5 2}(\mathbf{n = 6 5 )}$ & $\mathbf{2 5 3} \mathbf{( n = 6 4 )}$ & $\mathbf{z}^{\mathbf{c}}$ & $\mathbf{p}$ \\
\hline Tardive dyskinesia (n=55) & 15.4 & 32.3 & 37.5 & 2.78 & 0.005 \\
Parkinsonism (n=109) & 40.0 & 49.2 & 79.7 & 4.52 & 0.000 \\
Akathisia (n=9) & 7.7 & 6.2 & 0.0 & -2.07 & 0.039 \\
Tardive dystonia (n=11) & 1.5 & 6.2 & 9.4 & 1.92 & 0.055 \\
\hline
\end{tabular}

aMean period was 1.1 year (SD 0.6)

bPersistent movement disorder: 2 consecutive positive assessments with an interval of at least 3 months

cNonparametric test for trend across ordered groups (extension of the Wilcoxon rank-sum test)

\section{Discussion}

This study showed that persistent movement disorder remains highly prevalent in long-stay patients with chronic mental illness and long-term antipsychotic treatment. The high period frequency of $68 \%$ with at least a single drug-induced movement disorder is even more striking given the use of strict case definition criteria that had to be positive on at least two consecutive assessments. Clinical relevance of these findings is suggested not only because of the high frequency of these acute and tardive movement disorders, but also because persistence of movement disorder seems to be the rule. This implies that most patients on long-term antipsychotic treatment have persistent movement disorder which make this side effect a matter of urgent consideration.

Frequencies of TD, parkinsonism and dystonia were associated with older age, albeit the latter at trend significance only. In contrast, akathisia was negatively associated with older age, and even completely absent in the oldest age group. This observation could not be explained by dosage as a post-hoc analysis showed that total DDD equivalent at baseline and follow-up moments were neither strongly nor significantly associated with age $(r=-0.02, p=0.76 ; r=$ $-0.13, p=0.08 ; \mathrm{r}=-0.10, \mathrm{p}=0.27$, respectively). Furthermore, around $50 \%$ of the patients used more than one type of antipsychotic with a DDD equivalent above 2.3. This is a considerable high antipsychotic dosage, as the DDD is the assumed average daily dose for a drug used for its core (Rijcken et al., 2003). Yet, frequency of movement disorder between FGA and SGA did not differ.

We compared frequencies of parkinsonism between the UK Brain Bank definition and ours, and found similar results at baseline and follow-up; the same held for persistent parkinsonism. 


\section{Limitations}

First, it may be hypothesized that the varying number of follow-up assessments (from 1 to 2 ) in the participants may have contributed to an unstable estimate. However, frequency of persistent movement disorders in those with 1 and 2 follow-up assessments were similar (data not shown). Second, the cohort in the current study was representative of the population of patients with the most severe chronic mental illness requiring long-stay care, the target population for this study. Thus, results cannot be extrapolated to the entire population of psychiatric patients exposed to antipsychotics, in whom rates of movement disorder may be different. Third, in the current study, the mean follow-up time seemed sufficient (1.1 years) to detect a persistent movement disorder because the patients were on long-term antipsychotic treatment, i.e., were exposed for a sufficiently long period to develop a persistent movement disorder. Although this study cannot draw firm conclusions regarding the persistence of movement disorders in the long run, most long-term follow-up studies nevertheless report high persistence rates. Fourth, the classic model of movement disorders originating from antipsychotics is challenged by a large body of literature and two meta-analyses (Pappa and Dazzan, 2009;Koning et al., 2010) demonstrating higher prevalence rates of movement disorders in patients with a diagnosis of schizophrenia. These results provide a strong argument for the hypothesis that movement disorders may not exclusively result from antipsychotic treatment but also reflect a fundamental aspect of neurodevelopmental pathophysiology involving sensitization of dopaminergic nigrostriatal circuits (Chakos et al., 1996; Modestin et al., 2008;van Harten and Tenback, 2009; Mittal and Walker, 2010). There is no phenomenological difference between parkinsonism and dyskinesia related to schizophrenia versus drug-induced parkinsonism and dyskinesia. As a consequence, caution is required in interpreting the findings. Future prospective studies in populations of drug-naive patients with a first episode of psychosis before and after antipsychotic treatment are essential to make a distinction between primary (part of schizophrenia) and secondary (drug-induced) movement disorder. Even so, primary symptoms may develop in the course of schizophrenia making differentiation between primary and secondary symptoms difficult.

Although it is not possible to differentiate between primary and secondary movement disorders in long-stay patients, and the two types likely often occur in combination, distinguishing between the two types is of little consequence for treatment interventions which often consist of lowering the dosage of the antipsychotic, switching to an SGA (preferably clozapine), or adding an anticholinergic. 


\section{Strengths}

First, all assessments were performed by a single person, who was trained and retrained (in order to prevent 'drift') regularly by the senior author (PNvH), an expert in the assessment and diagnosis of movement disorders. Second, a naturalistic and pragmatic design was used in a representative chronic psychiatric population, reflecting real-life clinical practice (Tamminga, 2006), and therefore yielding high external validity. Third, definition of persistent movement disorder was based on 2 consecutive assessments over a period of minimally 3 months, which is in contrast with many previous studies in which case definition was defined cross-sectionally. Persistent movement disorder may be a more valid measure, as it more specifically defines the disorder category given the continuously fluctuating nature of the phenotypes under investigation.

The prevalence of movement disorder from previous studies, as mentioned below, concur with the current study for TD, but they tend to be lower for parkinsonism, and tend to be higher for akathisia as well as for tardive dystonia. However, previous studies do not match with the current study, given the fact that these used cross-sectional measures and did not focus on the vulnerable subgroup of long-stay patients in hospital.

\section{Tardive dyskinesia}

Reported prevalence rates of TD vary from $3 \%$ to $70 \%$ with a median rate of $24 \%$, most of the TD being mild, with higher rates in the elderly (Yassa and Jeste, 1992). Van Harten and colleagues (1996) reported a TD prevalence of $39.7 \%$. A recent meta-analysis concluded that age was a likely, although not quite conclusive, risk factor for TD (Tenback et al., 2009). Other risk factors have been suggested, but with little meta-analytic support (Tenback et al., 2009).

\section{Parkinsonism}

In the study by Modestin and colleagues (2008) the prevalence of parkinsonism in 1995 and $2003 / 4$ was $17 \%$ and $29 \%$, respectively. Janno and colleagues (2004) estimated the prevalence of parkinsonism at $23.2 \%$ and $72.7 \%$, according to DSM-IV criteria and Simpson-Angus Scale criteria, respectively. Van Harten and colleagues (1996) reported a parkinsonism prevalence of $36.1 \%$. Older age may be a risk factors for parkinsonism (Owens, 1999), but other studies showed a higher risk in younger patients (Keepers et al., 1983;Richardson et al., 1991). 


\section{Akathisia}

Modestin and colleagues (2008) reported a 14\% prevalence rate of akathisia that was constant over two time points. Janno and colleagues (2004) reported prevalence rates of $31.3 \%$ and $27.3 \%$, according to DSM-IV criteria and the Barnes scale, respectively. In the study by van Harten and colleagues (1996) the reported prevalence of akathisia was 9.3\%. In two retrospective studies in younger patients, neither age nor sex was related to tardive akathisia (Barnes and Braude, 1985). In another study, particularly younger patients taking higher dosage of (depot) antipsychotics were at risk of chronic akathisia (Halstead et al., 1994). In addition, prevalence of akathisia showed a decreasing trend with age (van Harten et al., 1996).

\section{Tardive dystonia}

Van Harten and Kahn (1999), reviewing 13 studies, calculated a mean prevalence of tardive dystonia of $5.3 \%$. Earlier studies tended to show lower prevalence rates for tardive dystonia than later ones, probably owing to respectively higher and lower thresholds used, and to differences in rating scales. Van Harten and colleagues (1996) reported a high prevalence (13.4\%) of tardive dystonia; the high rate was thought to relate to the fact that the group examined was black and/or the fact that a careful standard examination with two investigators with a comprehensive rating scale was applied. Other studies reported comparably high prevelances of 11\% (Hoffman et al., 1994) and 21.6\% (Sethi et al., 1990). Tardive dystonia is evenly distributed across the age of onset range from 13 to 72 years, and tends to generalize in younger patients (Factor et al., 2005). Patients developing dystonia in isolation tend to be younger than those with 'classical' TD (Owens, 1999).

Van Harten and colleagues (1996) found a high prevalence of one or more types of movement disorders (73.7\%). Furthermore, in the study by Janno and colleagues (2004), 61.6\% of the patients had at least one movement disorder according to DSM-IV criteria.

Having persistent drug-induced movement disorders seems to be the norm for long-stay patients with chronic mental illness and long-term antipsychotic treatment. We were surprised by the few notes about these side effects in the files of the patients, which has been found by others also (Factor et al., 2009;Esper and Factor, 2008;Friedman et al., 2004; Lerner et al., 2007). The relative lack of focus on movement disorder syndromes is reflected in the very low rate of DSM-IV axis I diagnosis of these in routine clinical practice. Several reasons may be responsible for this discrepancy between clinical reality and clinical attention. First, it is not common practice to do a systematic investigation toward drug-induced movement disorders, which will limit recognition. 
Second, clinicians may wrongly assume that drug-induced movement disorders are almost not treatable. In fact, the interventions to prevent or treat akathisia and parkinsonism are evidence based and are quite easy to implement in clinical practice. Although suggested strategies to prevent/treat TD (Soares-Weiser and Fernandez, 2007) or tardive dystonia (Owens, 1999) are not evidence-based, they resemble the strategies used to prevent acute movement disorders. In addition, novel treatment options are being developed, such as botulinum toxin, tetrabenazine, branched-chain amino acids, and, in very severe cases, deep brain stimulation (Leung and Breden, 2011;Kefalopoulou et al., 2009; Slotema et al., 2008; van Harten and Hovestadt, 2006; Richardson et al., 2003). Third, the introduction of the SGAs led to the expectation that drug-induced movement disorders would disappear but they only reduce the risk. Furthermore, antipsychotics are increasingly used for other indications as SGAs have strong mood stabilizing properties which will increase the absolute numbers of drug-induced movement disorders. Fourth, most patients with schizophrenia do not complain of their movement disorder (Macpherson and Collis, 1992;Arango et al., 1999;Emsley et al., 2010). Unawareness of movement disorder and subsequent lack of subjective complaints is a risk factor for diagnostic delay (Arango et al., 1999). In addition, the unawareness notwithstanding, a movement disorder has a stigmatizing effect on patients and a negative effect on quality of life. Therefore, active assessment and treatment of movement disorder, similar to the current increased focus on metabolic syndrome, is of paramount importance. Owens (1999) stated that movement disorder now can be seen as a quality-ofcare-issue. In addition, shared care decision making and informed consent is part of antipsychotic treatment (Laugharne et al., 2004). Systematic diagnosis may help physicians become more aware of movement disorders.

In conclusion, persistent movement disorder continues to be the norm for long-stay patients with chronic mental illness requiring long-term antipsychotic treatment, and therefore measures are required to remedy this situation, making it part of routine quality-control procedures. It may be considered somewhat ironic that long-stay patients with chronic mental illness pay a high price for the intensive care they receive, particularly because effects are likely mediated by the relatively high compliance with pharmacotherapy in these settings. Although long-stay settings are not present in abundance anymore, they are also not rare. In the U.S., over 200 state hospitals attend a declining but challenging patient population (Fisher et al., 2009) and the findings likely can be extended to the considerably larger group of patients who live in supervised residential settings. Systemic screening for movement disorder takes little time and can be easily implemented in clinical practice. In addition, given the clear age dependency of some movement disorders, elderly patients are a group of special concern. 


\section{Acknowledgements}

The authors are grateful to M. Hoornweg-van Beek (MSc), G.V. Boedijn (MSc), M. van Drie (MSc), R. Emons (MSc), A.E. Willems (MSc) for providing their assistance, and to all patients for participating in this study.

\section{References}

APA, 1992. Tardive dyskinesia : a task force report of the American Psychiatric Association The American Psychiatric Association, Washington, p. 282.

Arango, C., Adami, H., Sherr, J.D., Thaker, G.K. and Carpenter, W.T., Jr., 1999. Relationship of awareness of dyskinesia in schizophrenia to insight into mental illness. Am J Psychiatry. 156, 1097-9.

Ballesteros, J., Gonzalez-Pinto, A. and Bulbena, A., 2000. Tardive dyskinesia associated with higher mortality in psychiatric patients: results of a meta-analysis of seven independent studies. J Clin Psychopharmacol. 20, 188-194.

Barnes, T.R., 1989. A rating scale for drug-induced akathisia. Br J Psychiatry. 154, 672-6.

Barnes, T.R. and Braude, W.M., 1985. Akathisia variants and tardive dyskinesia. Arch Gen Psychiatry. 42, 874-8.

Broekema, W.J., de Groot, I.W. and van Harten, P.N., 2007. Simultaneous prescribing of atypical antipsychotics, conventional antipsychotics and anticholinergics-a European study. Pharm World Sci. 29, 126-130.

Burke, R.E., 1992. Neuroleptic-induced tardive dyskinesia variants. In: Lang A.E. and Weiner W.J. (Eds.), Drug-induced movement disorders, Futura publishing company, New York, pp. 167-98.

Burke, R.E., Fahn, S., Marsden, C.D., Bressman, S.B., Moskowitz, C. and Friedman, J., 1985. Validity and reliability of a rating scale for the primary torsion dystonias. Neurology. 35, 73-7.

Casey, D.E., 2006. Implications of the CATIE trial on treatment: extrapyramidal symptoms. CNS Spectr. 11, 25-31.

Chakos, M.H., Alvir, J.M., Woerner, M.G., Koreen, A., Geisler, S., Mayerhoff, D., Sobel, S., Kane, J.M., Borenstein, M. and Lieberman, J.A., 1996. Incidence and correlates of tardive dyskinesia in first episode of schizophrenia. Arch Gen Psychiatry. 53, 313-9.

Chong, S.A., Tay, J.A., Subramaniam, M., Pek, E. and Machin, D., 2009. Mortality rates among patients with schizophrenia and tardive dyskinesia. J Clin Psychopharmacol. 29, 5-8.

Correll, C.U., Leucht, S. and Kane, J.M., 2004. Lower risk for tardive dyskinesia associated with second-generation antipsychotics: a systematic review of 1-year studies. Am J Psychiatry. 161, $414-$ 25.

Correll, C.U. and Schenk, E.M., 2008. Tardive dyskinesia and new antipsychotics. Curr Opin Psychiatry. 21, 151-156.

Dean, C.E. and Thuras, P.D., 2009. Mortality and tardive dyskinesia: long-term study using the US National Death Index. Br J Psychiatry. 194, 360-364.

Emsley, R., Niehaus, D.J., Oosthuizen, P.P., Koen, L., Chiliza, B. and Fincham, D., 2010. Subjective awareness of tardive dyskinesia and insight in schizophrenia. Eur Psychiatry.

Esper, C.D. and Factor, S.A., 2008. Failure of recognition of drug-induced parkinsonism in the elderly. Mov Disord. 23, 401-404.

Factor, S.A., Lang, A.E., and Weiner, W.J., 2005. Drug induced movement disorders, 2nd ed edn. Blackwell Futura, Malden, Mass.

Factor, S.A., Leffler, J.B. and Murray, C.R. Drug-Induced Movement Disorders: A Clinical Review. Medscape, We Move: http://www.medscape.org/viewprogram/18880 . 2009. Ref Type: Internet Communication

Fahn, S. and Elton, R., 1987. UPDRS Development Committee. Unified Parkinson's Disease Rating Scale. In: Fahn S, Marsden CD, Calne DB, Goldstein M, eds. Recent Developments in Parkinson's Disease. Florham Park, NJ: Macmillan, pp. 153-163. 
Fisher, W.H., Barreira, P.J., Geller, J.L., White, A.W., Lincoln, A.K. and Sudders, M., 2001. Long-stay patients in state psychiatric hospitals at the end of the 20th century. Psychiatr Serv. 52, 10511056.

Fisher, W.H., Geller, J.L. and Pandiani, J.A., 2009. The changing role of the state psychiatric hospital. Health Aff (Millwood ). 28, 676-684.

Friedman, J.H., Fernandez, H.H. and Trieschmann, M.M., 2004. Parkinsonism in a nursing home: underrecognition. J Geriatr Psychiatry Neurol. 17, 39-41.

Guy, W., 1975. ECDEU assessment manual for psychopharmacology. Department of Health, Education and Welfare, Washington DC, pp. 534-537.

Guy, W., 1976. ECDEU assessment manual for psychopharmacology U.S. Dept. of Health, Education, and Welfare, Public Health Service, Alcohol, Drug Abuse, and Mental Health Administration, National Institute of Mental Health, Psychopharmacology Research Branch, Division of Extramural Research Programs, Rockville, Md, p. 603.

Halstead, S.M., Barnes, T.R. and Speller, J.C., 1994. Akathisia: prevalence and associated dysphoria in an in-patient population with chronic schizophrenia. Br J Psychiatry. 164, 177-83.

Hoffman, W.F., Bagdanoff, M.A. and Keepers, G.A., 1994. Prevalence of tardive dystonia in a chronically mentally ill population. Neuropsychopharmacology. 135S.

Janno, S., Holi, M., Tuisku, K. and Wahlbeck, K., 2004. Prevalence of neuroleptic-induced movement disorders in chronic schizophrenia inpatients. Am J Psychiatry. 161, 160-163.

Jones, P.B., Barnes, T.R., Davies, L., Dunn, G., Lloyd, H., Hayhurst, K.P., Murray, R.M., Markwick, A. and Lewis, S.W., 2006. Randomized controlled trial of the effect on Quality of Life of second- vs firstgeneration antipsychotic drugs in schizophrenia: Cost Utility of the Latest Antipsychotic Drugs in Schizophrenia Study (CUtLASS 1). Arch Gen Psychiatry. 63, 1079-1087.

Kahn, R.S., Fleischhacker, W.W., Boter, H., Davidson, M., Vergouwe, Y., Keet, I.P., Gheorghe, M.D., Rybakowski, J.K., Galderisi, S., Libiger, J., Hummer, M., Dollfus, S., Lopez-Ibor, J.J., Hranov, L.G., Gaebel, W., Peuskens, J., Lindefors, N., Riecher-Rossler, A. and Grobbee, D.E., 2008. Effectiveness of antipsychotic drugs in first-episode schizophrenia and schizophreniform disorder: an open randomised clinical trial. Lancet. 371, 1085-1097.

Keepers, G.A., Clappison, V.J. and Casey, D.E., 1983. Initial anticholinergic prophylaxis for neuroleptic-induced extrapyramidal syndromes. Arch Gen Psychiatry. 40, 1113-7.

Kefalopoulou, Z., Paschali, A., Markaki, E., Vassilakos, P., Ellul, J. and Constantoyannis, C., 2009. A double-blind study on a patient with tardive dyskinesia treated with pallidal deep brain stimulation. Acta Neurol Scand. 119, 269-273.

Koning, J.P., Tenback, D.E., van Os, J., Aleman, A., Kahn, R.S. and van Harten, P.N., 2010. Dyskinesia and parkinsonism in antipsychotic-naive patients with schizophrenia, first-degree relatives and healthy controls: a meta-analysis. Schizophr Bull. 36, 723-731.

Lambert, M., Conus, P., Eide, P., Mass, R., Karow, A., Moritz, S., Golks, D. and Naber, D., 2004. Impact of present and past antipsychotic side effects on attitude toward typical antipsychotic treatment and adherence. Eur Psychiatry. 19, 415-422.

Laugharne, J., Davies, A., Arcelus, J. and Bouman, W.P., 2004. Informing patients about tardive dyskinesia: A survey of clinicians' attitudes in three countries. Int J Law Psychiatry. 27, 101-108.

Lerner, V., Libov, I., Kaptsan, A., Miodownik, C., Dwolatzky, T. and Levine, J., 2007. The prevalence of neuroleptic drug-induced tardive movement subsyndromes among schizophrenic and schizoaffective patients residing in the southern region of Israel. Isr J Psychiatry Relat Sci. 44, 20-28.

Leucht, S., Corves, C., Arbter, D., Engel, R.R., Li, C. and Davis, J.M., 2009a. Second-generation versus first-generation antipsychotic drugs for schizophrenia: a meta-analysis. Lancet. 373, 31-41.

Leucht, S., Kissling, W. and Davis, J.M., 2009b. Second-generation antipsychotics for schizophrenia: can we resolve the conflict? Psychol Med. 39, 1591-1602.

Leung, J.G. and Breden, E.L., 2011. Tetrabenazine for the treatment of tardive dyskinesia. Ann Pharmacother. 45, 525-531.

Lewis, S. and Lieberman, J., 2008. CATIE and CUtLASS: can we handle the truth? Br J Psychiatry. 192, 161-163. 
Lieberman, J.A., Stroup, T.S., McEvoy, J.P., Swartz, M.S., Rosenheck, R.A., Perkins, D.O., Keefe, R.S., Davis, S.M., Davis, C.E., Lebowitz, B.D., Severe, J. and Hsiao, J.K., 2005. Effectiveness of antipsychotic drugs in patients with chronic schizophrenia. N Engl J Med. 353, 1209-1223.

Macpherson, R. and Collis, R., 1992. Tardive dyskinesia. Patients' lack of awareness of movement disorder. Br J Psychiatry. 160, 110-2.

Miller, D.D., Caroff, S.N., Davis, S.M., Rosenheck, R.A., McEvoy, J.P., Saltz, B.L., Riggio, S., Chakos, M.H., Swartz, M.S., Keefe, R.S., Stroup, T.S. and Lieberman, J.A., 2008. Extrapyramidal side-effects of antipsychotics in a randomised trial. Br J Psychiatry. 193, 279-288.

Mittal, V.A. and Walker, E.F., 2010. Letter to the Editor: Movement abnormalities and schizophrenia in DSM-V. Psychol Med. 1-3.

Modestin, J., Wehrli, M.V., Stephan, P.L. and Agarwalla, P., 2008. Evolution of neuroleptic-induced extrapyramidal syndromes under long-term neuroleptic treatment. Schizophr Res. 100, 97-107.

Owens, D.G.C., 1999. A guide to the extrapyramidal side-effects of antipsychotic drugs Cambridge University Press UK, New York, p. 351.

Pappa, S. and Dazzan, P., 2009. Spontaneous movement disorders in antipsychotic-naive patients with first-episode psychoses: a systematic review. Psychol Med. 39, 1065-1076.

Procyshyn, R.M., Kennedy, N.B., Tse, G. and Thompson, B., 2001. Antipsychotic polypharmacy: a survey of discharge prescriptions from a tertiary care psychiatric institution. Can J Psychiatry. 46, 334-339.

Richardson, M.A., Bevans, M.L., Read, L.L., Chao, H.M., Clelland, J.D., Suckow, R.F., Maher, T.J. and Citrome, L., 2003. Efficacy of the branched-chain amino acids in the treatment of tardive dyskinesia in men. Am J Psychiatry. 160, 1117-24.

Richardson, M.A., Haugland, G. and Craig, T.J., 1991. Neuroleptic use, parkinsonian symptoms, tardive dyskinesia, and associated factors in child and adolescent psychiatric patients. Am J Psychiatry. 148, 1322-8.

Rijcken, C.A., Monster, T.B., Brouwers, J.R. and de Jong-van den Berg, L.T., 2003. Chlorpromazine equivalents versus defined daily doses: how to compare antipsychotic drug doses? J Clin Psychopharmacol. 23, 657-659.

Robinson, D.G., Woerner, M.G., Alvir, J.M., Bilder, R.M., Hinrichsen, G.A. and Lieberman, J.A., 2002. Predictors of medication discontinuation by patients with first-episode schizophrenia and schizoaffective disorder. Schizophr Res. 57, 209-219.

Rosenheck, R., Perlick, D., Bingham, S., Liu-Mares, W., Collins, J., Warren, S., Leslie, D., Allan, E., Campbell, E.C., Caroff, S., Corwin, J., Davis, L., Douyon, R., Dunn, L., Evans, D., Frecska, E., Grabowski, J., Graeber, D., Herz, L., Kwon, K., Lawson, W., Mena, F., Sheikh, J., Smelson, D. and Smith-Gamble, V., 2003. Effectiveness and cost of olanzapine and haloperidol in the treatment of schizophrenia: a randomized controlled trial. Jama. 290, 2693-2702.

Sachdev, P.S., 2005. Neuroleptic-induced movement disorders: an overview. Psychiatr Clin North Am. 28, 255-74, $\mathrm{x}$.

Schooler, N.R. and Kane, J.M., 1982. Research diagnoses for tardive dyskinesia. Arch Gen Psychiatry. 39, 486-7.

Sethi, K.D., Hess, D.C. and Harp, R.J., 1990. Prevalence of dystonia in veterans on chronic antipsychotic therapy. Mov Disord. 5, 319-21.

Slotema, C.W., van Harten, P.N., Bruggeman, R. and Hoek, H.W., 2008. Botulinum toxin in the treatment of orofacial tardive dyskinesia: a single blind study. Prog Neuropsychopharmacol Biol Psychiatry. 32, 507-509.

Soares-Weiser, K. and Fernandez, H.H., 2007. Tardive dyskinesia. Semin Neurol. 27, 159-169.

Tamminga, C.A., 2006. Practical treatment information for schizophrenia. Am J Psychiatry. 163, 563565.

Taylor, D., 2010. Antipsychotic polypharmacy - confusion reigns. The Psychiatrist. 34, 41-43.

Tenback, D.E., van Harten, P.N., Slooff, C.J., Belger, M.A. and van Os, J., 2005. Effects of antipsychotic treatment on tardive dyskinesia: a 6-month evaluation of patients from the European Schizophrenia Outpatient Health Outcomes (SOHO) Study. J Clin Psychiatry. 66, 1130-1133. 
Tenback, D.E., van Harten, P.N. and van Os, J., 2009. Non-therapeutic risk factors for onset of tardive dyskinesia in schizophrenia: a meta-analysis. Mov Disord. 24, 2309-2315.

van Harten, P.N., 1998. Movement disorders associated with neuroleptics : the Curacao extrapyramidal syndromes study Utrecht, p. 124.

van Harten, P.N. and Hovestadt, A., 2006. Botulinum toxin as a treatment for tardive dyskinesia. Mov Disord. 21, 1276-1277.

van Harten, P.N. and Kahn, R.S., 1999. Tardive dystonia. Schizophr Bull. 25, 741-8.

van Harten, P.N., Matroos, G.E., Hoek, H.W. and Kahn, R.S., 1996. The prevalence of tardive dystonia, tardive dyskinesia, parkinsonism and akathisia The Curacao Extrapyramidal Syndromes Study: I. Schizophr Res. 19, 195-203.

van Harten, P.N. and Tenback, D.E., 2009. Movement disorders should be a criterion for schizophrenia in DSM-V. Psychol Med. 39, 1754-1755.

Weiden, P.J., 2007. EPS profiles: the atypical antipsychotics are not all the same. J Psychiatr Pract. 13, 13-24.

Woods, S.W., Morgenstern, H., Saksa, J.R., Walsh, B.C., Sullivan, M.C., Money, R., Hawkins, K.A., Gueorguieva, R.V. and Glazer, W.M., 2010. Incidence of tardive dyskinesia with atypical versus conventional antipsychotic medications: a prospective cohort study. J Clin Psychiatry.

Yassa, R. and Jeste, D.V., 1992. Gender differences in tardive dyskinesia: a critical review of the literature. Schizophr Bull. 18, 701-15. 



\title{
Predicting the incidence of antipsychotic- induced movement disorders in long- stay patients: A prospective study
}

\author{
P. Roberto Bakkera, Izaäk W. de Groot ${ }^{b}$, Jim van Os, d, Peter N. van Hartena,c \\ ${ }^{a}$ Psychiatric Centre GGZ Centraal, Amersfoort, The Netherlands \\ ${ }^{\mathrm{b}}$ Dimence, Centre for Mental Health Care, Deventer, The Netherlands \\ ${ }^{c}$ Department of Psychiatry and Psychology, South Limburg Mental Health Research and Teaching \\ Network, EURON, Maastricht University, Maastricht, The Netherlands \\ ${ }^{d}$ King's College London, King's Health Partners, Department of Psychosis Studies, Institute of \\ Psychiatry, London, United Kingdom
}

Submitted 


\section{Abstract}

\section{Background}

To assess risk factors for incident tardive dyskinesia (TD), parkinsonism, akathisia and tardive dystonia in long-stay patients on long-term antipsychotics.

\section{Method}

Naturalistic study of 209 long-stay patients with chronic mental illness requiring long-term antipsychotic treatment, examined by the same rater at least two times over a 4-year period, with a mean follow-up time of 1.1 years, with validated scales for TD, parkinsonism, akathisia, and tardive dystonia.

\section{Results}

Yearly incidence rates were $19.6 \%$ for TD, $21.6 \%$ for parkinsonism, $3.5 \%$ for akathisia and $0 \%$ for tardive dystonia. TD was positively associated with age (hazard ratio (HR) per year exposure $=1.04,95 \% \mathrm{CI}=1.02-1.06$ ). Parkinsonism was positively associated with age ( $\mathrm{HR}=1.03,95 \% \mathrm{CI}=1.02-1.04)$ and the total antipsychotic defined daily dose (DDD) (HR=1.07, 95\% CI=1.03-1.11). Risk factors did not predict akathisia and tardive dystonia.

\section{Conclusions}

Long-stay patients with chronic mental illness and long-term antipsychotic treatment have a disproportionately high risk of incident movement disorder, particularly individuals who are older (TD and parkinsonism), and on higher doses of antipsychotic medication (parkinsonism).

\section{Keywords}

movement disorder, tardive dyskinesia, parkinsonism, akathisia, tardive dystonia, antipsychotic-induced. 


\section{Introduction}

Tardive dyskinesia (TD), parkinsonism, akathisia and tardive dystonia are antipsychotic-induced movement disorders that remain a cause for concern in the treatment of patients with psychotic disorder. Movement disorders secondary to antipsychotics constitute a major reason for non-compliance, which results in an increased risk of psychotic relapse (Casey, 2006; Lambert et al., 2004;Robinson et al., 2002).

Although second generation antipsychotics (SGAs) may be associated with a lower incidence rate of movement disorder, these medications nevertheless still carry risk. For a detailed overview on SGAs we refer to our previous publication (Bakker et al., 2011).

A high risk group for movement disorders consists of patients with chronic mental illness and therefore chronically exposed to antipsychotic medication, particularly long-stay patients (i.e. patients institutionalized for long periods) with supervised medication regimes (Bakker et al., 2011).

Antipsychotic-induced movement disorders (Owens, 1999;Factor et al., 2005) can be divided into acute syndromes, such as parkinsonism and akathisia, that occur within hours/days or weeks after initiating antipsychotic treatment or increasing the antipsychotic dose (or cessation of anticholinergics), and tardive syndromes, such as TD and tardive dystonia, that develop after months or years of treatment. Given that combinations of acute and chronic movement disorders occur in patients undergoing long-term treatment with antipsychotics, prediction models should include both syndromes, i.e., the four major types of movement disorders (TD, parkinsonism, akathisia and tardive dystonia).

Given the above considerations, the aim of the current prospective study of movement disorder was to provide clinicians with risk information regarding new occurrences of movement disorders for prevention purposes in the population currently most at risk: long-stay patients with chronic mental illness requiring long-term antipsychotic treatment.

\section{Method}

\section{Participants}

A 4-year prospective naturalistic study (July 2003 - May 2007) was conducted with 209 patients with chronic mental illness in order to determine the incidence of and risk factors for the four major types of movement disorders (TD, parkinsonism, akathisia, and tardive dystonia). To this end, a cohort was drawn from patients in a general psychiatric hospital (GGZ Centraal, Amersfoort, the Netherlands). Full details of the study design and assessment of movement dis- 
orders have been published previously (Bakker et al., 2011). The cohort was representative of the population of patients with the most severe chronic mental illness requiring long-stay care, given that the hospital serves an epidemiological catchment area, is the only institute providing this type of care in this area, and patients were selected from a comprehensive list of all inpatients.

Of the patients assessed at baseline $(\mathrm{N}=207) 93.7 \%(\mathrm{n}=194)$ had one followup and $59.4 \%(n=123)$ had two follow-up assessments. Loss to follow-up was due to patients who were difficult to trace after leaving hospital, died or refused assessment after inclusion. Patients were examined by a trained psychiatrist (PRB), using a standard protocol, described by van Harten and colleagues (1996).

\section{Procedures}

The protocol was approved by the standing Institutional Review Board, 'Medisch-ethische Toetsingscommissie Instellingen Geestelijke Gezondheidszorg' (Review Board for Human Research in Psychiatry), the Netherlands [protocol number 377].

Written informed consent was obtained from each patient; consent obtained from the next of kin was neither necessary nor recommended by the Review Board for Human Research in Psychiatry.

\section{Measures}

Guided by previous literature, variables possibly affecting risk were extracted from patients' case notes including age, sex, BMI, self-reported handedness, diagnosis according to DSM-IV, ethnic group (classified as white and non-white), duration of hospitalization and history of electroconvulsive therapy (ECT). Negative symptoms were rated using the negative symptom subscale of the Positive and Negative Symptom Severity (PANSS) scale (Kay et al., 1987). The MINI sections for alcohol and drug use were administered, and information on tobacco intake (yes/no, number of cigarettes, cigars, etc; descriptors such as 'light', 'mild', 'heavy' and 'normal' use of tobacco) was collected. At baseline and at each follow-up assessment, current use of antipsychotic and anticholinergic medication was collected, and the global symptom rating of the Clinical Global Impression - Schizophrenia severity of illness (CGI-SCH SI) scale was completed. All clinical assessments were carried out by the same psychiatrist (PRB). Information on current use of the above medication was collected from the hospital and outpatient pharmacy databases.

The diagnosis 'schizophrenia' hereafter refers to DSM-IV codes 295.30, $295.10,295.20,295.90,295.60,295.70$, and other diagnoses of 'psychotic disorder' to $295.40,297.1,298.8,298.9$. 


\section{Statistical Analyses}

Incident case definition was based on two consecutive assessments meeting the requirements of Schooler and Kane's criteria for persistent movement disorder (Schooler and Kane, 1982) (hereafter: persistent movement disorder). Hence, a minimum of one baseline (free of movement disorder) and two follow-up assessments (with evidence of movement disorder at both) were necessary in order to define an incident case by the second follow-up. The yearly incidence rate was estimated by dividing the number of incident cases by the person-years between the first and second follow-up allocated to each patient who at baseline had a score of zero on the scale of a particular movement disorder. Incidence rate is presented as a percentage. Cumulative incidence was defined as the number of the above mentioned incident cases over the follow-up period divided by the number of subjects at risk in the population at baseline.

An alternative analysis was conducted with case definition based on a single occurrence of movement disorder at a single assessment (hereafter: fluctuating movement disorder). The reason for this was that movement disorders constantly fluctuate over time, so that inclusion in the regression of their repeated dichotomous single-occasion measures allowed for calculation of associations between one movement disorder with the other over time.

As the study design comprised repeated measures nested in the same patient, correlated error of non-independence had to be corrected for. Therefore, we performed multilevel Cox regression models with the measurement occasion (baseline and two follow-ups) as level 1, and subjects as level 2, with the STCOX cluster procedure of the STATA statistical program (StataCorp. 2009). Associations were expressed as hazard ratios and proportional-hazard assumptions were evaluated using the STATA STPHPLOT and STCOXKM graphical procedures, generating log-log plot of survival, and Kaplan-Meier and predicted survival plot, respectively. As these procedures are intended for discrete variables, the distribution of continuous variables was divided by its tertiles, creating tertile groups. For the Cox regression, all 207 patients were included; of the above mentioned variables possibly affecting risk, values missing at random were minimally 5 times imputed using the STATA ICE procedure within a bootstrap sample to relax normality assumption.

The weighted (for non-missing items) mean score of each movement disorder scale per assessment and of the PANSS negative symptom scale at baseline were included as continuous covariables. Of the CGI-SCH SI, the global score rated at each assessment was used. Continuous variables were mean-centered so that the intercept of the regression line corresponds to the estimated population mean of that variable (Kohler and Kreuter, 2009;Rabe-Hesketh and Skrondal, 2008).

From the full model, including all the above variables, variables with no impact were removed one by one, until only significant variables remained using 
the criterion of $\mathrm{p}<0.05$ (final model through backward stepwise regression) (Altman, 1999;Steyerberg, 2009). In order to assess extra-linearity, quadratic effects were included for continuous variables with $\mathrm{p}<0.05$ in the initial model (Cleves, 2008). Also, interactions between different variables were included.

Antipsychotic doses were converted to defined daily dose (DDD), for which we refer to our previous publication (Bakker et al., 2011). Anticholinergic medication was modeled as a dichotomous variable (yes/no).

\section{Results}

\section{Sample Characteristics}

Over the period of observation (mean=1.1 years, $S D=0.64$ ), of the 209 patients included, 207 participated in the study. One patient developed a brain tumor, another patient died after inclusion. All patients had a history of cumulative antipsychotic intake of minimally 1 year. Attrition was low at 9.8\%.

Most patients were white (85.0\%) and had chronic mental illness requiring long-term admission. At baseline ( $\mathrm{N}=207$, $\mathrm{men}=120$, women=87), the mean (SD) age was 47.4 (12.8) years; men 46.3 (12.8) and women 49.1 (12.7). The mean (SD) age at first admission was 25.0 (8.4) years; men 23.8 (7.6) and women 26.7 (9.3). The mean total duration of admission was 22.1 (13.1) years. Diagnoses according to DSM-IV Axis I as defined above were: schizophrenia 69.6\%, psychosis 5.3\%, affective disorder 13.5\%, other Axis I diagnosis 6.8\% and no Axis I (with an Axis II) diagnosis 4.8\%.

At baseline, first and second follow-up, range of antipsychotic use was 89.398.5\% of the patients; range of FGA use was $64.8-67.5 \%$ and of SGA 55.7-61.3\%; range of FGA only use was 33.0-37.3\% and SGA only 24.6-32.8\%; range of combined use of both FGA and SGA was 28.4-34.6\%; the range of $0,1,2,3$ and 4 antipsychotic(s) was $1.5-10.6 \%, 41.9-55.4 \%, 34.3-40.8 \%, 4.1-8.3 \%$ and $0.5-$ $1.6 \%$, respectively; range of total antipsychotic DDD was 2.3-2.5.

\section{Incidence of persistent movement disorders over period of observation}

Yearly incidence rates of persistent movement disorders were 19.6\% (95\% $\mathrm{CI}=10.7 \%-32.9 \%$ ) for $\mathrm{TD}, 21.6 \%$ (95\% CI=9.9\%-40.9\%) for parkinsonism, 3.5\% (95\% CI $=0.7 \%-10.1 \%$ ) for akathisia and $0 \%$ for tardive dystonia. Cumulative incidences were $15.9 \%, 17.7 \%, 2.7 \%$ and $0 \%$ respectively.

\section{Prediction of repeated movement disorders over period of observation}

In the final models, after backward elimination, results were as follows (Table 1). Fluctuating TD was positively associated with age (hazard ratio (HR) per 
year exposure=1.04, 95\% CI=1.02-1.06). Fluctuating parkinsonism also was positively associated with age $(\mathrm{HR}=1.03,95 \% \mathrm{CI}=1.02-1.04)$ and in addition with the total antipsychotic defined daily dose (DDD) ( $\mathrm{HR}=1.07,95 \% \mathrm{CI}=1.03$ 1.11). Fluctuating akathisia and tardive dystonia were not associated with any risk factor.

Table 1. Variables related to fluctuating movement disorders ${ }^{a}$. Final model through backward stepwise Cox regression of repeated measures

\begin{tabular}{|c|c|c|c|}
\hline Predictor variables & HR & $95 \% \mathrm{CI}$ & $\mathrm{p}$ \\
\hline \multicolumn{4}{|l|}{ Tardive dyskinesia } \\
\hline \multicolumn{4}{|l|}{ Baseline } \\
\hline $\mathrm{Age}^{\mathrm{b}}$ & 1.04 & 1.02 to 1.06 & 0.002 \\
\hline \multicolumn{4}{|l|}{ Parkinsonism } \\
\hline \multicolumn{4}{|l|}{ Baseline } \\
\hline $\mathrm{Age}^{\mathrm{b}}$ & 1.03 & 1.02 to 1.04 & 0.000 \\
\hline \multicolumn{4}{|l|}{ During follow-up } \\
\hline Total DDD equivalent antipsychotic use & 1.07 & 1.03 to 1.11 & 0.001 \\
\hline \multicolumn{4}{|l|}{ Akathisia } \\
\hline- & & & \\
\hline Tardive dystonia & & & \\
\hline
\end{tabular}

aMean period was 1.1 year (SD 0.6)

${ }^{b}$ Age per year (range $=21.28-85.75$ )

\section{Discussion}

The findings were that (i) long-stay patients with chronic mental illness and long-term antipsychotic treatment have a high risk of incident movement disorder, in particular TD and parkinsonism, (ii) higher age is an important predictor of TD and parkinsonism, and (iii) total antipsychotic defined daily dose (DDD) is an important predictor of parkinsonism. In addition, incidence rates were high for TD and parkinsonism, but, as follow-up data pertain to chronic patients, these may well represent a relapse of an earlier remitted movement disorder.

\section{Limitations}

This study had some limitations, for which we refer to our previous publication (Bakker et al., 2011) as well point to additional limitations. First, it can be hypothesized that age in the current study is not the real risk factor, as older patients in general have been treated over a longer period. Indeed, a post-hoc analysis showed a strong and significant correlation between age and years admitted ( $\mathrm{r}=0.79, \mathrm{p}=0.00)$, so age in the current study may be a proxy for length of treatment, which is difficult to disentangle further. Second, although in the current study many variables were analyzed in the Cox regression, it could nev- 
ertheless be argued that other important variables were not included, for example history of antipsychotic use, which was difficult to retrieve.

\section{Strengths}

First, all assessments were performed by a single person, who was trained and retrained (in order to prevent 'drift') regularly by the senior author (PNvH), an expert in the assessment and diagnosis of movement disorders. Second, a naturalistic and pragmatic design was used in a representative chronic psychiatric population, reflecting real-life clinical practice (Tamminga, 2006), and therefore yielding high external validity. Third, the use of both persistent and fluctuating movement disorder measures, in contrast with many previous studies in which case definition was defined cross-sectionally, may more validly reflect the phenotype, as it more specifically defines the disorder category given the continuously fluctuating nature of the phenotypes under investigation.

Since previous studies mentioned below, which used a cross-sectional approach and did not focus on the vulnerable subgroup of long-stay hospitalized patients, do not match with the current study, it is not easy to put the current results into context. Although the sample selection and prospective nature of the current study may explain the lack of consistency with some older studies, particularly given that careful meta-analysis indicates that studies of risk factors for movement disorders such as TD show very little consistency (Tenback et al., 2009), other possible explanations for these differences are (i) carryover effects (delayed response effects) after many years of antipsychotic usage in the population studied, and/or (ii) the relatively small sample size of the current study.

Prospective studies reported an association between TD and other druginduced movement disorders (Tenback et al., 2006;Sachdev, 2004), and between TD, tardive dystonia and akathisia (hyperkinetic movement disorders) (van Harten et al., 1997). An association between parkinsonism and akathisia was reported (Sachdev, 2005), but not in another study (Sandyk and Kay, 1990). A history of drug-induced parkinsonism predicted parkinsonism (Keepers and Casey, 1991). A history of akathisia (Keepers and Casey, 1991) and diabetes mellitus (Sandyk et al., 1991) predicted akathisia. Risk factors for tardive dystonia are essential postural tremor (Sachdev, 1993), tardive hyperkinetic movement disorders (dyskinesia and akathisia) (van Harten et al., 1997), and myoclonus (Burke et al., 1982).

A high female/male risk ratio of (severe) TD was reported in older age (Yassa and Jeste, 1992), but a low ratio in younger age (Owens, 1999). In a metaanalysis older age was a probable risk factor for TD (Tenback et al., 2009). 
Older age was a risk factor for parkinsonism in two studies (Moleman et al., 1986;Owens, 1999), but other studies showed a higher risk in younger patients (Keepers et al., 1983;Richardson et al., 1991). In one study, women were more affected by parkinsonism than men (Ayd and Baltimore, 1961), but another studie did not replicate this finding (van Harten et al., 1996). Higher prevalence in women may be confounded by older age (Owens, 1999).

In younger patients, neither age nor gender were associated with akathisia (Barnes and Braude, 1985). In a sample with a wider age range, younger age and higher dose of (depot) antipsychotics was associated with chronic akathisia (Halstead et al., 1994). Another study showed a decreasing trend with age (van Harten et al., 1996).

Increasing age is a risk for tardive dystonia, and patients developing dystonia in isolation tend to be younger than those with 'classical' and more comorbid TD (Owens, 1999). Studies report that tardive dystonia occurs more frequently in men than women (Owens, 1999), mediated possibly by earlier age of onset in men (Kiriakakis et al., 1998).

Several studies showed an association between TD and psychopathology (Tenback et al., 2007;Murray and van Os, 1998;Chakos et al., 1996). To our knowledge, earlier studies did not show an association between psychopathology and parkinsonism, akathisia or tardive dystonia.

In the neurological literature, the association between movement disorder and psychopathology is well established.

Patients with affective disorders may be more susceptible to (more severe) TD (Kane et al., 1985;Eberhard et al., 2006), irreversibility of TD (Mukherjee et al., 1986), and acute akathisia (Gardos et al., 1992). However, the association between affective disorders and TD may be confounded by intermittent antipsychotic usage that is associated with an increased risk for TD (van Harten et al., 1998).

One explanation for a lower incidence of movement disorders concerns the high serotonin 2A/dopamine 2 receptor-binding affinities ratio. However, risperidone, with one of the highest ratios, does not act as an SGA in terms of lower risk for movement disorder, whereas sulpiride - without serotonin affinity does (Owens, 1999). For tardive dystonia, no differences in rates have been reported as a function of type of antipsychotic (Kiriakakis et al., 1998).

High dose (Morgenstern and Glazer, 1993;Glazer et al., 1993) and high potency of antipsychotics (Leucht et al., 2009a;Leucht et al., 2009b) are risk factors for TD, and for akathisia (Sachdev, 2005). Antipsychotic-induced parkinsonism is strongly associated with dopamine antagonism and its occurrence therefore is dose-related with use of high-potency antipsychotics. Drugs with an intrinsic anticholinergic property have a lower prevalence of parkinsonism (Sachdev, 
2005; Friedman, 1992; Weiden, 1994). For tardive dystonia, no data are available as regards the influence of antipsychotic dose and potency.

In a meta-analysis non-white ethnic group and early movement disorder symptoms were risk factors for TD in schizophrenia (Tenback et al., 2009). Drugs and alcohol usage conferred a threefold increased risk for TD (van Os et al., 1997). A higher rate of TD was associated with right handedness in some studies (Barr et al., 1989;Brown et al., 1992;Kern et al., 1991;Morgenstern et al., 1996), whereas with non-right handedness in other studies (Joseph, 1990;McCreadie et al., 1982). ECT has been proposed as risk factor for TD (Owens, 1999).

Given many reported risk factors, but little in terms of consistency or metaanalytic work summarizing the findings, the approach used in the current study was agnostic and explorative, focusing particularly on the most important demographic and illness-related variables.

In conclusion, long-stay patients with chronic mental illness requiring long-term antipsychotic treatment have a disproportionately high risk of incident movement disorders, particularly individuals who are older (TD and parkinsonism), and on higher doses of antipsychotic medication (parkinsonism). Therefore, they deserve special attention. Although long-stay settings are not the norm anymore, they are not rare. In the U.S., over 200 state hospitals attend a declining but challenging patient population (Fisher et al., 2009) and the findings likely can be extended to the considerably larger group of patients who live in supervised residential settings. Systematic screening for movement disorders takes little time and can be easily implemented in clinical practice. Furthermore, given the clear age dependency of some movement disorders, elderly patients are a group of special concern. Future research on movement disorders may be served by the inclusion of (i) all four movement disorders, as done in the current study, since they may represent the pleiotropic effects of (partly) shared genetic factors (Koning et al., 2011), and (ii) scales for subjective well being and quality of life, to better assess patient impact.

\section{Acknowledgements}

The authors are grateful for M. Hoornweg-van Beek (MSc), G.V. Boedijn (MSc), M. van Drie (MSc), R. Emons (MSc), A.E. Willems (MSc), Saltro laboratory, hospital and outpatient pharmacies, and hospital staff for providing their assistance, and to all patients for participating in this study. 


\section{References}

Altman, D.G., 1999. Practical statistics for medical research Chapman \& Hall/CRC, Boca Raton, Fl.

Ayd, F.J. and Baltimore, M.D., 1961. A survey of drug-induced extrapyramidal reactions. J A M A. 175, 1054-1060.

Bakker, P.R., de Groot, I.W., van Os, J. and van Harten, P.N., 2011. Long-stay psychiatric patients: a prospective study revealing persistent antipsychotic-induced movement disorder. PLoS ONE. 6, e25588.

Barnes, T.R. and Braude, W.M., 1985. Akathisia variants and tardive dyskinesia. Arch Gen Psychiatry. 42, 874-8.

Barr, W.B., Mukherjee, S., Degreef, G. and Caracci, G., 1989. Anomalous dominance and persistent tardive dyskinesia. Biol Psychiatry. 25, 826-834.

Brown, K.W., White, T., Anderson, F. and McGilp, R., 1992. Handedness as a risk factor for neuroleptic-induced movement disorders. Biol Psychiatry. 31, 746-748.

Burke, R.E., Fahn, S., Jankovic, J., Marsden, C.D., Lang, A.E., Gollomp, S. and Ilson, J., 1982. Tardive dystonia: late-onset and persistent dystonia caused by antipsychotic drugs. Neurology. 32, 1335-46.

Casey, D.E., 2006. Implications of the CATIE trial on treatment: extrapyramidal symptoms. CNS Spectr. 11, 25-31.

Chakos, M.H., Alvir, J.M., Woerner, M.G., Koreen, A., Geisler, S., Mayerhoff, D., Sobel, S., Kane, J.M., Borenstein, M. and Lieberman, J.A., 1996. Incidence and correlates of tardive dyskinesia in first episode of schizophrenia. Arch Gen Psychiatry. 53, 313-9.

Cleves, M.A., 2008. An introduction to survival analysis using Stata, 2nd ed edn. Stata Press, College Station, Tex.

Eberhard, J., Lindstrom, E. and Levander, S., 2006. Tardive dyskinesia and antipsychotics: a 5-year longitudinal study of frequency, correlates and course. Int Clin Psychopharmacol. 21, 35-42.

Factor, S.A., Lang, A.E., and Weiner, W.J., 2005. Drug induced movement disorders, 2nd ed edn. Blackwell Futura, Malden, Mass.

Fisher, W.H., Geller, J.L. and Pandiani, J.A., 2009. The changing role of the state psychiatric hospital. Health Aff (Millwood ). 28, 676-684.

Friedman, J.H., 1992. Drug-induced parkinsonism. In: Weiner W.J. and Lamng A.E. (Eds.), Druginduced movement disorders, Futura Publishing, New York, pp. 41-85.

Gardos, G., Teicher, M.H., Lipinski, J.F., Jr., Matthews, J.D., Morrison, L., Conley, C. and Cole, J.O., 1992. Quantitative assessment of psychomotor activity in patients with neuroleptic-induced akathisia. Prog Neuropsychopharmacol Biol Psychiatry. 16, 27-37.

Glazer, W.M., Morgenstern, H. and Doucette, J.T., 1993. Predicting the long-term risk of tardive dyskinesia in outpatients maintained on neuroleptic medications. J Clin Psychiatry. 54,133-9.

Halstead, S.M., Barnes, T.R. and Speller, J.C., 1994. Akathisia: prevalence and associated dysphoria in an in-patient population with chronic schizophrenia. Br J Psychiatry. 164, 177-83.

Joseph, A.B., 1990. Non-right-handedness and maleness correlate with tardive dyskinesia among patients taking neuroleptics. Acta Psychiatr Scand. 81, 530-533.

Kane, J.M., Woerner, M. and Lieberman, J., 1985. Tardive dyskinesia: prevalence, incidence, and risk factors. Psychopharmacology Suppl. 2, 72-78.

Kay, S.R., Fiszbein, A. and Opler, L.A., 1987. The positive and negative syndrome scale (PANSS) for schizophrenia. Schizophr Bull. 13, 261-276.

Keepers, G.A. and Casey, D.E., 1991. Use of neuroleptic-induced extrapyramidal symptoms to predict future vulnerability to side effects. Am J Psychiatry. 148, 85-9.

Keepers, G.A., Clappison, V.J. and Casey, D.E., 1983. Initial anticholinergic prophylaxis for neuroleptic-induced extrapyramidal syndromes. Arch Gen Psychiatry. 40, 1113-7.

Kern, R.S., Green, M.F., Satz, P. and Wirshing, W.C., 1991. Patterns of manual dominance in patients with neuroleptic-induced movement disorders. Biol Psychiatry. 30, 483-492.

Kiriakakis, V., Bhatia, K.P., Quinn, N.P. and Marsden, C.D., 1998. The natural history of tardive dystonia. A long-term follow-up study of 107 cases. Brain. 121 ( Pt 11), 2053-66. 
Kohler, U. and Kreuter, F., 2009. Data analysis using stata, 2nd ed edn. Stata Press, College Station, Tex.

Koning, J.P., Vehof, J., Burger, H., Wilffert, B., Al Hadithy, A., Alizadeh, B., van Harten, P.N. and Snieder, H., 2011. Association of two DRD2 gene polymorphisms with acute and tardive antipsychoticinduced movement disorders in young Caucasian patients. Psychopharmacology (Berl).

Lambert, M., Conus, P., Eide, P., Mass, R., Karow, A., Moritz, S., Golks, D. and Naber, D., 2004. Impact of present and past antipsychotic side effects on attitude toward typical antipsychotic treatment and adherence. Eur Psychiatry. 19, 415-422.

Leucht, S., Corves, C., Arbter, D., Engel, R.R., Li, C. and Davis, J.M., 2009a. Second-generation versus first-generation antipsychotic drugs for schizophrenia: a meta-analysis. Lancet. 373, 31-41.

Leucht, S., Kissling, W. and Davis, J.M., 2009b. Second-generation antipsychotics for schizophrenia: can we resolve the conflict? Psychol Med. 39, 1591-1602.

McCreadie, R.G., Crorie, J., Barron, E.T. and Winslow, G.S., 1982. The Nithsdale schizophrenia survey: III. Handedness and tardive dyskinesia. Br J Psychiatry. 140, 591-594.

Moleman, P., Janzen, G., von Bargen, B.A., Kappers, E.J., Pepplinkhuizen, L. and Schmitz, P.I., 1986. Relationship between age and incidence of parkinsonism in psychiatric patients treated with haloperidol. Am J Psychiatry. 143, 232-4.

Morgenstern, H. and Glazer, W.M., 1993. Identifying risk factors for tardive dyskinesia among longterm outpatients maintained with neuroleptic medications. Results of the Yale Tardive Dyskinesia Study. Arch Gen Psychiatry. 50, 723-33.

Morgenstern, H., Glazer, W.M. and Doucette, J.T., 1996. Handedness and the risk of tardive dyskinesia. Biol Psychiatry. 40, 35-42.

Mukherjee, S., Rosen, A.M., Caracci, G. and Shukla, S., 1986. Persistent tardive dyskinesia in bipolar patients. Arch Gen Psychiatry. 43, 342-6.

Murray, R.M. and van Os, J., 1998. Predictors of outcome in schizophrenia. J Clin Psychopharmacol. $18,2 \mathrm{~S}-4 \mathrm{~S}$.

Owens, D.G.C., 1999. A guide to the extrapyramidal side-effects of antipsychotic drugs Cambridge University Press UK, New York, p. 351.

Rabe-Hesketh, S. and Skrondal, A., 2008. Multilevel and longitudinal modelling using stata, 2nd ed edn. Stata Press, College Station, Tex.

Richardson, M.A., Haugland, G. and Craig, T.J., 1991. Neuroleptic use, parkinsonian symptoms, tardive dyskinesia, and associated factors in child and adolescent psychiatric patients. Am J Psychiatry. 148, 1322-8.

Robinson, D.G., Woerner, M.G., Alvir, J.M., Bilder, R.M., Hinrichsen, G.A. and Lieberman, J.A., 2002. Predictors of medication discontinuation by patients with first-episode schizophrenia and schizoaffective disorder. Schizophr Res. 57, 209-219.

Sachdev, P., 1993. Clinical characteristics of 15 patients with tardive dystonia. Am J Psychiatry. 150, 498-500.

Sachdev, P., 2004. Early extrapyramidal side-effects as risk factors for later tardive dyskinesia: a prospective study. Aust N Z J Psychiatry. 38, 445-449.

Sachdev, P.S., 2005. Neuroleptic-induced movement disorders: an overview. Psychiatr Clin North Am. 28, 255-74, $\mathrm{x}$.

Sandyk, R. and Kay, S.R., 1990. Relationship of neuroleptic-induced akathisia to drug-induced parkinsonism. Ital J Neurol Sci. 11, 439-42.

Sandyk, R., Kay, S.R., Awerbuch, G.I. and Iacono, R.P., 1991. Risk factors for neuroleptic-induced movement disorders. Int J Neurosci. 61, 149-88.

Schooler, N.R. and Kane, J.M., 1982. Research diagnoses for tardive dyskinesia. Arch Gen Psychiatry. 39, 486-7.

StataCorp. 2009. Stata: Release 11. Statistical Software. College Station, TX: StataCorp LP.

Steyerberg, E.W., 2009. Clinical prediction models, a practical approach to development, validation, and updating Springer, New York.

Tamminga, C.A., 2006. Practical treatment information for schizophrenia. Am J Psychiatry. 163, 563565. 
Tenback, D.E., van Harten, P.N., Slooff, C.J. and van Os, J., 2006. Evidence that early extrapyramidal symptoms predict later tardive dyskinesia: a prospective analysis of 10,000 patients in the European Schizophrenia Outpatient Health Outcomes (SOHO) study. Am J Psychiatry. 163, 1438-1440.

Tenback, D.E., van Harten, P.N., Slooff, C.J. and van Os, J., 2007. Worsening of psychosis in schizophrenia is longitudinally associated with tardive dyskinesia in the European Schizophrenia Outpatient Health Outcomes study. Compr Psychiatry. 48, 436-440.

Tenback, D.E., van Harten, P.N. and van Os, J., 2009. Non-therapeutic risk factors for onset of tardive dyskinesia in schizophrenia: a meta-analysis. Mov Disord. 24, 2309-2315.

van Harten, P.N., Hoek, H.W., Matroos, G.E., Koeter, M. and Kahn, R.S., 1997. The inter-relationships of tardive dyskinesia, parkinsonism, akathisia and tardive dystonia: the Curacao Extrapyramidal Syndromes Study II. Schizophr Res. 26, 235-42.

van Harten, P.N., Hoek, H.W., Matroos, G.E., Koeter, M. and Kahn, R.S., 1998. Intermittent neuroleptic treatment and risk for tardive dyskinesia: Curacao Extrapyramidal Syndromes Study III. Am J Psychiatry. 155, 565-7.

van Harten, P.N., Matroos, G.E., Hoek, H.W. and Kahn, R.S., 1996. The prevalence of tardive dystonia, tardive dyskinesia, parkinsonism and akathisia The Curacao Extrapyramidal Syndromes Study: I. Schizophr Res. 19, 195-203.

van Os, J., Fahy, T., Jones, P., Harvey, I., Toone, B. and Murray, R., 1997. Tardive dyskinesia: who is at risk? Acta Psychiatr Scand. 96, 206-16.

Weiden, P.J., 1994. Neuroleptic-induced parkinsonism. In: Widiger T.A., Frances A.J. and Pincus H.A. (Eds.), DSM-IV source book, American Psychiatric Association, Washington DC.

Yassa, R. and Jeste, D.V., 1992. Gender differences in tardive dyskinesia: a critical review of the literature. Schizophr Bull. 18, 701-15. 

Part 2 - Prospective naturalistic study

\section{Part 2b-Genetic risk factors}




$$
(0
$$




\section{Candidate gene-based association study of antipsychotic-induced movement disorders in long-stay psychiatric patients: A prospective Study}

P. Roberto Bakkera, Egbert Bakkerb ${ }^{b}$, Najaf Amin', Cornelia M. van Duijnc, Jim van Os ${ }^{\mathrm{d}, \mathrm{e}}$, Peter N. van Harten ${ }^{\mathrm{a}, \mathrm{d}}$

\footnotetext{
${ }^{\text {a }}$ Psychiatric Centre GGZ Centraal, Amersfoort, The Netherlands

${ }^{b}$ Center for Human and Clinical Genetics, Leiden University Medical Center (LUMC), Leiden, the Netherlands

${ }^{\mathrm{c}}$ Department of Epidemiology, Erasmus MC, Rotterdam, The Netherlands

${ }^{\mathrm{d}}$ Department of Psychiatry and Psychology, South Limburg Mental Health Research and Teaching Network, EURON, Maastricht University Medical Centre, Maastricht, The Netherlands

${ }^{e}$ King's College London, King's Health Partners, Department of Psychosis Studies, Institute of Psychiatry, London, United Kingdom
}

Submitted 


\begin{abstract}

\section{Objective}

Four types of antipsychotic-induced movement disorders: tardive dyskinesia (TD), parkinsonism, akathisia and tardive dystonia, subtypes of TD (orofacial and limb truncal dyskinesia), subtypes of parkinsonism (rest tremor, rigidity, and bradykinesia), as well as a principal-factor of the movement disorders and their subtypes, were examined for association with variation in 10 candidate genes (PPP1R1B, BDNF, DRD3, DRD2, HTR2A, HTR2C, COMT, MnSOD, CYP1A2, and $R G S 2)$.
\end{abstract}

\title{
Method
}

Naturalistic study of 168 white long-stay patients with chronic mental illness requiring long-term antipsychotic treatment, examined by the same rater at least two times over a 4-year period, with a mean follow-up time of 1.1 years, with validated scales for TD, parkinsonism, akathisia, and tardive dystonia. The authors genotyped 31 SNPs, associated with movement disorders or schizophrenia in previous studies. Genotype and allele frequency comparisons were performed with multiple regression methods for continuous movement disorders.

\section{Results}

Various SNPs reached nominal significance: TD and orofacial dyskinesia with rs6265 and rs988748, limb truncal dyskinesia with rs6314, rest tremor with rs6275, rigidity with rs6265 and rs4680, bradykinesia with rs4795390, akathisia with rs4680, tardive dystonia with rs1799732, rs4880 and rs1152746. After controlling for multiple testing, no significant results remained.

\section{Conclusions}

The findings suggest that selected SNPs are not associated with a susceptibility to movement disorders. However, as the sample size was small and previous studies show inconsistent results, definite conclusions cannot be made. Replication is needed in larger study samples, preferably in longitudinal studies which take the fluctuating course of movement disorders and gene-environment interactions into account. 


\section{Introduction}

Antipsychotics are the central pillar in the treatment of psychotic disorder. However, these agents can induce movement disorders, which are associated with social stigmatization, physical disabilities and poorer quality of life. They also contribute to non-compliance, which results in an increased risk of psychotic relapse (Casey, 2006; Lambert et al., 2004;Robinson et al., 2002). Therefore, identification of patients that are prone to these side effects would be of clinical value. Antipsychotic-induced movement disorders (Owens, 1999;Factor et al., 2005) can be classified, on the one hand, into acute syndromes, that appear within hours/days or weeks after initiating antipsychotic treatment or increasing the antipsychotic dose (or cessation of anticholinergics), e.g. parkinsonism and akathisia, and, on the other hand, tardive syndromes, that develop after months or years of treatment with antipsychotics such as tardive dyskinesia (TD) and tardive dystonia. Initially, the term 'tardive' (delayed) was introduced to emphasize the late-onset types of movement disorders occurring during antipsychotic use. Yet the definition of tardive disorders in the current study emphasizes their persistence, which is clinically more important than their lateonset (Sachdev, 2005;Factor et al., 2005). As in patients on long term treatment, combinations of acute and tardive movement disorders can concur, prediction models should include all four antipsychotic-induced movement disorders.

Family studies suggest an important genetic component to the risk for movement disorders (Halliday et al., 2002;McCreadie et al., 2003;Muller et al., 2001;Fenton, 2000;Lerer, 2002;Lencer et al., 2004). A recent meta-analysis on the prevalence of dyskinesia and parkinsonism reported spontaneous dyskinesia and parkinsonism in antipsychotic naïve patients with schizophrenia, and a higher prevalence of dyskinesia and parkinsonism in healthy family members of patients with schizophrenia, compared to matched controls (Koning et al., 2010b).

Pharmacogenetic studies may identify genetic risk factors which underlie individual differences in response to antipsychotics (Reynolds, 2007;0hmori et al., 2003;Lerer, 2002), in theory paving the way for individually tailored medication prescriptions (Lerer and Segman, 2006). Knowledge of a minimal number of genetic susceptibility loci in candidate genes and demographic, clinical and drug-related risk factors would help the clinician to make a rational treatment choice.

It can be hypothesized that specific subtypes of movement disorders are more suitable for genetic analysis than a general movement disorder syndrome, as subtypes may better reflect the underlying biological heterogeneity in complex syndromes.

The phenotypes under study were TD, parkinsonism, akathisia, and tardive dystonia, subtypes of TD (orofacial and limb truncal dyskinesia), subtypes of 
parkinsonism (rest tremor, rigidity, and bradykinesia), as well as a principalfactor of the movement disorders and their subtypes.

The 10 candidate genes were PPP1R1B, BDNF, DRD3, DRD2, HTR2A, HTR2C, COMT, MnSOD, CYP1A2, and RGS2 (Text S1). The choice of these genes was hypothesis-driven, under the common disease/common variant (CDCV) hypothesis, which proposes that common diseases may be caused by common genetic variants (Wellcome Trust Case Control Consortium, 2007;Hemminki et al., 2008; Reich and Lander, 2001; Wang et al., 2005).

The aim of the current study was to determine the association between movement disorders and variations in these 10 candidate genes.

The prospective design of the current study extends hitherto cross-sectional work in the pharmacogenetic field of antipsychotic-induced movement disorders. Indeed, prospective assessment of fluctuating (repeated) movement disorders measures the phenotype more specifically and that increases the validity of the associations between movement disorders and risk factors.

\section{Method}

\section{Ethics statement}

The protocol was approved by the standing Institutional Review Board, 'Medisch-ethische Toetsingscommissie Instellingen Geestelijke Gezondheidszorg' (Review Board for Human Research in Psychiatry), the Netherlands [protocol number 377].

Written informed consent was obtained from each patient, hence, consent obtained from the next of kin was not necessary and not recommended by the Review Board for Human Research in Psychiatry.

\section{Subjects}

A 4-year prospective naturalistic study (July 2003 - May 2007) was conducted with 209 patients with chronic mental illness in order to determine the genetic risk factors of the four major types of movement disorders (TD, parkinsonism, akathisia, and tardive dystonia), subtypes of TD and parkinsonism, as well as a principal-factor of the movement disorders and their subtypes. To this end, a cohort was drawn from a general psychiatric hospital (GGZ Centraal, Amersfoort, the Netherlands). Full details of the study design and movement disorders have been published previously (Bakker et al., 2011) (Bakker and colleagues, submitted). The cohort was representative of the population of patients with the most severe chronic mental illness requiring long-stay care, given that the hospital serves an epidemiological catchment area, is the only institute providing 
this type of care in this area, and patients were selected from a comprehensive list of all inpatients.

Of the patients assessed at baseline $(\mathrm{N}=207) 93.7 \%(\mathrm{n}=194)$ had at least one follow-up and 59.4\% (n=123) had two follow-up assessments. Loss to follow-up was due to patients who were difficult to trace after leaving hospital, died or refused assessment after inclusion.

\section{Assessment}

Patients were examined by a trained psychiatrist (PRB), using a standard protocol, described by van Harten and colleagues (1996). In addition, subtypes of movement disorders were assessed using (i) the Abnormal Involuntary Movement Scale (AIMS) (Guy, 1975;Guy, 1976) with items 1-4 for orofacial and items 5-7 for limb truncal dyskinesia, (ii) the Unified Parkinson Disease Rating Scale (UPDRS) (Fahn and Elton, 1987) with item c3-c4 for 'rest tremor' (rest tremor, and action/postural tremor of hands); item c5 for rigidity; and items c1, c2, c6c12, and c14 for bradykinesia. This approach has been described previously by 3 members of our research team (AAH, JvO and $\mathrm{PvH}$ ) (Al Hadithy et al., 2009; Wilffert et al., 2009;Al Hadithy et al., 2008).

As movement disorders likely share genetic liability, a genetic association between the combined movement disorders and candidate genes is also required. To determine the association between the combined movement disorder and variation in 10 candidate genes, a principal-factor of the four major types of movement disorders and subtypes of TD and parkinsonism was calculated with the FACTOR procedure in the STATA statistical program (StataCorp. 2009).

Based on the literature published between 1976 and August 2011, we selected 10 candidate genes (Table 1 and Text S1) that (i) are involved in the dopaminergic and serotonergic systems which have been implicated in the development of movement disorders, and the gene coding for the free radical scavenging enzymes like manganese super oxide dismutase (MnSOD) based on the hypothesis of neuronal degeneration owing to toxic effects of free radicals on TD. Genes involved in the glutamatergic system that may also contribute to cumulative neural damage, were not selected as the extensive number of receptors in this system, like metabotropic receptors (mGluRs) and ionotropic receptors (iGluRs), merit separate analysis. 


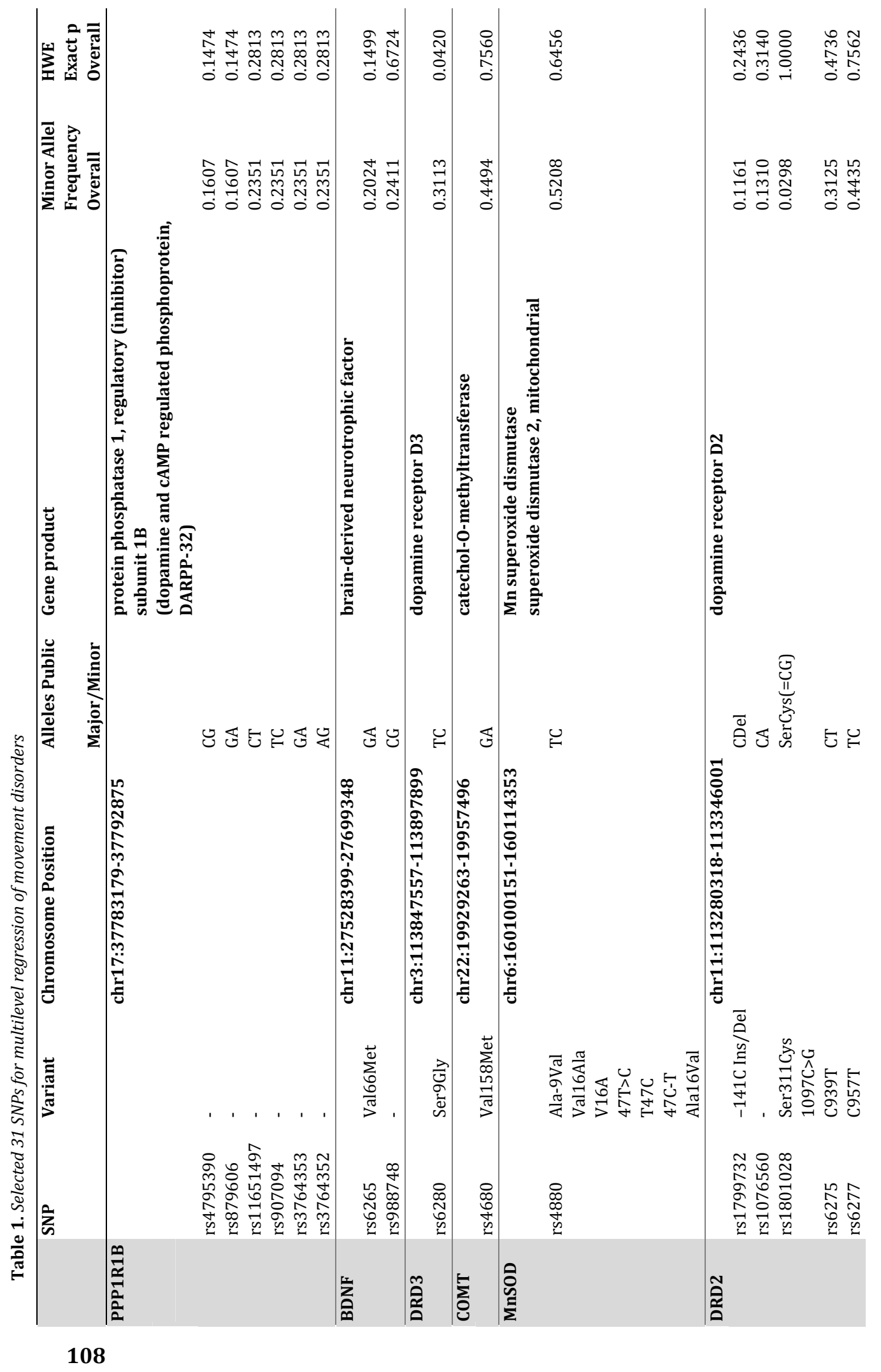




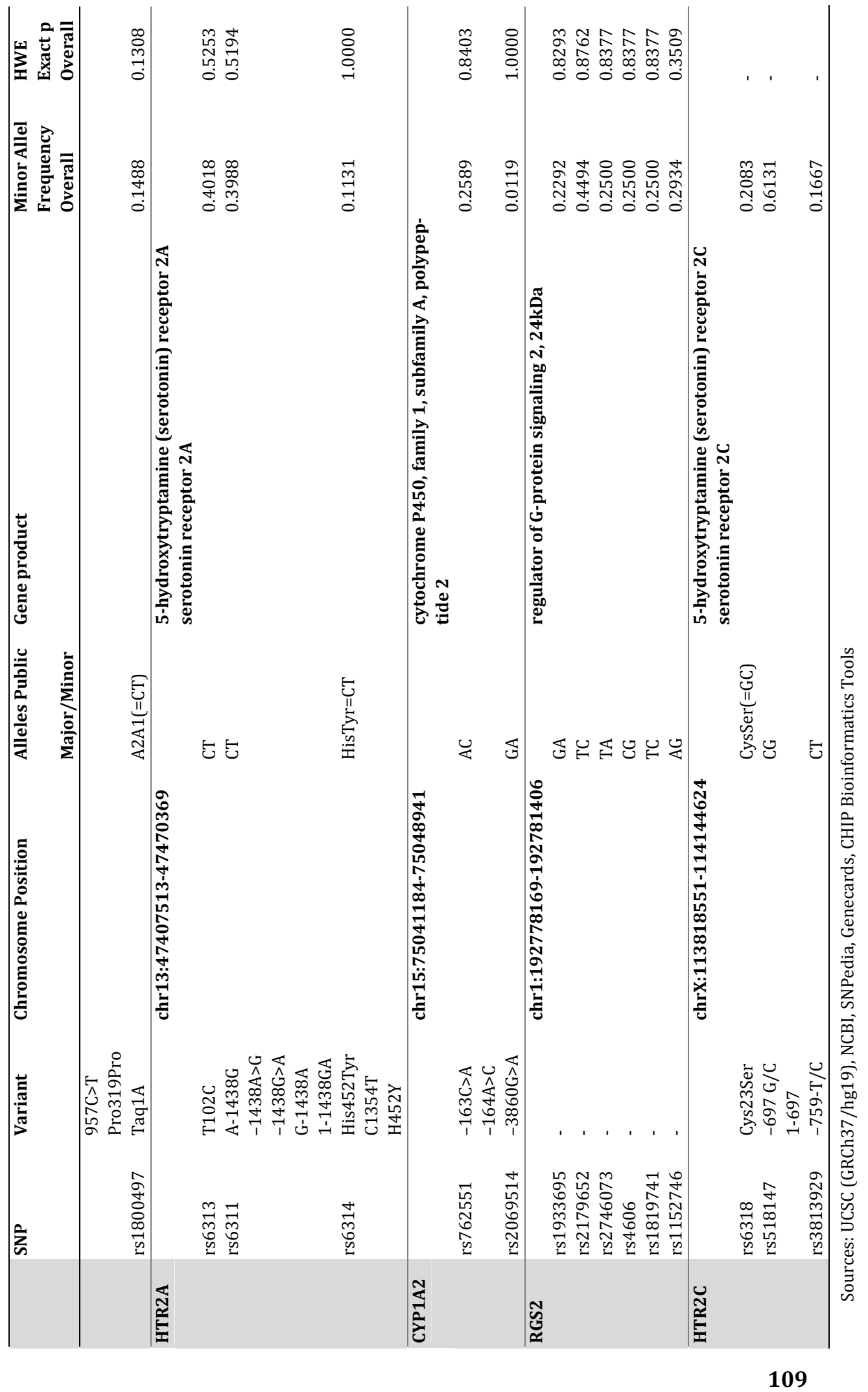


In addition, variables possibly affecting risk were extracted from patients' case notes including age, sex, BMI, self-reported handedness, diagnosis according to DSM-IV, ethnic group (classified as white and non-white), duration of hospitalization and history of electroconvulsive therapy (ECT). Negative symptoms were rated using the negative symptom subscale of the Positive and Negative Symptom Severity (PANSS) scale (Kay et al., 1987). The MINI sections for alcohol and drug use were administered, and information on tobacco intake (yes/no, number of cigarettes, cigars, etc; descriptors such as 'light', 'mild', 'heavy' and 'normal' use of tobacco) was collected. At baseline and at each follow-up assessment, current use of antipsychotic and anticholinergic medication was collected, and the global symptom rating of the Clinical Global Impression - Schizophrenia severity of illness (CGI-SCH SI) scale was completed. All clinical assessments were carried out by a psychiatrist (PRB). Information on current use of the above medication was collected from the hospital and outpatient pharmacy databases.

The diagnosis 'schizophrenia' hereafter refers to DSM-IV codes 295.30, $295.10,295.20,295.90,295.60,295.70$, and other diagnoses of 'psychotic disorder' to $295.40,297.1,298.8,298.9$.

\section{DNA extraction, Genotyping}

Two $10 \mathrm{ml}$ EDTA tubes of peripheral blood were drawn from participants, and genomic DNA was extracted from leucocytes by Autopure LS method (Qiangen) according to the manufacturer's protocols. We genotyped 31 SNPs (TaqMan® SNP Genotyping Assays method, Applied Biosystems, Foster City, California, USA) in 10 candidate gene regions, including SNPs previously reported as associated with movement disorders and schizophrenia.

\section{Statistical Analyses}

\section{Hardy Weinberg Equilibrium}

Only SNPs were included in the analyses that were not significantly outside Hardy-Weinberg Equilibrium (HWE) ( $p>0.05)$ in (i) the complete control sample (for a dichotomous trait) or (ii) the complete study sample (for a continuous trait). For the three SNPs in the X-chromosomal HTR2C gene, departure from HWE was not calculated.

Departure from the HWE was calculated with the GENASS and GENHW procedures in the STATA statistical program (StataCorp. 2009) for (i) the dichotomously defined persistent forms of movement disorders separately in both patients (with one movement disorder) and controls (without that movement disorder), respectively. Case definition of a persistent movement disorder was based on 2 consecutive assessments over a period of minimally 3 months, and 
required that individuals met case definition criteria at two consecutive assessments (hereafter: persistent movement disorder), meeting the requirements of Schooler and Kane's criteria for persistent movement disorder (Schooler and Kane, 1982), and (ii) the combined group of patients and controls, as continuous measures cannot be separated in both patients and controls.

\section{Association Tests for Single SNPS}

Only continuous movement disorder outcomes were used, given that continuous measures better handle the variability of movement disorders and generate more statistical power than cut off points (Steyerberg, 2009;Ziegler and König, 2006). Genotype and allele frequency comparisons were performed with multiple regression methods for continuous movement disorders, using the Armitage trend test, with the major allele (from our dataset of 168 selected white patients) as reference. The Armitage trend test assumes an additive effect by both alleles on the trait of interest, i.e. the mean effect on the trait by the heterozygous genotype (Major-Minor) is halfway the effects of the two homozygotes. (Major-Major and Minor-Minor).

\section{Regression analyses}

The regression analyses were conducted with movement disorder measures at a single assessment (hereafter: fluctuating movement disorder). The reason for this was that movement disorders constantly fluctuate over time, so that inclusion in the regression of their repeated single-occasion measures allowed for calculation of associations between one movement disorder with the other over time. As the study design comprised repeated measures nested in the same patient, clustering of observations in individuals needed to be corrected for. Therefore, multilevel random regression was used with the measurement occasion (baseline and two follow-ups) at level 1, and subjects at level 2, with the XTREG MLE routine of the STATA statistical program (StataCorp. 2009). Associations with explanatory variables were expressed as beta coefficients representing the change of continuous movement disorder outcome with 1 unit change of the exposure variable.

Using the dataset of 168 selected white patients, associations with predictors were adjusted for a priori, movement-disorder specific covariates as follows (Bakker and colleagues, submitted) age was adjusted for in the model of TD and TD subtypes; age and total antipsychotic use was adjusted for in the model of parkinsonism and its subtypes, and no covariates were introduced in the models of akathisia, tardive dystonia and the principal-factor.

\section{Correction for multiple testing}

In order to correct for multiple testing of single SNP tests, the Simes modification of the Bonferroni multiple-testing procedure was performed to control the False Discovery Rate (FDR) (Benjamini et al., 2004). Bonferroni correction is too 
conservative if tests are not independent of each other (as in this case when there is LD between markers); in this case FDR represents a less conservative alternative. We used the MULTPROC procedure in the STATA statistical program (StataCorp. 2009) for FDR calculation, and then the SMILEPLOT procedure calling MULTPROC to build a smile plot. A smile plot summarizes a set of multiple analyses, similarly as a Cochrane forest plot summarizes a meta-analysis, and separates by reference line rejected and non-rejected p-values (on a reverse log scale against the corresponding parameter estimates).

\section{Defined daily dose}

Antipsychotic doses were converted to defined daily dose (DDD), for which we refer to our previous publications (Bakker et al., 2011) (Bakker and colleagues, submitted). Anticholinergic medication was modeled as a dichotomous variable (yes/no).

\section{Results}

\section{Sample Characteristics}

Over the period of observation (mean=1.1 years, SD=0.64), of the 209 patients included at baseline, 207 participated in the study. One patient developed a brain tumor, another patient died after inclusion. All patients had a history of cumulative antipsychotic intake of minimally 1 year. Attrition rate was low at $9.8 \%$ over a 4 -year period.

Of the 207 patients, with chronic psychiatric illness requiring long-term admission, 199 participated in the genetic study. To prevent ethnic stratification resulting in spurious associations owing to differences in allele frequencies and risk of movement disorders, only white patients, representing the most prevalent group $(168=84.4 \%)$, were included in the analysis. At baseline, mean age expressed in years was 48.8 (SD 12.4); men 48.6 (SD 12.5) and women 49.1 (SD 12.2). Age at first admission, expressed in years, was 25.1 (SD 8.8); men 23.7 (SD 7.8) and women 27.1 (SD 9.7), respectively. The total duration of admission, expressed in years, was 23.4 (SD 12.9), men 24.4 (SD 12.5) and women 22.0 (SD 13.4). Diagnoses according to DSM-IV Axis I as defined above were: schizophrenia 112 (66.7\%), psychosis 9 (5.4\%), affective disorder 27 (16.1\%), other Axis I diagnosis 11 (6.6\%) and no Axis I diagnosis 9 (5.4\%).

\section{Association Analyses with SNPs}

Six redundant SNPs owing to strong linkage disequilibrium (LD) (Levwontin's $\mathrm{D}^{\prime}=1$, R-squared=1) were removed (Table 2): rs879606, rs907094, rs3764353, rs3764352 in PPP1R1B, and rs4606 and rs1819741 in RGS2. 
Table 2. Calculation of linkage disequilibrium (LD) between pairs of diallelic loci; Levwontin's D' (lower triangle) and R-squared (upper triangle)

\begin{tabular}{lcccccc}
\hline PPP1R1B & rs4795390 & rs879606 & rs11651497 & rs907094 & rs3764353 & rs3764352 \\
rs4795390 & - & 1.00 & 0.62 & 0.62 & 0.62 & 0.62 \\
rs879606 & 1.00 & - & 0.62 & 0.62 & 0.62 & 0.62 \\
rs11651497 & 1.00 & 1.00 & - & 1.00 & 1.00 & 1.00 \\
rs907094 & 1.00 & 1.00 & 1.00 & - & 1.00 & 1.00 \\
rs3764353 & 1.00 & 1.00 & 1.00 & 1.00 & - & 1.00 \\
rs3764352 & 1.00 & 1.00 & 1.00 & 1.00 & 1.00 & - \\
\hline RGS2 & rs1933695 & rs2179652 & rs2746073 & rs4606 & rs1819741 & rs1152746 \\
\hline rs1933695 & - & 0.24 & 0.10 & 0.10 & 0.10 & 0.03 \\
rs2179652 & 1.00 & - & 0.27 & 0.27 & 0.27 & 0.02 \\
rs2746073 & 1.00 & 1.00 & - & 1.00 & 1.00 & 0.00 \\
rs4606 & 1.00 & 1.00 & 1.00 & - & 1.00 & 0.00 \\
rs1819741 & 1.00 & 1.00 & 1.00 & 1.00 & - & 0.00 \\
rs1152746 & 0.46 & 0.22 & 0.02 & 0.02 & 0.02 & - \\
\hline
\end{tabular}

The following SNPs were excluded from analysis, due to deviation from HWE: all movement disorders - rs6280 (Table 1), as well as controls; TD - rs4795390; orofacial dyskinesia - rs4795390, rs1800497; limb truncal dyskinesia rs1800497; bradykinesia - rs1799732, rs6311.

The (multilevel) regression yielded significant coefficients, after adjustment for age, between tardive dyskinesia and $\operatorname{rs6265}(\mathrm{B}=0.19, \mathrm{p}=0.0072)$ as well as rs988748 $(\mathrm{B}=0.18, \mathrm{p}=0.0076)$; between orofacial dyskinesia and rs6265 $(\mathrm{B}=0.24, \mathrm{p}=0.0014)$ as well as $\mathrm{rs} 988748(\mathrm{~B}=0.23, \mathrm{p}=0.0019)$; and between limb truncal dyskinesia and $\operatorname{rs6314}(\mathrm{B}=-0.24, \mathrm{p}=0.0357)$. After adjustment for age and total antipsychotic DDD, associations were apparent between rest tremor and rs6275 $(\mathrm{B}=-0.14, \mathrm{p}=0.0140)$; between rigidity and rs6265 $(\mathrm{B}=-0.15$, $\mathrm{p}=0.0482)$ as well as rs4680 $(\mathrm{B}=0.14, \mathrm{p}=0.0303)$; and between bradykinesia and rs4795390 ( $\mathrm{B}=0.16, \mathrm{p}=0.0451)$. Without adjustment, associations were apparent between akathisia and rs4680 $(B=0.13, p=0.0289)$; between tardive dystonia and rs1799732 ( $\mathrm{B}=0.04, \mathrm{p}=0.0494)$, rs4880 ( $\mathrm{B}=-0.03, \mathrm{p}=0.0399)$, as well as rs1152746 ( $B=0.03, p=0.0456)$. After Simes correction for multiple testing of the above mentioned analyses, the number of rejected p-values was zero, with a corrected overall critical p-value of 0.00021 (Figure 1). 


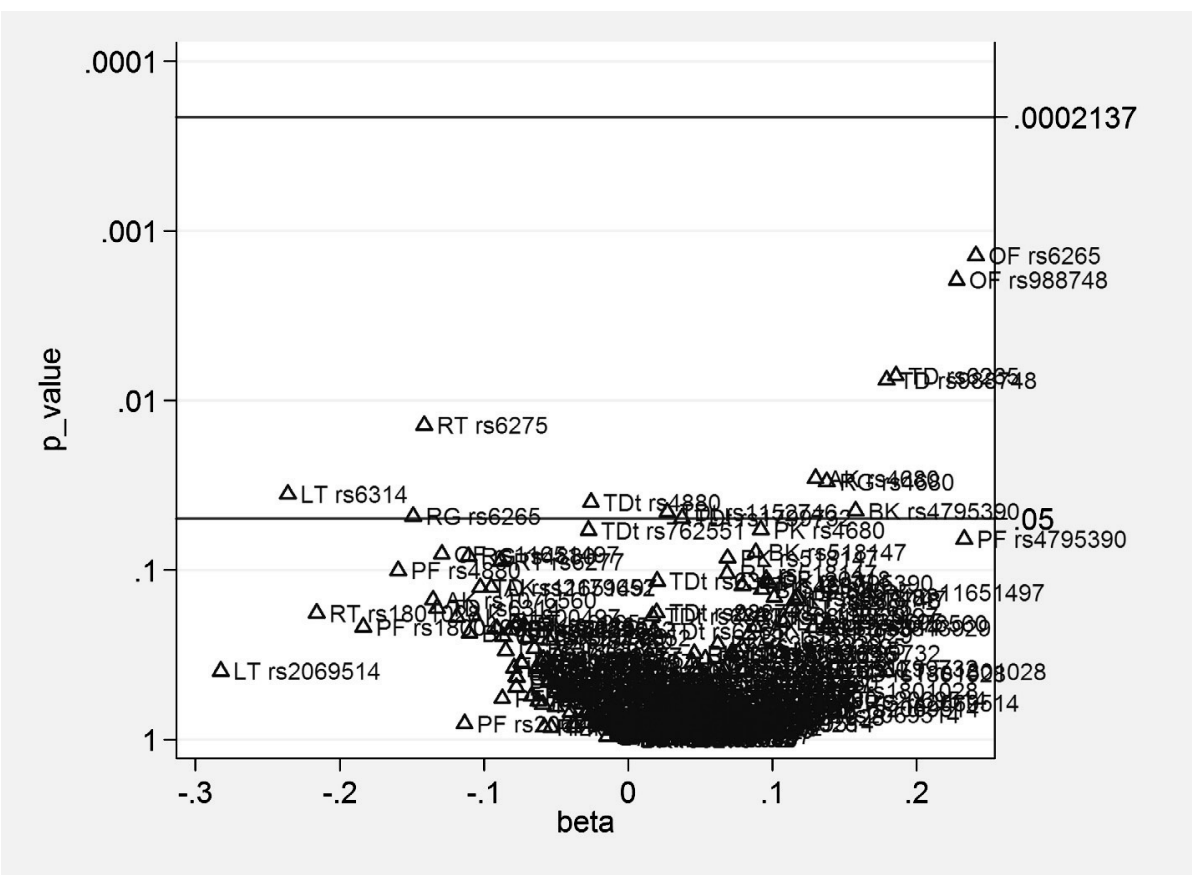

Figure 1. Smile plot summarizing set of multiple analyses after Simes correction for multiple testing. Corresponding p-values (on a reverse log scale against the corresponding parameter estimates). $T D=$ tardive dyskinesia, $O F=$ orofacial dyskinesia, $L T=l i m b$ truncal dyskinesia, $P K=$ parkinsonism, $R T=r e s t$ tremor, $R G=$ rigidity, $B K=$ bradykinesia, $A K=$ akathisia, $T D t=$ tardive dystonia and $P F=$ principal-factor.

\section{Discussion}

In a population with chronic mental illness, various SNPs in 10 candidate genes (PPP1R1B, BDNF, DRD3, DRD2, HTR2A, HTR2C, COMT, MnSOD, CYP1A2, and $R G S 2)$ reached nominally significant $(\mathrm{p} \leq 0.05)$ associations with drug-induced movement disorder. However, after controlling for multiple testing, our findings suggest that these single nucleotide polymorphism (SNP) are not associated with a susceptibility to movement disorders.

Another reason for the inconclusive findings could be explained by the fact that in a naturalistic setting it is possible to evaluate the overall impact of pharmacogenetic signals in the presence of a host of real-life variables that can override pharmacogenetic variation. The fact we did not observe a significant association may also attest to the possibility that each gene makes a small contribution that is often diluted or overridden by environmental and clinical variations. 


\section{Limitations}

This study had limitations, for which we refer to our previous publications (Bakker et al., 2011) (Bakker and colleagues, submitted) and additional limitations. First, as mentioned before, the relatively small sample size was the major limitation in this study. Still, the power in the current study may be increased as our patients had chronic mental illness, with a mean total duration of admission of 23.4 yrs (SD 12.9), which is a relatively long time for genetically susceptible patients to develop movement disorder. Also, we used continuous measures of movement disorder, which as a so-called intermediate quantitative trait is more informative about the underlying path in complex genetic diseases and thus generates more statistical power (Ziegler and König, 2006; Steyerberg, 2009). In addition, we used repeated measures for continuous movement disorders, which may give a more stable phenotype, and thus more power.

Second, some authors may argue that association studies of movement disorders in patient with a psychotic disorder will produce non-significant results, as this model is inadequate since movement disorders may share risk alleles with schizophrenia (Koning et al., 2010b). However, many movement disorders and schizophrenia are complex diseases caused by multiple genetic and environmental factors, which are probably only partly shared, as (i) clinical heterogeneity in schizophrenia is clear, (ii) evidence of pathophysiological and etiological heterogeneity is accumulating (Andreasen and Carpenter, Jr., 1993;McCormick and Flaum, 2005), and (iii) TD is a predictor for poor outcome of schizophrenia (Murray and van Os, 1998). Hence, it can be hypothesized that patients with movement disorders represent a subgroup of schizophrenia and the above mentioned model is adequate.

Third, some authors may contend that medication is an important confounder, which should have been included in our analysis. However, a confounding mechanism is difficult to envisage, as choice of medication would need to be associated with an SNP and, independently thereof, with the movement disorder outcome. Nevertheless, medication may modify SNP-movement disorder outcomes and may be included in future analyses as an interaction term.

\section{Strengths}

We refer to our previous publications (Bakker et al., 2011) (Bakker and colleagues, submitted). The importance of repeated measures should be noted, as case definition of repeated measures, rather than a single cross-sectional measure, for continuous movement disorders better reflects the continuously fluctuating nature in time of movement disorders, and therefore may represent a more suitable standard in future research. To the best of our knowledge only few paper in the literature address this issue. 
As the sample size of the current study is small and previous studies show inconsistent results, definite conclusions cannot be made. Yet the question is how to interpret these results. In our opinion, the findings of weak genetic signals need to be replicated in larger study samples, preferably in longitudinal studies which take the fluctuating course of movement disorders and gene-environment interactions into account (Howes and Kapur, 2009;van et al., 2010). Even though the current study is inconclusive, negative studies also ought to be reported as otherwise meta-analytic results in the future can be biased by positive studies that tend to be published more readily.

Various combinations of susceptibility genes may converge on synaptic processing in microcircuits, affecting a final common pathway of dysfunction and related symptoms, and secondary morphological alterations (Coyle, 2006; Ross et al., 2006). However, despite growing evidence from genetic association studies, genetics only explains a minor part of schizophrenia, a fact which supports the importance of other interacting factors, such as environmental factors, which play important roles in schizophrenia (Howes and Kapur, 2009). Neuropsychiatric disorders may reflect the complex interplay of not only genetic factors, but first and foremost of epigenetic, stochastic, and non-genetic factors (Braff et al., 2007). Consequently, at the moment it is too early to describe a genetic pathway of schizophrenia (Howes and Kapur, 2009) or movement disorders.

An important development in human (pharmaco) genetics since 2005 is the possibility of genome-wide association studies (GWASs) (Psychiatric GWAS Consortium, 2009) which have the advantage of a 'hypothesis free' and hence unbiased approach for examining new DNA variants which influence genetic susceptibility to many common diseases and can thus elucidate as yet unknown pathophysiological mechanisms.

After the choice of candidate genes in the current genetic association study was made, three GWASs of movement disorders were published: (i) the study by Inada e.a. (Inada et al., 2008) suggesting involvement of the GABA receptor signaling pathway in the development of therapy-resistant tardive dyskinesia, (ii) the study by Akelai e.a. (Alkelai et al., 2009) specifying EPF1, NOVA1, and FIGN as promising genes related to antipsychotic-induced parkinsonism, and (iii) the study by Åberg (Aberg et al., 2010) determining an association between parkinsonism and a SNP in ZNF202, a transcriptional repressor controlling the major protein in myelin, PLP1, related both to Pelizaeus-Merzbacher disease with parkinsonism as symptom, and schizophrenia.

The Psychiatric GWAS Consortium (PGC) has suggested that in the near future larger GWAS samples will detect more variants of common susceptibility with smaller effect sizes and that meta-analyses of GWAS should find more conclusive evidence for genetic associations. Meanwhile, new potentially promising 
genetic techniques are being implemented such as epigenetics and whole-exome sequencing as an alternative study design. Rare variants detected by these next generation sequencing technologies may yield a stronger signal than GWAS approaches. In our view, the common variant common disease/phenotype approach is challenged including the area of pharmacogenetics. Rare variants warrant more attention in future studies. Also, gene-environment-wide interaction studies (GEWIS) approaches are being suggested (Khoury and Wacholder, 2009). It seems legitimate to conclude that these new techniques offer more effective genetic linkage and association studies.

There is a need for more participatory research designs, especially in naturalistic studies in personalized medicine including psychiatry. However, Lehoux and colleagues pose the following question to be answered: 'what value does personalized medicine bring to health care?' (Lehoux, 2011) This important question refers to the unique context of personalized medicine where economic, political and social issues come together.

In conclusion, the findings suggest that selected SNPs are not associated with a susceptibility to movement disorders. However, replication is needed in larger study samples, preferably in longitudinal studies which take the fluctuating course of movement disorders and gene-environment interactions into account. The use of intermediate phenotypes, for example, laboratory based phenotypes (Braff et al., 2007), or more accurate measures of movement disorders, for example instrument measurement of lingual force variability as proposed by Koning and colleagues (2010a), which may represent a powerful alternative since instrument measurement detects subclinical movement disorders and is highly reliable. Moreover, (pharmaco) genetic studies may help elucidate common pathways in the development of movement disorders. With this information, an alternative World Health Organization Model List of Essential Medicines may be one that lists the 'minimal essential biomarkers' required for optimal pharmacotherapy (Ozdemir et al., 2006). However, on balance, our findings should be set in the context of interactions with both other genetic susceptibility loci and environmental factors, and, as rightly stated by Faraone and colleagues (1999) "any conclusion about the role of genes and environment must rely not on a single study or class of study but on the converging evidence provided by a variety of research paradigms."

Future research on movement disorders may be served by the inclusion of all four movement disorder, as performed in the current study, since they may represent pleiotropic effects from (partly) shared genetic factors (Koning et al., 2011).

\section{Acknowledgements}

The authors are grateful for M.J. Vollebregt (MSc) and C.T.M. Hettinga (BSc) for providing laboratory assistance and technical support. 
The authors are grateful for M. Hoornweg-van Beek (MSc), G.V. Boedijn (MSc), M. van Drie (MSc), R. Emons (MSc), A.E. Willems (MSc), I.W. de Groot (MSc), L. Broer (MSc), Saltro laboratory, hospital and outpatient pharmacies, hospital staff for providing their assistance, and to all patients for participating in this study.

\section{References}

Aberg, K., Adkins, D.E., Bukszar, J., Webb, B.T., Caroff, S.N., Miller, D.D., Sebat, J., Stroup, S., Fanous, A.H., Vladimirov, V.I., McClay, J.L., Lieberman, J.A., Sullivan, P.F. and van den Oord, E.J., 2010. Genomewide association study of movement-related adverse antipsychotic effects. Biol Psychiatry. 67, 279-282.

Al Hadithy, A.F., Wilffert, B., Bruggeman, R., Stewart, R.E., Brouwers, J.R., Matroos, G.E., Hoek, H.W. and van Harten, P.N., 2009. Lack of association between antipsychotic-induced Parkinsonism or its subsymptoms and rs4606 SNP of RGS2 gene in African-Caribbeans and the possible role of the medication: the Curacao extrapyramidal syndromes study X. Hum Psychopharmacol. 24, 123-128.

Al Hadithy, A.F., Wilffert, B., Stewart, R.E., Looman, N.M., Bruggeman, R., Brouwers, J.R., Matroos, G.E., van Os, J., Hoek, H.W. and van Harten, P.N., 2008. Pharmacogenetics of parkinsonism, rigidity, rest tremor, and bradykinesia in African-Caribbean inpatients: differences in association with dopamine and serotonin receptors. Am J Med Genet B Neuropsychiatr Genet. 147B, 890-897.

Alkelai, A., Greenbaum, L., Rigbi, A., Kanyas, K. and Lerer, B., 2009. Genome-wide association study of antipsychotic-induced parkinsonism severity among schizophrenia patients. Psychopharmacology. Published online.

Andreasen, N.C. and Carpenter, W.T., Jr., 1993. Diagnosis and classification of schizophrenia. Schizophr Bull. 19, 199-214.

Bakker, P.R., de Groot, I.W., van Os, J. and van Harten, P.N., 2011. Long-stay psychiatric patients: a prospective study revealing persistent antipsychotic-induced movement disorder. PLoS ONE. 6, e25588.

Benjamini, Y., Bretz, F. and Sarkar, S.K., 2004. Recent developments in multiple comparison procedures Institute of Mathematical Statistics, Beachwood, Ohio.

Braff, D.L., Freedman, R., Schork, N.J. and Gottesman, I.I., 2007. Deconstructing schizophrenia: an overview of the use of endophenotypes in order to understand a complex disorder. Schizophr Bull. 33, 21-32.

Casey, D.E., 2006. Implications of the CATIE trial on treatment: extrapyramidal symptoms. CNS Spectr. 11, 25-31.

Coyle, J.T., 2006. Glutamate and schizophrenia: beyond the dopamine hypothesis. Cell Mol Neurobiol. 26, 365-384.

Factor, S.A., Lang, A.E., and Weiner, W.J., 2005. Drug induced movement disorders, 2nd ed edn. Blackwell Futura, Malden, Mass.

Fahn, S. and Elton, R., 1987. UPDRS Development Committee. Unified Parkinson's Disease Rating Scale. In: Fahn S, Marsden CD, Calne DB, Goldstein M, eds. Recent Developments in Parkinson's Disease. Florham Park, NJ: Macmillan, pp. 153-163.

Faraone, S.V., Tsuang, M.T. and Tsuang, B.W., 1999. Genetic of mental disorders The Guilford Press, New York.

Fenton, W.S., 2000. Prevalence of spontaneous dyskinesia in schizophrenia. J Clin Psychiatry. 61 Suppl 4, 10-4.

Guy, W., 1975. ECDEU assessment manual for psychopharmacology. Department of Health, Education and Welfare, Washington DC, pp. 534-537. 
Guy, W., 1976. ECDEU assessment manual for psychopharmacology U.S. Dept. of Health, Education, and Welfare, Public Health Service, Alcohol, Drug Abuse, and Mental Health Administration, National Institute of Mental Health, Psychopharmacology Research Branch, Division of Extramural Research Programs, Rockville, Md, p. 603.

Halliday, J., Farrington, S., Macdonald, S., MacEwan, T., Sharkey, V. and McCreadie, R., 2002. Nithsdale Schizophrenia Surveys 23: movement disorders. 20-year review. Br J Psychiatry. 181, 422-7.

Hemminki, K., Forsti, A. and Bermejo, J.L., 2008. The 'common disease-common variant' hypothesis and familial risks. PLoS ONE. 3, e2504.

Howes, O.D. and Kapur, S., 2009. The dopamine hypothesis of schizophrenia: version III--the final common pathway. Schizophr Bull. 35, 549-562.

Inada, T., Koga, M., Ishiguro, H., Horiuchi, Y., Syu, A., Yoshio, T., Takahashi, N., Ozaki, N. and Arinami, T., 2008. Pathway-based association analysis of genome-wide screening data suggest that genes associated with the gamma-aminobutyric acid receptor signaling pathway are involved in neuroleptic-induced, treatment-resistant tardive dyskinesia. Pharmacogenet Genomics. 18, 317 323.

Kay, S.R., Fiszbein, A. and Opler, L.A., 1987. The positive and negative syndrome scale (PANSS) for schizophrenia. Schizophr Bull. 13, 261-276.

Khoury, M.J. and Wacholder, S., 2009. Invited commentary: from genome-wide association studies to gene-environment-wide interaction studies--challenges and opportunities. Am J Epidemiol. 169, 227-230.

Koning, J.P., Tenback, D.E., Kahn, R.S., Van Schelven, L.J. and van Harten, P.N., 2010a. Instrument measurement of lingual force variability reflects tardive tongue dyskinesia. J Med Eng Technol. 34, 71-77.

Koning, J.P., Tenback, D.E., van Os, J., Aleman, A., Kahn, R.S. and van Harten, P.N., 2010b. Dyskinesia and parkinsonism in antipsychotic-naive patients with schizophrenia, first-degree relatives and healthy controls: a meta-analysis. Schizophr Bull. 36, 723-731.

Koning, J.P., Vehof, J., Burger, H., Wilffert, B., Al Hadithy, A., Alizadeh, B., van Harten, P.N. and Snieder, H., 2011. Association of two DRD2 gene polymorphisms with acute and tardive antipsychoticinduced movement disorders in young Caucasian patients. Psychopharmacology (Berl).

Lambert, M., Conus, P., Eide, P., Mass, R., Karow, A., Moritz, S., Golks, D. and Naber, D., 2004. Impact of present and past antipsychotic side effects on attitude toward typical antipsychotic treatment and adherence. Eur Psychiatry. 19, 415-422.

Lehoux, P., 2011. Moving Beyond Our Mutual Ignorance. Or, How would Engaging the Public Benefit the Personalized Medicine Community? Current Pharmacogenomics and Personalized Medicine. 9, 76-79.

Lencer, R., Eismann, G., Kasten, M., Kabakci, K., Geithe, V., Grimm, J. and Klein, C., 2004. Family history of primary movement disorders as a predictor for neuroleptic-induced extrapyramidal symptoms. Br J Psychiatry. 185, 465-471.

Lerer, B. and Segman, R.H., 2006. Pharmacogenetics of antipsychotic therapy: pivotal research issues and the prospects for clinical implementation. Dialogues Clin Neurosci. 8, 85-94.

Lerer, B., 2002. Pharmacogenetics of psychotropic drugs Cambridge University Press, Cambridge, UK.

McCormick, L.M. and Flaum, M., 2005. Diagnosing schizophrenia circa 2005: how and why? Curr Psychiatry Rep. 7, 311-315.

McCreadie, R.G., Thara, R., Srinivasan, T.N. and Padmavathi, R., 2003. Spontaneous dyskinesia in first-degree relatives of chronically ill, never-treated people with schizophrenia. Br J Psychiatry. 183, 45-49.

Muller, D.J., Schulze, T.G., Knapp, M., Held, T., Krauss, H., Weber, T., Ahle, G., Maroldt, A., Alfter, D., Maier, W., Nothen, M.M. and Rietschel, M., 2001. Familial occurrence of tardive dyskinesia. Acta Psychiatr Scand. 104, 375-379.

Murray, R.M. and van Os, J., 1998. Predictors of outcome in schizophrenia. J Clin Psychopharmacol. $18,2 \mathrm{~S}-4 \mathrm{~S}$. 
Ohmori, O., Shinkai, T., Hori, H., Matsumoto, C. and Nakamura, J., 2003. A perspective on molecular genetic studies of tardive dyskinesia: one clue for individualized antipsychotic drug therapy. Prog Neuropsychopharmacol Biol Psychiatry. 27, 581-586.

Owens, D.G.C., 1999. A guide to the extrapyramidal side-effects of antipsychotic drugs Cambridge University Press UK, New York, p. 351.

Ozdemir, V., Aklillu, E., Mee, S., Bertilsson, L., Albers, L.J., Graham, J.E., Caligiuri, M., Lohr, J.B. and Reist, C., 2006. Pharmacogenetics for off-patent antipsychotics: reframing the risk for tardive dyskinesia and access to essential medicines. Expert Opin Pharmacother. 7, 119-133.

Psychiatric GWAS Consortium Coordinating Committee, 2009. Genomewide Association Studies: History, Rationale, and Prospects for Psychiatric Disorders. American Journal of Psychiatry. 166, 540-556.

Reich, D.E. and Lander, E.S., 2001. On the allelic spectrum of human disease. Trends Genet. 17, 502510.

Reynolds, G.P., 2007. The impact of pharmacogenetics on the development and use of antipsychotic drugs. Drug Discov Today. 12, 953-959.

Robinson, D.G., Woerner, M.G., Alvir, J.M., Bilder, R.M., Hinrichsen, G.A. and Lieberman, J.A., 2002. Predictors of medication discontinuation by patients with first-episode schizophrenia and schizoaffective disorder. Schizophr Res. 57, 209-219.

Ross, C.A., Margolis, R.L., Reading, S.A., Pletnikov, M. and Coyle, J.T., 2006. Neurobiology of schizophrenia. Neuron. 52, 139-153.

Sachdev, P.S., 2005. Neuroleptic-induced movement disorders: an overview. Psychiatr Clin North Am. 28, 255-74, $\mathrm{x}$.

Schooler, N.R. and Kane, J.M., 1982. Research diagnoses for tardive dyskinesia. Arch Gen Psychiatry. 39, 486-7.

StataCorp. 2009. Stata: Release 11. Statistical Software. College Station, TX: StataCorp LP.

Steyerberg, E.W., 2009. Clinical prediction models, a practical approach to development, validation, and updating Springer, New York.

van Harten, P.N., Matroos, G.E., Hoek, H.W. and Kahn, R.S., 1996. The prevalence of tardive dystonia, tardive dyskinesia, parkinsonism and akathisia The Curacao Extrapyramidal Syndromes Study: I. Schizophr Res. 19, 195-203.

van Os, J., Kenis, G. and Rutten, B.P., 2010. The environment and schizophrenia. Nature. 468, 203212.

Wang, W.Y., Barratt, B.J., Clayton, D.G. and Todd, J.A., 2005. Genome-wide association studies: theoretical and practical concerns. Nat Rev Genet. 6, 109-118.

Wellcome Trust Case Control Consortium, 2007. Genome-wide association study of 14,000 cases of seven common diseases and 3,000 shared controls. Nature. 447, 661-678.

Wilffert, B., Al Hadithy, A.F., Sing, V.J., Matroos, G., Hoek, H.W., van Os, J., Bruggeman, R., Brouwers, J.R. and van Harten, P.N., 2009. The role of dopamine D3, 5-HT2A and 5-HT2C receptor variants as pharmacogenetic determinants in tardive dyskinesia in African-Caribbean patients under chronic antipsychotic treatment: Curacao extrapyramidal syndromes study IX. J Psychopharmacol. 23, 652-659.

Ziegler, A. and König, I.R., 2006. A statistical approach to genetic epidemiology, concepts and applications Wiley-VCH, Weinheim. 


\section{Supporting Text S1 (Chapter 6)}

\section{Genes}

A systematic literature review was conducted of the literature published between 1976 and August 2011, with the help of Medline, EMBASE and PsychINFO using key words (genetic) polymorphism(s), tardive dyskinesia, extrapyramidal (syndrome/disorder), drug-induced, antipsychotic(s), adverse effect/event, schizophrenia. In addition, all relevant references cited in these articles were also retrieved.

\section{Tardive dyskinesia}

The dopaminergic and serotonergic systems of neurotransmission have been implicated in the development of movement disorders.

Genes involved in dopaminergic signaling, possibly associated with the development of TD, include those coding for: (i) Dopamine 3 receptor (DRD3), with evidence from meta-analyses for an association between Ser9Gly (rs6280) and TD (Lerer et al., 2002;Bakker et al., 2006), but no or little evidence in a recent meta-analysis (Tsai et al., 2010b), confirming the observation of progressive reduction of meta-analytic effects over time in genetic studies (Lencz and Malhotra, 2009;Xiao and Boehnke, 2009); (ii) Dopamine 2 receptor (DRD2), with evidence from two meta-analyses for an association between Taq1A (rs1800497) and TD (Zai et al., 2007;Bakker et al., 2008). In a recent study with Korean patients, 5 SNPs in DRD2 (-141Ins/Del/Taq1D/NcoI/Ser311Cys/ Taq1A) showed no association with TD and TD severity, or the haplotype of these 5 SNPs with TD (Park et al., 2011). Another recent study found evidence for an association between -141Ins/Del (rs1799732) and TD (Koning et al., 2011); (iii) Brain-derived neurotrophic factor $(B D N F)$, albeit to date without reported association between Val66Met (rs6265) and TD (Wang et al., 2010;Kang et al., 2008a). Furthermore, Xu and colleagues (2008) showed that the $(\mathrm{GT})_{\mathrm{n}}$ repeat polymorphism of the $B D N F$ gene may be an independent contributor to chlorpromazine-induced TD, akathisia and parkinsonism; and (iv) Catechol-0-methyltransferase (COMT), with evidence from one meta-analysis for an association between Val158Met (rs4680) and TD, where the Val-variant had a risk increasing effect on TD (Bakker et al., 2008). A study reported that one of six SNPs (rs165599) in the COMT gene may be associated with TD in men, and a sex-stratified meta-analysis showed a significant association between Val158Met (rs4680) and TD, where the ValVal-genotype had a risk increasing 
effect on TD using the fixed-effect model unadjusted for sex, and in females using the random effect model (Zai et al., 2010b).

Serotonergic genes studied in TD include those coding for: (i) Serotonin 2A receptor (HTR2A), with evidence for an association of TD with T102C (rs6313) detected by Lerer and colleagues (2005), also after adjustment for age, by pooled meta-analysis, and with the T102C-His452Tyr haplotype, while other studies failed to find significant effects for rs6313 (Herken et al., 2003; Deshpande et al., 2005). For Hist452Tyr (rs6314), in HTR2A, no association with TD was detected (Lerer et al., 2005), nor for A-1438G (rs6311) (Herken et al., 2003;Deshpande et al., 2005). rs6311 was significantly associated with TD in a Turkish population, however only when cumulative antipsychotic intake was considered (Boke et al., 2007); (ii) Serotonin 2C receptor (HTR2C), with evidence for an association between $-697 \mathrm{G} / \mathrm{C}$ ( $\mathrm{rs518147)}$ and TD, but not for -759-T/C (rs3813929) or the haplotype of both (Zhang et al., 2002). For Cys23Ser (rs6318) an age-related effect with AIMS was found (Segman and Lerer, 2002). Another study did not detect differences in allele frequencies of 997A, $-759 \mathrm{~T}$ or $-697 \mathrm{C}$ between groups of TD, non-TD and controls, whereas the 23Ser allele was significantly higher in patients with movement disorders, with a similar trend using haplotypes of these 4 SNPs (Gunes et al., 2008). Furthermore, both $-697 \mathrm{G} / \mathrm{C}$ and $-759-\mathrm{T} / \mathrm{C}$ polymorphisms were associated with the emergence of TD (Rizos et al., 2009).

Findings in a recent study of TD with 128 candidate genes (amongst them dopamine, serotonin) did not support significant results for either novel or prior associations from the literature (Tsai et al., 2010a). Similarly, in a recent study, no association was found between serotonergic genes (amongst others HTR2A, HTR2C) and movement disorders (Al-Janabi et al., 2009).

Another study showed that limb truncal, but not orofaciolingual, TD was associated with Ser9Gly (DRD3) and Cys23Ser (HTR2C) in a Russian population, whereas neither subform of TD with associated with A-1438G (HTR2A) (Al Hadithy et al., 2009a).

A polymorphism in intron 1 of $C Y P 1 A 2(-163 C>A ; C Y P 1 A 2 * 1 \mathrm{~F}$ allele; rs762551) appears to affect the inducibility of CYP1A2 by smoking (MacLeod SL et al., 1998; Sachse et al., 1999). The CYP1A2*1C allele (-3860G>A; rs2069514) also results in a lower activity in smokers (Nakajima et al., 1999). A meta-analysis did not find an association between both SNPs in CYP1A2 and TD (Bakker et al., 2008). Furthermore, Tiwari and colleagues (2007) did not find significant results between TD and different SNPs in CYP1A2, nor did Boke and colleagues (2007) for rs762551 in a Turkish population.

Complementary to the 'dopamine supersensitivity hypothesis' on TD, the hypothesis of neuronal degeneration owing to toxic effects of free radicals has been proposed, and free radical scavenging enzymes like manganese super ox- 
ide dismutase (MnSOD) have been investigated (Tsai et al., 1998). A metaanalysis showed genetic association with TD in Ala-9Val in MnSOD (Bakker et al., 2008). However, a more recent study with subsequent meta-analysis did not find significant results between MnSOD Ala-9Val (rs4880) and TD (Zai et al., 2010 a) confirming the observation of progressive reduction of meta-analytic effects over time in genetic studies (Lencz and Malhotra, 2009; Xiao and Boehnke, 2009). A significant association between Ala-9Val and severity of TD, but not TD as dichotomous outcome, has been reported (Kang et al., 2008b). Another study by al Hadithy and colleagues (2010) found a significant association between Ala-9Val and orofaciolingual TD in a Russian population. A recent study reported no evidence for an association between Ala-9Val and TD in Han Chinese (Liu et al., 2010).

A relatively new and interesting candidate gene is $P P P 1 R 1 B$, which encodes phosphatase 1, regulatory (inhibitor) subunit 1B (PPP1R1B), also known as dopamine and cAMP regulated phosphoprotein of $32 \mathrm{kDa}$ (DARPP-32), an important regulatory molecule in both the dopaminergic (Yoshimi et al., 2008) and glutamatergic signaling pathways, which is selectively expressed in neostriatal spiny neurons (Hu et al., 2007). Deficit of DARPP-32 in striatonigral neurons decreased basal and cocaine-induced locomotion and stopped L-DOPA induced dyskinetic behaviors. On the other hand, the deficit of DARPP-32 in striatopallidal neurons produced a strong increase in locomotor activity and a strongly reduced cataleptic reaction to haloperidol (Bateup et al., 2010). To date, only one study examined TD and PPP1R1B, however without result (Tiwari et al., 2009).

More details on this topic can be found in the recent extensive review by Lee and Kang (Lee and Kang, 2011).

\section{Parkinsonism}

The pharmacological explanation of antipsychotic-induced parkinsonism (AIP) is antagonism of the nigrostriatal dopamine D2 receptor (Reynolds, 2004;Sachdev, 2005). One study in an African-Caribbean population found a significant association between the -141Ins/Del polymorphism in DRD2 and rigidity in males, as well as between the Cys23Ser polymorphism and bradykinesia (Al Hadithy et al., 2008).

The regulator of G-protein signaling 2 (RGS2) may play a role in AIP, as it is involved in HTR2A and muscarinic receptor (M1 and M3) signaling, and antagonism of these receptors results in a decrease of AIP (Al Hadithy et al., 2009b).

Greenbaum and colleagues (2007) reported a significant association between rs4606 in RGS2 and AIP in Jewish participants, which was confirmed by a replication study in an African-American subsample from a mixed population with whites (Greenbaum et al., 2009). Another study did not confirm this asso- 
ciation in an African-Caribbean population (Al Hadithy et al., 2009b), which may be explained by the lower use of atypical antipsychotics in the latter study, most of these agents being HTR2A antagonists and muscarinic receptor (M1 and M3) antagonists (Al Hadithy et al., 2009b). A recent study in a Japanese population found an association between rs4606 and parkinsonism, which disappeared when covariates were considered (Higa et al., 2010).

\section{Akathisia}

An association between the Ser9Gly polymorphism in DRD3 and the risk to develop akathisia has been reported (Eichhammer et al., 2000). A recent study found evidence for an association between Taq1D (rs1800498) and akathisia (Koning et al., 2011).

\section{Tardive dystonia}

Genes coding for CYP2D6, DRD2 and DRD3 did not show an association with tardive dystonia (Mihara et al., 2002).

\section{Gene-gene interactions}

Combined pharmacokinetic and pharmacogenetic aspects of antipsychotics may help finding subpopulations liable to develop TD (Ozdemir et al., 2006;Ozdemir et al., 2001; Faraone et al., 1999). Segman and colleagues (2000) suggested that the variance of orofacial tardive dyskinesia (OFD) explained by DRD3 and HTR2C may be as high as $20.9 \%$. Carriership of both risk-alleles explained $4.2 \%$ en $4.7 \%$, respectively. Carriers of the risk $D R D 3$-Gly allele and the risk-genotype A2-A2 of CYP17 displayed the highest rate of orofacial, distal and incapacitation scores on the AIMS (Segman et al., 2002). DRD3- and CYP1A2-genotypes together accounted for most of the variance of the severest form of TD, the explained variance being $>50 \%$ (Basile et al., 2002). In one study, in a Chinese Han population, Ser9Gly in $D R D 3$ was not associated with TD, however in combination with Ala-9Val in MnSOD it was (Zhang et al., 2003).

In an African-Caribbean population, evidence for association was reported between the AIMS and (i) Ser9Gly (DRD3) in females, (ii) Ser9Gly with Cys23Ser (HTR2C) or A-1438G (HTR2A) in males, (iii) Cys23Ser (HTR2C) with A-1438G (HTR2A) in males (Wilffert et al., 2009).

One study found evidence for association between a haplotype containing rs3732782, rs905568, and rs7620754 in the 5' region of DRD3 on the one hand, and both TD and AIMS on the other, as well as evidence for interaction between $B D N F$ (rs11030104) and DRD3 polymorphisms (rs2087017, rs167770, rs7633291 and rs9825563) and the AIMS, albeit not for BNDF genetic markers in isolation (Zai et al., 2009). 
One study showed a significant association between BDNF Val66Met and AIMS orofacial scores, and a trend of higher AIMS total and limb-trunk scores. However, AIMS scores and the combination of $D R D 3$ ser9gly with $B D N F$ val66met were not associated. Furthermore, TD was not associated with DRD3 or BDNF (Liou et al., 2004).

One study found a significant combined association between val66met in $B D N F$ and $-50 \mathrm{~T} / \mathrm{C}$ in GSK-3beta polymorphisms on the one hand and TD on the other, but not with any of the polymorphisms separately (Park et al., 2009).

\section{References}

Al Hadithy, A.F., Ivanova, S.A., Pechlivanoglou, P., Semke, A., Fedorenko, O., Kornetova, E., Ryadovaya, L., Brouwers, J.R., Wilffert, B., Bruggeman, R. and Loonen, A.J., 2009a. Tardive dyskinesia and DRD3, HTR2A and HTR2C gene polymorphisms in Russian psychiatric inpatients from Siberia. Prog Neuropsychopharmacol Biol Psychiatry. 33, 475-481.

Al Hadithy, A.F., Ivanova, S.A., Pechlivanoglou, P., Wilffert, B., Semke, A., Fedorenko, O., Kornetova, E., Ryadovaya, L., Brouwers, J.R. and Loonen, A.J., 2010. Missense polymorphisms in three oxidative-stress enzymes (GSTP1, SOD2, and GPX1) and dyskinesias in Russian psychiatric inpatients from Siberia. Hum Psychopharmacol. 25, 84-91.

Al Hadithy, A.F., Wilffert, B., Bruggeman, R., Stewart, R.E., Brouwers, J.R., Matroos, G.E., Hoek, H.W. and van Harten, P.N., 2009b. Lack of association between antipsychotic-induced Parkinsonism or its subsymptoms and rs4606 SNP of RGS2 gene in African-Caribbeans and the possible role of the medication: The Curacao extrapyramidal syndromes study X. Hum Psychopharmacol. 24, 123-128.

Al Hadithy, A.F., Wilffert, B., Stewart, R.E., Looman, N.M., Bruggeman, R., Brouwers, J.R., Matroos, G.E., van Os, J., Hoek, H.W. and van Harten, P.N., 2008. Pharmacogenetics of parkinsonism, rigidity, rest tremor, and bradykinesia in African-Caribbean inpatients: differences in association with dopamine and serotonin receptors. Am J Med Genet B Neuropsychiatr Genet. 147B, 890-897.

Al-Janabi, I., Arranz, M.J., Blakemore, A.I., Saiz, P.A., Susce, M.T., Glaser, P.E., Clark, D. and de Leon, J., 2009. Association study of serotonergic gene variants with antipsychotic-induced adverse reactions. Psychiatr Genet. 19, 305-311.

Bakker, P.R., van Harten, P.N. and van Os, J., 2006. Antipsychotic-induced tardive dyskinesia and the Ser9Gly polymorphism in the DRD3 gene: a meta analysis. Schizophr Res. 83, 185-192.

Bakker, P.R., van Harten, P.N. and van Os, J., 2008. Antipsychotic-induced tardive dyskinesia and polymorphic variations in COMT, DRD2, CYP1A2 and MnSOD genes: a meta-analysis of pharmacogenetic interactions. Mol Psychiatry. 13, 544-556.

Basile, V.S., Masellis, M., Potkin, S.G. and Kennedy, J.L., 2002. Pharmacogenomics in schizophrenia: the quest for individualized therapy. Hum Mol Genet. 11, 2517-30.

Bateup, H.S., Santini, E., Shen, W., Birnbaum, S., Valjent, E., Surmeier, D.J., Fisone, G., Nestler, E.J. and Greengard, P., 2010. Distinct subclasses of medium spiny neurons differentially regulate striatal motor behaviors. Proc Natl Acad Sci U S A. 107, 14845-14850.

Boke, O., Gunes, S., Kara, N., Aker, S., Sahin, A.R., Basar, Y. and Bagci, H., 2007. Association of serotonin $2 \mathrm{~A}$ receptor and lack of association of CYP1A2 gene polymorphism with tardive dyskinesia in a Turkish population. DNA Cell Biol. 26, 527-531.

Deshpande, S.N., Varma, P.G., Semwal, P., Rao, A.R., Bhatia, T., Nimgaonkar, V.L., Lerer, B. and Thelma, B.K., 2005. II. Serotonin receptor gene polymorphisms and their association with tardive dyskinesia among schizophrenia patients from North India. Psychiatr Genet. 15, 157-158. 
Eichhammer, P., Albus, M., Borrmann-Hassenbach, M., Schoeler, A., Putzhammer, A., Frick, U., Klein, H.E. and Rohrmeier, T., 2000. Association of dopamine D3-receptor gene variants with neuroleptic induced akathisia in schizophrenic patients: a generalization of Steen's study on DRD3 and tardive dyskinesia. Am J Med Genet. 96, 187-91.

Faraone, S.V., Tsuang, M.T. and Tsuang, B.W., 1999. Genetic of mental disorders The Guilford Press, New York.

Greenbaum, L., Smith, R.C., Rigbi, A., Strous, R., Teltsh, O., Kanyas, K., Korner, M., Lancet, D., BenAsher, E. and Lerer, B., 2009. Further evidence for association of the RGS2 gene with antipsychotic-induced parkinsonism: protective role of a functional polymorphism in the 3 'untranslated region. Pharmacogenomics J. 9, 103-110.

Greenbaum, L., Strous, R.D., Kanyas, K., Merbl, Y., Horowitz, A., Karni, O., Katz, E., Kotler, M., Olender, T., Deshpande, S.N., Lancet, D., Ben-Asher, E. and Lerer, B., 2007. Association of the RGS2 gene with extrapyramidal symptoms induced by treatment with antipsychotic medication. Pharmacogenet Genomics. 17, 519-528.

Gunes, A., Dahl, M.L., Spina, E. and Scordo, M.G., 2008. Further evidence for the association between 5-HT2C receptor gene polymorphisms and extrapyramidal side effects in male schizophrenic patients. Eur J Clin Pharmacol. 64, 477-482.

Herken, H., Erdal, M.E., Boke, O. and Savas, H.A., 2003. Tardive dyskinesia is not associated with the polymorphisms of 5-HT2A receptor gene, serotonin transporter gene and catechol-omethyltransferase gene. Eur Psychiatry. 18, 77-81.

Higa, M., Ohnuma, T., Maeshima, H., Hatano, T., Hanzawa, R., Shibata, N., Sakai, Y., Suzuki, T. and Arai, H., 2010. Association analysis between functional polymorphism of the rs4606 SNP in the RGS2 gene and antipsychotic-induced Parkinsonism in Japanese patients with schizophrenia: results from the Juntendo University Schizophrenia Projects (JUSP). Neurosci Lett. 469, 55-59.

Hu, J.X., Yu, L., Shi, Y.Y., Zhao, X.Z., Meng, J.W., He, G., Xu, Y.F., Feng, G.Y. and He, L., 2007. An association study between PPP1R1B gene and schizophrenia in the Chinese population. Prog Neuropsychopharmacol Biol Psychiatry. 31, 1303-1306.

Kang, S.G., Choi, J.E., An, H., Lim, S.W., Lee, H.J., Han, C., Kim, Y.K., Kim, S.H., Cho, S.N., Lee, M.S., Joe, S.H., Jung, I.K. and Kim, L., 2008a. No association between the brain-derived neurotrophic factor gene Val66Met polymorphism and tardive dyskinesia in schizophrenic patients. Prog Neuropsychopharmacol Biol Psychiatry. 32, 1545-1548.

Kang, S.G., Choi, J.E., An, H., Park, Y.M., Lee, H.J., Han, C., Kim, Y.K., Kim, S.H., Cho, S.N., Joe, S.H., Jung, I.K., Kim, L. and Lee, M.S., 2008b. Manganese superoxide dismutase gene Ala-9Val polymorphism might be related to the severity of abnormal involuntary movements in Korean schizophrenic patients. Prog Neuropsychopharmacol Biol Psychiatry. 32, 1844-1847.

Koning, J.P., Vehof, J., Burger, H., Wilffert, B., Al Hadithy, A., Alizadeh, B., van Harten, P.N. and Snieder, H., 2011. Association of two DRD2 gene polymorphisms with acute and tardive antipsychoticinduced movement disorders in young Caucasian patients. Psychopharmacology (Berl).

Lee, H.J. and Kang, S.G., 2011. Genetics of tardive dyskinesia. Int Rev Neurobiol. 98, 231-264.

Lencz, T. and Malhotra, A.K., 2009. Pharmacogenetics of antipsychotic-induced side effects. Dialogues Clin Neurosci. 11, 405-415.

Lerer, B., Segman, R.H., Fangerau, H., Daly, A.K., Basile, V.S., Cavallaro, R., Aschauer, H.N., McCreadie, R.G., Ohlraun, S., Ferrier, N., Masellis, M., Verga, M., Scharfetter, J., Rietschel, M., Lovlie, R., Levy, U.H., Meltzer, H.Y., Kennedy, J.L., Steen, V.M. and Macciardi, F., 2002. Pharmacogenetics of tardive dyskinesia: combined analysis of 780 patients supports association with dopamine D3 receptor gene Ser9Gly polymorphism. Neuropsychopharmacology. 27, 105-19.

Lerer, B., Segman, R.H., Tan, E.C., Basile, V.S., Cavallaro, R., Aschauer, H.N., Strous, R., Chong, S.A., Heresco-Levy, U., Verga, M., Scharfetter, J., Meltzer, H.Y., Kennedy, J.L. and Macciardi, F., 2005. Combined analysis of 635 patients confirms an age-related association of the serotonin 2A receptor gene with tardive dyskinesia and specificity for the non-orofacial subtype. Int J Neuropsychopharmacol. 8, 411-425. 
Liou, Y.J., Liao, D.L., Chen, J.Y., Wang, Y.C., Lin, C.C., Bai, Y.M., Yu, S.C., Lin, M.W. and Lai, I.C., 2004. Association analysis of the dopamine D3 receptor gene ser9gly and brain-derived neurotrophic factor gene val66met polymorphisms with antipsychotic-induced persistent tardive dyskinesia and clinical expression in Chinese schizophrenic patients. Neuromolecular Med. 5, 243-251.

Liu, H., Wang, C., Chen, P.H., Zhang, B.S., Zheng, Y.L., Zhang, C.X., Meng, H.Q., Wang, Y., Chen, d.C., Xiu, M.H., Kosten, T.R. and Zhang, X.Y., 2010. Association of the manganese superoxide dismutase gene Ala-9Val polymorphism with clinical phenotypes and tardive dyskinesia in schizophrenic patients. Prog Neuropsychopharmacol Biol Psychiatry. 34, 692-696.

MacLeod, S.L., Tang, Y-M., Yokoi, T., Kamataki, T., Doublin, S. and Lawson, B., 1998. The role of a recently discovered genetic polymorphism in the regulation of the human CYP1A2 gene. Proc Am Assoc Cancer Res. 39, 396.

Mihara, K., Kondo, T., Higuchi, H., Takahashi, H., Yoshida, K., Shimizu, T. and Kaneko, S., 2002. Tardive dystonia and genetic polymorphisms of cytochrome P4502D6 and dopamine D2 and D3 receptors: a preliminary finding. Am J Med Genet. 114, 693-695.

Nakajima, M., Yokoi, T., Mizutani, M., Kinoshita, M., Funayama, M. and Kamataki, T., 1999. Genetic polymorphism in the 5 '-flanking region of human CYP1A2 gene: effect on the CYP1A2 inducibility in humans. J Biochem (Tokyo). 125, 803-808.

Ozdemir, V., Aklillu, E., Mee, S., Bertilsson, L., Albers, L.J., Graham, J.E., Caligiuri, M., Lohr, J.B. and Reist, C., 2006. Pharmacogenetics for off-patent antipsychotics: reframing the risk for tardive dyskinesia and access to essential medicines. Expert Opin Pharmacother. 7, 119-133.

Ozdemir, V., Basile, V.S., Masellis, M. and Kennedy, J.L., 2001. Pharmacogenetic assessment of antipsychotic-induced movement disorders: contribution of the dopamine D3 receptor and cytochrome P450 1A2 genes. J Biochem Biophys Methods. 47, 151-157.

Park, S.W., Lee, J.G., Kong, B.G., Lee, S.J., Lee, C.H., Kim, J.I. and Kim, Y.H., 2009. Genetic association of BDNF val66met and GSK-3beta-50T/C polymorphisms with tardive dyskinesia. Psychiatry Clin Neurosci. 63, 433-439.

Park, Y.M., Kang, S.G., Choi, J.E., Kim, Y.K., Kim, S.H., Park, J.Y., Kim, L. and Lee, H.J., 2011. No Evidence for an Association between Dopamine D2 Receptor Polymorphisms and Tardive Dyskinesia in Korean Schizophrenia Patients. Psychiatry Investig. 8, 49-54.

Reynolds, G.P., 2004. Receptor mechanisms in the treatment of schizophrenia. J Psychopharmacol. $18,340-345$.

Rizos, E.N., Siafakas, N., Katsantoni, E., Lazou, V., Sakellaropoulos, K., Kastania, A., Kossida, S., Chatzigeorgiou, K.S., Arsenis, G., Zerva, L., Katsafouros, K. and Lykouras, L., 2009. Association of the dopamine D3 receptor Ser9Gly and of the serotonin 2C receptor gene polymorphisms with tardive dyskinesia in Greeks with chronic schizophrenic disorder. Psychiatr Genet. 19, 106-107.

Sachdev, P.S., 2005. Neuroleptic-induced movement disorders: an overview. Psychiatr Clin North Am. 28, 255-74, $\mathrm{x}$.

Sachse, C., Brockmoller, J., Bauer, S. and Roots, I., 1999. Functional significance of a C-->A polymorphism in intron 1 of the cytochrome P450 CYP1A2 gene tested with caffeine. Br J Clin Pharmacol. 47, 445-449.

Segman, R.H., Heresco-Levy, U., Finkel, B., Inbar, R., Neeman, T., Schlafman, M., Dorevitch, A., Yakir, A., Lerner, A., Goltser, T., Shelevoy, A. and Lerer, B., 2000. Association between the serotonin 2C receptor gene and tardive dyskinesia in chronic schizophrenia: additive contribution of 5HT2Cser and DRD3gly alleles to susceptibility. Psychopharmacology (Berl). 152, 408-413.

Segman, R.H., Heresco-Levy, U., Yakir, A., Goltser, T., Strous, R., Greenberg, D.A. and Lerer, B., 2002. Interactive effect of cytochrome P450 17alpha-hydroxylase and dopamine D3 receptor gene polymorphisms on abnormal involuntary movements in chronic schizophrenia. Biol Psychiatry. 51, 261-263.

Segman, R.H. and Lerer, B., 2002. Age and the relationship of dopamine D3, serotonin 2C and serotonin 2A receptor genes to abnormal involuntary movements in chronic schizophrenia. Mol Psychiatry. 7,137-139. 
Tiwari, A.K., Deshpande, S.N., Lerer, B., Nimgaonkar, V.L. and Thelma, B.K., 2007. Genetic susceptibility to Tardive Dyskinesia in chronic schizophrenia subjects: V. Association of CYP1A2 1545 C>T polymorphism. Pharmacogenomics J. 7, 305-311.

Tiwari, A.K., Souza, R.P., Zai, C.C., Mueller, D.J., Remington, G., Meltzer, H.Y., Lieberman, J.A., Potkin, S.G., Kennedy, J.L. Lack of association of the Dopamine and cAMP-regulated phosphoprotein (MW=32 kDa; DARPP-32; PPP1R1B) gene to Tardive Dyskinesia in chronic schizophrenia patients (SOBP, Vancouver, May 14-16, 2009).

Tsai, G., Goff, D.C., Chang, R.W., Flood, J., Baer, L. and Coyle, J.T., 1998. Markers of glutamatergic neurotransmission and oxidative stress associated with tardive dyskinesia. Am J Psychiatry. 155, 1207-1213.

Tsai, H.T., Caroff, S.N., Miller, D.D., McEvoy, J., Lieberman, J.A., North, K.E., Stroup, T.S. and Sullivan, P.F., 2010a. A candidate gene study of Tardive dyskinesia in the CATIE schizophrenia trial. Am J Med Genet B Neuropsychiatr Genet. 153B, 336-340.

Tsai, H.T., North, K.E., West, S.L. and Poole, C., 2010b. The DRD3 rs6280 polymorphism and prevalence of tardive dyskinesia: a meta-analysis. Am J Med Genet B Neuropsychiatr Genet. 153B, 57 66.

Wang, Y., Wang, J.D., Wu, H.R., Zhang, B.S., Fang, H., Ma, Q.M., Liu, H., Chen, d.C., Xiu, M.H., Hail, C.N., Kosten, T.R. and Zhang, X.Y., 2010. The Val66Met polymorphism of the brain-derived neurotrophic factor gene is not associated with risk for schizophrenia and tardive dyskinesia in Han Chinese population. Schizophr Res. 120, 240-242.

Wilffert, B., Al Hadithy, A.F., Sing, V.J., Matroos, G., Hoek, H.W., van Os, J., Bruggeman, R., Brouwers, J.R. and van Harten, P.N., 2009. The role of dopamine D3, 5-HT2A and 5-HT2C receptor variants as pharmacogenetic determinants in tardive dyskinesia in African-Caribbean patients under chronic antipsychotic treatment: Curacao extrapyramidal syndromes study IX. J Psychopharmacol. 23, 652-659.

Xiao, R. and Boehnke, M., 2009. Quantifying and correcting for the winner's curse in genetic association studies. Genet Epidemiol. 33, 453-462.

Xu, M.Q., St Clair, D., Feng, G.Y., Lin, Z.G., He, G., Li, X. and He, L., 2008. BDNF gene is a genetic risk factor for schizophrenia and is related to the chlorpromazine-induced extrapyramidal syndrome in the Chinese population. Pharmacogenet Genomics. 18, 449-457.

Yoshimi, A., Takahashi, N., Saito, S., Ito, Y., Aleksic, B., Usui, H., Kawamura, Y., Waki, Y., Yoshikawa, T., Kato, T., Iwata, N., Inada, T., Noda, Y. and Ozaki, N., 2008. Genetic analysis of the gene coding for DARPP-32 (PPP1R1B) in Japanese patients with schizophrenia or bipolar disorder. Schizophr Res. 100, 334-341.

Zai, C.C., De Luca, V., Hwang, R.W., Voineskos, A., Muller, D.J., Remington, G. and Kennedy, J.L., 2007. Meta-analysis of two dopamine D2 receptor gene polymorphisms with tardive dyskinesia in schizophrenia patients. Mol Psychiatry. 12, 794-795.

Zai, C.C., Tiwari, A.K., Basile, V., De Luca, V., Muller, D.J., Voineskos, A.N., Remington, G., Meltzer, H.Y., Lieberman, J.A., Potkin, S.G. and Kennedy, J.L., 2010a. Oxidative stress in tardive dyskinesia: genetic association study and meta-analysis of NADPH quinine oxidoreductase 1 (NQO1) and Superoxide dismutase 2 (SOD2, MnSOD) genes. Prog Neuropsychopharmacol Biol Psychiatry. 34, 50-56.

Zai, C.C., Tiwari, A.K., De Luca, V., Muller, D.J., Bulgin, N., Hwang, R., Zai, G.C., King, N., Voineskos, A.N., Meltzer, H.Y., Lieberman, J.A., Potkin, S.G., Remington, G. and Kennedy, J.L., 2009. Genetic study of BDNF, DRD3, and their interaction in tardive dyskinesia. Eur Neuropsychopharmacol. 19, 317-328.

Zai, C.C., Tiwari, A.K., Muller, D.J., De Luca, V., Shinkai, T., Shaikh, S., Ni, X., Sibony, D., Voineskos, A.N., Meltzer, H.Y., Lieberman, J.A., Potkin, S.G., Remington, G. and Kennedy, J.L., 2010b. The catechol0-methyl-transferase gene in tardive dyskinesia. World J Biol Psychiatry. 11, 803-812.

Zhang, Z.J., Zhang, X.B., Hou, G., Yao, H. and Reynolds, G.P., 2003. Interaction between polymorphisms of the dopamine D3 receptor and manganese superoxide dismutase genes in susceptibility to tardive dyskinesia. Psychiatr Genet. 13, 187-192. 
Zhang, Z.J., Zhang, X.B., Sha, W.W., Zhang, X.B. and Reynolds, G.P., 2002. Association of a polymorphism in the promoter region of the serotonin 5-HT2C receptor gene with tardive dyskinesia in patients with schizophrenia. Mol Psychiatry. 7, 670-671. 


\section{Chapter 7}

\section{Antipsychotic-induced movement disorders in long-stay psychiatric patients and 45 tag single nucleotide polymorphisms (SNPs) in 7 candidate genes: A prospective study}

P. Roberto Bakkera, Asmar F.Y. Al Hadithyb, Najaf Aminc, Cornelia M. van Duijnc, Jim van Os $^{\text {d,e }}$, Peter N. van Harten ${ }^{\mathrm{a}, \mathrm{d}}$

\footnotetext{
${ }^{\text {a }}$ Psychiatric Centre GGZ Centraal, Amersfoort, The Netherlands

${ }^{\mathrm{b}}$ Hospital Pharmacy, Erasmus MC, Rotterdam, The Netherlands

${ }^{\mathrm{c}}$ Department of Epidemiology, Erasmus MC, Rotterdam, The Netherlands

${ }^{\mathrm{d}}$ Department of Psychiatry and Psychology, South Limburg Mental Health Research and Teaching Network, EURON, Maastricht University Medical Centre, Maastricht, The Netherlands

${ }^{e}$ King's College London, King's Health Partners, Department of Psychosis Studies, Institute of Psychiatry, London, United Kingdom
}

In preparation 


\begin{abstract}

\section{Objective}

Four types of antipsychotic-induced movement disorders: tardive dyskinesia (TD), parkinsonism, akathisia and tardive dystonia, subtypes of TD (orofacial and limb truncal dyskinesia), subtypes of parkinsonism (rest tremor, rigidity, and bradykinesia), as well as a principal-factor of the movement disorders and their subtypes, were examined for association with variation in 7 candidate genes (GRIN1B, GRIN1A, HSPG2, DRD3, HTR2C, DRD4, and NQO1).
\end{abstract}

\title{
Method
}

Naturalistic study of 168 white long-stay patients with chronic mental illness requiring long-term antipsychotic treatment, examined by the same rater at least two times over a 4-year period, with a mean follow-up time of 1.1 years, with validated scales for TD, parkinsonism, akathisia, and tardive dystonia. The authors genotyped 45 tag SNPs in 7 candidate genes, associated with movement disorders or schizophrenia in previous studies. Genotype and allele frequency comparisons were performed with multiple regression methods for continuous movement disorders.

\section{Results}

Various SNPs reached nominal significance: TD with rs1345423, rs7192557, rs1650420, as well as rs11644461; orofacial dyskinesia with rs7192557, rs1650420, as well as rs4911871; limb truncal dyskinesia with rs1345423, rs7192557, rs1650420, as well as rs11866328; bradykinesia with rs2192970; and akathisia with rs324035. After controlling for multiple testing, no significant results remained.

\section{Conclusions}

The findings suggest that selected SNPs are not associated with a susceptibility to movement disorders. However, as the sample size was small and previous studies show inconsistent results, definite conclusions cannot be made. Replication is needed in larger study samples, preferably in longitudinal studies which take the fluctuating course of movement disorders and gene-environment interactions into account. 


\section{Introduction}

Soon after the introduction of antipsychotic medication in 1952, movement disorders emerged as a complication of treatment. To date, they remain a major concern in antipsychotic treatment. Of the different movement disorders, tardive dyskinesia (TD) is the most extensively investigated. TD and other movement disorders are associated with social stigmatization, physical disabilities and poorer quality of life. In addition, they play a role in non-compliance and, therefore, risk of psychotic relapse (Casey, 2006;Lambert et al., 2004; Robinson et al., 2002).

A central problem in the management of movement disorders is the lack of clear genetic and non-genetic risk factors that would allow for early identification and prevention. It would be helpful if movement disorders could be predicted from a minimal number of genetic susceptibility loci in candidate genes in combination with demographic, clinical or pharmacological data. In order to identify individuals at risk, pharmacogenetic studies of genetic factors that contribute to interpersonal differences in susceptibility for medication-related adverse effects are needed (Lerer, 2002). Family studies suggest an important genetic component to the risk for movement disorders (Halliday et al., 2002;McCreadie et al., 2003;Muller et al., 2001;Fenton, 2000;Lerer, 2002;Lencer et al., 2004). A recent meta-analysis on the prevalence of dyskinesia and parkinsonism reported spontaneous dyskinesia and parkinsonism in antipsychotic naïve patients with schizophrenia, and a higher prevalence of dyskinesia and parkinsonism in healthy family members of patients with schizophrenia, compared to matched controls (Koning et al., 2010b).

Antipsychotic-induced movement disorders (Owens, 1999;Factor et al., 2005) can be classified as acute or tardive. Acute syndromes appear within days or weeks after starting antipsychotics or increasing the dosage. Examples of these are parkinsonism and akathisia. Tardive syndromes develop after months or years of treatment with antipsychotics, examples being TD and tardive dystonia. Initially, the term 'tardive' (delayed) was introduced to emphasize the late-onset types of movement disorders occurring during antipsychotic use. Yet the definition of tardive disorders in the current study emphasizes their persistence, which is clinically more important than their late-onset (Sachdev, 2005;Factor et al., 2005). Given the fact that in patients on long-term treatment, combinations of acute and tardive movement disorders can concur, prediction models should include all four antipsychotic-induced movement disorders. Furthermore, as subtypes of movement disorder may better reflect the underlying biological heterogeneity, separate examination of each subtype is also warranted.

The phenotypes under study were TD, parkinsonism, akathisia, and tardive dystonia, subtypes of TD (orofacial and limb truncal dyskinesia), subtypes of 
parkinsonism (rest tremor, rigidity, and bradykinesia), as well as a principalfactor of the movement disorders and their subtypes.

The 7 candidate genes were GRIN1B, GRIN1A, HSPG2, DRD3, HTR2C, DRD4, and NQO1 on the other (Text S1). The choice of these genes was hypothesis-driven, under the common disease/common variant (CDCV) hypothesis, which proposes that common diseases may be caused by common genetic variants (Wellcome Trust Case Control Consortium, 2007;Hemminki et al., 2008; Reich and Lander, 2001; Wang et al., 2005).

The aim of the current study was to determine the association between movement disorders and variations in these 7 candidate genes.

The prospective design of the current study extends hitherto cross-sectional work in the pharmacogenetic field of antipsychotic-induced movement disorders. Indeed, prospective assessment of fluctuating (repeated) movement disorders measures the phenotype more specifically and that increases the validity of the associations between movement disorders and risk factors.

\section{Method}

\section{Ethics statement}

The protocol was approved by the standing Institutional Review Board, 'Medisch-ethische Toetsingscommissie Instellingen Geestelijke Gezondheidszorg' (Review Board for Human Research in Psychiatry), the Netherlands [protocol number 377].

Written informed consent was obtained from each patient, hence, consent obtained from the next of kin was not necessary and not recommended by the Review Board for Human Research in Psychiatry.

\section{Subjects}

A 4-year prospective naturalistic study (July 2003 - May 2007) was conducted with 209 patients with chronic mental illness in order to determine the genetic risk factors of the four major types of movement disorders (TD, parkinsonism, akathisia, and tardive dystonia), subtypes of TD and parkinsonism, as well as a principal-factor of the movement disorders and their subtypes. To this end, a cohort was drawn from a general psychiatric hospital (GGZ Centraal, Amersfoort, the Netherlands). Full details of the study design and movement disorders have been published previously (Bakker et al., 2011) (Bakker and colleagues, two submitted). The cohort was representative of the population of patients with the most severe chronic mental illness requiring long-stay care, given that the hospital serves an epidemiological catchment area, is the only institute pro- 
viding this type of care in this area, and patients were selected from a comprehensive list of all inpatients.

Of the patients assessed at baseline $(\mathrm{N}=207) 93.7 \%(\mathrm{n}=194)$ had at least one follow-up and 59.4\% (n=123) had two follow-up assessments. Loss to follow-up was due to patients who were difficult to trace after leaving hospital, died or refused assessment after inclusion.

\section{Assessment}

Patients were examined by a trained psychiatrist (PRB), using a standard protocol, described by van Harten and colleagues (1996). In addition, subtypes of movement disorders were assessed using (i) the Abnormal Involuntary Movement Scale (AIMS) (Guy, 1975;Guy, 1976) with items 1-4 for orofacial and items 5-7 for limb truncal dyskinesia, (ii) the Unified Parkinson Disease Rating Scale (UPDRS) (Fahn and Elton, 1987) with item c3-c4 for 'rest tremor' (rest tremor, and action/postural tremor of hands); item c5 for rigidity; and items c1, c2, c6c12, and c14 for bradykinesia. This approach has been described previously by 3 members of our research team $(\mathrm{AAH}, \mathrm{JvO}$ and $\mathrm{PvH}$ ) (Al Hadithy et al., 2009; Wilffert et al., 2009;Al Hadithy et al., 2008).

As movement disorders likely share genetic liability, a genetic association between the combined movement disorders and candidate genes is also required. To determine the association between the combined movement disorder and variation in 7 candidate genes, a principal-factor of the four major types of movement disorders and subtypes of TD and parkinsonism was calculated with the FACTOR procedure in the STATA statistical program (StataCorp. 2009.).

Based on the literature published between 1976 and October 2011, we selected 7 candidate genes (Table 1 and Text S1) that (i) are involved in the dopaminergic and serotonergic systems or (ii) included the gene coding for heparan sulfate proteoglycan 2 or genes involved in the protection of neurotoxicity, all which have been implicated in the development of movement disorders. 


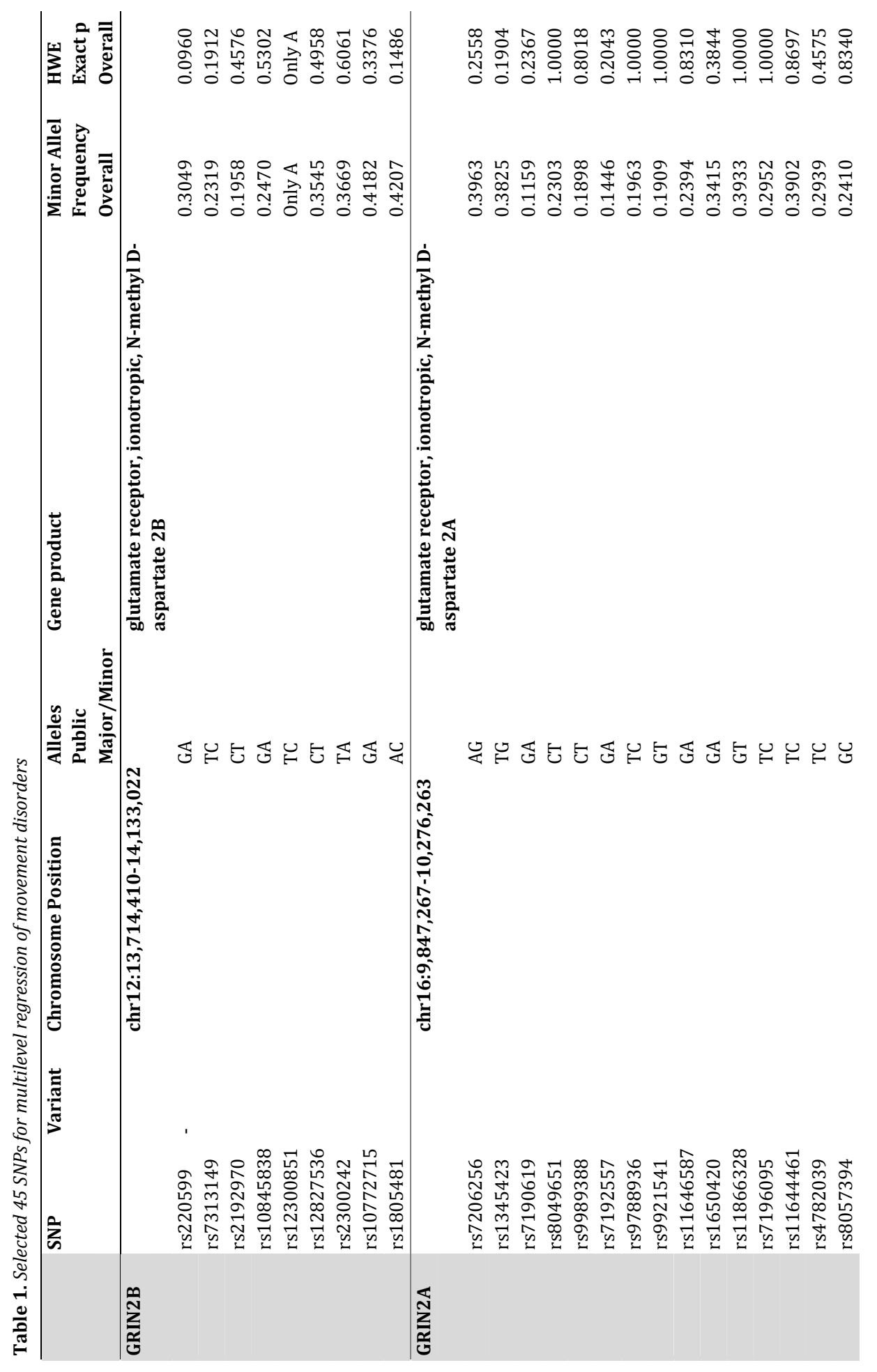




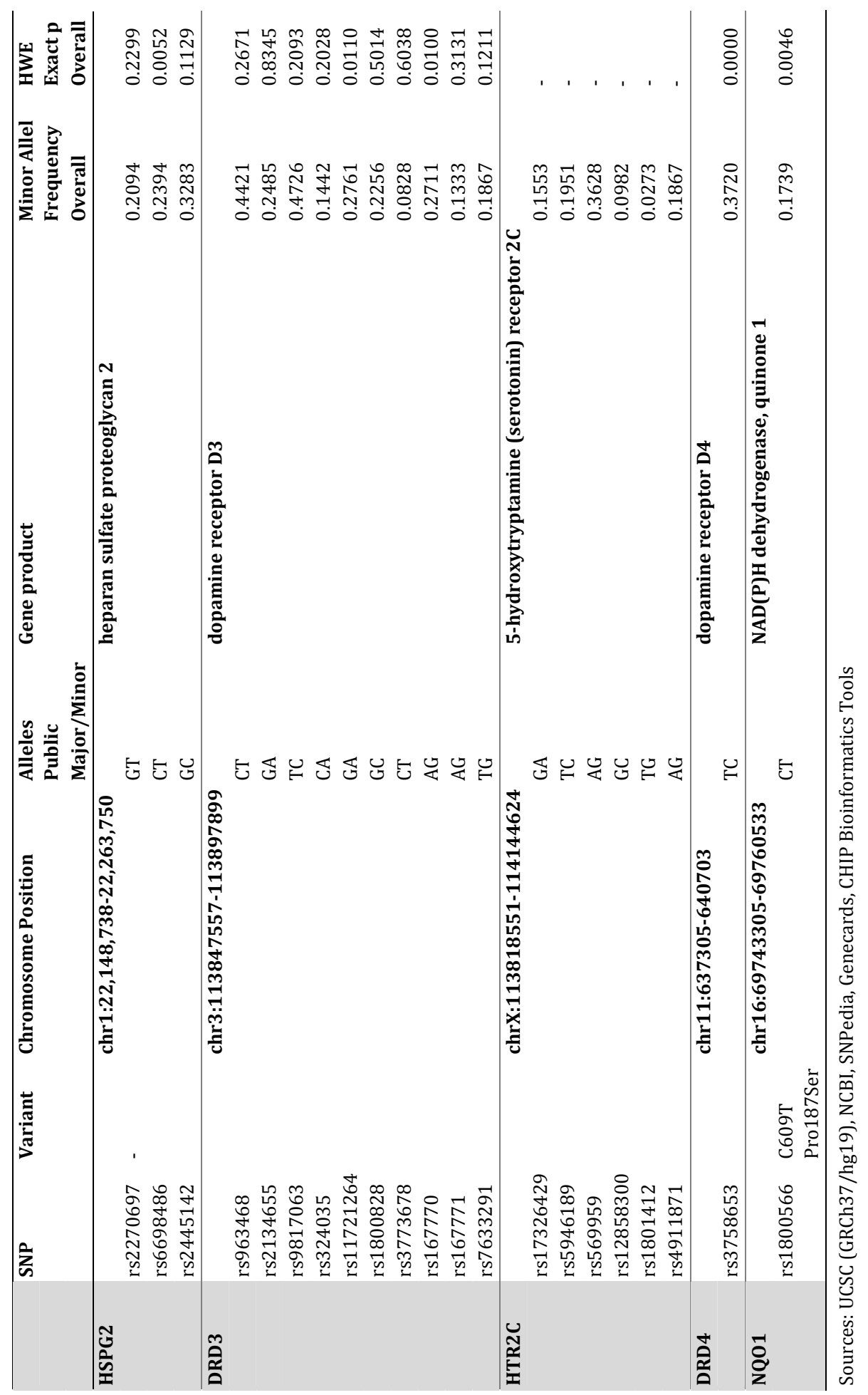


In addition, variables possibly affecting risk were extracted from patients' case notes including age, sex, BMI, self-reported handedness, diagnosis according to DSM-IV, ethnic group (classified as white and non-white), duration of hospitalization and history of electroconvulsive therapy (ECT). Negative symptoms were rated using the negative symptom subscale of the Positive and Negative Symptom Severity (PANSS) scale (Kay et al., 1987). The MINI sections for alcohol and drug use were administered, and information on tobacco intake (yes/no, number of cigarettes, cigars, etc; descriptors such as 'light', 'mild', 'heavy' and 'normal' use of tobacco) was collected. At baseline and at each follow-up assessment, current use of antipsychotic and anticholinergic medication was collected, and the global symptom rating of the Clinical Global Impression - Schizophrenia severity of illness (CGI-SCH SI) scale was completed. All clinical assessments were carried out by a psychiatrist (PRB). Information on current use of the above medication was collected from the hospital and outpatient pharmacy databases.

The diagnosis 'schizophrenia' hereafter refers to DSM-IV codes 295.30, $295.10,295.20,295.90,295.60,295.70$, and other diagnoses of 'psychotic disorder' to $295.40,297.1,298.8,298.9$.

\section{Gene and tSNP selection, DNA extraction, Genotyping}

Two $10 \mathrm{ml}$ EDTA tubes of peripheral blood were drawn from participants, and genomic DNA was extracted from leucocytes by Autopure LS method (Qiangen) according to the manufacturer's protocols.

The tag SNPs were selected using a web-based tool freely available on the internet (SNPinfo Web Server; http://www.niehs.nih.gov/snpinfo) (Nagaraj et al., 2009). The following criteria have been applied for the selection of the tag SNPs (tSNPs): localization in the gene including $1000 \mathrm{bp}$ upstream and downstream (5'- and 3' flanking regions), LD threshold=0.8, Minor Allele Frequency $(\mathrm{MAF}) \geq 0.1$, Maximal distance between SNPs for calculation of LD $=250000 \mathrm{bp}$, Genotype data = "European" [dbSNP].

Additionally, we have forced 2 SNPs in the tagging, one in the HTR2C (Cys23Ser, rs6318) and one in the DRD3 (Ser9Gly, rs6280) genes, since the available literature suggests that these SNPs may be clinically important. Furthermore, we have genotyped a SNP in SOD2 oxidative stress enzyme (Ala9Val, rs4880).

In the case of GRIN2A and GRIN2B our search query resulted in too many tSNPs. We have therefore limited our selection to only those tSNPs that capture at least 10 other SNPs.

After the selection process, we have genotyped 48 SNPs in the 7 candidate gene regions by the use of Veracode (GoldenGate) Assay (Illumina, San Diego, California, USA). Two of the selected SNPs in HTR2C (rs6318 and rs3813929) and rs4880 in SOD2 have already been analyzed (TaqMan® SNP Genotyping 
Assays method, Applied Biosystems, Foster City, California, USA) in a previous study (Bakker and colleagues, submitted) and were therefore excluded from the analyses. However, the genotypes obtained by the TaqMan ${ }^{\circledR}$ method were compared to those obtained by Illumina's Veracode method; genotype data were in agreement and the quality of genotyping was assumed to be good.

\section{Statistical Analyses}

\section{Hardy Weinberg Equilibrium}

Only SNPs were included in the analyses that were not significantly outside Hardy-Weinberg Equilibrium (HWE) $(p>0.05)$ in (i) the complete control sample (for a dichotomous trait) or (ii) the complete study sample (for a continuous trait). For the six SNPs in the X-chromosomal HTR2C gene, departure from HWE was not calculated.

Departure from the HWE was calculated with the GENASS and GENHW procedures in the STATA statistical program (StataCorp. 2009) for (i) the dichotomously defined persistent forms of movement disorders separately in both patients (with one movement disorder) and controls (without that movement disorder), respectively. Case definition of a persistent movement disorder was based on 2 consecutive assessments over a period of minimally 3 months, and required that individuals met case definition criteria at two consecutive assessments (hereafter: persistent movement disorder), meeting the requirements of Schooler and Kane's criteria for persistent movement disorder (Schooler and Kane, 1982), and (ii) the combined group of patients and controls, as continuous measures cannot be separated in both patients and controls.

\section{Association Tests for Single SNPS}

Only continuous movement disorder outcomes were used, given that continuous measures better handle the variability of movement disorders and generate more statistical power than cut off points (Steyerberg, 2009;Ziegler and König, 2006). Genotype and allele frequency comparisons were performed with multiple regression methods for continuous movement disorders, using the Armitage trend test, with the major allele (from our dataset of 168 selected white patients) as reference. The Armitage trend test assumes an additive effect by both alleles on the trait of interest, i.e. the mean effect on the trait by the heterozygous genotype (Major-Minor) is halfway the effects of the two homozygotes. (Major-Major and Minor-Minor).

\section{Regression analyses}

The regression analyses were conducted with movement disorder measures at a single assessment (hereafter: fluctuating movement disorder). The reason for 
this was that movement disorders constantly fluctuate over time, so that inclusion in the regression of their repeated single-occasion measures allowed for calculation of associations between one movement disorder with the other over time. As the study design comprised repeated measures nested in the same patient, clustering of observations in individuals needed to be corrected for. Therefore, multilevel random regression was used with the measurement occasion (baseline and two follow-ups) at level 1, and subjects at level 2, with the XTREG MLE routine of the STATA statistical program (StataCorp. 2009). Associations with explanatory variables were expressed as beta coefficients representing the change of continuous movement disorder outcome with 1 unit change of the exposure variable.

Using the dataset of 168 selected white patients, associations with predictors were adjusted for a priori, movement-disorder specific covariates as follows (Bakker and colleagues, submitted) age was adjusted for in the model of TD and TD subtypes; age and total antipsychotic use was adjusted for in the model of parkinsonism and its subtypes, and no covariates were introduced in the models of akathisia, tardive dystonia and the principal-factor.

\section{Correction for multiple testing}

In order to correct for multiple testing of single SNP tests, the Simes modification of the Bonferroni multiple-testing procedure was performed to control the False Discovery Rate (FDR) (Benjamini et al., 2004). Bonferroni correction is too conservative if tests are not independent of each other; in this case FDR represents a less conservative alternative. We used the MULTPROC procedure in the STATA statistical program (StataCorp. 2009) for FDR calculation, and then the SMILEPLOT procedure calling MULTPROC to build a smile plot. A smile plot summarizes a set of multiple analyses, similarly as a Cochrane forest plot summarizes a meta-analysis, and separates by reference line rejected and nonrejected p-values (on a reverse log scale against the corresponding parameter estimates).

\section{Defined daily dose}

Antipsychotic doses were converted to defined daily dose (DDD), for which we refer to our previous publications (Bakker et al., 2011) (Bakker and colleagues, submitted). Anticholinergic medication was modeled as a dichotomous variable (yes/no). 


\section{Results}

\section{Sample Characteristics}

Over the period of observation (mean=1.1 years, SD=0.64), of the 209 patients included at baseline, 207 participated in the study. One patient developed a brain tumor, another patient died after inclusion. All patients had a history of cumulative antipsychotic intake of minimally 1 year. Attrition rate was low at 9.8\% over a 4-year period.

Of the 207 patients, with chronic psychiatric illness requiring long-term admission, 199 participated in the genetic study. To prevent ethnic stratification resulting in spurious associations owing to differences in allele frequencies and risk of movement disorders, only white patients, representing the most prevalent group (168=84.4\%), were included in the analysis. At baseline, mean age expressed in years was 48.8 (SD 12.4); men 48.6 (SD 12.5) and women 49.1 (SD 12.2). Age at first admission, expressed in years, was 25.1 (SD 8.8); men 23.7 (SD 7.8) and women 27.1 (SD 9.7), respectively. The total duration of admission, expressed in years, was 23.4 (SD 12.9), men 24.4 (SD 12.5) and women 22.0 (SD 13.4). Diagnoses according to DSM-IV Axis I as defined above were: schizophrenia 112 (66.7\%), psychosis 9 (5.4\%), affective disorder 27 (16.1\%), other Axis I diagnosis 11 (6.6\%) and no Axis I diagnosis 9 (5.4\%).

\section{Association Analyses with SNPs}

The following SNPs were excluded from analysis, due to deviation from HWE: all movement disorders - rs6698486, rs11721264, rs167770, rs3758653 and rs1800566 (Table 1), as well as controls; TD - rs10845838, rs7206256 and rs7633291; orofacial dyskinesia - rs10845838 and rs2445142; limb truncal dyskinesia - rs7633291; parkinsonism, rest tremor and bradykinesia rs2445142. In addition, rs12300851 was removed as it contained only A alleles.

The (multilevel) regression yielded significant coefficients, after adjustment for age, between TD and rs1345423 ( $B=-0.13, p=0.0421), \operatorname{rs7192557}(B=0.22$, $\mathrm{p}=0.0159), \mathrm{rs} 1650420(\mathrm{~B}=0.16, \mathrm{p}=0.0193)$, as well as $\mathrm{rs11644461}(\mathrm{B}=-0.13$, $\mathrm{p}=0.0385)$; between orofacial dyskinesia and $\operatorname{rs7192557}(\mathrm{B}=0.22, \mathrm{p}=0.0291)$, rs1650420 $(\mathrm{B}=0.16, \mathrm{p}=0.0336)$, as well as $\mathrm{rs} 4911871 \quad(\mathrm{~B}=-0.18, \mathrm{p}=0.0131)$; between limb truncal dyskinesia and rs1345423 ( $\mathrm{B}=-0.18, \mathrm{p}=0.0190)$, rs7192557 $(\mathrm{B}=0.22, \mathrm{p}=0.0430), \operatorname{rs} 1650420(\mathrm{~B}=0.16, \mathrm{p}=0.0471)$, as well as rs11866328 $(B=0.16, p=0.0330)$. After adjustment for age and total DDD equivalents, associations were apparent between bradykinesia and rs2192970 (B=0.16, $\mathrm{p}=0.0349$ ). Without adjustment, associations were apparent between akathisia and rs324035 ( $\mathrm{B}=-0.20, \mathrm{p}=0.0392)$, as well as the principal-factor and rs10772715 ( $B=-0.20, p=0.0362)$. After Simes correction for multiple testing of 
the above mentioned analyses, the number of rejected p-values was zero, with a corrected overall critical p-value of 0.00013 (Figure 1).

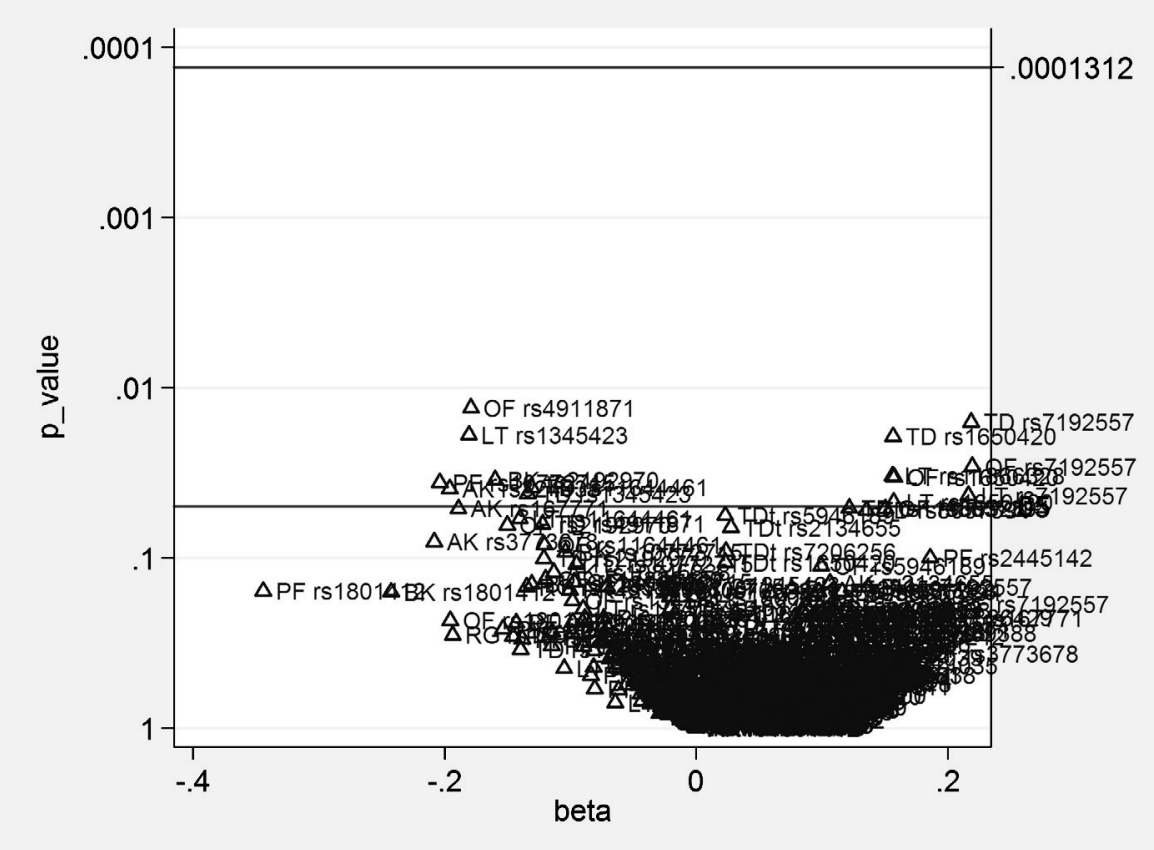

Figure 1. Smile plot summarizing set of multiple analyses after Simes correction for multiple testing of single nucleotide polymorphisms (SNPS) without HWE deviation. Corresponding p-values (on a reverse log scale against the corresponding parameter estimates). TD=tardive dyskinesia, OF=orofacial dyskinesia, LT=limb truncal dyskinesia, PK=parkinsonism, RT=rest tremor, RG=rigidity, BK=bradykinesia, AK=akathisia, $T D t=$ tardive dystonia and $P F=$ principal-factor.

\section{Discussion}

In a population with chronic mental illness, various SNPs in 7 candidate genes (GRIN1B, GRIN1A, HSPG2, DRD3, HTR2C, DRD4, and NQO1) reached nominally significant $(\mathrm{p} \leq 0.05)$ associations with drug-induced movement disorders. However, after controlling for multiple testing, our findings suggest that these single nucleotide polymorphism (SNP) are not associated with a susceptibility to movement disorders.

Another reason for the inconclusive findings could be explained by the fact that in a naturalistic setting it is possible to evaluate the overall impact of pharmacogenetic signals in the presence of a host of real-life variables that can override pharmacogenetic variation. The fact we did not observe a significant association may also attest to the possibility that each gene makes a small contribution that is often diluted or overridden by environmental and clinical variations. 


\section{Limitations}

This study had limitations, for which we refer to our previous publications (Bakker et al., 2011) (Bakker and colleagues, two submitted). In addition, some authors may argue that the SNPs with HWE deviation should not be excluded from the analyses, as SNPs in HWE could in reality be also out of HWE owing to lack of power. Therefore, we performed a post-hoc analysis with all SNPs, i.e. also those deviating from HWE, which resulted in one extra nominal significant result, which also did not survive Simes correction for multiple testing (Figure 2).

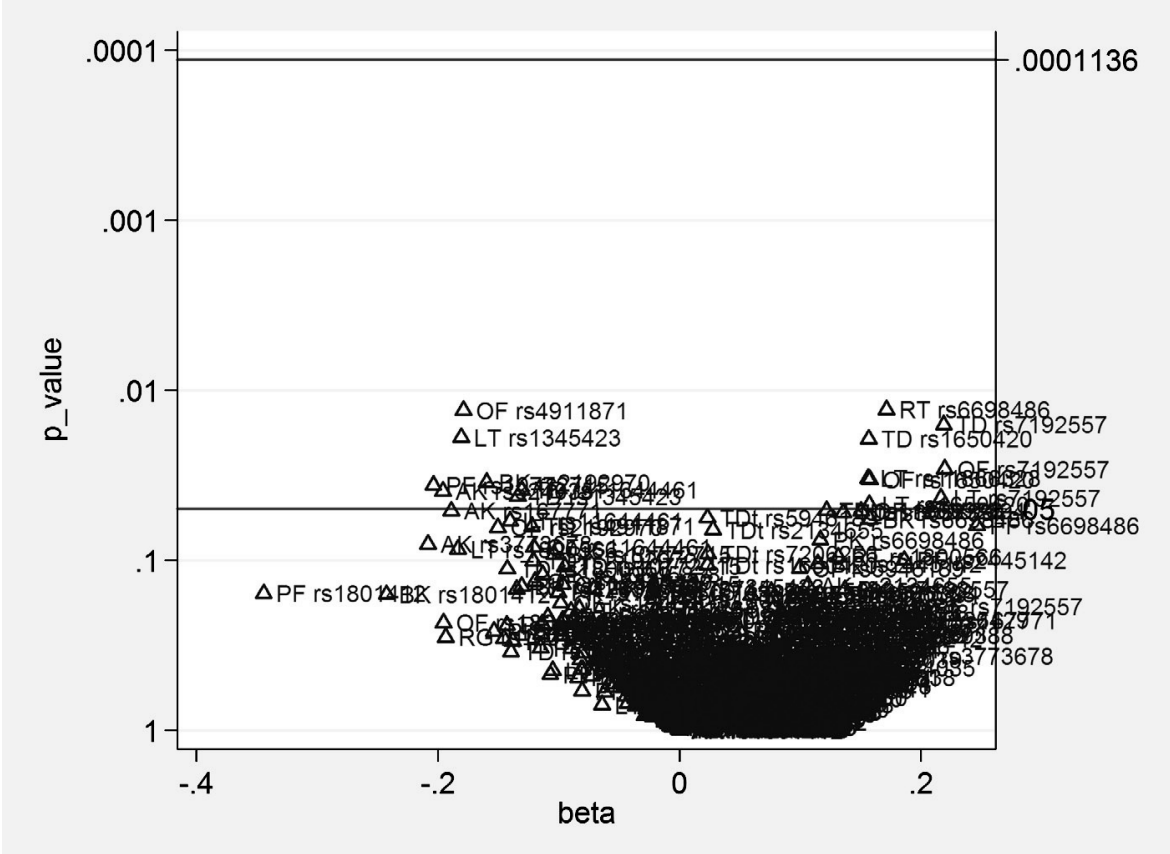

Figure 2. Smile plot summarizing set of multiple analyses after Simes correction for multiple testing of all single nucleotide polymorphisms (SNPS). Corresponding p-values (on a reverse log scale against the corresponding parameter estimates). TD=tardive dyskinesia, OF=orofacial dyskinesia, LT=limb truncal dyskinesia, $P K=$ parkinsonism, $R T=$ rest tremor, $R G=$ rigidity, BK=bradykinesia, AK=akathisia, TDt=tardive dystonia and $P F=$ principal-factor.

\section{Strengths}

We refer to our previous publications (Bakker et al., 2011) (Bakker and colleagues, two submitted). The importance of repeated measures should be noted, as case definition of repeated measures, rather than a single cross-sectional measure, for continuous movement disorders better reflects the continuously fluctuating nature in time of movement disorders, and therefore may represent 
a more suitable standard in future research. To the best of our knowledge only few paper in the literature address this issue.

As the sample size of the current study is small and previous studies show inconsistent results, definite conclusions cannot be made. Yet the question is how to interpret these results. In our opinion, the findings of weak genetic signals need to be replicated in larger study samples, preferably in longitudinal studies which take the fluctuating course of movement disorders and gene-environment interactions into account (Howes and Kapur, 2009; van Os et al., 2010). Even though the current study is inconclusive, negative studies also ought to be reported as otherwise meta-analytic results in the future can be biased by positive studies that tend to be published more readily. We further refer to our previous publication (Bakker and colleagues, submitted).

In conclusion, the findings suggest that selected SNPs are not associated with a susceptibility to movement disorders. However, replication is needed in larger study samples, preferably in longitudinal studies which take the fluctuating course of movement disorders and gene-environment interactions into account. The use of intermediate phenotypes, for example, laboratory based phenotypes (Braff et al., 2007), or more accurate measures of movement disorders, for example instrument measurement of lingual force variability as proposed by Koning and colleagues (2010a), which may represent a powerful alternative since instrument measurement detects subclinical movement disorders and is highly reliable. Moreover, (pharmaco) genetic studies may help elucidate common pathways in the development of movement disorders. Future research on movement disorders may be served by the inclusion of all four movement disorder, as performed in the current study, since they may represent pleiotropic effects from (partly) shared genetic factors (Koning et al., 2011).

\section{Acknowledgements}

The authors are very grateful for Prof. dr. Anton Loonen (University of Groningen, Groningen, the Netherlands) for generously facilitating the genotyping analyses. The authors are also grateful for the staff of the Genome Analysis Facility of the Genetics Department of the University Medical Center Groningen (UMCG, Groningen, the Netherlands) for their kind technical assistance.

The authors are also grateful for M. Hoornweg-van Beek (MSc), G.V. Boedijn (MSc), M. van Drie (MSc), R. Emons (MSc), A.E. Willems (MSc), I.W. de Groot (MSc), L. Broer (MSc), Saltro laboratory, hospital and outpatient pharmacies, hospital staff for providing their assistance, and to all patients for participating in this study. 


\section{References}

Al Hadithy, A.F., Wilffert, B., Bruggeman, R., Stewart, R.E., Brouwers, J.R., Matroos, G.E., Hoek, H.W. and van Harten, P.N., 2009. Lack of association between antipsychotic-induced Parkinsonism or its subsymptoms and rs4606 SNP of RGS2 gene in African-Caribbeans and the possible role of the medication: the Curacao extrapyramidal syndromes study X. Hum Psychopharmacol. 24, 123-128.

Al Hadithy, A.F., Wilffert, B., Stewart, R.E., Looman, N.M., Bruggeman, R., Brouwers, J.R., Matroos, G.E., van Os, J., Hoek, H.W. and van Harten, P.N., 2008. Pharmacogenetics of parkinsonism, rigidity, rest tremor, and bradykinesia in African-Caribbean inpatients: differences in association with dopamine and serotonin receptors. Am J Med Genet B Neuropsychiatr Genet. 147B, 890-897.

Bakker, P.R., de Groot, I.W., van Os, J. and van Harten, P.N., 2011. Long-stay psychiatric patients: a prospective study revealing persistent antipsychotic-induced movement disorder. PLoS ONE. 6, e25588.

Benjamini, Y., Bretz, F. and Sarkar, S.K., 2004. Recent developments in multiple comparison procedures Institute of Mathematical Statistics, Beachwood, Ohio.

Braff, D.L., Freedman, R., Schork, N.J. and Gottesman, I.I., 2007. Deconstructing schizophrenia: an overview of the use of endophenotypes in order to understand a complex disorder. Schizophr Bull. 33, 21-32.

Casey, D.E., 2006. Implications of the CATIE trial on treatment: extrapyramidal symptoms. CNS Spectr. 11, 25-31.

Factor, S.A., Lang, A.E., and Weiner, W.J., 2005. Drug induced movement disorders, 2nd ed edn. Blackwell Futura, Malden, Mass.

Fahn, S. and Elton, R., 1987. UPDRS Development Committee. Unified Parkinson's Disease Rating Scale. In: Fahn S, Marsden CD, Calne DB, Goldstein M, eds. Recent Developments in Parkinson's Disease. Florham Park, NJ: Macmillan, pp. 153-163.

Fenton, W.S., 2000. Prevalence of spontaneous dyskinesia in schizophrenia. J Clin Psychiatry. 61 Suppl 4, 10-4.

Guy, W., 1975. ECDEU assessment manual for psychopharmacology. Department of Health, Education and Welfare, Washington DC, pp. 534-537.

Guy, W., 1976. ECDEU assessment manual for psychopharmacology U.S. Dept. of Health, Education, and Welfare, Public Health Service, Alcohol, Drug Abuse, and Mental Health Administration, National Institute of Mental Health, Psychopharmacology Research Branch, Division of Extramural Research Programs, Rockville, Md, p. 603.

Halliday, J., Farrington, S., Macdonald, S., MacEwan, T., Sharkey, V. and McCreadie, R., 2002. Nithsdale Schizophrenia Surveys 23: movement disorders. 20-year review. Br J Psychiatry. 181, 422-7.

Hemminki, K., Forsti, A. and Bermejo, J.L., 2008. The 'common disease-common variant' hypothesis and familial risks. PLoS ONE. 3, e2504.

Howes, O.D. and Kapur, S., 2009. The dopamine hypothesis of schizophrenia: version III--the final common pathway. Schizophr Bull. 35, 549-562.

Kay, S.R., Fiszbein, A. and Opler, L.A., 1987. The positive and negative syndrome scale (PANSS) for schizophrenia. Schizophr Bull. 13, 261-276.

Koning, J.P., Tenback, D.E., Kahn, R.S., Van Schelven, L.J. and van Harten, P.N., 2010a. Instrument measurement of lingual force variability reflects tardive tongue dyskinesia. J Med Eng Technol. 34, 71-77.

Koning, J.P., Tenback, D.E., van Os, J., Aleman, A., Kahn, R.S. and van Harten, P.N., 2010b. Dyskinesia and parkinsonism in antipsychotic-naive patients with schizophrenia, first-degree relatives and healthy controls: a meta-analysis. Schizophr Bull. 36, 723-731.

Koning, J.P., Vehof, J., Burger, H., Wilffert, B., Al Hadithy, A., Alizadeh, B., van Harten, P.N. and Snieder, H., 2011. Association of two DRD2 gene polymorphisms with acute and tardive antipsychoticinduced movement disorders in young Caucasian patients. Psychopharmacology (Berl). 
Lambert, M., Conus, P., Eide, P., Mass, R., Karow, A., Moritz, S., Golks, D. and Naber, D., 2004. Impact of present and past antipsychotic side effects on attitude toward typical antipsychotic treatment and adherence. Eur Psychiatry. 19, 415-422.

Lencer, R., Eismann, G., Kasten, M., Kabakci, K., Geithe, V., Grimm, J. and Klein, C., 2004. Family history of primary movement disorders as a predictor for neuroleptic-induced extrapyramidal symptoms. Br J Psychiatry. 185, 465-471.

Lerer, B., 2002. Pharmacogenetics of psychotropic drugs Cambridge University Press, Cambridge, UK.

McCreadie, R.G., Thara, R., Srinivasan, T.N. and Padmavathi, R., 2003. Spontaneous dyskinesia in first-degree relatives of chronically ill, never-treated people with schizophrenia. Br J Psychiatry. 183, 45-49.

Muller, D.J., Schulze, T.G., Knapp, M., Held, T., Krauss, H., Weber, T., Ahle, G., Maroldt, A., Alfter, D., Maier, W., Nothen, M.M. and Rietschel, M., 2001. Familial occurrence of tardive dyskinesia. Acta Psychiatr Scand. 104, 375-379.

Nagaraj, A.K., Pai, N.B. and Rao, S., 2009. A comparative study of sexual dysfunction involving risperidone, quetiapine, and olanzapine. Indian J Psychiatry. 51, 265-271.

Owens, D.G.C., 1999. A guide to the extrapyramidal side-effects of antipsychotic drugs Cambridge University Press UK, New York, p. 351.

Reich, D.E. and Lander, E.S., 2001. On the allelic spectrum of human disease. Trends Genet. 17, 502510.

Robinson, D.G., Woerner, M.G., Alvir, J.M., Bilder, R.M., Hinrichsen, G.A. and Lieberman, J.A., 2002. Predictors of medication discontinuation by patients with first-episode schizophrenia and schizoaffective disorder. Schizophr Res. 57, 209-219.

Sachdev, P.S., 2005. Neuroleptic-induced movement disorders: an overview. Psychiatr Clin North Am. 28, 255-74, $\mathrm{x}$.

Schooler, N.R. and Kane, J.M., 1982. Research diagnoses for tardive dyskinesia. Arch Gen Psychiatry. 39, 486-7.

StataCorp. 2009. Stata: Release 11. Statistical Software. College Station, TX: StataCorp LP.

Steyerberg, E.W., 2009. Clinical prediction models, a practical approach to development, validation, and updating Springer, New York.

van Harten, P.N., Matroos, G.E., Hoek, H.W. and Kahn, R.S., 1996. The prevalence of tardive dystonia, tardive dyskinesia, parkinsonism and akathisia The Curacao Extrapyramidal Syndromes Study: I. Schizophr Res. 19, 195-203.

van Os, J., Kenis, G. and Rutten, B.P., 2010. The environment and schizophrenia. Nature. 468, 203212.

Wang, W.Y., Barratt, B.J., Clayton, D.G. and Todd, J.A., 2005. Genome-wide association studies: theoretical and practical concerns. Nat Rev Genet. 6, 109-118.

Wellcome Trust Case Control Consortium, 2007. Genome-wide association study of 14,000 cases of seven common diseases and 3,000 shared controls. Nature. 447, 661-678.

Wilffert, B., Al Hadithy, A.F., Sing, V.J., Matroos, G., Hoek, H.W., van Os, J., Bruggeman, R., Brouwers, J.R. and van Harten, P.N., 2009. The role of dopamine D3, 5-HT2A and 5-HT2C receptor variants as pharmacogenetic determinants in tardive dyskinesia in African-Caribbean patients under chronic antipsychotic treatment: Curacao extrapyramidal syndromes study IX. J Psychopharmacol. 23, 652-659.

Ziegler, A. and König, I.R., 2006. A statistical approach to genetic epidemiology, concepts and applications Wiley-VCH, Weinheim. 


\section{Supporting Text S1 (Chapter 7)}

\section{Genes}

A systematic literature review was conducted of the literature published between 1976 and Oktober 2011, with the help of Medline, EMBASE and PsychINFO using key words (genetic) polymorphism(s), tardive dyskinesia, extrapyramidal (syndrome/disorder), drug-induced, antipsychotic(s), adverse effect/event, schizophrenia. In addition, all relevant references cited in these articles were also retrieved.

\section{Tardive dyskinesia}

The dopaminergic and serotonergic systems of neurotransmission have been implicated in the development of movement disorders.

Genes involved in dopaminergic signaling, possibly associated with the development of TD, include those coding for: (i) Dopamine 3 receptor (DRD3), for which we refer to our previous publication (Bakker and colleagues, submitted), and (ii) Dopamine 4 receptor (DRD4), as clozapine's atypical action may be attributed to its 10 times stronger dopamine 4 receptor affinity than dopamine 2 or 3 (Wong and Van Tol, 2003;Seeman et al., 1997;Seeman et al., 1998;Van Tol et al., 1992; Van Tol et al., 1991), with evidence for an association between 4 tag SNPs haplotype (rs3758653, rs916457, rs762502 and rs11246226) and TD in Caucasian men, but not the separate SNPs or the exon 3 variable number tandem-repeat (exon 3 VNTR) in the combined sample of men and women (Zai et al., 2009). A former study in an North Indian population (Srivastava et al., 2006) showed an significant association between the $120 \mathrm{bp}$ duplication allele in DRD4 and TD, but not the exon 3 VNTR or $-521 \mathrm{C} / \mathrm{T}$ (rs1800955). A study in Korean patients (Lee et al., 2007) did not find evidence for an association between -521 C/T (rs1800955) polymorphism and TD. Another study showed association between the 'short' variant of the exon 3 VNTR in DRD4 and TD at trend significance (Lattuada et al., 2004). Segman and colleagues (2003) did not show an association between the $120 \mathrm{bp}$ duplication allele nor the exon 3 VNTR and TD.

The serotonin 2C receptor (HTR2C) gene has been studied in TD, for which we refer to our previous publication (Bakker and colleagues, submitted).

\section{Oxidative stress-mediated neurotoxic damage}

The neuronal degeneration hypothesis, in the context of neuronal death or neurotoxicity, has been proposed as an alternative to the 'dopamine supersensitiv- 
ity hypothesis' in the development of TD (Andreassen and Jorgensen, 2000;Tsai et al., 1998). One argument for the neuronal degeneration hypothesis is that the supersensitivity hypothesis may not fit the clinical course of TD because: (i) although hypersensitivity seems to be a universal response to D2-receptor antagonists, not all patients develop TD, (ii) TD tends to display an irreversible course, whereas dopamine supersensitivity diminishes gradually upon cessation of antipsychotics, and (iii) the risk for TD is markedly elevated with age, but the dopamine supersensitivity response may be dampened with increasing age (Ozdemir et al., 2006).

Genes involved in the protection of neurotoxicity, possibly associated with the development of TD, include those coding for: (i) NAD(P)H:quinone oxidoreductase (NQO1) (Hori et al., 2003), implicated against neurotoxic stress, albeit with no evidence in a recent study with subsequent meta-analysis for an association between Pro187Ser (rs1800566, C609T) and TD (Zai et al., 2010), (ii) glutamate receptor, ionotropic, N-methyl D-aspartate 2B (GRIN2B), albeit without evidence for an association between the association between three polymorphisms (T-200G, C366G and C2664T) in GRIN2B and TD (Liou et al., 2007), iii) glutamate receptor, ionotropic, N-methyl D-aspartate 2A (GRIN2A), without evidence for an association between 15 polymorphisms (same as in the current study) in GRIN2A (Loonen et al., 2011).

More details on this topic can be found in the recent extensive review by Lee and Kang (Lee and Kang, 2011).

\section{HSPG2 (heparan sulfate proteoglycan 2) gene}

Two studies showed a significant association between rs2445142 in HSPG2 and TD (Greenbaum et al., 2011;Syu et al., 2010), a SNP originally found in a genome-wide study performed by the latter group (Inada et al., 2008).

\section{Parkinsonism}

The pharmacological explanation of antipsychotic-induced parkinsonism (AIP) is antagonism of the nigrostriatal dopamine D2 receptor (Reynolds, 2004;Sachdev, 2005).

Dopamine 4 receptor (DRD4) as explanation for lower AIP in atypical action is mentioned by Seeman and colleagues (Seeman et al., 1997;Seeman et al., 1998).

\section{Akathisia}

An association between the Ser9Gly polymorphism in DRD3 and the risk to develop akathisia has been reported (Eichhammer et al., 2000). 


\section{Tardive dystonia}

To the best of our knowledge, studies between genes coding for GRIN1B, GRIN1A, HSPG2, DRD3, HTR2C, DRD4, and NQO1 and tardive dystonia have not been performed yet.

\section{Gene-gene interactions}

We refer to our previous publication (Bakker and colleagues, submitted).

\section{References}

Andreassen, O.A. and Jorgensen, H.A., 2000. Neurotoxicity associated with neuroleptic-induced oral dyskinesias in rats. Implications for tardive dyskinesia? Prog Neurobiol. 61, 525-541.

Eichhammer, P., Albus, M., Borrmann-Hassenbach, M., Schoeler, A., Putzhammer, A., Frick, U., Klein, H.E. and Rohrmeier, T., 2000. Association of dopamine D3-receptor gene variants with neuroleptic induced akathisia in schizophrenic patients: a generalization of Steen's study on DRD3 and tardive dyskinesia. Am J Med Genet. 96, 187-91.

Greenbaum, L., Alkelai, A., Zozulinsky, P., Kohn, Y. and Lerer, B., 2011. Support for association of HSPG2 with tardive dyskinesia in Caucasian populations. Pharmacogenomics J.

Hori, H., Ohmori, O., Matsumoto, C., Shinkai, T. and Nakamura, J., 2003. NAD(P)H: quinone oxidoreductase (NQ01) gene polymorphism and schizophrenia. Psychiatry Res. 118, 235-239.

Inada, T., Koga, M., Ishiguro, H., Horiuchi, Y., Syu, A., Yoshio, T., Takahashi, N., Ozaki, N. and Arinami, T., 2008. Pathway-based association analysis of genome-wide screening data suggest that genes associated with the gamma-aminobutyric acid receptor signaling pathway are involved in neuroleptic-induced, treatment-resistant tardive dyskinesia. Pharmacogenet Genomics. 18, 317323.

Lattuada, E., Cavallaro, R., Serretti, A., Lorenzi, C. and Smeraldi, E., 2004. Tardive dyskinesia and DRD2, DRD3, DRD4, 5-HT2A variants in schizophrenia: an association study with repeated assessment. Int J Neuropsychopharmacol. 7, 489-493.

Lee, H.J. and Kang, S.G., 2011. Genetics of tardive dyskinesia. Int Rev Neurobiol. 98, 231-264.

Lee, H.J., Kang, S.G., Choi, J.E., Paik, J.W., Kim, Y.K., Kim, S.H., Lee, M.S., Joe, S.H., Jung, I.K. and Kim, L., 2007. No association between dopamine D4 receptor gene $-521 \mathrm{C} / \mathrm{T}$ polymorphism and tardive dyskinesia in schizophrenia. Neuropsychobiology. 55, 47-51.

Liou, Y.J., Wang, Y.C., Chen, J.Y., Bai, Y.M., Lin, C.C., Liao, D.L., Chen, T.T., Chen, M.L., Mo, G.H. and Lai, I.C., 2007. Association analysis of polymorphisms in the N-methyl-D-aspartate (NMDA) receptor subunit 2B (GRIN2B) gene and tardive dyskinesia in schizophrenia. Psychiatry Res. 153, 271275.

Loonen, A.J.M., Ivanova, S.A., Pechlivanoglou, P., Rudikov, E., Zhukova, I., Al Hadithy, A.F.Y., Alifirova, V., Brouwers, J.R.B.J., Semke, A. and Wilffert, B., 2011. NMDA receptor co-determines vulnerability to develop dyskinesia in Huntington's Disease and levodopa-induced dyskinesia but not tardive dyskinesia. European Neuropsychopharmacology. Conference: 11th ECNP Regional Meeting St. Petersburg Russian Federation.

Ozdemir, V., Aklillu, E., Mee, S., Bertilsson, L., Albers, L.J., Graham, J.E., Caligiuri, M., Lohr, J.B. and Reist, C., 2006. Pharmacogenetics for off-patent antipsychotics: reframing the risk for tardive dyskinesia and access to essential medicines. Expert Opin Pharmacother. 7, 119-133.

Reynolds, G.P., 2004. Receptor mechanisms in the treatment of schizophrenia. J Psychopharmacol. $18,340-345$.

Sachdev, P.S., 2005. Neuroleptic-induced movement disorders: an overview. Psychiatr Clin North Am. 28, 255-74, x. 
Seeman, P., Corbett, R. and Van Tol, H.H., 1997. Atypical neuroleptics have low affinity for dopamine D2 receptors or are selective for D4 receptors. Neuropsychopharmacology. 16, 93-110.

Seeman, P., Corbett, R. and Van Tol, H.H., 1998. Dopamine D4 receptors may alleviate antipsychoticinduced parkinsonism. Adv Pharmacol. 42, 478-482.

Segman, R.H., Goltser, T., Heresco-Levy, U., Finkel, B., Shalem, R., Schlafman, M., Yakir, A., Greenberg, D., Strous, R., Lerner, A., Shelevoy, A. and Lerer, B., 2003. Association of dopaminergic and serotonergic genes with tardive dyskinesia in patients with chronic schizophrenia. Pharmacogenomics J. 3, 277-283.

Srivastava, V., Varma, P.G., Prasad, S., Semwal, P., Nimgaonkar, V.L., Lerer, B., Deshpande, S.N. and Thelma, B.K., 2006. Genetic susceptibility to tardive dyskinesia among schizophrenia subjects: IV. Role of dopaminergic pathway gene polymorphisms. Pharmacogenet Genomics. 16, 111-117.

Syu, A., Ishiguro, H., Inada, T., Horiuchi, Y., Tanaka, S., Ishikawa, M., Arai, M., Itokawa, M., Niizato, K., Iritani, S., Ozaki, N., Takahashi, M., Kakita, A., Takahashi, H., Nawa, H., Keino-Masu, K., ArikawaHirasawa, E. and Arinami, T., 2010. Association of the HSPG2 gene with neuroleptic-induced tardive dyskinesia. Neuropsychopharmacology. 35, 1155-1164.

Tsai, G., Goff, D.C., Chang, R.W., Flood, J., Baer, L. and Coyle, J.T., 1998. Markers of glutamatergic neurotransmission and oxidative stress associated with tardive dyskinesia. Am J Psychiatry. 155, 1207-1213.

Van Tol, H.H., Bunzow, J.R., Guan, H.C., Sunahara, R.K., Seeman, P., Niznik, H.B. and Civelli, O., 1991. Cloning of the gene for a human dopamine D4 receptor with high affinity for the antipsychotic clozapine. Nature. 350, 610-614.

Van Tol, H.H., Wu, C.M., Guan, H.C., Ohara, K., Bunzow, J.R., Civelli, O., Kennedy, J., Seeman, P., Niznik, H.B. and Jovanovic, V., 1992. Multiple dopamine D4 receptor variants in the human population. Nature. 358, 149-152.

Wong, A.H. and Van Tol, H.H., 2003. The dopamine D4 receptors and mechanisms of antipsychotic atypicality. Prog Neuropsychopharmacol Biol Psychiatry. 27, 1091-1099.

Zai, C.C., Tiwari, A.K., Basile, V., De Luca, V., Muller, D.J., King, N., Voineskos, A.N., Remington, G., Meltzer, H.Y., Lieberman, J.A., Potkin, S.G. and Kennedy, J.L., 2009. Association study of tardive dyskinesia and five DRD4 polymorphisms in schizophrenia patients. Pharmacogenomics J. 9, 168-174.

Zai, C.C., Tiwari, A.K., Basile, V., De Luca, V., Muller, D.J., Voineskos, A.N., Remington, G., Meltzer, H.Y., Lieberman, J.A., Potkin, S.G. and Kennedy, J.L., 2010. Oxidative stress in tardive dyskinesia: genetic association study and meta-analysis of NADPH quinine oxidoreductase 1 (NQO1) and Superoxide dismutase 2 (SOD2, MnSOD) genes. Prog Neuropsychopharmacol Biol Psychiatry. 34, $50-56$. 


$$
(0
$$




\section{Chapter 8}

\section{Discussion/conclusion}




\section{Part 1 - Meta-analyses}

The meta-analyses indicate that TD may be associated with functional variations in DRD3 (Chapter 2), COMT, DRD2, and MnSOD alleles (Chapter 3). These analyses suggest multiple genetic influences on TD, indicative of pharmacogenetic interactions. Although the associations are not strong, the effects underlying them may be subject to interactions with other loci that, when identified, may have acceptable predictive power.

\section{Part 2 - Prospective naturalistic study}

\section{Part 2a - Non-genetic risk factors}

The findings were that (i) having persistent drug-induced movement disorders seems to be the norm for long-stay patients with chronic mental illness and long-term antipsychotic treatment (Chapter 4); (ii) these patients have a high risk of incident movement disorder, in particular TD and parkinsonism; (iii) higher age is an important predictor of TD and parkinsonism; and (iv) total antipsychotic defined daily dose (DDD) is an important predictor of parkinsonism (Chapter 5).

The high period frequency (68\%) of at least a one drug-induced movement disorder was striking, especially given our use of strict case definition criteria that had to be positive on at least two consecutive assessments. These findings are clinically relevant not only because in the frequency of both acute and tardive movement disorders, but also because persistence in movement disorders seems pervasive. This implies that most patients on long-term antipsychotic treatment have a persistent movement disorder, which makes this a side effect which needs urgent consideration.

Since previous studies, which used a cross-sectional approach and did not focus on the vulnerable subgroup of long-stay hospitalized patients, do not match with the current study (see Chapters 4 and 5 for details), it is not easy to put the current results into context.

Previous studies concur with the prevalence of movement disorders found in the current study with regard to TD, but in those studies the prevalence tends to be lower for parkinsonism and higher for akathisia and tardive dystonia.

In addition to age and total antipsychotic DDD, the current study did not find other risk factors reported in previous studies. Although the sample selection and prospective nature of the current study may explain the lack of consistency with some older studies, particularly given that careful meta-analysis 
indicates that studies of risk factors for movement disorders such as TD show very little consistency (Tenback et al., 2009), other possible explanations for these differences are (i) carryover effects (delayed response effects) after many years of antipsychotic usage in the population studied, and/or (ii) the relatively small sample size of the current study.

\section{Part $2 b$ - Genetic risk factors}

Various SNPs in 17 candidate genes (PPP1R1B, BDNF, DRD3, DRD2, HTR2A, HTR2C, COMT, MnSOD, CYP1A2, and RGS2) (Chapter 6) and (GRIN1B, GRIN1A, HSPG2, DRD3, HTR2C, DRD4, and NQO1) (Chapter 7) reached nominal significance in association with drug-induced movement disorders. However, after controlling for multiple testing, our findings suggest that these SNPs are not associated with a susceptibility to movement disorders.

As the sample size of the current study is small and previous studies show inconsistent results, definite conclusions cannot be made. Yet the question is how to interpret these results. In our opinion, they may reflect weak genetic signals which need to be replicated in larger study samples, preferably in longitudinal studies which take the fluctuating course of movement disorders and geneenvironment interactions into account (Howes and Kapur, 2009; van Os et al., 2010).

\section{Prevention of movement disorders}

\section{Quality-of-care}

We were surprised by the paucity of notes in the patient files about movement disorder side effects, an observation made by others as well (Factor et al., 2009;Esper and Factor, 2008;Friedman et al., 2004;Lerner et al., 2007). The relative lack of focus on movement disorder syndromes is reflected in the very low rate of DSM-IV Axis I diagnoses of movement disorders found in routine clinical practice. Several factors may account for this discrepancy between clinical reality and clinical attention. First, it is not common practice to conduct a systematic examination for drug-induced movement disorders, which omission limits their recognition. Second, clinicians may wrongly assume that druginduced movement disorders are almost not treatable. In fact, the interventions to prevent or treat akathisia and parkinsonism are evidence-based and are quite easy to implement in clinical practice. Although suggested strategies for preventing/treating TD (Soares-Weiser and Fernandez, 2007) or tardive dystonia (Owens, 1999) are not evidence-based, they resemble the strategies used to prevent acute movement disorders. In addition, novel treatment options are being developed, such as botulinum toxin, tetrabenazine, branched-chain amino 
acids, and, in very severe cases, deep brain stimulation (Leung and Breden, 2011;Kefalopoulou et al., 2009;Slotema et al., 2008;van Harten and Hovestadt, 2006; Richardson et al., 2003). Third, the introduction of SGAs led to the expectation that drug-induced movement disorders would disappear, but in fact they only reduce the risk. Furthermore, antipsychotics are increasingly used for other indications since SGAs have strong mood stabilizing properties, which will increase the absolute numbers of drug-induced movement disorders. Fourth, most patients with schizophrenia do not complain of their movement disorder (Macpherson and Collis, 1992;Arango et al., 1999;Emsley et al., 2010). Patients' unawareness of movement disorders and consequent lack of complaints represent a risk factor for diagnostic delay (Arango et al., 1999). In addition, their unawareness notwithstanding, a movement disorder has a stigmatizing effect on patients and a negative effect on quality of life. Therefore active assessment and treatment of movement disorders, like the current concern about metabolic syndrome, is of paramount importance. Owens (1999) stated that movement disorder now can be seen as a quality-of-care issue. In addition, shared care decision making and informed consent by patients should be part of antipsychotic treatment (Laugharne et al., 2004). Systematic diagnosis may help physicians to become more aware of movement disorders.

\section{Challenges}

\section{Poorly understood pathophysiology}

The core problem in the prevention and treatment of movement disorders may be their poorly understood pathophysiology. The classic model in which movement disorders originate from antipsychotics is challenged by a large body of literature and two meta-analyses (Pappa and Dazzan, 2009;Koning et al., 2010b) demonstrating higher prevalence rates of movement disorders in patients with a diagnosis of schizophrenia. These results provide a strong argument for the hypothesis that movement disorders may not result exclusively from antipsychotic treatment but also reflect a fundamental aspect of neurodevelopmental pathophysiology involving the sensitization of dopaminergic nigrostriatal circuits (Chakos et al., 1996;Modestin et al., 2008;van Harten and Tenback, 2009; Mittal and Walker, 2010). Therefore, van Harten and Tenback (2009) have proposed that movement disorders, like dyskinesia and parkinsonism, be considered as a candidate A criterion for schizophrenia.

\section{Spectrum condition}

It is noteworthy that movement disorders may fulfill the criteria for classifying a trait as a spectrum condition of a disorder, in this case schizophrenia: heritability, familial link, cosegregation, and biological and clinical plausibility (Faraone et al., 1999). Spectrum conditions refer to mild psychopathology of little clinical 
significance among relatives without the full disorder. The advantage for research of spectrum conditions in contrast to a full disorder is that they may have fewer risk factors and therefore less complex chain of mechanisms (pathways) leading to their onset, which could make research easier to perform. (Pharmaco) genetic studies may help elucidate these common pathways in the development of both spectrum conditions and the full disorder.

\section{Future research}

\section{Follow-up studies}

Prospective studies in populations of drug-naïve patients with a first episode of psychosis before and after antipsychotic treatment could be crucial for distinguishing between primary (part of schizophrenia) and secondary (druginduced) movement disorders. Even so, primary symptoms may develop over the course of schizophrenia, making differentiation between primary and secondary symptoms almost impossible.

\section{Genetic studies}

As mentioned before, the findings of weak genetic signals need to be replicated in larger study samples, preferably in longitudinal studies which take the fluctuating course of movement disorders and gene-environment interactions into account (Howes and Kapur, 2009; van Os et al., 2010). However, despite growing evidence from genetic association studies, genetics only explains a minor part of schizophrenia, a fact which supports the importance of other interacting factors, such as environmental factors, which play important roles in schizophrenia (Howes and Kapur, 2009). Neuropsychiatric disorders may reflect the complex interplay of not only genetic factors, but first and foremost of epigenetic, stochastic, and non-genetic factors (Braff et al., 2007).

An important development in human (pharmaco) genetics since 2005 is the possibility of genome-wide association studies (GWASs) (Psychiatric GWAS Consortium, 2009) which have the advantage of a 'hypothesis free' and hence unbiased approach for examining new DNA variants which influence genetic susceptibility to many common diseases and can thus elucidate as yet unknown pathophysiological mechanisms.

The Psychiatric GWAS Consortium (PGC) has suggested that in the near future larger GWAS samples will detect more variants of common susceptibility with smaller effect sizes and that meta-analyses of GWAS should find more conclusive evidence for genetic associations. Meanwhile, new potentially promising genetic techniques such as whole-genome sequencing and epigenetics are being implemented. Also, gene-environment-wide interaction studies (GEWIS) approaches are being suggested (Khoury and Wacholder, 2009). It seems legiti- 
mate to conclude that these new techniques offer more effective genetic linkage and association studies.

\section{New perspective}

All in all, it seems legitimate to conclude that future research projects into antipsychotic-induced movement disorders may take advantage of a new perspective on common pathways of movement disorders. For example:

\section{Directed acyclic graphs}

Pathways can be visualized by analytical graphs such as directed acyclic graphs (DAGs, also known as "causal diagrams" or "causal pathways") which conceptualize the relationships between all of the important variables (e.g., schizophrenia, movement disorder, antipsychotics, genes, etc.) as a precise theoretical model. DAGs depict explicitly, in an easy and flexible way, confounding effects ("backdoor paths") and collider effects (two causal pathways). The latter is important as adjusting for colliders creates confounding (Szklo and Nieto, 2007)(p161) (Rothman et al., 2008) (p183).

For example, Figure 1 shows a (hypothetical) DAG of the relationships between different (genetic) risk factors and outcomes, i.e., schizophrenia, movement disorder, and diabetes mellitus. This graph demonstrates that both paths [Genes II $\rightarrow$ Diabetes $\rightarrow$ Movement Disorder] and [Antipsychotic(s) $\rightarrow$ Diabetes $\rightarrow$ Movement Disorder] collide ('converge'). Therefore adjusting for diabetes leads to confounding. Also, antipsychotics can be a confounder between movement disorders and diabetes. This example shows that DAGs may easily uncover potential problems. However, DAGs have limitations since they cannot deal with effect modification and many variables (Szklo and Nieto, 2007)(p163).

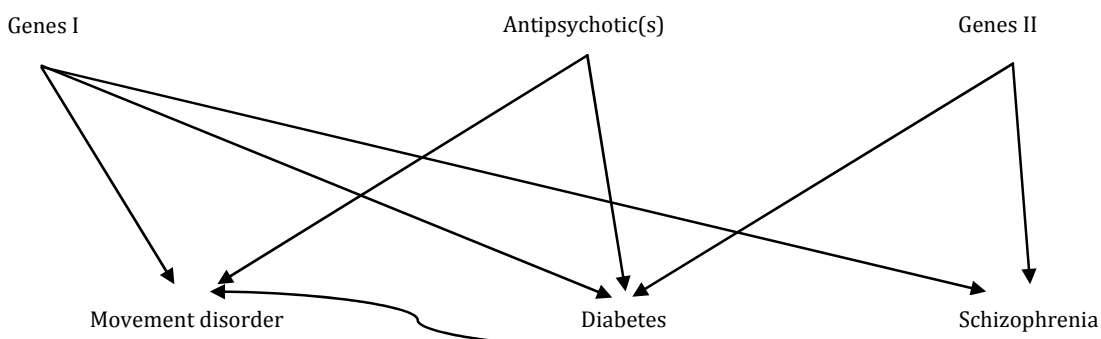

Figure 1. DAG of movement disorders, schizophrenia, and diabetes mellitus (hypothetical)

\section{Rothman's sufficient-component cause model}

Rothman's sufficient-component cause model (or sufficient-cause model) permits the postulation of different sufficient causes comprising a collection of collaborating risk factors (also known as "causal components") "sufficient to produce the disease in the individual" (Rothman et al., 2008)(p8). This model can 
also identify proximal (biological markers of risk), intermediate, and distal sufficient causes, hence describing a chain of causality (Szklo and Nieto, 2007)(p379). For example, long-stay setting, antipsychotic use, and genetic susceptibility could (hypothetically) be part of proximate, intermediate, and distal sufficient causes respectively, of a movement disorder (Figure 2).

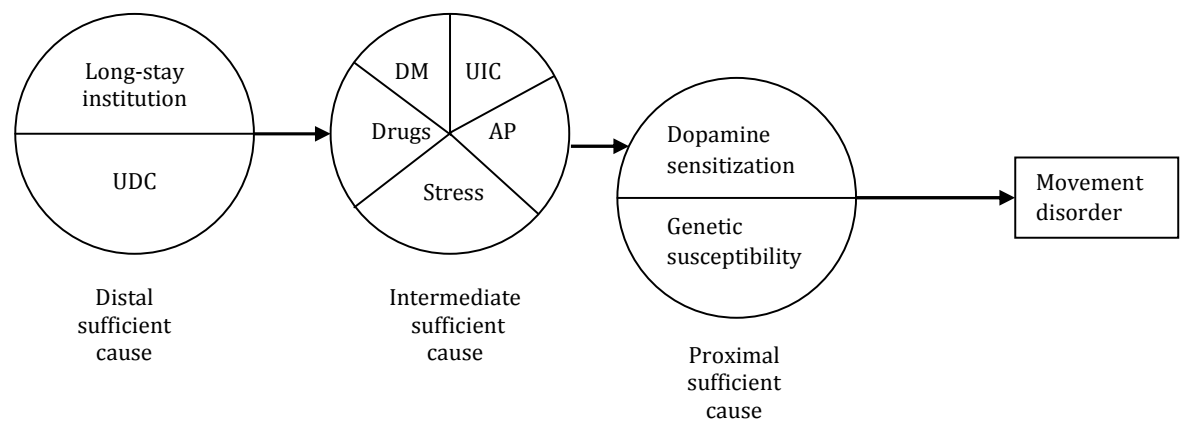

Figure 2. Causal components and sufficient causes of movement disorders (hypothetical) UDC = unknown distal causal component; UIC = unknown intermediate causal component; DM = diabetes mellitus, $\mathrm{AP}=$ antipsychotic(s)

\section{Interactions}

The sufficient-component cause model shows that risk factors in complex diseases plausibly interact non-additively, since these risk factors may be neither necessary nor sufficient to produce disease, and frequently co-participate in similar pathways (Rothman et al., 2008) ${ }^{\text {(p81) }}$ (Zammit et al., 2010a;Kendler and Gardner, 2010). Although in psychiatry there is great interest in these interactions (gene-environment, environment-environment and gene-gene), concerns are being raised about the correct underlying interaction model (additive versus multiplicative), as are doubts about the recent interpretation of pathogenesis increasingly identified in a growing number of interaction studies (Zammit et al., 2010b).

New research designs to help understand gene-environment causality are in progress. For example, contrary to between-subject cross-sectional designs, longitudinal within-subject (longitudinal and multilevel) designs with repeated assessments (Rabe-Hesketh and Skrondal, 2008) are being implemented. They have the advantage of being free of between-subject confounding (Molenaar and Campbell, 2009), may reveal the dynamics of behavior (movements), and therefore elucidate gene-environment causality. Of importance are the so called momentary assessment tools (Myin-Germeys et al., 2009), examples being the Experience Sampling Method (ESM) by Csikszentmihalyi and Larson (1987) and 'PsyMate' by Myin-Germeys (2011). 
In conclusion, persistent movement disorders continue to be the norm among long-stay patients with chronic mental illness requiring long-term antipsychotic treatment. These patients have a disproportionately high risk of incident movement disorders, particularly individuals who are older (TD and parkinsonism), and on higher doses of antipsychotic medication (parkinsonism). Therefore measures are required to remedy this situation, as a part of routine qualitycontrol procedures. It may be ironic that long-stay patients with chronic mental illness pay a high price for the intensive care they receive, particularly because the side effects are likely mediated by the relatively high compliance with pharmacotherapy in these settings. Systematic screening for movement disorders takes little time and can be easily implemented in clinical practice. Furthermore, given the clear age dependency of some movement disorders, elderly patients are a group of special concern.

The findings from the genetic studies suggest that selected SNPs are not associated with a susceptibility to movement disorders. However, on balance, our findings should be set in the context of interactions with both other genetic susceptibility loci and environmental factors.

These findings suggest that future research on movement disorders may be served by:

- Including all four movement disorders, as in the current study, since they may represent the pleiotropic effects of (partially) shared genetic factors (Koning et al., 2011).

- Enhancing the quality of data sets by (i) using repeated (momentary) measures as standard measures, e.g., characterizing Parkinson's tremor with an iPhone (Lemoyne et al., 2010), (ii) including larger study samples, (iii) using intermediate phenotypes, such as laboratory-based phenotypes (Braff et al., 2007), or more accurate measures of movement disorders, for example instrument measurement of lingual force variability (Koning et al., 2010a), which may represent powerful alternatives since instrument measurement detects subclinical movement disorders and is highly reliable.

- Using scales for subjective well-being and quality of life, to better assess the emotional impact of movement disorders on daily life.

- Identifying common pathways in the development of movement disorders. With this information, an alternative World Health Organization Model List of Essential Medicines may be one that lists the 'minimal essential biomarkers' required for optimal pharmacotherapy (Ozdemir et al., 2006).

- Collaborating on a wider level, i.e. internationally. Important initiatives are (i) the EUropean network of national schizophrenia networks studying Gene-Environment Interactions (EU-GEI, www.eu-gei.eu) and (ii) the Network of Investigator Networks sponsored by the global Human Genome Epi- 
demiology Network (HuGENet, www.cdc.gov/genomics/hugenet) (Ioannidis et al., 2006).

Finally, as rightly stated by Faraone and colleagues (1999), "any conclusion about the role of genes and environment must rely not on a single study or class of study but on the converging evidence provided by a variety of research paradigms."

\section{References}

Arango, C., Adami, H., Sherr, J.D., Thaker, G.K. and Carpenter, W.T., Jr., 1999. Relationship of awareness of dyskinesia in schizophrenia to insight into mental illness. Am J Psychiatry. 156, 1097-9.

Braff, D.L., Freedman, R., Schork, N.J. and Gottesman, I.I., 2007. Deconstructing schizophrenia: an overview of the use of endophenotypes in order to understand a complex disorder. Schizophr Bull. 33, 21-32.

Chakos, M.H., Alvir, J.M., Woerner, M.G., Koreen, A., Geisler, S., Mayerhoff, D., Sobel, S., Kane, J.M., Borenstein, M. and Lieberman, J.A., 1996. Incidence and correlates of tardive dyskinesia in first episode of schizophrenia. Arch Gen Psychiatry. 53, 313-9.

Csikszentmihalyi, M. and Larson, R., 1987. Validity and reliability of the Experience-Sampling Method. J Nerv Ment Dis. 175, 526-536.

Emsley, R., Niehaus, D.J., Oosthuizen, P.P., Koen, L., Chiliza, B. and Fincham, D., 2010. Subjective awareness of tardive dyskinesia and insight in schizophrenia. Eur Psychiatry.

Esper, C.D. and Factor, S.A., 2008. Failure of recognition of drug-induced parkinsonism in the elderly. Mov Disord. 23, 401-404.

Factor, S.A., Leffler, J.B. and Murray, C.R. Drug-Induced Movement Disorders: A Clinical Review. Medscape, We Move: http://www.medscape.org/viewprogram/18880 . 2009. Ref Type: Internet Communication

Faraone, S.V., Tsuang, M.T. and Tsuang, B.W., 1999. Genetic of mental disorders The Guilford Press, New York.

Friedman, J.H., Fernandez, H.H. and Trieschmann, M.M., 2004. Parkinsonism in a nursing home: underrecognition. J Geriatr Psychiatry Neurol. 17, 39-41.

Howes, O.D. and Kapur, S., 2009. The dopamine hypothesis of schizophrenia: version III--the final common pathway. Schizophr Bull. 35, 549-562.

Ioannidis, J.P., Gwinn, M., Little, J., Higgins, J.P., Bernstein, J.L., Boffetta, P., Bondy, M., Bray, M.S., Brenchley, P.E., Buffler, P.A., Casas, J.P., Chokkalingam, A., Danesh, J., Smith, G.D., Dolan, S., Duncan, R., Gruis, N.A., Hartge, P., Hashibe, M., Hunter, D.J., Jarvelin, M.R., Malmer, B., Maraganore, D.M., Newton-Bishop, J.A., O'Brien, T.R., Petersen, G., Riboli, E., Salanti, G., Seminara, D., Smeeth, L., Taioli, E., Timpson, N., Uitterlinden, A.G., Vineis, P., Wareham, N., Winn, D.M., Zimmern, R. and Khoury, M.J., 2006. A road map for efficient and reliable human genome epidemiology. Nat Genet. 38, 3-5.

Kefalopoulou, Z., Paschali, A., Markaki, E., Vassilakos, P., Ellul, J. and Constantoyannis, C., 2009. A double-blind study on a patient with tardive dyskinesia treated with pallidal deep brain stimulation. Acta Neurol Scand. 119, 269-273.

Kendler, K.S. and Gardner, C.O., 2010. Interpretation of interactions: guide for the perplexed. Br J Psychiatry. 197, 170-171.

Khoury, M.J. and Wacholder, S., 2009. Invited commentary: from genome-wide association studies to gene-environment-wide interaction studies--challenges and opportunities. Am J Epidemiol. 169, 227-230. 
Koning, J.P., Tenback, D.E., Kahn, R.S., Van Schelven, L.J. and van Harten, P.N., 2010a. Instrument measurement of lingual force variability reflects tardive tongue dyskinesia. J Med Eng Technol. 34, 71-77.

Koning, J.P., Tenback, D.E., van Os, J., Aleman, A., Kahn, R.S. and van Harten, P.N., 2010b. Dyskinesia and parkinsonism in antipsychotic-naive patients with schizophrenia, first-degree relatives and healthy controls: a meta-analysis. Schizophr Bull. 36, 723-731.

Koning, J.P., Vehof, J., Burger, H., Wilffert, B., Al Hadithy, A., Alizadeh, B., van Harten, P.N. and Snieder, H., 2011. Association of two DRD2 gene polymorphisms with acute and tardive antipsychoticinduced movement disorders in young Caucasian patients. Psychopharmacology (Berl).

Laugharne, J., Davies, A., Arcelus, J. and Bouman, W.P., 2004. Informing patients about tardive dyskinesia: A survey of clinicians' attitudes in three countries. Int J Law Psychiatry. 27, 101-108.

Lemoyne, R., Mastroianni, T., Cozza, M., Coroian, C. and Grundfest, W., 2010. Implementation of an iPhone for characterizing Parkinson's disease tremor through a wireless accelerometer application. Conf Proc IEEE Eng Med Biol Soc. 2010, 4954-4958.

Lerner, V., Libov, I., Kaptsan, A., Miodownik, C., Dwolatzky, T. and Levine, J., 2007. The prevalence of neuroleptic drug-induced tardive movement subsyndromes among schizophrenic and schizoaffective patients residing in the southern region of Israel. Isr J Psychiatry Relat Sci. 44, 20-28.

Leung, J.G. and Breden, E.L., 2011. Tetrabenazine for the treatment of tardive dyskinesia. Ann Pharmacother. 45, 525-531.

Macpherson, R. and Collis, R., 1992. Tardive dyskinesia. Patients' lack of awareness of movement disorder. Br J Psychiatry. 160, 110-2.

Mittal, V.A. and Walker, E.F., 2010. Letter to the Editor: Movement abnormalities and schizophrenia in DSM-V. Psychol Med. 1-3.

Modestin, J., Wehrli, M.V., Stephan, P.L. and Agarwalla, P., 2008. Evolution of neuroleptic-induced extrapyramidal syndromes under long-term neuroleptic treatment. Schizophr Res. 100, 97-107.

Molenaar, P.C.M. and Campbell, C.G., 2009. The New Person-Specific Paradigm in Psychology. Current Directions in Psychological Science. 18, 112-117.

Myin-Germeys, I., Birchwood, M. and Kwapil, T., 2011. From environment to therapy in psychosis: a real-world momentary assessment approach. Schizophr Bull. 37, 244-247.

Myin-Germeys, I., Oorschot, M., Collip, D., Lataster, J., Delespaul, P. and van Os, J., 2009. Experience sampling research in psychopathology: opening the black box of daily life. Psychol Med. 39, 1533-1547.

Owens, D.G.C., 1999. A guide to the extrapyramidal side-effects of antipsychotic drugs Cambridge University Press UK, New York, p. 351.

Ozdemir, V., Aklillu, E., Mee, S., Bertilsson, L., Albers, L.J., Graham, J.E., Caligiuri, M., Lohr, J.B. and Reist, C., 2006. Pharmacogenetics for off-patent antipsychotics: reframing the risk for tardive dyskinesia and access to essential medicines. Expert Opin Pharmacother. 7, 119-133.

Pappa, S. and Dazzan, P., 2009. Spontaneous movement disorders in antipsychotic-naive patients with first-episode psychoses: a systematic review. Psychol Med. 39, 1065-1076.

Psychiatric GWAS Consortium Coordinating Committee, 2009. Genomewide Association Studies: History, Rationale, and Prospects for Psychiatric Disorders. American Journal of Psychiatry. 166, 540-556.

Rabe-Hesketh, S. and Skrondal, A., 2008. Multilevel and longitudinal modelling using stata, 2nd ed edn. Stata Press, College Station, Tex.

Richardson, M.A., Bevans, M.L., Read, L.L., Chao, H.M., Clelland, J.D., Suckow, R.F., Maher, T.J. and Citrome, L., 2003. Efficacy of the branched-chain amino acids in the treatment of tardive dyskinesia in men. Am J Psychiatry. 160, 1117-24.

Rothman, K.J., Greenland, S. and Lash, T.L., 2008. Modern epidemiology, 3rd ed., thoroughly rev. and updated edn. Wolters Kluwer Health/Lippincott Williams \& Wilkins, Philadelphia.

Slotema, C.W., van Harten, P.N., Bruggeman, R. and Hoek, H.W., 2008. Botulinum toxin in the treatment of orofacial tardive dyskinesia: a single blind study. Prog Neuropsychopharmacol Biol Psychiatry. 32, 507-509.

Soares-Weiser, K. and Fernandez, H.H., 2007. Tardive dyskinesia. Semin Neurol. 27, 159-169. 
Szklo, M. and Nieto, F.J., 2007. Epidemiology: beyond the basics, 2nd ed edn. Jones and Bartlett Publishers, Sudbury, Mass.

Tenback, D.E., van Harten, P.N. and van Os, J., 2009. Non-therapeutic risk factors for onset of tardive dyskinesia in schizophrenia: a meta-analysis. Mov Disord. 24, 2309-2315.

van Harten, P.N. and Hovestadt, A., 2006. Botulinum toxin as a treatment for tardive dyskinesia. Mov Disord. 21, 1276-1277.

van Harten, P.N. and Tenback, D.E., 2009. Movement disorders should be a criterion for schizophrenia in DSM-V. Psychol Med. 39, 1754-1755.

van Os, J., Kenis, G. and Rutten, B.P., 2010. The environment and schizophrenia. Nature. 468, 203212.

Zammit, S., Lewis, G., Dalman, C. and Allebeck, P., 2010a. Examining interactions between risk factors for psychosis. Br J Psychiatry. 197, 207-211.

Zammit, S., Owen, M.J. and Lewis, G., 2010b. Misconceptions about gene-environment interactions in psychiatry. Evid Based Ment Health. 13, 65-68. 

Summary 
A high risk group for movement disorders consists of long-stay patients with chronic mental illness and, therefore chronic exposure to antipsychotic medication, particularly when they reside in long-stay settings with supervised medication regimes.

The overall aim of this thesis entitled "Drug-induced movement disorders in longstay psychiatric patients - Genetic and non-genetic risk factors: A prospective $s t u d y "$ was to assess the frequency and the genetic and non-genetic risk factors of drug-induced movement disorders in long-stay patients with chronic mental illness and long-term antipsychotic treatment. Its prospective design extends hitherto cross-sectional work in the field of antipsychotic-induced movement disorders. Indeed, prospective assessment of both persistent and fluctuating (repeated) movement disorders measures the phenotype more specifically and that increases the validity of the associations between movement disorders and risk factors.

Chapter 1 provides an introduction to the antipsychotic-induced movement disorders, which constitute a major reason for medication non-compliance and thus result in an increased risk of psychotic relapse. The chapter emphasizes the importance of prospective studies of movement disorders in the population currently most at risk: long-stay patients with chronic mental illness requiring long-term antipsychotic treatment. The chapter also discusses recent experts' critical comments on the regrettable neglect of movement disorders since the introduction of the second generation antipsychotics (SGAs), as these modern, possibly safer, antipsychotics associated with a lower incidence of movement disorder nevertheless still pose risks.

The concept of genetic studies is introduced with (i) an overview of pharmacogenetics, pharmacogenomics, and population-based association studies, (ii) their importance for individually tailored drug prescriptions, (iii) genetic methodological problems, such as sample heterogeneity, small effects of multiple genes, (epi) genetic interactions, pleiotropy and small sample size, and (iv) the genetics of movement disorders and their relationship to schizophrenia.

Finally, Chapter 1 introduces the phenomenology and assessment of movement disorders. Antipsychotic-induced movement disorders can be divided into acute syndromes, such as parkinsonism and akathisia, that occur within hours/days or weeks after initiating antipsychotic treatment or increasing the antipsychotic dose (or cessation of anticholinergics), and tardive syndromes, such as tardive dyskinesia (TD) and tardive dystonia, that develop after months or years of treatment. Given that combinations of acute and chronic movement disorders occur in patients undergoing long-term treatment with antipsychotics, prediction models should include both syndromes, i.e., the four major types of movement disorders (TD, parkinsonism, akathisia and tardive dystonia). Initially, the term 'tardive' (delayed) was introduced to emphasize the late-onset 
types of movement disorders occurring during antipsychotic use. Yet the definition of tardive disorders in the current study emphasizes their persistence, which is clinically more important than their late-onset.

Meta-analyses were conducted of the genes that are thought to be associated with TD, namely DRD3 (Chapter 2), COMT, DRD2, CYP1A2, and MnSOD (Chapter 3 ). The meta-analyses indicate that TD may be associated with functional variations in DRD3, COMT, DRD2, and MnSOD alleles. These analyses suggest multiple genetic influences on TD, indicative of pharmacogenetic interactions. Although the associations are not strong, the effects underlying them may be subject to interactions with other loci that, when identified, may have acceptable predictive power.

In keeping with the aim of this thesis, a 4-year prospective naturalistic study (July 2003 - May 2007) was conducted with 209 patients with chronic mental illness in order to determine the frequency of the four major types of movement disorders (TD, parkinsonism, akathisia, and tardive dystonia) and the genetic and non-genetic risk factors of incident movement disorders. To this end, a cohort was drawn from patients in a general psychiatric hospital (GGZ Centraal, Amersfoort, the Netherlands). Inclusion criteria were minimum age of 18 years and cumulative exposure to antipsychotics of at least 1 year. Exclusion criteria were a history of neurological disorders affecting motor function. The cohort was representative of the population of patients with the most severe chronic mental illness requiring long-stay care, given that the hospital serves an epidemiological catchment area, is the only institute providing this type of care in this area, and patients were selected from a comprehensive list of all inpatients.

Chapter 4 focuses on the assessment of the frequency of persistent movement disorders, and subsequently Chapter 5 of the non-genetic risk factors for incident movement disorders.

The results show that persistent movement disorders are still the norm for long-stay patients with chronic mental illness requiring long-term antipsychotic treatment. The high period frequency of $68 \%$ with at least a single drug-induced movement disorder is even more striking given the use of strict case definition criteria, which had to be positive on at least two consecutive assessments. Clinical relevance of these findings is suggested not only because of the high frequency of these acute and tardive movement disorders, but also because persistence of movement disorders seems to be the rule. This implies that most patients on long-term antipsychotic treatment have persistent movement disorders, which make this side effect a matter of urgent consideration. These patients have a disproportionately high risk of incident movement disorders, particularly individuals who are older (TD and parkinsonism) and/or on higher doses of antipsychotic medication (parkinsonism), expressed as total defined 
daily dose (DDD). Therefore measures are required to remedy this situation as a part of routine quality-control procedures. It may be ironic that long-stay patients with chronic mental illness pay a high price for the intensive care they receive, particularly because the side effects are likely mediated by the relatively high compliance with pharmacotherapy in these settings. Systematic screening for movement disorders takes little time and can be easily implemented in clinical practice. Furthermore, given the clear age dependency of some movement disorders, elderly patients are a group of special concern.

Since previous studies used cross-sectional measures and did not focus on the vulnerable subgroup of long-stay patients in hospital, it is difficult to place the current results into context.

Previous studies concur with the prevalence of movement disorders found in the current study with regard to TD, but in those studies the prevalence tends to be lower for parkinsonism and higher for akathisia and tardive dystonia.

In addition to age and total antipsychotic DDD, the current study did not find other risk factors reported in previous studies. Although the sample selection and prospective nature of the current study may explain the lack of consistency with some older studies, particularly given that careful meta-analysis indicates that studies of risk factors for movement disorders such as TD show very little consistency, other possible explanations for these differences are (i) carryover effects (delayed response effects) after many years of antipsychotic usage in the population studied, and/or (ii) the relatively small sample size of the current study.

The aim of Chapters 6 and 7 was to examine the genetic association between the four major types of movement disorders (TD, parkinsonism, akathisia, and tardive dystonia), subtypes of TD (orofacial and limb truncal dyskinesia) and parkinsonism (rest tremor, rigidity, and bradykinesia), as well as a principalfactor of the movement disorders and their subtypes on the one hand, and variation in 17 candidate genes, PPP1R1B, BDNF, DRD3, DRD2, HTR2A, HTR2C, COMT, $M n S O D, C Y P 1 A 2$, and RGS2 (Chapter 6) and GRIN1B, GRIN1A, HSPG2, DRD3, HTR2C, DRD4, and NQO1 (Chapter 7) on the other. It may be hypothesized that subtypes of movement disorders are more suitable for genetic analysis than the use of a general movement disorder syndrome, as subtypes may better reflect the underlying biological heterogeneity in complex syndromes.

Various single nucleotide polymorphism (SNP) in these 17 candidate genes reached nominal significance in association with drug-induced movement disorders. However, after controlling for multiple testing, our findings suggest that these SNPs are not associated with a susceptibility to movement disorders.

As the sample size of the current study is small and previous studies show inconsistent results, definite conclusions cannot be made. Yet the question is how to interpret these results. In our opinion, they may reflect weak genetic 
signals which need to be replicated in larger study samples, preferably in longitudinal studies which take the fluctuating course of movement disorders and gene-environment interactions into account.

Finally, Chapter 8 discusses the results of the meta-analyses, as well as the most striking findings of the current study in long-stay patients with chronic mental illness and long-term antipsychotic usage, with a discussion of a prevention perspective for drug-induced movement disorders.

We were surprised by the paucity of notes in the patient files about movement disorder side effects, an observation made by others as well. The relative lack of focus on movement disorder syndromes is reflected in the very low rate of DSM-IV Axis I diagnoses of movement disorders found in routine clinical practice. Several reasons may explain this discrepancy between clinical reality and clinical attention, e.g., systematic examination for drug-induced movement disorders is not common practice, clinicians may wrongly assume that druginduced movement disorders are almost not treatable, the introduction of the SGAs wrongly led to the presumption that drug-induced movement disorders had disappeared, most patients with schizophrenia do not complain of their movement disorder which results in diagnostic delay. Therefore active assessment and treatment of movement disorders, like the current concern about metabolic syndrome, is of paramount importance, and can be seen as a qualityof-care issue. In addition, shared care decision making and informed consent by patients should be part of antipsychotic treatment. Systematic diagnosis may help physicians become more aware of movement disorders.

The core problem in the prevention and treatment of movement disorders may be their poorly understood pathophysiology. The classic model in which movement disorders originate from antipsychotics is challenged by a large body of literature and two meta-analyses demonstrating higher prevalence rates of movement disorders in patients with a diagnosis of schizophrenia. These results provide a strong argument for the hypothesis that movement disorders may not result exclusively from antipsychotic treatment but also reflect a fundamental aspect of neurodevelopmental pathophysiology involving the sensitization of dopaminergic nigrostriatal circuits. It is noteworthy that movement disorders may fulfill the criteria for classifying a trait as a spectrum condition of a disorder, in this case schizophrenia: heritability, familial link, cosegregation, and biological and clinical plausibility. Spectrum conditions refer to mild psychopathology of little clinical significance among relatives without the full disorder. The advantage for research of spectrum conditions in contrast to a full disorder is that they may have fewer risk factors and therefore less complex chain of mechanisms (pathways) leading to their onset, which could make research easier to perform. (Pharmaco) genetic studies may help elucidate these common pathways in the development of both spectrum conditions and the full disorder. 
Prospective studies in populations of drug-naïve patients with a first episode of psychosis before and after antipsychotic treatment could be crucial for distinguishing between primary (part of schizophrenia) and secondary (druginduced) movement disorders. Even so, primary symptoms may develop over the course of schizophrenia, making differentiation between primary and secondary symptoms almost impossible.

Despite growing evidence from genetic association studies, genetics only explains a minor part of schizophrenia, a fact which supports the importance of other interacting factors, such as environmental factors, which play important roles in schizophrenia. Neuropsychiatric disorders may reflect the complex interplay of not only genetic factors, but first and foremost of epigenetic, stochastic, and non-genetic factors.

An important development in human (pharmaco) genetics since 2005 is the possibility of genome-wide association studies (GWASs) with the advantage of a 'hypothesis free' and hence unbiased approach for revealing new DNA variants influencing genetic susceptibility to many common diseases, and elucidating new pathophysiological mechanisms.

The Psychiatric GWAS Consortium (PGC) has suggested that in the near future larger GWAS samples will detect more variants of common susceptibility with smaller effect sizes and that meta-analyses of GWAS should find more conclusive evidence for genetic associations. Meanwhile, new potentially promising genetic techniques such as whole-genome sequencing and epigenetics are being implemented. Also, gene-environment-wide interaction studies (GEWIS) approaches are being suggested. It seems legitimate to conclude that these new techniques could offer more effective genetic linkage and association studies.

These findings suggest that future research on movement disorders may be served by:

- Including all four movement disorders, as done in the current study, since they may represent the pleiotropic effects of (partially) shared genetic factors.

- Enhancing the quality of data sets by (i) using repeated (momentary) measures as standard measures, e.g., characterizing Parkinson's tremor with an iPhone, (ii) including larger study samples, (iii) using intermediate phenotypes, such as laboratory-based phenotypes, or more accurate measures of movement disorders, for example instrument measurement of lingual force variability, which may represent powerful alternatives since instrument measurement detects subclinical movement disorders and is highly reliable.

- Using scales for subjective well-being and quality of life, to better assess the emotional impact of movement disorders on daily life.

- Identifying common pathways in the development of movement disorders. With this information, an alternative World Health Organization Model List 
of Essential Medicines may be one that lists the 'minimal essential biomarkers' required for optimal pharmacotherapy.

- Collaborating on a wider level, i.e. internationally. Important initiatives are (i) the EUropean network of national schizophrenia networks studying Gene-Environment Interactions (EU-GEI, www.eu-gei.eu) and (ii) the Network of Investigator Networks sponsored by the global Human Genome Epidemiology Network (HuGENet, www.cdc.gov/genomics/hugenet). 



\section{Samenvatting}


Langdurig opgenomen patiënten met een chronische psychiatrische aandoening, en daarom chronische blootstelling aan antipsychotische medicatie, vormen een groep met een hoog risico op bewegingstoornissen. Dit geldt in het bijzonder voor patiënten in langdurig verblijf waar medicatie onder toezicht wordt gegeven.

Het doel van dit proefschrift getiteld "Door medicatie geïnduceerde bewegingsstoornissen bij langdurig opgenomen psychiatrische patiënten - Genetische en niet-genetische risicofactoren: Een prospectieve studie" was het analyseren van de frequentie en de genetische en niet-genetische risicofactoren voor bewegingsstoornissen door medicatie bij langdurig opgenomen patiënten met een chronische psychiatrische aandoening en langdurige behandeling met antipsychotica. De prospectieve onderzoeksopzet breidt het tot nu toe cross-sectionele werk op het gebied van bewegingsstoornissen door antipsychotica uit. Een prospectieve beoordeling van zowel persisterende als fluctuerende (herhaalde) bewegingsstoornissen meet in feite het fenotype specifieker en dit verhoogt de validiteit van de associaties tussen bewegingsstoornissen en risicofactoren.

Hoofdstuk 1 is een inleiding over bewegingsstoornissen door antipsychotica, die een belangrijke reden zijn voor medicatie-ontrouw, met als gevolg een verhoogd risico op een nieuwe psychose. Het hoofdstuk benadrukt het belang van prospectieve studies naar bewegingsstoornissen in de populatie die op dit moment het meeste risico loopt: langdurig opgenomen patiënten met een chronische psychiatrische aandoening waarvoor een langdurige antipsychoticumbehandeling nodig is. Het hoofdstuk bespreekt ook de recente kritische opmerkingen van deskundigen over de betreurenswaardige verwaarlozing van bewegingsstoornissen sinds de invoering van de tweede generatie antipsychotica (SGA's), aangezien het gebruik van deze moderne, mogelijk veiliger antipsychotica, met een lagere incidentie voor bewegingstoornissen, het risico hierop niet uitsluit.

Het concept van genetische studies wordt geïntroduceerd met (i) een overzicht van de farmacogenetica, farmacogenomica, en associatiestudies op populatieniveau, (ii) hun belang voor medicatievoorschrift op individuele maat, (iii) genetisch methodologische problemen, zoals steekproefheterogeniteit, kleine effecten van multipele genen, (epi)genetische interacties, pleiotropie en kleine steekproef, en (iv) de genetica van bewegingsstoornissen en hun relatie met schizofrenie.

Tot slot introduceert Hoofdstuk 1 de fenomenologie en de beoordeling van bewegingsstoornissen. Bewegingsstoornissen door antipsychotica kunnen worden onderverdeeld in acute syndromen, zoals parkinsonisme en acathisie, die binnen enkele uren/dagen of weken optreden na het starten van de antipsychoticumbehandeling of het verhogen van de antipsychoticumdosis (of beëindiging van de anticholinergica) en tardieve syndromen, zoals tardieve dyskinesie (TD) en tardieve dystonie, die zich na maanden of jaren van de behandeling ontwik- 
kelen. Aangezien combinaties van acute en chronische bewegingsstoornissen voorkomen bij patiënten die langdurig een antipsychoticum gebruiken, dienen voorspellende modellen beide syndromen te omvatten, dat wil zeggen, de vier hoofdtypen bewegingsstoornissen (TD, parkinsonisme, acathisie en tardieve dystonie). Aanvankelijk werd de term 'tardief' (vertraagd) type geïntroduceerd om het late ontstaan van bewegingsstoornissen die optreden tijdens antipsychoticumgebruik te benadrukken. Echter, in de huidige studie benadrukt de definitie van tardieve stoornissen hun persistentie, die klinisch veel belangrijker is dan hun late ontstaan.

Meta-analyses werden uitgevoerd van genen die worden verondersteld geassocieerd te zijn met TD, namelijk DRD3 (Hoofdstuk 2), COMT, DRD2, CYP1A2, en MnSOD (Hoofdstuk 3). De meta-analyses geven aan dat TD mogelijk geassocieerd is met functionele variaties in DRD3-, COMT-, DRD2- en MnSOD-allelen. Deze analyses suggereren multipele genetische invloeden op TD, duidend op farmacogenetische interacties. Hoewel de associaties niet sterk zijn, kunnen de onderliggende effecten mogelijk onderdeel zijn van interacties met andere loci, die, wanneer eenmaal geïdentificeerd, een aanvaardbaar voorspellend vermogen hebben.

Conform het doel van dit proefschrift, werd een 4-jarige prospectieve naturalistische studie (juli 2003 - mei 2007) uitgevoerd met 209 patiënten met een chronische psychiatrische aandoening om de frequentie van de vier hoofdtypen bewegingsstoornissen (TD, parkinsonisme, acathisie en tardieve dystonie) en de genetische en niet-genetische risicofactoren voor incidente bewegingsstoornissen te bepalen. Met dit doel werd een cohort geselecteerd uit patiënten in een algemeen psychiatrisch ziekenhuis (GGZ Centraal, Amersfoort, Nederland). Inclusiecriteria waren een leeftijd van 18 jaar of ouder en een cumulatieve blootstelling aan antipsychotica van ten minste 1 jaar. Exclusiecriterium was een voorgeschiedenis van neurologische aandoeningen die motorische functies beinvloeden. Het cohort was representatief voor de populatie patiënten met de meest ernstige chronische psychiatrische aandoeningen die langdurige zorg nodig hebben, aangezien de instelling een epidemiologisch verzorgingsgebied bedient, de instelling als enige deze vorm van zorg aanbiedt in deze regio, en de patiënten geselecteerd werden uit een uitgebreide lijst van alle opgenomen patiënten.

Hoofdstuk 4 richt zich op de vaststelling van de frequentie van persisterende bewegingsstoornissen, en Hoofdstuk 5 op de vaststelling van niet-genetische risicofactoren voor incidente bewegingsstoornissen.

De resultaten geven weer dat persisterende bewegingsstoornissen nog altijd de norm zijn bij langdurig opgenomen patiënten met een chronische psychiatrische aandoening waarvoor een langdurige antipsychoticumbehandeling nodig 
is. De hoge periode-frequentie van $68 \%$ met minstens één bewegingstoornis door medicatie is des te opvallender aangezien er strikte gevals-definitiecriteria zijn gebruikt, waarbij ten minste twee opeenvolgende evaluaties positief moesten zijn. De klinische relevantie van deze bevindingen komt niet alleen naar voren door de hoge frequentie van acute en tardieve bewegingsstoornissen, maar ook doordat persistentie van bewegingsstoornissen de regel lijkt te zijn. Dit betekent dat de meeste patiënten met een langdurige antipsychoticumbehandeling persisterende bewegingsstoornissen hebben, wat deze bijwerking tot een urgente kwestie maakt. Deze patiënten hebben een onevenredig hoog risico op incidente bewegingsstoornissen, met name diegenen die ouder zijn (TD en parkinsonisme) en/of op hogere doses antipsychotica zitten (parkinsonisme), uitgedrukt in totale gedefinieerde dagelijkse dosis (defined daily dose, DDD). Daarom zijn maatregelen nodig om deze situatie te verhelpen als onderdeel van routineprocedures voor kwaliteitsbewaking. Het is ironisch dat juist langdurig opgenomen patiënten met een chronische psychiatrische aandoening een hoge prijs betalen voor de intensieve zorg die zij krijgen, met name omdat de bijwerkingen waarschijnlijk het gevolg zijn van de relatief hoge medicatietrouw binnen deze instellingen. Systematische screening van bewegingsstoornissen kost weinig tijd en kan eenvoudig worden geïmplementeerd in de klinische praktijk. Verder behoeven oudere patiënten extra aandacht, gezien de duidelijke relatie tussen leeftijd en sommige bewegingsstoornissen.

Omdat eerdere studies cross-sectioneel van opzet waren en zich niet richtten op de kwetsbare subgroep van langdurig opgenomen patiënten binnen instellingen, is het moeilijk om de huidige resultaten in de juiste context te plaatsen.

De prevalentie van bewegingsstoornissen in eerdere studies komt overeen met de huidige studie naar TD, maar deze studies laten een trend zien naar een lagere prevalentie van parkinsonisme en een hogere prevalentie van acathisie en tardieve dystonie.

Behalve leeftijd en totale $D D D$ van antipsychotica, vond de huidige studie geen andere risicofactoren zoals gerapporteerd in eerdere studies. Hoewel de steekproef en het prospectieve karakter van de huidige studie mogelijk het gebrek in consistentie met een aantal oudere studies zou kunnen verklaren, met name gezien het feit dat een zorgvuldige meta-analyse aangeeft dat onderzoek naar risicofactoren voor bewegingsstoornissen zoals TD weinig consistentie laat zien, zijn er andere mogelijke verklaringen voor deze verschillen, te weten (i) nawerking (vertraagde responseffecten; carryover effects) na vele jaren antipsychoticumgebruik in de bestudeerde populatie en/of (ii) de relatief kleine steekproef van de huidige studie.

Het doel van de Hoofdstukken 6 en 7 was om de genetische associatie te onderzoeken tussen enerzijds de vier hoofdtypen bewegingsstoornissen (TD, parkinsonisme, acathisie en tardieve dystonie), subtypen van TD (orofaciale en le- 
dematenromp dyskinesie) en parkinsonisme (rust tremor, rigiditeit en bradykinesie), en een principal-factor van de bewegingsstoornissen en hun subtypen, en anderzijds de variatie in 17 genen, $P P P 1 R 1 B, B D N F, D R D 3, D R D 2, H T R 2 A, H T R 2 C$, COMT, MnSOD, CYP1A2 en RGS2 (Hoofdstuk 6) en GRIN1B, GRIN1A, HSPG2, DRD3, HTR2C, DRD4, en NQO1 (Hoofdstuk 7). Subtypen van bewegingsstoornissen kunnen hypothetisch gezien geschikter zijn voor genetische analyse dan het gebruik van een algemeen bewegingsstoornis-syndroom, aangezien subtypen een betere afspiegeling van de onderliggende biologische heterogeniteit in complexe ziektebeelden zouden kunnen zijn.

Diverse enkel-nucleotide polymorfismen (SNP's; Single nucleotide polymorphisms, SNPS) in deze 17 kandidaatgenen bereikten een nominale significantie in associatie met bewegingsstoornissen door medicatie. Echter, na correctie voor multipel testen (multiple testing), suggereren onze bevindingen dat deze SNP's niet geassocieerd zijn met een kwetsbaarheid voor bewegingsstoornissen.

Aangezien de steekproefgrootte van de huidige studie klein is en eerdere studies inconsistente resultaten weergeven, kunnen er geen definitieve conclusies worden getrokken. De vraag is nu hoe men deze resultaten moet interpreteren. Naar onze mening weerspiegelen ze mogelijk zwakke genetische signalen die gerepliceerd moeten worden in grotere steekproeven, bij voorkeur in longitudinale studies waarin het fluctuerende verloop van bewegingsstoornissen en gen-omgevingsinteracties meegenomen worden.

Tot slot, bespreekt Hoofdstuk 8 de resultaten van de meta-analyses, en de meest opvallende bevindingen van de huidige studie naar langdurig opgenomen patienten met een chronische psychiatrische aandoening en lange termijn antipsychoticumgebruik, met een beschouwing vanuit een preventief perspectief van bewegingsstoornissen door medicatie.

We waren verbaasd over de schaarse aantekeningen in de medische dossiers over bewegingsstoornissen als bijwerking, wat anderen ook hebben opgemerkt. De relatief weinige aandacht voor bewegingsstoornissen komt tot uiting in de dagelijkse klinische praktijk door het zeer lage aantal DSM-IV diagnoses van bewegingsstoornissen op de As I. Verschillende redenen kunnen deze discrepantie tussen de klinische realiteit en klinische zorg verklaren, bijvoorbeeld: systematisch onderzoek naar bewegingsstoornissen door medicatie is geen routine, artsen gaan er ten onrechte van uit dat bewegingsstoornissen door medicatie bijna niet te behandelen zijn, de introductie van de SGA's hebben ten onrechte de suggestie gewekt dat bewegingsstoornissen door medicatie zijn verdwenen, de meeste patiënten met schizofrenie klagen niet over hun bewegingsstoornis wat tot diagnostische vertraging leidt. Daarom is actieve beoordeling en behandeling van bewegingsstoornissen van het grootste belang, zoals dit nu het geval is bij het metabool syndroom, wat gezien kan worden als een onderdeel van kwaliteit van zorg. Bovendien zouden een gezamenlijke besluitvorming betreffende de behandeling (shared care decision making) en een instem- 
mingsverklaring (informed consent) door patiënten deel uit moeten maken van de antipsychoticumbehandeling. Systematische diagnostiek zou artsen bewust kunnen maken van bewegingsstoornissen.

De kern van het probleem bij de preventie en behandeling van bewegingsstoornissen is mogelijk hun slecht begrepen pathofysiologie. Het klassieke model waarbij bewegingsstoornissen afkomstig zijn van antipsychotica staat onder druk door een grote hoeveelheid aan literatuur en twee meta-analyses die een hogere prevalentie van bewegingsstoornissen tonen bij patiënten met schizofrenie. Deze resultaten ondersteunen de hypothese dat bewegingsstoornissen niet uitsluitend het gevolg zijn van behandeling met antipsychotica, maar wijzen ook op een fundamenteel aspect van de pathofysiologie in de neuroontwikkeling met betrekking tot de sensibilisatie van de dopaminerge nigrostriatale circuits. Het is interessant dat bewegingsstoornissen mogelijk voldoen aan de criteria voor het classificeren van een eigenschap (trait) als een spectrumconditie van een aandoening, in dit geval schizofrenie: erfelijkheid (heritability), familiaire link, cosegregatie, en biologische en klinische plausibiliteit. Spectrumcondities hebben betrekking op milde psychopathologie die van weinig klinisch belang is bij familieleden die niet aan de volle stoornis leiden. Onderzoek naar spectrumcondities heeft in tegenstelling tot onderzoek naar de volle stoornis als voordeel dat het mogelijk eenvoudiger uitvoerbaar is door het kleiner aantal risicofactoren en de daarom minder complexe keten van mechanismen (pathways) die leiden tot hun ontstaan. (Farmaco)genetische studies helpen mogelijk deze gemeenschappelijke pathways van zowel spectrumcondities als de volledige stoornis te verhelderen.

Prospectieve studies in populaties van medicatie-naïeve patiënten met een eerste psychotische episode voor en na een antipsychoticumbehandeling zijn mogelijk van cruciaal belang om primaire (deel van schizofrenie uitmakende) en secundaire (medicatiegeïnduceerde) bewegingsstoornissen van elkaar te onderscheiden. Niettemin kunnen primaire symptomen zich ontwikkelen in de loop van schizofrenie, wat het onderscheid tussen primaire en secundaire symptomen bijna onmogelijk maakt.

Ondanks de groeiende evidentie uit genetische-associatiestudies, verklaart genetica slechts een klein deel van schizofrenie, een feit dat het belang van andere interactiefactoren, zoals omgevingsfactoren, ondersteunt die een belangrijke rol spelen bij schizofrenie. Neuropsychiatrische stoornissen kunnen een afspiegeling zijn van het complexe samenspel van niet alleen genetische factoren, maar in de eerste plaats van epigenetische, stochastische en niet-genetische factoren.

Een belangrijke ontwikkeling sinds 2005 in de (farmaco)genetica bij mensen is de mogelijkheid van genoom-brede associatiestudies (genome-wide association studies, GWASs) die het voordeel hebben van een 'hypothesevrije' en dus aselecte benadering voor het vinden van nieuwe DNA-varianten die van invloed 
zijn op genetische kwetsbaarheid voor veel voorkomende ziekten, en die nieuwe pathofysiologische mechanismen ophelderen.

Volgens het Psychiatrische GWAS Consortium (Psychiatric GWAS Consortium, $P G C$ ) zullen in de nabije toekomst grotere GWAS-steekproeven meer algemene varianten vinden die verantwoordelijk zijn voor een verhoogde kwetsbaarheid met kleinere effecten en zullen GWAS-meta-analyses betere evidentie voor genetische associaties leveren. In de tussentijd worden nieuwe potentieel veelbelovende genetische technieken ingevoerd zoals whole-genome sequencing en epigenetica, en worden gen-omgevingsinteractie-brede studies (geneenvironment-wide interaction studies, GEWIS) benaderingen voorgesteld. Het lijkt gerechtvaardigd te concluderen dat deze nieuwe technieken efficiëntere genetische koppelings- en associatiestudies zouden kunnen bieden.

Deze conclusies suggereren dat toekomstig onderzoek naar bewegingsstoornissen gebaat kan zijn bij:

- Inclusie van alle vier bewegingsstoornissen, zoals dat gedaan is in de huidige studie, omdat zij de pleiotrope effecten van (deels) gezamenlijke genetische factoren vertegenwoordigen.

- Verbetering van de kwaliteit van datasets door (i) het gebruik van herhaalde (momentane) maten als standaardmaten, zoals het karakteriseren van de parkinsontremor met een iPhone, (ii) inclusie van grotere steekproeven, (iii) het gebruik van intermediaire fenotypen, zoals fenotypen op laboratoriumniveau of meer nauwkeurige metingen van bewegingsstoornissen, bijvoorbeeld instrumentele meting van de tongkrachtvariabiliteit, die mogelijk betere alternatieven zijn aangezien instrumentele metingen subklinische bewegingsstoornissen aan het licht brengen en zeer betrouwbaar zijn.

- Gebruik van meetschalen voor subjectief welbevinden en kwaliteit van leven, om beter de emotionele gevolgen van bewegingsstoornissen in het dagelijks leven in te schatten.

- Het identificeren van algemene pathways die een rol spelen bij de ontwikkeling van bewegingsstoornissen. Met deze informatie kan er een alternatieve Werelgezondheidsorganisatie-Lijst van Essentiële Medicatie komen die de 'minimale essentiële biomarkers' vermeldt die vereist zijn voor een optimale farmacotherapie.

- Samenwerking op een breder niveau, dat wil zeggen op internationaal niveau. Belangrijke initiatieven zijn (i) het EUropees netwerk van nationale schizofrenienetwerken voor het bestuderen van Gen-OmgevingsInteracties (EUropean network of national schizophrenia networks studying GeneEnvironment Interactions; EU-GEI, www.eu-gei.eu) en (ii) het Netwerk van OnderzoekersNetwerk gesponsord door het wereldwijde Humane Genoom Epidemiologie-Netwerk (Network of Investigator Networks sponsored by the glo- 
bal Human Genome Epidemiology Network; HuGENet, www.cdc.gov/genomics/hugenet). 



\section{Resumen}


Un grupo con alto riesgo de trastornos del movimiento comprende a los pacientes con larga estancia hospitalaria, con enfermedades mentales crónicas y consecuentemente con exposición crónica a medicación antipsicótica, especialmente cuando están expuestos a largas hospitalizaciones y a regímenes supervisados de medicina.

El objetivo general de esta tesis doctoral titulada "Trastornos del movimiento inducidos por fármacos en pacientes psiquiatricos de larga hospitalización - Factores de riesgo genéticos y no genéticos: Un estudio prospectivo" era evaluar la frecuencia y los factores de riesgo genéticos y no genéticos de trastornos del movimiento inducidos por fármacos en pacientes de hospitalización de larga duración con enfermedades mentales crónicas y en tratamiento antipsicótico prolongado. Su diseño prospectivo se extiende a estudios hasta ahora transversales en la area de los trastornos del movimiento inducidos por antipsicóticos. En efecto, la evaluación prospectiva de los trastornos del movimiento tanto persistente como fluctuante (repetido) mide el fenotipo de manera mas específica y esto aumenta la validez de las asociaciones entre los trastornos del movimiento y los factores de riesgo.

El capítulo 1 presenta una introducción a los trastornos del movimiento inducidos por antipsicóticos, los cuales son una causa importante del incumplimiento de la terapia médica, y así conllevan a un riesgo aumentado de una recaída psicótica. El capítulo enfatiza la importancia de estudios prospectivos acerca de los trastornos del movimiento en la población actualmente con el riesgo mas alto: pacientes de hospitalización prolongada con enfermedades mentales crónicas que requieren tratamiento antipsicótico prolongado. El capítulo también presenta comentarios críticos recientes de expertos sobre la neglicencia lamentable en lo que concierne a los trastornos del movimiento desde la introducción de los antipsicóticos de segunda generación (ASG), visto que estos antipsicoticos modernos, posiblemente más seguros, asociados a una incidencia más baja de trastornos del movimiento no obstante todavía conllevan a un riesgo moderado.

El concepto de los estudios genéticos se introduce con (i) una introducción general de la farmacogenética, la farmacogenómica, y de estudios de asociación de base poblacional, (ii) su importancia para adaptar individualmente la prescripción de los medicamentos, (iii) los problemas metodológicos genéticos, como la heterogeneidad de muestra, los efectos pequeños de múltiples genes, las interacciones (epi) genéticas, la pleiotropía y el tamaño limitado de la muestra, y (iv) la genética de los trastornos del movimiento y su relación a la esquizofrenia.

Por último, el Capítulo 1 introduce la fenomenología y la evaluación de los trastornos del movimiento. Los trastornos del movimiento inducidos por antipsicóticos pueden dividirse en síndromes agudos, como el parkinsonismo y la acatisia, que ocurren pocos días o semanas después de iniciar el tratamiento antipsicótico o aumentar la dosis del fármaco (o después de la suspensión de 
fármacos anticolinérgicos), y síndromes tardíos, como la discinesia tardía (DT) y la dystonía tardía, que se desarrollan después de meses o años de tratamiento. Visto que combinaciones de trastornos del movimiento agudos y crónicos ocurren en pacientes con tratamiento antipsicótico prolongado, los modelos de predicción deben incluir ambos síndromes, es decir, los cuatro tipos mayores de trastornos del movimiento (DT, parkinsonismo, acatisia y distonía). Inicialmente, el término "tardío" se introdujo para referirse a los trastornos del movimiento de aparición tardía que ocurren durante el uso de antipsicóticos. Sin embargo, en el estudio actual la definición de trastornos tardíos se refiere a su persistencia, que es clínicamente más importante que su inicio tardío.

Metaanálisis de los genes que son considerados como asociados a la DT, tales como el DRD3 (Capítulo 2), COMT, DRD2, CYP1A2, y MnSOD (Capítulo 3) se llevaron a cabo. Los metaanálisis indican que DT podría estar asociada con variaciones funcionales de los alelos en DRD3, COMT, DRD2 y MnSOD. Estos análisis sugieren múltiples influencias genéticas en la DT, que es un indicativo de interacciones farmacogenéticas. Aunque las asociaciones no sean fuertes, sus efectos podrían ser susceptibles a interacciones con otros loci que, cuando identificados, podrían tener un poder predictivo importante.

De acuerdo con el objetivo de esta tesis, un estudio prospectivo y naturalístico de 4 años (julio 2003 - mayo 2007) fue realizado con 209 pacientes con enfermedades mentales crónicas para determinar la frecuencia de los cuatro tipos mayores de los trastornos del movimiento (DT, parkinsonismo, acatisia, y dystonía tardía) y los factores de riesgo genéticos y no genéticos de los trastornos del movimiento incidentes. Para este fin, una cohorte de pacientes fue extraída de un hospital psiquiátrico general (GGZ Centraal, Amersfoort, los Países Bajos). Los criterios de inclusión fueron edad mínima de 18 años, y exposición cumulativa a antipsicóticos de por lo menos 1 año. Los criterios de exclusión fueron: una historia de trastornos neurológicos que afecten a la función motora. La cohorte fue representante de la población de pacientes con enfermedades mentales crónicas con el cuadro mas grave que requiera asistencia en hospitalización prolongada, visto que el hospital atiende una zona de captación epidemiológica, es el único instituto que se encarga de este tipo de asistencia en esta área, y los pacientes fueron seleccionados de una lista completa de todos los pacientes hospitalizados.

El capítulo 4 se enfoca a la evaluación de la frecuencia de los trastornos del movimiento persistentes, y luego, el Capítulo 5 de los factores de riesgo no genéticos de los trastornos del movimiento incidentes.

Los resultados demuestran que los trastornos del movimiento persistentes son todavía la norma en pacientes de hospitalización prolongada con enfermedades mentales crónicas que requieren tratamiento antipsicótico prolongado. La 
alta frecuencia periódica del $68 \%$ de por lo menos un trastorno del movimiento llama la atención dado el uso de criterios severos para la definición del caso, que tuvo que ser positivo al menos dos evaluaciones consecutivas. La relevancia clínica de estos hallazgos no es sólo a causa de la frencuencia alta de estos trastornos del movimiento agudos y tardíos, si no también porque la persistencia de los trastornos del movimiento parece ser la regla. Esto implica que la mayoría de los pacientes con tratamiento antipsicótico prolongado presentan trastornos del movimiento persistentes, que hacen de este efecto secundario un asunto de consideración urgente. Estos pacientes tienen un riesgo desproporcionadamente alto de trastornos del movimiento incidente, especialmente individuos de edad avanzada (DT y parkinsonismo) y/o en dosis antipsicótica más alta (parkinsonismo), expresada como el total de la dosis diaria definida (defined daily dose, $D D D$ ). Por eso se requieren medidas para solucionar esta situación como parte de los procedimientos rutinarios de control de calidad. Irónicamente los pacientes de hospitalización de larga duración con enfermedades mentales crónicas pagan un costo elevado por su asistencia intensiva, sobre todo porque los efectos secundarios probablemente se facilitizan en estas clínicas donde el cumplimiento de la farmacoterapia es relativamente alto. El examen sistemático de los trastornos del movimiento toma poco tiempo y se puede aplicar fácilmente en la práctica clínica. Por otra parte, dada la relación evidente entre la edad y algunos trastornos del movimiento, los pacientes de edad avanzada son un grupo de preocupación especial.

Visto que los estudios precedentes utilizaron evaluaciones transversales y no se centraron en el subgrupo vulnerable de pacientes de hospitalización de larga duración, es difícil situar los resultados actuales en un contexto general. Los estudios precedentes coinciden con la prevalencia de los trastornos del movimiento del estudio actual respecto a la DT, pero en estos estudios la prevalencia tiende a ser más baja para el parkinsonismo y más alta para la acatisia y la dystonía tardía.

Además de la edad y la $D D D$ de los antipsicóticos en total, el estudio actual no encontró otros factores de riesgo reportados en los estudios anteriores. Aunque la selección de muestra y la característica prospectiva del estudio actual puedan explicar la falta de consistencia con algunos de los estudios anteriores, especialmente visto que un metaanálisis cuidadoso indica que estudios de factores de riesgo para trastornos del movimiento como la DT demuestran muy poca consistencia, otras explicaciones posibles para estas diferencias son (i) los efectos de prórroga (efectos de respuesta retrasados; carryover effects) después de muchos años de uso de antipsicóticos en la población estudiada, y/o (ii) el tamaño muestral relativamente pequeño del estudio actual.

El objetivo de los Capítulos 6 y 7 era examinar la asociación genética entre los cuatro tipos mayores de trastornos del movimiento (DT, parkinsonismo, acati- 
sia, y dystonía tardía), los subtipos de la DT (discinesia orofacial, de los miembros y del tronco) y el parkinsonismo (temblor de reposo, rigidez, bradikinesia), al igual que un factor principal de los trastornos del movimiento y sus subtipos por una parte, y la variación en 17 genes candidatos, $P P P 1 R 1 B, B D N F, D R D 3$, DRD2, HTR2A, HTR2C, COMT, MnSOD, CYP1A2, y RGS2 (Capítulo 6) y GRIN1B, GRIN1A, HSPG2, DRD3, HTR2C, DRD4, y NQO1 (Capítulo 7) por otro. Se podría pensar que los subtipos de los trastornos del movimiento son más apropiados para el análisis genético que el uso de un síndrome de trastorno del movimiento general, visto que como subtipos podrían reflejar mejor la heterogeneidad biológica fundamental en síndromes complejos.

Varios polimorfismos simples puntuales (single-nucleotide polymorphisms, SNPS) en estos 17 genes candidatos alcanzaron significacia estadística nominal en asociación con los trastornos del movimiento inducidos por fármacos. Sin embargo, después de controlar por compariciones múltiples, nuestros hallazgos sugieren que estos SNPs no están asociados con la susceptibilidad a trastornos del movimiento.

Como el tamaño muestral del estudio actual es pequeño y los estudios precedentes demuestran resultados contradictorios, no se pueden hacer conclusiones definitivas. La pregunta es cómo interpretar estos resultados. En nuestra opinión, ellos pueden reflejar señales genéticas tenues que se necesitan replicar en muestras de estudio más grandes, preferiblemente en estudios longitudinales que tienen en cuenta el curso fluctuante de los trastornos del movimiento e interacciones genetico-ambientales.

Por último, el Capítulo 8 discute los resultados de los metaanálisis, al igual que los hallazgos más llamativos del estudio actual en los pacientes de hospitalización de larga duración con enfermedades mentales crónicas, y exposición crónica a la medicación antipsicótica, con una discusión desde una perspectiva de prevención de los trastornos del movimiento inducidos por fármacos.

Nos sorprendimos por la escasez de notas en las historias clínicas acerca los trastorno de movimiento como efectos secundarios, una observación hecha por otros también. La falta relativa de interés en síndromes de trastorno del movimiento se refleja en la tasa muy baja de diagnóstico de trastornos del movimiento del Eje I del DSM-IV encontrados en la práctica clínica rutinaria. Varias razones podrían explicar esta discrepancia entre la realidad clínica y atención clínica, por ejemplo, el examen sistemático de los trastornos del movimiento inducidos por fármacos no es la práctica habitual, los clínicos podrían asumir erroneamente que los trastornos del movimiento inducidos por fármacos casi no son tratables, la introducción de los ASG llevó erroneamente a la suposición que los trastornos del movimiento inducidos por fármacos habían desaparecido, la mayoría de los pacientes con esquizofrenia no se quejan de su trastorno del movimiento que es una causa importante del diagnóstico tardío. Por eso, la evaluación activa y el tratamiento activo de los trastornos del movimiento, como la 
preocupación actual por el síndrome metabólico, son de suma importancia, y se puede ver como un asunto de calidad de la atención médica. Además, la toma de decisiones compartida (shared care decision making) y el consentimiento informativo (informed consent) por pacientes deberían formar parte del tratamiento antipsicótico. El diagnóstico sistemático podría ayudar a los médicos a tomar conciencia de los trastornos del movimiento.

El problema fundamental en la prevención y el tratamiento de los trastornos del movimiento podría ser su patofisología poco ententida. El modelo clásico donde los trastornos del movimiento se originan por antipsicóticos son desafiados por una colección amplia de literatura y dos metaanálisis que demuestran tasas más altas de prevalencia de trastornos del movimiento en pacientes con un diagnóstico de esquizofrenia. Estos resultados proporcionan un argumento de peso a favor de la hipótesis que los trastornos del movimiento no resultan exclusivamente del tratamiento antipsicótico pero también reflejan un aspecto fundamental de la patofisología del desarrollo neurológico ya que están involucrados en la sensibilización de los circuitos nigroestriados dopaminérgicos. Es interesante que los trastornos del movimiento podrían cumplir a los criterios para clasificar un rasgo como una condición de espectro de un trastorno, en este caso esquizofrenia: heritabilidad, vínculo familiar, cosegregación, y la plausibilidad biológica y clínica. Las condiciones del espectro se refieren a la psicopatología tenue de relevancia clínica pequeña entre parientes sin el trastorno completo. Para la investigación, las condiciones del espectro, contrariamente a un trastorno completo, se benefician de sus menores factores de riesgo y por eso su cadena de mecanismos menos compleja llevando a su inicio, que podría hacer la investigación más fácil de realizar. Los estudios (fármaco) genéticos podrían ayudar a aclarar estas vías comunes en el desarrollo de no sólo condiciones de espectro sino el trastorno completo.

Los estudios prospectivos en poblaciones de pacientes no pretratados con un primer episodio de psicosis antes y después del tratamiento con antipsicóticos podría ser crucial para distinguir entre los trastornos del movimiento primarios (parte de la esquizofrenia) y secundarios (inducidos por fármacos). Aún así, los síntomas primarios podrían desarrollarse a lo largo de la esquizofrenia, con lo cual la diferenciación entre síntomas primarios y secundarios sería casi imposible.

A pesar de la evidencia acumulada de estudios genéticos de asociación, la genética sólo explica una parte perqueña de la esquizofrenia, un hecho que apoya la importancia de otros factores que interactúan, como factores ambientales, que juegan papeles importantes en la esquizofrenia. Los trastornos neuropsiquiátricos podrían reflejar la interacción compleja de no sólo factores genéticos, pero en primerísimo lugar de factores epigenéticos, estocásticos y no genéticos.

Un desarrollo importante en la (fármaco) genética humana desde el 2005 es la posibilidad de los estudios de asociación genómica amplia (genome-wide association study, GWASs) a favor de un enfoque 'libre de hipótesis' y por eso sin 
sesgo estadístico para revelar nuevas variantes reveladoras del ADN que influyen la susceptibilidad genética a muchas enfermedades comunes, y para aclarar nuevos mecanismos patofisiológicos.

El Consorcio Psiquiátrico de GWAS (Psychiatric GWAS Consortium, PGC) ha sugerido que en un futuro próximo muestras más grandes de GWAS discernirán más variantes de la susceptibilidad común con tamaños de efecto más pequeños y que metaanálisis de GWAS deberían encontrar evidencia más definitiva de asociaciones genéticas. Mientras tanto, nuevas técnicas genéticas potencialmente prometedoras como la secuenciación completa del genoma (whole-genome sequencing) y epigenética se están aplicando. También, enfoques de estudios de interacciones genético-ambientales amplias (gene-environment-wide interaction studies, GEWIS) han sido sugeridos. Parece legítimo concluir que estas nuevas técnicas podrían ofrecer estudios genéticos de ligamiento y asociación más efectivos.

Estas conclusiones sugieren que la investigación futura sobre los trastornos del movimiento podría sacar provecho de:

- La incluisión de todos los cuatro trastornos del movimiento, como realizado en el estudio actual, visto que ellos pueden representar los efectos pleiotrópicos de los factores genéticos (parcialmente) compartidos.

- La mejoría de la calidad de los conjuntos de datos por (i) el empleo de medidas repetidas (momentáneas) como medidas estándar, por ejemplo, caracterizar el temblor de Parkinson con un iPhone, (ii) la inclusión de muestras de estudio más grandes, (iii) la utilización de fenotipos intermedios, como fenotipos a base de estudios de laboratorio, o como las medidas más exactas de los trastornos del movimiento, por ejemplo la medida mediante de instrumentos de la variabilidad de la fuerza lingual, que podría representar alternativas robustas ya que como medida instrumental discierne los trastornos del movimiento subclínicos y es sumamente seguro.

- La utilización de escalas para el bienestar subjetivo y la calidad de vida, para valorar mejor el impacto emocional de los trastornos del movimiento en la vida cotidiana.

- La identificación de vias comunes en el desarrollo de los trastornos del movimiento. Con esta información, una Lista de Modelo alternativa de Medicinas Esenciales de la Organización Mundial de la Salud podría ser una que enumere los 'biomarcadores esenciales mínimos' requiridos para la farmacoterapia óptima.

- Colaborar a un nivel más amplio, es decir internacionalmente. Las iniciativas importantes son (i) la red EUropea de las redes nacionales de la esquizofrenia que estudian Interacciones Genético-Ambientales (EUropean network of national schizophrenia networks studying Gene-Environment Interactions; EU-GEI, www.eu-gei.eu) y (ii) la Red de las Redes de Investigador patrocinada por la 
Red global de Epidemiología del Genoma Humano (Network of Investigator Networks sponsored by the global Human Genome Epidemiology Network; HuGENet, www.cdc.gov/genomics/hugenet). 

Dankwoord 
Om te beginnen wil ik alle deelnemers aan mijn onderzoek hierbij bedanken. Zonder uw medewerking was dit proefschrift nooit tot stand gekomen. Onderzoek is van groot belang voor het verbeteren van patiëntenzorg, en door uw deelname heeft $u$ hieraan een belangrijke bijdrage geleverd.

Ik vond onze samenwerking altijd heel plezierig. Ik herinner mij de leuke en interessante gesprekken die ik met $u$ had, en ook de humor van velen. Daarom nogmaals heel hartelijk dank aan alle deelnemers!

Ik heb het altijd interessant gevonden om dingen te onderzoeken en vond het een uitdaging om antwoorden te vinden op fundamentele vragen. In de praktijk werd mij als arts al snel duidelijk wat het belang is van wetenschappelijk onderzoek voor het welzijn van mijn patiënten. Kortom: ik vind onderzoek zowel leuk als belangrijk.

Veel mensen hebben een bijdrage geleverd aan dit promotie-onderzoek, waarvoor ik hun allen zeer erkentelijk ben. Vanwege het grote aantal loop ik uiteraard het risico iemand over te slaan. Dank dus ook aan degenen die ik eventueel vergeten ben.

Allereerst wil ik mijn beide promotores, prof. dr. Peter van Harten en prof. dr. Jim van Os, bedanken.

Peter, ik ken je al elf jaar. Eerst als A-opleider, daarna als onderzoeksbegeleider, vervolgens als copromotor en nu als promotor. Jij bent degene die mij in de gelegenheid heeft gesteld om met dit onderzoek te starten tijdens mijn opleiding tot psychiater. Jouw grote deskundigheid, inhoudelijke kennis en didactische kwaliteiten heb ik in al deze jaren als zeer inspirerend en leerzaam ervaren. Je rustige en subtiele manier van aanmoedigen en bijsturen vond ik heel prettig, omdat ik zo de ruimte had om mijn onderzoek inhoudelijk een eigen kleur te geven. Mijn passie voor onderzoek naar bewegingsstoornissen en hun behandeling komt rechtstreeks van jou. Verder heb jij mij de gouden regels geleerd voor het schrijven van een goed wetenschappelijk artikel.

Jim, vanwege de afstand tussen Maastricht en Amsterdam hebben wij veel via e-mail gecommuniceerd. Dit verliep heel goed dankzij jouw communicatieve vaardigheden: je gaf mij altijd korte, bondige aanwijzingen, die mij dan meteen weer een stuk verder brachten. Ik was ook altijd onder de indruk van de snelheid waarmee je reageerde; ik hoefde maar even naar buiten te kijken of je antwoord zat alweer in mijn mailbox. Het was alsof je als het ware digitaal over mijn schouder meekeek. Jouw brede kennis, creativiteit, didactische vaardigheden en enthousiasme zijn voor mij van grote betekenis geweest. Verder heb je mij het vertrouwen gegeven om nieuwe onderzoeksmethodieken uit te proberen. Ik ben blij dat je mij de analyses zelf hebt laten doen onder jouw begeleiding en instructies, want zo heb ik veel kunnen leren over statistiek en het analyseren van data. 
Erik de Groot, jij was onderzoekscoördinator in de tijd dat ik met mijn onderzoek begon en hebt een grote rol gespeeld aan het begin van mijn onderzoek. Alle logistieke zaken, zoals financiën en communicatie met personen en instanties, heb jij voor mij gedaan. Jouw organisatietalent heb ik altijd zeer bewonderd. Daarnaast heb jij veel kennis en inzicht in huis over wetenschappelijk onderzoek, die mij zeer goed van pas kwam.

Verder wil ik de onderzoeksassistenten bedanken voor al het goede werk dat zij hebben verricht. Marijn Hoornweg-van Beek, Gerard Boedijn, Martijn van Drie, Robbert Emons en Anne Willems (ook later, als onderzoekscoördinator). Jullie hebben alle data ingevoerd en dat hebben jullie snel en goed gedaan. Verder hebben jullie de logistiek rondom de bezoeken van patiënten georganiseerd, zodat alles op rolletjes liep.

Dr. Diederik Tenback, jij bent een wetenschappelijk onderzoeker pur sang: jouw enthousiasme voor dit schitterende vak werkt voor mij zeer aanstekelijk.

Prof. dr. Iris Sommer, ik heb je leren kennen tijdens het psychiatrie-onderwijs op Zon en Schild. In die periode hebben wij veel gepraat over wetenschappelijk onderzoek en cultuur. Wij hebben veel gezamenlijke interesses. Iris, ik ben je dankbaar voor de adviezen rondom wetenschappelijk onderzoek, de fijne gesprekken, je vertrouwen en je vriendschap.

Jeroen Koning, wij deelden als promovendi het onderwerp bewegingsstoornissen, en altijd hadden wij geanimeerde gesprekken over het onderzoek op dit gebied. Ik herinner mij hoe ik tijdens en na onze gesprekken telkens nieuwe ideeën kreeg.

Prof. dr. Egbert Bakker, Ellen Vollebregt en Chris Hettinga van het Leids Universitair Medisch Centrum (LUMC), veel dank voor het doen van de genotyperingen en het meedenken over de genetische-associatiestudie.

Dan is er prof. dr. Anton Loonen van de Rijksuniversiteit Groningen (RUG). Anton, ik leerde je allereerst kennen als een van de docenten in de Corsendonkcursus en ben altijd onder de indruk geweest van je grote kennis van de (psycho)farmacologie. Ik vind je een sympathiek persoon en ben je zeer erkentelijk voor het doen van de genotyperingen en de facilitatie op dit gebied. In deze context wil ik ook de staf van Universitair Medisch Centrum Groningen (UMCG) bedanken voor de assistentie.

Dr. Asmar Al Hadithy, genetisch onderzoek naar bewegingsstoornissen is ons beider hartstocht. Dit leverde interessante gesprekken op. Veel dank voor het selecteren van de tag SNP's. 
De leden van de raad van bestuur, dr. Thea Heeren, dr. Bas Schreuder en ir. Henk ter Avest, de voormalige directeuren van de Meregaard te Almere, Bas Koevoet, Frits Liefferink, Matthijs Weening, de huidige directeuren Roelfina Zuidema en Tinus Smallenbroek, en Innova wil ik bedanken voor de ruimte (lees: in tijd en geld) voor het uitvoeren van mijn promotie-onderzoek. Ook wil ik mijn collega's bedanken voor hun belangstelling.

Zonder het programma Primas, voorheen Hecktive, zou ik niet over de medicatiedata hebben kunnen beschikken voor de analyses. Hiervoor ben ik Dolf Heck en Bert Koot, de programmeurs en ontwerpers van dit fantastische medicatieprogramma, zeer erkentelijk. Walter Broekema, Mariska de Roo en Nardy Dietz, apothekers op Zon en Schild, en Robbert Emons, onderzoeksassistent, wil ik danken voor het faciliteren van de medicatiedata.

De verpleegkundige teams, unithoofden, managers en secretaressen op Zon en Schild hebben hun kostbare tijd vrijgemaakt om het mij mogelijk te maken patienten uit te nodigen voor mijn onderzoek, waarvoor ik hun zeer dankbaar ben.

Ook wil ik mijn dank uitspreken aan de Open Ankh, die mijn promotieonderzoek heeft gefinancierd.

Ik wil dank zeggen aan de bibliothecaressen van Zon en Schild, die (altijd heel snel) vele artikelen voor mij hebben besteld. Zonder al deze literatuur had ik geen referenties gehad.

Ook wil ik prof. dr. Cornelia van Duijn bedanken. Cornelia, ik leerde je kennen toen ik een aantal cursussen genetische epidemiologie volgde bij het Netherlands Institute for Health Sciences (NIHES)/Erasmus MC. Deze cursussen volgde ik omdat ik binnen mijn promotie-onderzoek ook genetische-associatiestudies wilde doen. Genetisch onderzoek heeft altijd mijn belangstelling gehad, en die is mede door jouw liefde voor dit interessante vak alleen maar groter geworden. Uiteindelijk besloot ik om de master of science in genetische epidemiologie te doen, die ik vorig jaar heb afgerond. Jij was mijn tutor, wat ik als heel prettig en inspirerend heb ervaren.

Dr. Najaf Amin, Najaf I would like to thank you for being my tutor at the master of science in genetic epidemiology program at NIHES/Erasmus MC. Your suggestions were crucial for choosing and performing the correct genetic analyses.

Astrid Vrakking (toen coördinator bij NIHES/Erasmus MC), ik wil je bedanken voor het opstellen van mijn rooster voor de master of science in genetische epidemiologie, dat speciaal aangepast was aan mijn klinisch werk. Dit rooster heeft mede geholpen om alle cursussen naadloos in elkaar over te laten gaan. 
Linda Broer (NIHES/Erasmus MC), dank voor je goede adviezen bij de genetische analyses en gouden tips bij het statistisch programma R.

Neşe Direk, ik heb je tijdens mijn master of science leren kennen als collegapsychiater uit Turkije en medestudent in de opleiding tot master of science. Wij hebben veel met elkaar gemeen en zijn inmiddels vrienden. Dank voor je vriendschap en de inspirerende gesprekken.

Dr. Natalia Rivera, ci siamo conosciuti durante il master di scienza in epidemiologia genetica. Ti ringrazio per l'amicizia e per gli scambi scientifici di questi ultimi anni.

Dessa Brashear en Lucie Voskuil, veel dank voor het controleren en corrigeren van mijn Engels respectievelijk Nederlands. Querida dr. Angela GonzálezZuloeta Ladd, muchas gracias por tu amistad, por el placer de conocerte, y por controlar y corregir mi Español. También quisiera agradecer a Angela y a la dr. Sandra Lopez Leon por su consejo en los meta-análisis. Anneleen Doornebal, ik ben heel blij en dankbaar dat jij mijn proefschrift op fouten hebt gecontroleerd en gecorrigeerd.

Lieve Marjan Kruize. Jij hebt mij geholpen met het selecteren van foto's uit je database en zo bijgedragen aan de prachtige cover van mijn proefschrift.

Tevens, wil ik Elsa Misdom en Len Cuppens (Universiteit Maastricht), en Ruud Leliveld (Datawyse) bedanken voor hun adviezen, begeleiding en logistiek rondom mijn promotie.

Mijn paranimfen, Hanneke van Dijk-du Mortier en Yvette Roke. Ik ken jullie beiden van de opleiding psychiatrie en jullie hebben, net als ik, liefde voor wetenschappelijk onderzoek. Ook jullie zijn met een promotie-onderzoek bezig. Ik ben heel blij dat jullie de rol van paranimf op je hebben willen nemen. Heel veel dank voor alle organisatie rondom mijn promotie.

Dhr. R. Nielander en mevr. R.E.C. Nielander, jullie waren mijn eerste leraren in Nederland. Dank dat jullie mij geholpen hebben de Nederlandse taal machtig te worden.

Prof. dr. Joep Bor, wat promotie-onderzoek betreft, was jij voor mij een belangrijke inspirator.

Lieve mama en papa ( $\dagger$ ), ik wil jullie bedanken voor jullie onvoorwaardelijke liefde en vertrouwen. Jullie hebben mij alle vrijheid gegeven om mij te ontwikkelen in de richting die bij mij past, en daarbij hoort ook wetenschappelijk on- 
derzoek. Het doorzetten en gefocust blijven op een doel heb ik niet van een vreemde. Ik ben heel blij dat ik dit van jullie meegekregen heb, en hóé jullie dat aan mij hebben doorgegeven, is weer een interessante wetenschappelijk vraag!

Mijn overige (schoon)familieleden en vrienden, bedankt voor jullie steun, vertrouwen en liefde.

Lieve Tom, mijn allerliefste, dank voor je geduld, je liefde, je relativerende humor, en je hulp bij het proefschrift. Jij bent mijn man.

En Koen ten slotte, mijn lieve zoon, ik draag dit boek aan jou op. Promoveren is belangrijk, maar jij, Koen, bent mijn alles. 

Curriculum Vitae 
Rob (Pieter Roberto) Bakker was born July 21st, 1962, in Caracas, Venezuela, of Dutch parents. At the age of 12 he and his family moved to the Netherlands. He attended medical school at VU University in Amsterdam prior to his psychiatric training at Zon en Schild in Amersfoort.

He became interested in scientific research at a young age, and later in clinical work. While in medical school together with Dr. A.J. Kuiper he undertook an epidemiological study on the quality of treatment in the Department of Endocrinology and Gender. Afterwards he carried out genetic research into antigen presenting cells at the Department of Cell Biology and Immunology with Prof. E.C.M. Hoefsmit.

He began a Ph.D. programme during his psychiatric training, under the supervision of Prof. Peter van Harten (at the time also the supervisor of psychiatric training) and Prof. Jim van Os. He also started his master of science in genetic epidemiology at Netherlands Institute for Health Sciences (NIHES)/Erasmus MC, under the supervision of Prof. Cornelia van Duijn and Dr. Najaf Amin, which he finished September 2011.

He is married to Tom Doornebal. They have one son, Koen. 